\title{
THE LEARNING EXPERIENCES OF NEW ZEALAND SECONDARY SCHOOL STUDENTS WITH CHRONIC HEALTH CONDITIONS
}

\author{
By \\ Mabél R. Hamon
}

Submitted to Victoria University of Wellington in fulfillment of requirements for a doctoral thesis

Wellington, New Zealand

December 2015 
I dedicate this thesis with great love to my daughters who inspired me to learn more about how to help young people with chronic health conditions in school,

Alexandra Emerson Hamon and Caitlin Noel Hamon. 


\begin{abstract}
Chronic health conditions ( $\mathrm{CHC}$ ) in New Zealand adolescents are on the rise as medical advances continue. Exact numbers of the student population ranges from approximately 17\% (Adolescent Health Research Group, 2008) to as high as $37 \%$ (Ministry of Health, 2008a). Pasifika and Māori youth are especially hard hit by the increase in numbers of CHCs in New Zealand. Young people with a CHC face additional challenges in the physical, cognitive, and psychosocial domains their healthy peers do not. Prior research shows CHCs can negatively affect learning. This study used Interpretative Phenomenological Analysis (Smith, 1995), generally used in nursing and psychological research, and focused on the learning experiences of New Zealand secondary school students with a CHC. It emphasized and gave voice to these students' experiences that affected their learning. Data were collected from 24 participants in seven secondary schools in a major New Zealand city, through semistructured individual interviews and focus groups.

Despite a wide range of $\mathrm{CHCs}$ and ages represented within the overall cohort of students, they shared many commonalities. Participants considered themselves no different from their peers in school, even as they discussed the different effects and difficulties of their respective $\mathrm{CHCs}$, such as the impact of pain or inability to concentrate. They considered school important and did not want to miss class due to either a CHC or its treatment. The physical, cognitive, and psychosocial impacts of CHCs make learning challenging, especially when students encounter skepticism and teachers with insufficient knowledge of CHCs to meet their learning needs. This lack of understanding or knowledge regarding $\mathrm{CHCs}$ and how they impact the student caused additional strain but these young people retained their interest in school, regardless of school decile or ethnicity. Students took responsibility for their learning and attributed learning success to their efforts and coping strategies with strong support given by parents. Teachers or others within the school who knew about the $\mathrm{CHC}$ were seen as helpful and understanding; protective factors which contributed to their learning. New and career educators and policy makers in New Zealand need additional instruction in New Zealand on the impact of CHCs on learning as well as greater encouragement of communication between parents and schools regarding health to help these adolescents in their education.
\end{abstract}




\section{ACKNOWLEDGEMENTS}

Although a PhD can be a solitary journey, I did not have do this alone. My thanks to my supervisors, Dr. Lex McDonald and Dr. Jeff Sigafoos, for their support, advice, and assistance during my PhD journey. Thanks to Dr. Stephanie Doyle who came onboard late in the journey, but provided wonderful, constant support and encouraging advice. I humbly thank my husband and daughters for their unfailing love and encouragement throughout the time I was away doing this research. I appreciate all the support, encouragement, and time to listen that Carolyn Tait gave me. I received much support from many generous people, but I thank especially Azra Moeed, Simon Croft, Phillippa Hayes, Lizzie Towl, Amy De Boer, Ann Hardie, Ernie R., and Sheila Law, especially those who opened doors for me, which was invaluable.

A prayerful and humble thank you for all the blessings the Good Lord provided me including new caring friends, like Chantel Mitchener, Chris Bowden, and Delia Baskerville who were always there with support when challenges arose. I feel privileged to have met some of the kindest, most generous people in New Zealand who

opened their homes to me. I am grateful for the countless sessions Chris and I spent discussing phenomenology, human development, and Simon's Cat. God bless all my friends and family who sent me notes of encouragement, hilarious cards, and who never doubted I would finish this despite many challenges. Please accept my humble and heartfelt thanks. Thank you to my Manor family: Truphena, Tuyen, Zawadi, Anita, Huong, Hue, Upendo, Milka, Antonio, and Tien, for the warm friendship, invaluable support, sense of family, shared meals, learning about different cultures, and all the laughter. I am the richer for it.

A special heartfelt thank you for the trust of the participants of this study who shared their stories, and to their schools who opened their doors to allow this study to occur. Their humble courage and remarkable resiliency were and are inspirational! Thank you to Sandra Bennett, M.D., for her support and oversight during the last four years. My gratitude to Victoria University of Wellington for faith in my abilities, providing a perfect place to learn and work, and generous scholarships. Thank you to FGR and PGSA for the workshops and support systems, and Zealandia for the opportunity to serve my community. This has truly been an amazing learning experience of a lifetime. 


\section{TABLE OF CONTENTS}

$\begin{array}{lll}\text { ABSTRACT } & \text { iii }\end{array}$

ACKNOWLEDGEMENTS iv

TABLE OF CONTENTS v v

TABLE OF FIGURES $\quad x$

LIST OF TABLES $\quad x$

CHAPTER ONE INTRODUCTION

1.1 Aim of Research 1

1.2 Background 1

1.2.1 Definition of chronic health condition 1

$\begin{array}{lll}\text { 1.2.2 Definition of adolescent } & 1\end{array}$

1.2.3 Why is this a concern? 2

1.3 Purpose of study 2

1.4 Research Question 3

1.5 Research Approach 3

1.6 Researcher's Perspective 5

1.7 Significance of Study 5

CHAPTER TWO LITERATURE REVIEW OF CHRONIC ILLNESS AND ADOLESCENTS 6

$\begin{array}{ll}2.1 \text { Introduction } & 6\end{array}$

2.1.1 Literature Review Criteria 6

2.2 Models of Illness Used in Research 8

$\begin{array}{llr}2.2 .1 & \text { Introduction } & 8\end{array}$

2.2.2 Biomedical Model 9

2.2.3 Social Model of Disability 9

$\begin{array}{lll}2.2 .4 & \text { Biopsychosocial Model } & 10\end{array}$

2.2.5 Summary of Models 12

2.3 Literature Review 13

$\begin{array}{lll}2.3 .1 & \text { Reviews } & 13\end{array}$

$\begin{array}{lll}\text { 2.3.1.1 Adolescent age factor } & 14\end{array}$

2.3.2 Quantitative and Qualitative Studies of Adolescents with CHC 15

$\begin{array}{lll}2.3 .3 & 19\end{array}$ 
2.4 How Chronic Health Conditions Impact Adolescent Development 21

$\begin{array}{lll}2.4 .1 & \text { Introduction } & 21\end{array}$

$\begin{array}{lll}2.4 .2 & \text { Physical } & 22\end{array}$

$\begin{array}{lll}2.4 .3 & \text { Cognitive } & 26\end{array}$

$\begin{array}{lll}2.4 .4 & \text { Psychosocial } & 28\end{array}$

2.4.5 Summary 32

2.5 Family 33

2.6 Chronic Illness and Education $\quad 35$

2.6.1 Introduction 35

2.6.2 Absenteeism 35

$\begin{array}{lll}2.6 .3 & \text { Educators } & 36\end{array}$

2.6.4 Nurses, Physicians, and School 39

$\begin{array}{lll}2.6 .5 & \text { Summary } & 40\end{array}$

2.7 New Zealand Context 41

2.7.1 New Zealand Research 41

2.7.2 Māori and Pasifika 46

$\begin{array}{lll}2.8 \text { Conclusion } & 49\end{array}$

CHAPTER THREE METHODOLOGY

$\begin{array}{lll}3.1 & \text { Introduction } & 51\end{array}$

3.2 Research Questions 51

3.3 Research Framework 51

3.4 Phenomenology 52

3.4.1 Phenomenologists and Bracketing 54

3.5 Phenomenological Method Design $\quad 54$

3.6 Ethical Clearance and Informed Consent 57

$\begin{array}{lll}3.7 & \text { Participants } & 58\end{array}$

$\begin{array}{lll}3.8 & \text { Recruitment } & 60\end{array}$

3.9 Procedures $\quad 62$

$\begin{array}{lll}3.9 .1 & \text { Online questionnaire } & 62\end{array}$

$\begin{array}{lll}\text { 3.9.2. Individual interviews } & 63\end{array}$

$\begin{array}{lll}3.9 .3 & \text { Focus group interviews } & 64\end{array}$

3.10 Data Collection 64

$\begin{array}{lll}3.10 .1 & \text { Questionnaire. }\end{array}$ 
3.10.1.1 Pilot online questionnaire $\quad 64$

3.10.1.2 Study questionnaire $\quad 64$

3.10.2 Individual interviews 66

3.10.2.1 Pilot Interview 66

$\begin{array}{lll}\text { 3.10.2.2 Individual Interviews } & 67\end{array}$

$\begin{array}{lll}\text { 3.10.2.3 Focus group interviews } & 71\end{array}$

3.11 Data Analysis: Interpretive Phenomenological Analysis 73

$\begin{array}{ll}3.12 \text { Limitations } & 76\end{array}$

$\begin{array}{ll}3.13 \text { Trustworthiness } & 78\end{array}$

$\begin{array}{ll}3.14 \text { Summary } & 81\end{array}$

CHAPTER FOUR THE CHRONIC HEALTH CONDITION EXPERIENCE and IT'S SOMETHING THAT'S BECOME A PART OF ME 83

$\begin{array}{lll}4.1 & \text { Introduction } & 83\end{array}$

4.2 Findings 84

4.3 The Chronic Health Condition Experience. 85

$\begin{array}{lll}4.3 .1 & \text { Diagnosis } & 86\end{array}$

4.3.1.1 Noticing and changing $\quad 86$

4.3.1.2 Bart, Bridget, Esau $\quad 88$

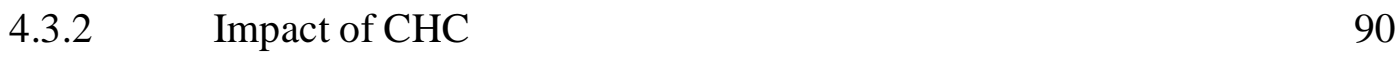

$\begin{array}{lll}\text { 4.3.2.1 Physical impact } & 90\end{array}$

4.3.2.2 Cognitive 97

$\begin{array}{lll}\text { 4.3.2.3 Psychosocial } & 100\end{array}$

$\begin{array}{lll}\text { 4.3.3 Missing Out } & 101\end{array}$

$\begin{array}{lll}\text { 4.3.3.1 Activities } & 101\end{array}$

$\begin{array}{lll}\text { 4.3.3.2 School } & 102\end{array}$

$\begin{array}{lll}4.3 .4 & \text { Coping } & 104\end{array}$

4.3.5 Summary of Superordinate Theme The Chronic Illness Experience 108

4.4 “It’s Part of My Personality." 109

$\begin{array}{lll}\text { 4.4.1 Introduction } & 109\end{array}$

4.4.2 “Accept You for Who You Are." 109

$\begin{array}{lll}\text { 4.4.3 "It's Not A Big Deal." } & 115\end{array}$

$\begin{array}{lll}\text { 4.4.4 NCEA and Future Plans } & 119\end{array}$

$\begin{array}{lll}\text { 4.4.5 Outlier, Esau } & 122\end{array}$ 
4.4.6 Summary of Superordinate Theme "It's Part of My Personality." 123

$\begin{array}{lll}4.5 & \text { Chapter Summary } & 124\end{array}$

\section{CHAPTER FIVE IT'S HARD AND LEARNING HAPPENS WHEN} YOU HAVE HELP

$\begin{array}{lll}5.1 \text { Introduction } & 125\end{array}$

$\begin{array}{ll}5.2 \text { Learning Context } & 126\end{array}$

5.2.1 Learning Environment Definition 126

$\begin{array}{ll}\text { 5.2.2 Learning Environment Participants } & 128\end{array}$

$\begin{array}{ll}5.3 \text { It's Hard. } & 130\end{array}$

$\begin{array}{lll}5.3 .1 & 130\end{array}$

5.3.2 Not Understanding 131

$\begin{array}{ll}5.3 .3 \quad \text { "It's hard." } & 137\end{array}$

$\begin{array}{lll}5.3 .4 & \text { One more thing } & 140\end{array}$

$\begin{array}{lll}\text { 5.3.5 Bullying } & 142\end{array}$

5.3.6 Summary of Superordinate Theme "It's Hard." 144

5.4 Learning Can Happen When You Have Help. 144

$\begin{array}{lll}5.4 .1 & 144\end{array}$

$\begin{array}{ll}\text { 5.4.2 Parents and Friends Help } & 145\end{array}$

5.4.2.1 Parents 145

$\begin{array}{ll}\text { 5.4.2.2 Friends } & 148\end{array}$

$\begin{array}{lll}5.4 .3 & \text { School Support } & 149\end{array}$

5.4.3.1 “They help you." 149

5.4.3.2 Safe 159

5.4.4 Summary of Superordinate Theme "Learning Can Happen

When You Have Help.” 160

$\begin{array}{lll}5.5 & \text { Summary } & 161\end{array}$ 
CHAPTER SIX DISCUSSION

$\begin{array}{lll}6.1 & \text { Introduction } & 162\end{array}$

6.2 The Chronic Health Condition Experience 163

$\begin{array}{lll}6.3 & \text { It's Part of My Personality. } & 168\end{array}$

$\begin{array}{ll}6.4 \text { It's Hard } & 171\end{array}$

6.5 Learning Can Happen When You Have Help 175

$\begin{array}{ll}6.6 \text { Conclusion } & 180\end{array}$

CHAPTER SEVEN CONCLUSION 182

$\begin{array}{lll}7.1 & \text { Introduction } & 182\end{array}$

$\begin{array}{lll}7.2 & \text { Strengths and Contributions } & 183\end{array}$

$\begin{array}{lll}7.3 & \text { Implications and Recommendations } & 185\end{array}$

$\begin{array}{ll}\text { REFERENCES } & 189\end{array}$

$\begin{array}{ll}\text { LIST OF APPENDICES } & 208\end{array}$

APPENDIX 1: INTRODUCTION LETTER TO PRINCIPALS 209

APPENDIX 2: INFORMATION SHEET FOR PRINCIPALS/
BOARD OF TRUSTEES

APPENDIX 3: CONSENT FROM PRINCIPALS/BOARD OF TRUSTEES 212

APPENDIX 4: INVITATION/INFORMATION TO STUDENTS 214

APPENDIX 5: REFERRAL LETTER TO STUDENTS FROM STAFF 215

APPENDIX 6: INFORMATION LETTER TO PARENTS/CAREGIVERS 216

APPENDIX 7: INFORMATION SHEET INTERVIEW/

FOCUS GROUP STUDENTS 218

APPENDIX 8: CONSENT FORM INTERVIEW/
FOCUS GROUP STUDENTS

APPENDIX 9: INDIVIDUAL SEMI-STRUCTURED INTERVIEW/
FOCUS GROUP QUESTIONS FOR STUDENTS

APPENDIX 10: INFORMATION SHEET FOR PARENTS/

CAREGIVERS OF STUDENTS UNDER 16

APPENDIX 11: CONSENT FORM FOR PARENTS/

CAREGIVERS (STUDENTS UNDER 16) 223

APPENDIX 12: CONFIDENTIALITY RESEARCH ASSISTANT
AGREEMENT

APPENDIX 13: QUESTIONNAIRE FOR ADOLESCENTS 225

APPENDIX 14: EXAMPLES OF CODES WITH DEFINITIONS AND STUDENT TEXT 230

APPENDIX 15: DEFINITIONS OF CODES, CLUSTERS, AND THEMES 231 


\section{TABLE OF FIGURES}

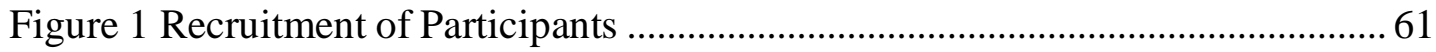

Figure 2 Process of Interpretative Phenomenological Analysis ................................. 75

\section{LIST OF TABLES}

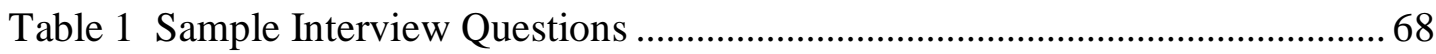

Table 2 Individual Interview Participant Demographics .......................................... 70

Table 3 Focus Group Participant Demographics .................................................... 72

Table 4 Superordinate Themes and Subthemes from Interviews ............................... 85

Appendix 14 Examples of Codes with Definitions and Student Text ......................230

Appendix 15 Definitions, Codes, Clusters, and Themes........................231 


\section{CHAPTER ONE INTRODUCTION}

\subsection{Aim of Research}

The aim of this study is to investigate the learning experiences of students with chronic health conditions (CHC) in a New Zealand context. This chapter defines CHC and adolescence, introduces describes the background of how the education of students is affected by a CHC, the purpose of the study, the research question, describes the theoretical framework, an overview of the study, and the significance of the study.

\subsection{Background}

\subsubsection{Definition of chronic health condition}

The National Health Committee (2007) using the World Health Organization and other countries' definition as a guideline, defines a CHC as "an ongoing, long term or recurring condition that can have a significant impact upon a person's life" (p. 7). It also posits while symptoms may vary in severity and complexity, the impact can be seen across the wider health, social, and financial context of an individual's life. Michaud, Suris, and Viner (2007) discuss the difficulty in defining what a CHC is and discussion has included the duration, limitations or impairments in cognitive, physical, or psychosocial domains or the clinical course of the health condition. As this study was conducted in New Zealand, it is appropriate to use the National Health Committee's definition (2007) which operates under New Zealand's Ministry of Health. Chronic illness (CI), chronic health condition (CHC), and chronic condition (CC) will be interchangeable terms within the confines of this study. Acute illness is not to be confused with chronic illness. Acute illnesses are short, intense periods of ill health: the flu, the measles, chicken pox, or mumps.

\subsubsection{Definition of adolescent}

The definition of adolescence varies among health organizations and researchers; for this study, the WHO definition of adolescence being from 10 to 19 years old is used (Michaud et al., 2007). The terms young people, teenagers, and adolescents are used interchangeably within this study. According to the Adolescent Health Research Group (2008a), approximately $17 \%$ of the student population in New Zealand has a CHC or 
chronic illness. There is some evidence the prevalence of $\mathrm{CHC}$ may be even higher in New Zealand than reported by the Adolescent Health Research Group. Specifically, the New Zealand Ministry of Health (2008a) reported as many as $37 \%$ of young people between the ages of 15 and 24 may have a physical or mental health condition that has lasted for more than six months. Although there is a significant disparity between the two numbers cited above, it is still indicative that there is a sizable population of young people with a chronic health condition.

\subsubsection{Why is this a concern?}

What makes CHCs a concern for teachers is that many of these illnesses can strike a child at any age and adversely affect a child's education. A CHC can have a major impact upon a student's educational experience (Grinyer, 2007; Wodrich \& Cunningham, 2008). In New Zealand, one impact is that students with a CI tend to leave the educational environment sooner than their healthier peers (Ministry of Health, 2008a; Ward, 2005). Teenagers affected by CHCs are moving through a critical developmental stage (Reeve \& Lincoln, 2002; Rey-Casserly \& Meadows, 2008). They are faced with major life decisions regarding preparation for adulthood, living alone, career, possibly pursuing tertiary education, (Farrant \& Watson, 2004; Thies \& Walsh, 1999; Wallander \& Varni, 1998).

\subsection{Purpose of study}

Literature and systematic reviews have analyzed studies on adolescents with a particular CHC (e.g., asthma, diabetes, epilepsy) with discussions focusing upon issues resulting from a CHC or quality of life (Armstrong, 2006; Brown, Pikler, Lavish, Keune, \& Hutto, 2008; Cheung \& Wirrell, 2006; Hohepa, Schofield, \& Kolt, 2004; Meijer, Sinnema, Bijstra, Mellenbergh, \& Wolter, 2000). In New Zealand, although some qualitative studies have discussed $\mathrm{CHC}$ and students (Dickinson, Smythe, \& Spence, 2006; Farrant \& Watson, 2004), many studies on adolescents with a CHC have been quantitative and focused on particular illnesses (asthma and diabetes) and treatment effect with very little, if any, mention of the impact upon their education (e.g., Paddison, Alpass, \& Stephens, 2008; Paterson, Moss-morris, \& Butler, 1999).

Examining the learning experiences of adolescent students in New Zealand which may involve the classroom, home, and activities, brings attention to how students 
experience their learning and can show what supports are in place for these students with CI within and outside their school. A qualitative study describing how the student with CI experiences learning can offer teachers, health professionals, and parents the opportunity to learn and understand what the experienced reality is for these students and begin to fill the gap that currently exists in this area within New Zealand.

Many qualitative studies have investigated the psychologist's, school counselor's, health provider's (medical), or parental point of view with fewer studies, comparatively speaking, examining the secondary student's viewpoint specifically in regard to learning. They have not included in their discussions how the adolescent with $\mathrm{CHC}$ experiences learning and how this affects their learning experience. Since treatment and illness can impact the cognitive abilities of these students, it is critical to determine how they are learning and how teachers can build upon this success. Moreover, determining what supports students feel are in place for learning and what communication (if any) occurs amongst all the key stakeholders in this arena will shed light on the growing population of students with CI. These students with $\mathrm{CHC}$ are the primary stakeholders in their futures and as educators, we must know what is working, how it is working, and share that information.

\subsection{Research Question}

The key question underpinning this research project was what are the learning experiences of students with chronic health conditions? The sub questions were:

a) How, if at all, does their $\mathrm{CHC}$ affect their learning experience?

b) Where/what learning environments do they participate in and from whom are they learning?

\subsection{Research Approach}

The qualitative researcher seeks to explore and understand the meaning of a phenomenon or experience, in this case, the perspectives of the students described above. This require more in-depth description than a study based on numerical data can provide. A qualitative approach was deemed appropriate for gathering this information, as it focuses on understanding the meaning of the phenomena. Husserl developed phenomenology as way of understanding the true nature of being, of understanding the 
nature and essence of an experience or phenomenon and this could be achieved by bracketing the researcher's, or inquirer's (outsider) perspective, prior knowledge, and possible bias through in-depth reflexivity (1970). The knower's, or insider's experience could then be accessed by the inquirer through a thorough description. Heidegger, Husserl's student, diverged from Husserl as he believed true understanding of a phenomenon or experience required more than a thorough description and that it was impossible for the inquirer to bracket all presuppositions or knowledge of the phenomenon. Understanding occurred if there was an interpretation of the description. This interpretation ensued as a result of the interaction of the inquirer and knower and developed phenomenology into a methodology (Heidegger, 1962) as well as a philosophical stance.

The use of a phenomenological methodology for collecting data allowed the student's lived experience of learning, which encompasses more than the classroom, to be given voice. (Moustakas, 1994). This method provided an opportunity to examine the learning experiences of students with a $\mathrm{CHC}$ and those involved within it, e.g., parents, teachers, schools, peers. To date, the lack of published studies in this area shows that chronically ill students in New Zealand have not had an opportunity to comment upon, much less describe, what is helping them in their learning environment. I used semi-structured digitally recorded interviews with individual students and focus groups to collect data as well as note keeping and recording my impressions immediately after interviews. Member checking occurred during the interviews and when they reviewed their transcribed interviews, when I sought further clarification to ensure I understood what they were sharing.

Interpretive Phenomenological Analysis (IPA) (Smith, 1995) was used to analysis the interviews given by the participants. This form of analysis enables the researcher to explore the meaning making the participant gives to the experience (the question being asked) and recognizes that the experience being discussed deserves more than mere description and should be interpreted in order to increase knowledge and awareness of this experience. It allowed me to explore the meaning making the participant gave to the experience of being an adolescent with a $\mathrm{CHC}$ in school through asking participants semistructured questions. 


\subsection{Researcher's Perspective}

Qualitative research acknowledges the active role the researcher plays within the interaction of researcher and participant and thus, it is important to acknowledge any bias or preconceived ideas the researcher holds. In this case, as a school teacher and a mother of two children who have CHCs, I had to acknowledge and reflexively set aside my experiences of what my daughters experienced when they were young adolescents as well as that of being a teacher with students who had CHCs. In my analysis of the data in my study, I also had to set aside my own personal experience of a CHC. I describe this further in Section 3.

\subsection{Significance of Study}

The number of young people with CHCs is rising in New Zealand (National Health Committee, 2007). Since both illness and treatment affect these students' in the cognitive, physical, and/or psychosocial domains, it is critical to determine how they are learning, what learning support is available, and how teachers can help mitigate these impacts upon students' learning success. To date, the lack of published studies in this area in New Zealand shows that students with $\mathrm{CHC}$ in New Zealand have not had the opportunity to comment upon, much less describe, what is helping them learn. The experiences of students with a $\mathrm{CHC}$ can provide further insight into what programs in place at school or individuals are providing these students to achieve learning success. Other studies in New Zealand have focused upon one, two, or, occasionally, three related CHCs whereas this study has a variety of CHCs and shows common threads students have experienced. Using phenomenology as a theoretical, methodological, and analytical tool enabled me to reach an understanding of the essence or heart of the students' experiences of learning when they have a CHC. Finally, this study was not guided by a deficit approach; semi-structured questions and prompts used were geared towards the positive in order to explore what has helped these young people in their learning experiences and contribute to the foundations of learning already in place in schools. This study enabled young people's voices in New Zealand schools to be heard and contributed to education, psychological, and health literature. 


\section{CHAPTER TWO \\ LITERATURE REVIEW OF CHRONIC ILLNESS AND \\ ADOLESCENTS}

\subsection{Introduction}

Adolescence is an important stage in human development during which rapid physiological, psychosocial, and cognitive changes occur (Ferguson \& Walker, 2014). During normative development, adolescents move from childhood to adolescence and from adolescence to emerging adulthood. Improved medical technology and research have led to more children surviving serious illnesses and diseases that once limited their lifespan (e.g., Bessel, 2001; Shiu, 2004; Wishnietsky \& Wishnietsky, 2004). A chronic health condition in this study, as discussed in Chapter 1, is a condition that lasts for 3 months or longer, requires medical attention, and has a significant impact upon an individual. This definition includes a health issue that results in limited strength or mobility, or impacts cognitively. In this study, chronic illness, chronic health condition, and chronic condition are interchangeable terms. Adolescents with a CHC must cope not only with the changes occurring during this developmental period of their lives, but with additional issues that make these transitions more difficult than it is for their healthy peers. Educators, school personnel, peers, and health providers provide some measure of support, either educationally or psychosocially, for the adolescent with a $\mathrm{CHC}$ and are part of the milieu of these students; it is informative to identify and understand recent research regarding the educational context for adolescent students with a $\mathrm{CHC}$.

\subsubsection{Literature Review Criteria}

For the following review, a literature search was conducted using Victoria University's database and included the following computerized databases: ELSEVIER, ERIC, Google Scholar Search, MEDLINE, ProQuest, PsycINFO, Wiley InterScience, and ProQuest. A range of keywords were used: ADHD, adolescent, adolescence, agency, Asperger's syndrome, autism spectrum disorder (ASD), asthma, medical model of illness, biopsychosocial model, cancer, cerebral palsy, Crohn's disease, chronic health condition, chronic illness, development, diabetes, disability, eczema, education, educators, epilepsy, 
family, health, identity, impact, issues, Māori, migraines, New Zealand, nurse, Pasifika, peer, phenomenology, psychosocial, qualitative, secondary, social model of disability, spina bifida, school, teachers, traumatic brain injury, traumatic head injury, voice, young people, youth.

Criteria for selection of articles consisted of the following:

1. Discussion of illness or treatment effects on the adolescent's development, education, family, health care, and/or quality of life.

2. Adolescent, health care provider, parent, peer, nurse, psychologist, or school counsellor, and teacher points of view.

3. Medical discussion of the impact of an illness and/or its treatment on the cognitive or physical and/or psychosocial abilities or development of adolescents.

4. Most articles selected were published after 1990 in order to be current. Selection of articles prior to this date occurred if subject matter pertained to New Zealand or was often cited in other studies.

5. Articles were peer reviewed, published in scholarly journals, and in English.

6. Books and articles discussing theoretical perspectives in understanding CHC were included. National surveys regarding adolescent health in New Zealand were also sought.

7. Exclusion search terms criteria were adult, child*, dementia, elderly, infant*, mental illness, middle age*, mid-life, and primary.

Wanting to discover or explore a particular phenomenon can present several challenges to the researcher. This chapter sets the stage for my research by a description of what recent research has revealed regarding youth and CHCs through a review of quantitative, qualitative studies as well as literature reviews and meta-analyses. The approach towards illness that a researcher uses may influence how the research is conducted. Three approaches which may be used when conducting research with adolescents with a $\mathrm{CHC}$ are the medical model, the social model of disability, and the biopsychosocial model of illness and these are explained within this chapter. Knowledge of the developmental changes which occur during adolescence and how CHCs impact this critical life stage is essential in order to have a more informed understanding of what these 
young people may be experiencing. I introduce and briefly describe the possible biological, cognitive, and psychosocial effects of these $\mathrm{CHCs}$ on the development of adolescents. Complete analytical descriptions of CHCs found in New Zealand are not necessary within the confines of this study as the focus was these adolescents' experiences in learning when they have a CHC and not the CHC itself. Family and ethnic factors are identified as these contextual factors can also influence an adolescent's attitude towards the CHC. Subsequently, this literature review specifically addresses studies regarding absenteeism, educators, and health care providers, including nurses, and how these factors and individuals may affect the adolescent student's learning experience. It was important to look at research regarding $\mathrm{CHCs}$ and young people that has occurred within New Zealand as this provided significant contextual information and this study occurred in New Zealand. Background information of the particular topic, in this case, New Zealand adolescents with a chronic health condition and education, was important to ensure I understood not only how a CHC may physically affect a teenager, but what material was available regarding their education and the impact of a $\mathrm{CHC}$ on their learning.

\subsection{Models of Illness Used in Research}

\subsubsection{Introduction}

The process of development for an adolescent is a time of swift and complicated transformations in the cognitive, physical, and emotional domains. When a CHC is present, this process is disrupted and made more complex. Researchers studying CHCs and adolescents may approach the topic from a medical model, the social model of disability, or the biopsychosocial model. In the medical model, the focus is upon the individual pathological changes within the individual's body caused by disease or health and how these changes impact cognitive, physical, and behavioral functions (Halfon, Houtrow, Larson, \& Newacheck, 2012). The social model of disability considers the context of the individual and how the individual interacts within this context (Quick, 2013), taking into account the role of how environment, "practices of inclusion and exclusion, and discrimination" impact the individual (Halfon et al., 2012, p. 16). The biopsychosocial model is more complex; it includes the physiological changes as well as the roles of environment (the socioeconomic, cultural, familial, and environmental 
circumstances of the individual), and the personal contexts of the individual, such as thoughts, emotions, and behavior. In this model, these combined factors influence how the $\mathrm{CHC}$ can impact the person. By incorporating the environmental, cultural, biological and cognitive characteristics of the individual, the biopsychosocial model provides a picture that is holistic and encompassing (O'Donohue \& Tolle, 2009; Williams, Holmbeck, \& Greenley, 2002). It is beyond the scope of this study to expound the various complexities of each model. Rather, it is my intent to present a brief description of these models and how they may be used within research of adolescents with a CHC.

\subsubsection{Biomedical Model}

The biomedical (or medical) model directs attention to what the adolescent cannot do because of the illness or medical condition. Research regarding $\mathrm{CHCs}$ in adolescents have used the medical model of illness to explain the psychosocial impact of the CHC upon the adolescent and presents the $\mathrm{CHC}$ as a deficit or issue that needs to be resolved (Abrams, Hazen, \& Penson, 2007; Polvere, 2014). Doctors are trained to diagnose, via the description of symptoms and subsequent testing, what is wrong [my italics] with the patient; the illness or medical condition is something negative and physiological that happens to the individual and the doctor must identify it correctly and prescribe a treatment to make the condition disappear or alleviate the symptoms. Although there is acknowledgement that $\mathrm{CHC}$ can affect the psychosocial functions of an individual, it does not take into account how socioeconomic, social support, health resources, or cultural factors can affect adaptability to a CHC. Quite often it has been used in quantitative studies of adolescents with a CHC to describe its impact on the quality of life (QOL) of these young people (Baca, Vickrey, Vasser, \& Berg, 2011; Bauld, Anderson, \& Arnold, 1998; Hampel \& Petermann, 2006). The primary focus is upon the person and the biological dysfunction, which may be treated by or with medical interventions, with no real emphasis on the environment (Richter, 1999; Halfon et al., 2012).

\subsubsection{Social Model of Disability}

The social model of disability, on the contrary, directs attention to the environment and society and the 'lack of fit' between the individual with impairments and the surrounding environment (Halfon et al., 2012, Simmons, 2010). The social model of 
disability focuses upon the idea that a $\mathrm{CHC}$ is a social construct and economic and social inequalities imposed upon those with a $\mathrm{CC}$ or disability form barriers to good health and good health outcomes (Bury, 1991; Jackson, 2012; Simmons, 2010). It arose in the latter part of the twentieth century as a movement, or political instrument of the disabled who felt cast out and "excluded from and denied access to many of the key sites of power and privilege" (Huge \& Paterson, 1997, p. 325), not only in the political realm but in places such as schools or shopping centers. It holds that society must change its view of disability as this disenfranchises those with disabilities and creates barriers for those who are ill and accommodate those with impairments (Simmons, 2010). The impetus and role of the social model of disability is not only to be used as a research tool, but to provide "an adequate theoretical basis for emancipatory politics" (Huges \& Paterson, 1997, p. 337). It has been used in disability research, and it is a viable, useful instrument shedding light on the need for legislation regarding access, and employment for those who are impaired (Simmons, 2010). This is seen as an achievable goal that will benefit society as a whole, especially those who, due to physical or mental impairments cannot currently fully participate because of the barriers in place (Halfon et al, 2012; Huges \& Paterson, 1997).

\subsubsection{Biopsychosocial Model}

The strength of the biopsychosocial (BPS) model of illness in research is in its incorporation of the elements that surround the individual with a $\mathrm{CHC}$ and brings together the medical and social models of illness and disability (Warner \& Hauser, 2009; White, Driver, \& Warren, 2008). This model takes into consideration the biological, cognitive, and/or other external or internal variables such as family, health resources, health behaviours, social support, and cultural and socioeconomical influences of the individual with a CHC and his or her environment (Dashiff, McCaleb, \& Cull, 2006; Eckert, Loffredo, \& O'Connor, 2009; Levy et al., 2006; Williams et al., 2002). The BPS approach has been used in research of rehabilitation of people with disabilities (Edwards, Patrick,

\& Topolski, 2010; White et al., 2008) as well as in adolescent health psychology (i.e., Williams et al., 2002), taking into account the constant interaction between the CHC and the individual. For example, for the teenager with diabetes, elevated blood sugar due to poor control can delay pubertal growth. Conversely, the insulin treatment necessary to control blood sugar can also delay pubertal growth (Eckert et al., 2009). Each CHC has 
its own characteristics and the diagnosis, symptoms, and treatment can vary dependent upon the individual. The severity or the frequency and treatment of the $\mathrm{CHC}$ can be dependent upon a variety of factors. Does it have acute episodes (epilepsy, asthma)? Does it require surgery or chemotherapy (cancer) or does it require constant monitoring and adjustments to treatment (e.g., blood sugar in diabetes requires adjustment to dosage of insulin) (La Greca \& Mackey, 2009; Warner \& Hauser, 2009)? WHO’s discussion paper on adolescents with chronic conditions pointed out that type 1 diabetes varied among richer and poorer communities within countries and that there were higher incidences of CHCs in less privileged, impoverished areas than in those with higher incomes (Suris, Michaud, \& Viner, 2004). Other considerations in CHC research has involved cultural, community, church, and family networks which can provide emotional support for the adolescent and his family, thus the mores of these groups also affect how a CHC is seen and treated (Ministry of Health, 2008a, 2008b). Within the secondary school context, knowledge of how the CHC may impact the student physically, emotionally, and/or cognitively during adolescent development can assist parents and teachers in providing a supportive learning environment for the teenager with a $\mathrm{CHC}$.

McLaren posits that Engel's biopsychosocial model is neither a model nor a theory and this is because "unless there is an integrating theory already in place, gathering biological, psychological and sociological data about people will only yield scattered lumps of information that do not relate to each other in any coherent sense" (McLaren, 1998, p. 91). He states the theory does not work as a theory although it is used for teaching purposes in psychiatry as it "legitimized the concept of talking to people as people" (p. 91). Herman cedes that the BPS model is difficult to implement into general practice as it is time-consuming and can be cumbersome for doctors attempting to need the needs of office practice and patient care (Herman, 2005). There is considerable evidence, however, that research has found the biopsychosocial model to be useful (e.g., Dashiff et al., 2006; Edwards et al., 2010; Michaud et al., 2007; Warner \& Hauser, 2009; White, Driver, \& Warren, 2008). 


\subsubsection{Summary of Models}

In summation, the medical model in research can provide biological information as to how the $\mathrm{CHC}$ impacts or can impact development and possible psychosocial effects of the $\mathrm{CHC}$ although it approaches $\mathrm{CHC}$ as a deficit within the individual, needing to be repaired. The social model of disability takes into account cultural, societal, and socioeconomic factors as to how a CHC is approached but stresses that disability is socially produced. Although it is used in some disability research, it is used primarily to generate societal change. The biopsychosocial model of illness incorporates a wider variety of factors including the biological, cognitive, and societal influences that occur within and around the individual and has been often used in international CHC research as it considers "the role that an individual's biological, psychological, and social factors play" (White et al., 2008, p. 9) within the context of the individual's CHC. Many researchers, when referring to what model of illness they are using, have focused upon the biopsychosocial model as an approach to understanding adolescents and how CHCs affect them (e.g., Dashiff et al., 2006; Eckert et al., 2009; Levy et al., 2006; Michaud et al., 2007). However, there are quantitative and qualitative studies involving adolescents and CHCs which do not discuss models of illness (Berntsson, Berg, Brydolf, \& Hellström, 2006; Dickinson \& O’Reilly, 2004; Erickson et al., 2014; Lynch \& Spence, 2007).

In this study, I seek to understand the experiences of adolescents' learning when

they have a CHC. An understanding of what is occurring developmentally is necessary as is some understanding of the CHCs themselves and how these may affect the teenager. As their contexts in learning are school and home, it is valuable if I have some knowledge of how school and family contexts may affect adolescents with a CHC. The biopsychosocial approach has been used in research of adolescents and CHCs and, as it can take into account a wide variety of factors, I consider it a useful approach in this research. I disagree with McLaren's position that taking into account biological, psychological and/or sociological data about people will provide unrelated information. I suggest, as others have before (e.g., Edwards et al., 2010; White et al., 2008), that these factors are interrelated and, in this study, can have a definite effect on how an adolescent with CHC learns. 


\subsection{Literature Review}

\subsubsection{Reviews}

Much of the literature on CHCs and adolescents or adolescents and children is situated in international studies with a large number of studies occurring in the United States. The majority of studies, literature reviews, and meta-analyses were, as a rule, found in medical, psychological, nursing, and disability journals. Finding studies within education journals was a formidable task with some studies found in journals such as the Journal of School Health (e.g., Hayes-Bohn and colleagues' study of diabetes management in school, 2004) or Childhood Education (e.g., Frieman and Settel's discussion on what classroom teachers should know about children with CHC, 1994).

Literature reviews often used a biopsychosocial model when reviewing other studies (Levy et al., 2006; Kearney, 2007; Kelly, Zebracki, Holmbeck, \& Gershenson, 2008). Literature or systematic reviews frequently emphasized illness impact upon adolescents with stress on a particular issue such as, for example, psychosocial aspects, sleep disturbance effects, or social competence and did not include discussion of illness models (e. g., Abrams et al., 2007; Camfferman, Kennedy, Gold, Martin, \& Lushington, 2010; Martinez, Smith Carter, \& Legato, 2011). Abrams and colleagues' (2007) examined research concerned with how adolescents' experiences with cancer affected their psychosocial development. They discussed studies that explored educational issues for adolescents such as re-entry to school and found programs exist that offer education and assistance in support for teachers, parents, and young people, but did not discuss any studies regarding how these adolescents experienced learning. The majority of studies in Camfferman et al.'s review explored sleep disturbance effects from eczema primarily on children under the age of 12 years, although there were studies on children from ages 5 to 16 years, 13 to 14 years, and under 18 years old (2010). They found sleep disturbance associated with problematic behavior as well as neurocognitive defects and reduced quality of life for these children. Martinez et al. (2011) conducted a meta-analysis of children with a $\mathrm{CHC}$ regarding their social competence. They focused upon empirical studies of participants below the age of 18 years and with a $\mathrm{CHC}$, which also included obesity, and considered social competence to be composed of social skills, social 
performance and social adjustment. These studies used self-reports and included parent, teacher, and peer reports and concluded further research in how social competence is measured is needed and that children with a $\mathrm{CHC}$ need social skills programs to meet any deficit in their competency. How social performance or adjustment impacted their education was not addressed.

In regard to health, adolescents, and education within literature reviews, topics varied from a broad examination of CHCs impact on an issue such as absenteeism or school refusal behaviours to a review of interventions for students with autism spectrum disorders (e.g., Kearney, 2008; Machalicek, O’Reilly, Beretvas, Sigafoos, \& Lancioni, 2007). Kearney's review on absenteeism and school refusal behavior used a biopsychosocial approach including studies that explored $\mathrm{CHCs}$, contextual risk factors such as homelessness, school violence, or parental involvement. Looking at intervention programs, he included programs involving medical, community, and school-based professionals. Machalicek et al. (2007) examined interventions for students with ASD who exhibited challenging behavior in classrooms, finding teachers were positively involved in implementing these interventions within quite busy classroom settings.

\subsubsection{Adolescent age factor}

Reviews and studies either of adolescents or including adolescents vary greatly regarding age range (e.g., Camfferman et al., 2010; Kearney, 2007; Machalicek et al., 2007). For example, Machalicek et al.'s (2007) review looked at interventions used with children aged 3 to 21 years, while Kearney's (2008) review of school absenteeism and school refusal behavior focused on ages 5 to 17 years. This is an important point as many reviews and studies, when looking at a $\mathrm{CHC}$ in children include a wide range of ages and do not always attend to the different developmental stages which can impact the physical, cognitive, and psychosocial domains of the child. In their literature review examining the challenges for adolescents with a CHC, Sawyer, Drew, Yeo, and Britto (2007) specifically address the difficulty of how surveys, studies, and/or reviews do not recognize adolescence as a separate developmental period "by grouping adolescents with children (0 to 14 years) or with adults (15 to 34 years)" (p. 1481). 
One difficulty that may arise due to age variability and not recognizing adolescent development as a separate period, is in examining compliance in children. For example, primary school children may not have an issue with treatment compliance, as their parents are responsible for ensuring this. Dashiff et al. (2006) collected data from adolescents aged between 11 to 15 years old with type 1 diabetes (T1D) regarding coping strategies, self-care, and compliance. They found self-care decreased as adolescents became older. An adolescent with T1D who is 11 years old is more likely to be monitored and assisted with treatment compliance by parental oversight than one who is 15 years old and who is seeking more independence from parents as part of that developmental stage. When the age range varies significantly such as the 2010 Camfferman and colleagues study, while generalities may be found, there may also be other limitations. For example, the Camfferman and colleagues' (2010) study of sleep and neurocognitive function in children with eczema looked at 6 years old to 16 years old participants. A possible limitation of Camfferman and colleagues (2010) study is that neurocognitive function in children who are 6 years old will not be the same as those who are 16 years old due to growth in cognitive and developmental abilities, although they may experience similar issues with symptoms. Thus, sleep and neurocognitive function may have more effect on adolescent individuals than those who are in primary school. A major difficulty, which can occur when there is such a wide range of ages in adolescent research, is that this inconsistency makes it difficult to find commonalities that can help inform health or school policy regarding adolescents and $\mathrm{CHC}$.

\subsubsection{Quantitative and Qualitative Studies of Adolescents with CHC}

Most quantitative and qualitative studies were illness specific, such as studies on either children or adolescents with ASD, asthma, cancer, Crohn's disease, diabetes, epilepsy, traumatic head injuries and focused upon a specific aspect of the illness, such as quality of life or the psychosocial impact of the particular CHC although they did not discuss an illness model (Armstrong, 2006; Brown et al., 2008; Cheung \& Wirrell, 2006; Hohepa et al., 2004; McGhan, 2002; Shaw \& McCabe, 2008; Simpson, Mundschenk, \& Heflin, 2011). Simpson at al. (2011) discussed improving the education of students with ASD while others, such as Shaw and McCabe (2008), studied CHC and specific issues 
such as reintegration to school after a lengthy absence and the supports students require, or psychosocial issues, for example, in adolescents with cancer (Armstrong, 2006).

Quantitative methodologies have been used to research adolescent perspectives regarding specific illness impact on their quality of life, psychosocial issues, family, or transition into adulthood (Baca et al., 2011; Edwards et al., 2003) or its impact on compliance or social competency (Dashiff et al., 2006; Kyngäs, 2000; Meijer et al., 2002). Baca et al. (2011) examined the impact of seizure frequency and seizure remission in relation to quality of life for 613 children with epilepsy using a questionnaire with a nine year follow-up and including parent report. The average age of the children at the beginning of the study was 4.4 years old, however, at the nine year follow-up, some participants were 18 years old. Edwards and his colleagues (2003) used a BPS approach to conduct a study of adolescents, aged 11 to 18 years, with conditions these young people perceived as causing limitations in their activities. These conditions varied from asthma to vision or hearing difficulties, spina bifida, injury, or mental retardation to name a few. Edwards et al. (2003) found that 46 percent of the adolescents felt they missed out on activities and experienced stigma in school although policies were in place to prevent these. In their study using the medical model, Cheung and Wirrel (2006) examined the viewpoints of adolescents from 13 to 18 years, finding that epilepsy was seen by teenagers without it as having a more negative impact on adolescents than other CHCs. Meijer and colleagues (2002) also used a BPS approach in exploring how coping styles influenced psychosocial adjustment in 84 adolescents aged 13 to 16 years old who had a $\mathrm{CHC}$ (asthma, cystic fibrosis, eczema, or juvenile chronic arthritis). These studies of different psychosocial variables such as social activities, self-esteem, social anxiety and social skills found that these were instrumental and directly related to coping styles and psychosocial functioning and adjustment. The exploration of young people's perspectives when they have a $\mathrm{CHC}$ on their quality of life or other psychosocial issues can contribute to parental, teacher, counsellor or health provider knowledge in assisting these adolescents as they transition from childhood to emerging adulthood.

Adolescents spend at least six hours a day at school and as such, it is helpful to know what are their experiences in learning, specifically if or how the CHC impacts upon the young person's education (Shiu, 2001; Thies, 1998). In this regard, many studies 
emphasized parent, teacher, teacher-parent perspectives or parent-health provider perspectives (Olson, Seidler, Goodman, Gaelic, \& Nordgren, 2004; Wodrich \& Cunningham, 2008; Shiu, 2004). Often findings showed that teachers had limited information or knowledge regarding how $\mathrm{CHC}$ affected student learning. For example, Olson and colleagues (2004) looked at school professionals' perceptions of CHC impact in a quantitative study in 23 elementary schools. These professionals (teachers and other staff) within the schools had specific concerns regarding some diseases and issues, such as adequate training for teachers, but overall these participants believed there was little impact of CHCs on students' learning abilities. Wodrich and Spencer (2007) investigated how school psychologists assisted educators with accommodations for children with CHCs. They found half of their sample $(\mathrm{N}=50)$ needed and used special services within school and while teachers were willing to make classroom accommodations, they had limited information regarding what accommodations were appropriate. A year later, Wodrich (2008) published that the teachers in the previous study did not associate poor academic performance with health. Shiu (2004) examined parent and teacher perspectives in New South Wales regarding educational services for students with CHC. She learnt participants often emphasized the need for resources such as additional teacher and teacher aide time to assist students to catch up on missed classroom instruction. She also reported participants stressed training was needed regarding how to teach children with a CHC. These studies all point to a disconnect of necessary information and training reaching those who clearly need this knowledge: teachers entrusted with educating children.

Fewer studies investigated adolescents' perspectives of their $\mathrm{CHC}$ and education (e.g., McNelis, Johnson, Huberty, \& Austin, 2005; Shiu, 2004). Shiu's (2004) study cited above found the participants expressed concern regarding children feeling isolated from peers due to absence or inability to participate fully in activities. Further investigation of what these students felt or experienced in this regard could have yielded information allowing the schools to assist or accommodate these students. McNelis and her colleagues (2005) identified a pattern of poorer academic achievement associated with epileptic seizure frequency in their quantitative study, of children aged 8 to 15 years. While this study was helpful in examining students with epilepsy, there were many variables present which were not very helpful in addressing adolescents and academic achievement 
specifically. Teacher and parental report were included and the difference in age of the children as well as seizure frequency and onset were some of the variables influencing data results. The importance, however, of the finding of academic achievement being significantly associated with seizure severity is critical in raising teacher awareness of achievement in school for students with a seizure disorder.

Several qualitative studies have taken a phenomenological approach to explore students' experiences of particular illnesses, for example, coping with conditions such as ASD, T1D, and cancer (Huws \& Jones, 2008; Schur, Gamsu, \& Barley, 1999; Wu, Chin, Haase, \& Chen, 2009). Huws and Jones used IPA to examine the experiences of nine adolescents aged 16 to 21 years, diagnosed with autism, and found that some individuals felt it was beneficial as it explained their previous experiences and behavior. Others felt being diagnosed with autism was harmful and felt they would be perceived with prejudice or discrimination and the label would set them apart from their peers as being different. Once informed, they experienced a sense of loss of self although the diagnosis explained behavioral patterns (Huws \& Jones, 2008). Huws and Jones (2008) found that, whether the diagnosis was seen as beneficial or negatively, the young people formed a new identity which incorporated the ASD diagnosis. However, the adolescents did not want to be connected to the label of autism. Schur and colleagues (1999) were interested in adolescents' perspectives of coping with diabetes. They interviewed eight adolescents aged 16 to 22 years. The young people felt distress when diagnosed with diabetes, but developed coping skills as they came to terms with having it. They, too, felt that having diabetes set them apart from their peers. Wu and colleagues (2009) interviewed ten adolescents (12 to 18 years) who received chemotherapy treatment. While the young people all felt pain and needed emotional help from their parents to bear it, Schur et al. (1999) found these students were resilient and used hope in the future to cope with their pain and experience. These studies did not specifically mention a model of illness looking at the physiological and psychological factors that impacted young people's coping with and adapting to a $\mathrm{CHC}$.

Other researchers have also used a phenomenological approach to increase understanding in the perceived gap of knowledge of adolescents' experiences with a CHC, but have not included a model of illness (Lightfoot, Wright, \& Sloper, 1999; Lynch \& 
Spence, 2007; Meuleners, Binns, Lee, \& Lower, 2002; Wang, Brown, \& Horner, 2010). Lightfoot and colleagues (1999) interviewed 33 high school students in the United Kingdom with a variety of $\mathrm{CHCs}$ and looked at how $\mathrm{CHCs}$ impacted school life. Students considered school attendance a high priority and wanted their health professionals to assist them in maximizing school attendance with minimal disruption from either their $\mathrm{CHC}$ or its treatment. Wang et al. (2010) used a phenomenological approach in Taiwan investigating adolescents, aged 12 to 16 years, with T1D and their school experiences. Students said they wanted to self-manage, assume the responsibility of self-care upon themselves, and not be either a burden to their parents or different from their peers, regardless of negative and positive experiences. In the Meuleners et al. (2002) Delphi study, teachers', parents', and health professionals' perspectives were sought regarding what aspects of QOL were important for a young person with a CHC. Participants felt adolescent attitude, family relationships, and peer relations were very important for young people with a $\mathrm{CHC}$, but overall the study found that teachers were not well informed regarding $\mathrm{CHC}$ and adolescents. In these researchers' view, using phenomenology enabled students to share experiences through the use of descriptive narrative, allowing the researcher to gain the 'insider's' perspective of these experiences. These studies did not mention an illness approach or model, but they did show the biological impact of the $\mathrm{CHC}$ and contextual factors were related.

\subsubsection{Adolescent voice}

Sartain, Clarke, and Heyman (2000) studied children's perceptions of their CHC and stressed the important factor that if we are to understand how they experience a CHC, we must be prepared to listen to their voices. In their discussion, they touch upon the marginalization of some members of society and the lack of their voice in discussions regarding their circumstance. Sartain and colleagues (2000) found their participants, regardless of their age, were not only capable of describing their experience, but that hearing their voice was important and could be used to aid service providers in meeting their needs. Other studies support this finding. Mandel and Qazilbash (2005) examined a health care service delivery program for youth. They specifically sought youths' voices in the firm belief that those who benefit from services should have a voice in designing and critiquing said services. They found that prior to their study, needed services had 
been overlooked by staff and administration. Accessing and listening to young people's voices enabled the program to implement changes needed to meet the health needs of their student population (Mandel \& Qazilbash, 2005). In 2004, Smith, Gaffney, and Nairn conducted a postal study of 821 year 11 New Zealand students and 438 staff regarding student health rights in school. An important point the study made is that "children and young people are active, competent agents, who are able to articulate their needs and assess the effectiveness of their school environment in promoting health" (p. 95). They also found that the physical and psychosocial well-being at school was closely related to academic achievement. When students perceived they were able to confide and trust in their teachers or other staff in the school environment, they felt supported and more able to focus on academic issues (Smith et al., 2004).

A strong argument promoting student voice is that research focused on problems constructed by adult lenses can overlook the real-life experiences of the adolescents (Wong, Zimmerman, \& Parker, 2010). O’Neil (2014) and Sartain and colleagues (2000) support this view; Sartain and colleagues (2000) suggested that a possible explanation for the adult lens may be society's concern of protecting those who are younger. But they posit this view makes the child's voice passive and delegitimizes the important and vital information that can contribute to research regarding children and CHCs (Sartain et al., 2000). O'Neil (2014) in promoting children's voices in educational research, discussed the ethical considerations of their involvement in research and advocated the need of researchers in this area to be continually reflexive and engage with young people as “competent social actors" (p. 229). Mandel and Qazibash (2005) also promote the need and importance of listening and heeding young people's voices. Young people with a $\mathrm{CHC}$ have firsthand knowledge of how their $\mathrm{CHC}$ affects them. By engaging and listening to adolescent voices in research, we can continue to develop programs and policies that can best serve their needs (Mandel \& Qazibash, 2005) not only in health centers, but in schools as well. It is important to increase children's' agency and voice in educational research precisely because "education is an integral feature of children's social worlds" (p. 229). Eiser (1990) puts forward that those with a CHC are not a homogenous group; it can be difficult to find strategies to help them all. I postulate it is helpful to discover how learning is affected amongst a group of adolescents with diverse CHCs to find 
commonalities. A positive step in this direction is to hear the adolescents tell us directly what is helping them learn to assist in improving teacher training and awareness of the impact of CHCs on learning.

Literature reviews, quantitative, and qualitative studies exploring adolescents and CHCs frequently examine specific CHCS and the impact these have upon adolescents, either physically or psychosocially. Adolescent development is a period of marked physical, cognitive, and emotional growth which can influence the course of a CHC or its treatment as well as, conversely, the $\mathrm{CHC}$ can influence the rate of physical, cognitive, and/or emotional maturation of the adolescent. Studies specifically focused on adolescents provide useful information of adolescents and CHCs. They recognize young people undergoing the developmental stage of adolescence have a greater cognitive and psychosocial understanding of themselves and a $\mathrm{CHC}$ than younger children and can provide helpful insights in how CHCs affect them. This research is helpful for professionals working with adolescents who have CHCs as it broadens the knowledge base and can improve programs, interventions, and policies in providing health care or education. Following is a description of normative adolescent development and how a CHC may affect this development.

\subsection{How Chronic Health Conditions Impact Adolescent Development}

\subsubsection{Introduction}

Adolescence is a rapid period of growth in which the individual progresses from childhood to adolescence and from adolescence to emerging adulthood (O'Donohue \& Tolle, 2009; Schlozman, 2002). As seen above, literature regarding the exact time span of adolescence varies but for this discussion regarding development, adolescence is considered to be the ages between 10 and 21 years old (Eckert et al., 2009). During adolescence, the normative developmental changes occur in all three domains: cognitively, physiologically, and emotionally. Having a $\mathrm{CHC}$ presents additional challenges for these adolescents as there are issues they face that their peers without a $\mathrm{CHC}$ do not. When an adolescent has a CHC, additional considerations which must be taken into account, such as if and how the CHC or its treatment affects these changes. 
Some issues may primarily occur in one domain, but there can be considerable overlap into other areas, as will be demonstrated.

If the CHC was present during the young person's childhood, he or she must endure adjustments to the treatment regime as he or she grows physiologically (ReedKnight, Lewis, \& Blount, 2011; Simeonsson, McMillen, \& Huntington, 2002). Some CHCs affect pubertal development such as Crohn's Disease or Addison's disease (ReedKnight et al., 2011). Treatment and modifications can affect the cognitive and, possibly, emotional domains until the proper medication and/or dosage are found. Some treatments can have adverse side effects (chemotherapy for cancer, prednisone for asthma or eczema). The impact of illness and treatment differ in symptoms and management and can be a source of contention and challenge for the young person. Some illnesses are highly visible (eczema, cancer) while others are less so (Type 1 diabetes, asthma) and may remit or relapse unpredictably (Shiu, 2001). These issues can affect the adolescent's selfconcept during a period when the young person does not want to stand out negatively from peers. This section addresses how a CHC can impact developmentally in the different domains.

\subsubsection{Physical}

Physically, adolescents undergo puberty as well as physiologically growing taller and gaining weight more rapidly than at any other time since infancy. Pubertal changes varysome adolescents may mature sooner than others and females generally mature faster than males (Eckart et al., 2009; Simeonsson et al., 2002). Puberty signals the development of secondary sexual characteristics such as breast development and menarche in girls, the growth of pubic hair, and phallic growth, voice changes, and facial hair growth in boys (Eckert et al., 2009). During adolescence, emphasis is placed on body image and appearance. Body parts do not all grow at the same pace and a rapid weight gain can occur, adding to teenagers possibly feeling more sensitive about their body or weight (Huebner, 2009; Jackson, 2012). During this period, adolescents do not want to be more conspicuous than their peers and physically developing faster or slower than their peers can make them feel different. 
When a $\mathrm{CHC}$ is present during adolescence, these normative physiological and pubertal developments can be negatively impacted by a CHC such as diabetes or Crohn's disease (Eckert et al., 2009; La Greca \& Mackay, 2009; Reed-Knight et al., 2011). When an adolescent has a CHC (diagnosed when the teenager was younger) or is medically presenting symptoms of a $\mathrm{CHC}$, diagnosis and treatment can be more difficult due to the physical and hormonal changes occurring during this time (Dobbie \& Mellor, 2008; Eckert at al., 2009). During pubertal development, insulin-like growth factors involved with growth "may be impaired in children with diabetes to their likeness with insulin used for treating diabetes" (Eckert et al., 2009, p. 33). This can be managed with proper metabolic (glycemic) control, however, it is not uncommon for young girls who struggle with body image issues to skip a treatment (La Greca \& Mackay, 2009). Poor glycemic control can interfere with continued pubertal development (Eckert et al., 2009; La Greca \& Mackay, 2009). Puberty can impact in other ways. Engel (2009) points out that once girls have reached puberty, it is not unusual for them to have migraines, which can become chronic during menstruation. Early onset (or precocious) puberty can occur in children with spina bifida and/or cerebral palsy (Murphy \& Young, 2005). Pubertal development and bone growth can be delayed by the long-term use of steroids to treat severe asthma, eczema, and inflammatory bowel disease (IBD) (Mushtaq \& Ahmed, 2002; Quick, 2013; Warrington \& Bostwick, 2006).

A CHC can not only affect pubertal development, but also have other physical effects (Michaud et al., 2007; Sawyer et al., 2007). Sleep deprivation, fatigue, and pain are some of the biological effects incurred by chronic illnesses (Shaw \& McCabe, 2008). Adolescents require more sleep than when younger (Mitru, Millrood, \& Mateika, 2002). Grigg-Damberger (2004) found teenagers need about nine and a half hours of sleep daily which provide the body time for the internal mechanisms to work. In their review, Mitru and colleagues (2002) discuss how sleep impacts learning and behavior in adolescents contend sleep deprivation can cause a loss of cognitive efficiency as well as a loss in the ability to focus. More recently, Vallido, Peters, O’Brien, and Jackson (2009) analyzed studies related to adolescence and sleep and found studies showing reduced academic performance and a lack of ability to concentrate. Eczema, a common, inflammatory skin condition, affects the sleep cycle with nocturnal wakefulness from intense scratching 
and pain (Camfferman, Kennedy, Gold, Martin, et al., 2010; Camfferman, Kennedy, Gold, Simpson, \& Lushington, 2013; Gill \& Coad, 2007). Asthmatics can have difficulty sleeping resulting in daytime tiredness (Li, Huang, Thompson, Tuli, Huang, De Walk et al., 2014). An adolescent with asthma may go to school with a general feeling of malaise but not be sick enough to warrant staying at home (Gill \& Goad, 2007). Tiredness can lead to an inability to concentrate, making learning difficult. The negative impact of a $\mathrm{CHC}$ on sleep can cause issues in other areas. School performance can suffer as well as social interaction. It is problematic to be with others or learn when a young person has difficulty paying attention and feels sleepy throughout the day (Rhee, Fairbanks, \& Butz, 2014).

A combination of sleep deprivation, pain from a $\mathrm{CHC}$ such as eczema or IBD, and the general feeling of malaise result in poorer school performance (Vallido et al., 2009). Students with cerebral palsy, Crohn's disease, migraines, or who have suffered a traumatic head injury (THI) can, at times, have unbearable pain requiring the individual to disengage from others and seek relief (Engel, 2009; Helvig \& Minick, 2013; Powers, Patton, Hommel, \& Hershey, 2003; Reed-Knight et al., 2011). Studies show that adolescents who suffer from migraines experience much the same psychological, physical, and social effects other youth experience with a $\mathrm{CHC}$ such as pain, depression or anxiety, or absenteeism which affects friendships and peer relationships, and can result in decreased school performance (Engel, 2009; Helvig \& Minick, 2013).

The diagnosis of the illness can be a lengthy process with possible misdiagnosis, tests involving blood work, MRI's, x-rays, hospital stays, and accordingly, coping with the illness can be a struggle (Dobbie \& Mellor, 2008; Thies, 1999). The illness can impose various limitations - for example, dietary measures may be needed for diabetes and physical exertions may be limited for students with asthma or epilepsy. Physical limitations can mean less time with peers or friends, and dietary measures or taking the time to test blood glucose may prove to be too difficult for adolescents with diabetes to adhere to in order to be with friends (Edwards et al., 2003). Type 1 diabetes (T1D) requires constant self-observation-finger pricking several times a day to check blood sugar, calculating and adjusting insulin injections dependent upon blood sugar numbers, and watching food intake (Eckert et al., 2009). Adolescents with epilepsy may have to 
take daily medication twice or three times a day and may have limitations on what sports or activities they can participate in or may need someone with them when participating (Kyngäs, 2000). Students with cancer or spina bifida (SB) may find activities are limited for a variety of reasons, for example, students find themselves fatigued or ill from chemotherapy or radiation, or the teenager may feel he or she cannot participate due to his or her own physical limitations (Sawin et al., 2003).

Chronic health conditions or treatments can have symptoms that can cause the adolescent to stand out during a developmental period when emphasis is placed on body image and appearance (Krueger \& Kendall, 2001; Saunders, 2014). Difficulties with bladder and bowel control from CHCs such as Crohn's disease or cerebral palsy can have a detrimental effect on adolescents who are very self-conscious and do not wish to be distinctive from their peers (Rose \& Holmbeck, 2007; Saunders, 2014). The severity of Crohn's disease, with the accompanying odor and bowel control issues can affect the teenager feeling ashamed and refraining from being with their friends (Saunders, 2014), affecting socialization. The use of a crutch, braces, or a wheelchair is not uncommon if $\mathrm{CP}$ has affected the arms or legs. Some adolescents are unwilling to identify themselves as having a $\mathrm{CHC}$ because they consider themselves normal and not disabled; they did not see themselves as any different from their peers (Boice, 1998). Others worry that a physical manifestation of their illness may negatively affect their peers' opinions (Saunders, 2014). For example, those with ADHD may have a lower self-concept based upon receiving negative reactions when ADHD typical behavior such as hyperactivity, increased impulsivity, and aggression, associated with negative behavior and symptomatic of ADHD, are displayed (Krueger \& Kendall, 2001). They may, then, prefer not to share the diagnosis.

Some illnesses require a complexity of treatment, such as surgery and chemotherapy for cancer, and this can present another difficulty with development in the psychosocial domain (Armstrong, 2006). An adolescent undergoing treatment for cancer is likely to miss more school and leisure time with friends than his or her healthy peers. Physically, hair and weight loss are common side effects (Abrams et al., 2007; Grinyer, 2007). Individuals who are prescribed corticosteroids for asthma or eczema cannot stop taking the medication abruptly as this can lead to withdrawal symptoms such as nausea, headaches, and dizziness. Other CHCS use steroids as treatment. Long-term use of 
prednisone can result in agitation, insomnia, irritability, distractibility (Warrington \& Bostwick, 2006) as well as adversely impact linear growth as discussed above. Acute rheumatic fever (ARF) can result, without proper diagnosis and treatment, not only in prolonged hospital stays, but in cardiac surgery and congestive heart failure (Gilbert, Wilson, \& Finucane, 2011). Children with ARF and the resulting complications can remain in hospital for several weeks. Frequent or long-term absences, overt physical effects such as hair or weight loss, or limitations on physical activities can all set adolescents apart during a period in their lives when being with their peers is very important (Gilbert et al., 2011, Reed-Knight et al., 2011).

Because adolescents are in a state of growth, changes in physiology can change the symptoms of or dosages of medications for a $\mathrm{CHC}$ making its management more difficult (Eckert et al., 2009). The impact of illness and treatment differ in symptoms and management and can be a source of contention and challenge for the young person (Michaud et al., 2007). An individual with a CHC may have a relapse unexpectedly, s resulting in hospital stays. These issues can impact the adolescent's self-identity especially when the young person does not want to stand out negatively from peers.

\subsubsection{Cognitive}

Cognitively, adolescents develop the ability to think abstractly and hypothetically, exploring 'what if' scenarios with more awareness and understanding of different possible outcomes in a given situation (Huebner, 2009; Steinberg, 2007). These changes in the cognitive ability of adolescents are a challenge for them. A CHC that affects the ability to focus, concentrate, or a basic bodily function such as sleep, negatively impacts the adolescent's ability to learn. Recent research has found that while the adolescent brain is developing, some areas are not completely developed until later (Huebner, 2009; Steinberg, 2007). These areas have been linked to impulse control and decision-making skills (Huebner, 2009; Steinberg, 2007) and can be impacted by some conditions that affect the central nervous system, such as leukemia or cerebral palsy (Armstrong, 2006). Partial seizures which can occur with epilepsy can also interrupt the process of learning as it can take several minutes after a partial seizure for the student to focus again. Subtle changes in the brain can happen with epilepsy and seizures and these can affect learning 
causing fatigue and difficulties with memory and attention (McNelis et al., 2005; Wodrich, Kaplan, \& Deering, 2006).

The presence of a CHC, such as cancer, diabetes, or Crohn's disease, adds additional challenges when it interferes with cognitive processes (Holmes, Cant, Fox, Lampert, \& Greer, 1999; Huebner, 2009), making it difficult to concentrate or focus. Cognitive discrepancies can result in a lack of ability to sustain attention, speed of processing, and decision making skills (Huebner, 2009). The presence of ADHD can affect how adolescents are able to concentrate or follow through when directions are given (Krueger \& Kendall, 2001). Although children and adolescents with SB have not shown any intellectual impairment, learning difficulties do occur (English, Barnes, Fletcher, Dennis, \& Raghubar, 2010). If hydrocephalus (spinal fluid that does not drain and causes pressure to the brain) occurs, these children may have short attention spans, difficulties with memory, and below average verbal skills (Kelly et al., 2008). Some medications to treat CHC can be benign, having little or few side effects that affect cognitive abilities (Armstrong, 2006; Shaw \& McCabe, 2008). Others can effectively disrupt learning by impacting memory, impaired concentration and hearing, slower information processing ability, loss of previous abilities, and nausea or other gastrointestinal problems (Shaw \& McCabe, 2008). Steroids, used to treat several illnesses, are often associated with psychiatric symptoms and impairment of cognitive abilities (Mushtaq \& Ahmed, 2002). The impact of treatment of a CI, such as asthma, leukemia, or diabetes, on a child's cognitive development can be varied: confusion, depressed mood, difficulty with memory, fatigue, impaired concentration and/or anxiety impaired spatial abilities (Armstrong, 2006; Mitru et al., 2002; Thies, 1999). Antidepressants used to treat depression may cause blurred vision or insomnia (Thies, 1999).

In their respective studies of acute lymphoblastic leukemia (ALL) effects on children, Rey-Casserly and Meadows (2008) and Boydell, Stasiulis, Greenberg, Greenberg, and Spiegler (2008) discuss the 'late effects' of cancer fighting treatments on the cognitive abilities of survivors. Late effects occur as a result of the consequence of a disease and its treatment, such as radiation treatment of the brain for cancer, which can produce longterm cognitive effects and impacts all cancer patients. Holmes and colleagues reviewed a series of studies regarding risk factors associated with cognitive functioning in children 
with type 1 diabetes and found several studies verifying poor metabolic control results in lower intellectual functioning and poorer academic performance (1999). Eckert and associates (2009) confirm poor metabolic control, which can be problematic in adolescent compliance, impairs the ability to learn new information and problem solve. While some research shows show that a $\mathrm{CHC}$ is not necessarily a precursor to poorer educational achievement (e.g., Joe, Joe, \& Rowley, 2009), there is a definite correlation between a CHC and academic success (Shiu, 2001; Thies, 1999).

\subsubsection{Psychosocial}

Psychosocially, adolescents are at a key stage establishing their identity, autonomy, independence from their parents, and making plans for their future with development of their identity seen as one of the most important tasks of this period (Eiser, 1990; O’Donohue \& Tolle, 2009). They experience more self-awareness and are more conscious of their body image. They believe everyone is thinking about them as much as they think about themselves (Elkind, 1967; O’Donohue \& Tolle, 2009). Teenagers believe in their own uniqueness regarding their emotions and have a belief in their immortality, "a personal fable" (Elkind, 1967). This belief in their personal fable can influence the risktaking in which adolescents engage, such as driving recklessly, with the belief that they will not be in an accident, or having unprotected sex in the belief that sexually transmitted illness or pregnancy will not happen to them. During adolescence moral values and spirituality are explored with some values rejected and others integrated (Sturdevant \& Spear, 2002). For example, when presented with a cause such as saving whales from hunting, teenagers are more willing to subscribe and support it than before, understanding the cruelty and impact of hunting on whales and the environment (O'Donohue \& Tolle, 2009). Identity development occurs as children mature, become more self-aware and form their self-conception. When social acceptance is of paramount importance to teenagers, having a $\mathrm{CHC}$, with its attendant impact on social interactions and communication with others, can adversely affect identity formation and peer relationships (Eiser, 1990). Teenagers learn about trust and intimacy during adolescence and what it is like to be in a close relationship with others (Huebner, 2009). Spending more time with friends allows for the development of social skills as well as independence. They are inclined to share 
minimal information about their activities with their parents and prefer to spend more time with their friends than with their parents (Huebner, 2009).

Peer opinion becomes more important during this stage (O’Donohue \& Tolle, 2009; Sturdevant \& Spear, 2002). Being different can affect identity development at a time when teenagers want most to fit in with their peers. Cheung and Wirrell (2006) found teens with epilepsy saw themselves as different although there were no visible signs of their condition. Their study of adolescents with and without epilepsy learnt that those without epilepsy had more misconceptions about it particularly than other illnesses, such as epilepsy causing mental handicaps or epileptic seizures resulting in injury to others. Awareness that there misconceptions of this kind can cause an adolescent with a CHC that is visible or invisible to internalize anxiety or depression and to withdraw from others. Cancer treatments resulting in loss of hair occurring at a time when body image and identity are being formed can adversely affect the adolescent, creating a negative selfimage (Quick, 2013).

Teenagers with ASD may find acceptance by their peers difficult because of their struggles with social interactions (e.g., Huws \& Jones, 2008). Difficulties with voice modulation, eye contact, repetitive motions, and lack of empathy with others can make them stand apart from their classmates and lead to isolation (Huws \& Jones, 2008; Rao, Beidel, \& Murray, 2008; Sheffield, Fiorenza, \& Sofronoff, 2004). This can disrupt peer relations during an age when being conspicuous negatively can create a stigma, either felt or enacted (Saunders, 2014). Goffman's definition of stigma "an attribute that is deeply discrediting” (p. 13) is still used in research regarding stigma (Saunders, 2014). The literature also speaks to dual concepts of stigma: enacted and felt (Olsson, C. A., Boyce, Toumbourou, \& Sawyer, 2005; Saunders, 2014; Scambler \& Hopkins, 1986). Enacted stigma is visually discrimination towards an individual resulting in being socially disapproved or unacceptable and felt stigma is a fear of possible negative consequence from others, such as being socially ostracized (Olsson et al., 2005; Saunders, 2014). Teasing or bullying from peers due to the CHC may create a negative self-image and possibly cause the teenager to withdraw into him or herself, affecting psychosocial development (Nassau \& Drotar, 1997). 
Hormonal influences, keenly experienced during adolescence, also influence psychosocial development (Kelly et al., 2008; Michaud et al., 2007). Having a CHC adds another dimension to this stage. As discussed above, a CHC such as Addison's disease or diabetes can interfere with and slow pubertal development, resulting in the adolescent being or feeling different from his peers. An individual with Crohn's disease can find bowel control difficult to manage, such as having severe diarrhea sometimes between 10 and 20 times a day. This severe diarrhea leaves the young person's body unable to absorb needed nutrients (vitamins, minerals) which could result in delayed pubertal development (Reed-Knight et al., 2011). Slow or too rapid pubertal growth with the resultant hormonal imbalances can affect the self-image and cause negative emotional challenges during a period when the adolescent does not want to stand out as different from his or her peers (Warner \& Hauser, 2009).

It is not uncommon that during adolescence compliance with medication regiments is poorer than amongst younger age children (Hayes-Bohn, Neumark-Sztainer, Mellin, \& Patterson, 2004; Miller \& Jawad, 2014). Adherence to treatment can be seen as interfering with the teenager's autonomy during a time when this is being developed (Dashiff et al., 2006). When teenagers want to be normal and not want to stand out from their peers and peer pressure is strong, this can create conflict within the adolescent, cause noncompliance with the treatment protocols, and have negative physical and cognitive effects as explained above (Schlozman, 2002). This is a concern as adolescents do not want to be seen as different from their peers and leaving class for treatment, for example, can set them apart. Studies have discussed the need of teenagers with a CHC to feel 'normal' but have not defined the term itself (Ferguson \& Walker, 2012; Michaud et al., 2007; Shaw \& McCabe, 2008; Shiu, 2001). Ferguson and Walker (2012) in their qualitative study of young people between the ages of 10 and 18 years with a CHC found their participants resisted being seen as different than their friends or peers. They wanted to be accepted, but not stand out. "They wanted to be treated like 'normal' kids" (p. 236). Other studies and metaanalyses have found that for adolescents with a $\mathrm{CHC}$, being the same as their peers meant being 'normal' even if that led to non-compliance to regimes which potentially made them feel 'different' (Michaud et al., 2007; Suris et al., 2004; Williams et al., 2002). 
Studies regarding $\mathrm{CHC}$ and adolescents point out psychological distress is not uncommon, with concerns about peer reaction to the disease, a lack of self-confidence, and not wanting to be singled out being common denominators among teenagers (Shaw \& McCabe, 2008; Shiu, 2001; Wallander \& Varni, 1998). Learning to navigate these difficulties and overcome them can be a challenge, and adolescents may become resentful that they cannot "wish it away'. While adolescents adapt to $\mathrm{CHCs}$ and can show exceptional strength and resilience compared to their healthier peers, many, with the rigors of the disease demanding good control of medication or decreased physical activity, such as asthma or diabetes, still experience psychological problems such as anxiety or oppositional behavior (Rose \& Holmbeck, 2007; Shiu, 2001, 2004; Schlozman, 2002). When a CHC impacts a student negatively (either physically or psychosocially), some young people may be reluctant to seek help from professionals because of fears regarding confidentiality (Cigularov, Chen, Thurber, \& Stallones, 2008; Farrant \& Watson, 2004; Sheffield et al., 2004). Positive or negative influence from peers and the family dynamic can also affect how the adolescent deals and manages the CHC (Eiser, 1990). If there are higher incidents of negative risk-taking in the teenager's milieu, such as smoking or substance abuse, there is a greater tendency for the teenager to engage in this behavior (Neinstein, 2001). This behavior can negatively impact the effects of the CHC on the adolescent, exacerbating the condition or negating treatment (Williams et al., 2002). Teenagers have a strong desire to be normal and the physical manifestations of a CHC or its treatment are reminders that the adolescent with a $\mathrm{CHC}$ differs from peers without a CHC (Eiser, 1990).

Literature reviews, meta-analysis of studies, and quality of life studies emphasize the need of these students to be socially acceptable (Michaud et al., 2007; Wallander \& Varni, 1989). Adolescents spend more time with friends and practice social skills; amongst other things, this is where they learn which behaviors are acceptable and which are not. The social environment of the student with a CHC can have a positive impact on the psychosocial make-up and adjustment of the child (Wallander \& Varni, 1989). There are national and local $\mathrm{CHC}$ support groups or online $\mathrm{CHC}$ support networks that can provide coping strategies and understanding for these young people, alleviating the isolation that can occur when a teenager believes no one understands, teenagers prefer to be with their 
friends (Olsson et al., 2005). Shiu (2001) contends that in school the teenager is seen as a person, not a patient. For the adolescent, being with his or her peers and being in school may be as important as his or her health (Shaw \& McCabe, 2008; Shiu, 2004; St. Leger \& Campbell, 2008).

\subsubsection{Summary}

Adolescents undergo a rapid change of growth physiologically, cognitively, and psychosocially. As seen, a CHC or its treatment can influence normative adolescent development. Some illnesses are sporadic such as asthma, an illness on the rise in New Zealand (Asher et al., 2008; Holt, Kljadovic, \& Reid, 2003). Others require constant vigilance: diabetes, juvenile rheumatoid arthritis (JRA), Crohn's Disease, (Scott, Whitcombe, Bouchier, \& Dunn et al., 2004; Thies, 1999; Wishnietsky \& Wishnietsky, 2004). Some CHCs impact pubertal development and treatment and its modifications can affect the cognitive and, possibly, emotional domains until the proper medication and/or dosage are found. During adolescence, young people are developing their self-concept, they mature and become more self-aware. The literature regarding adolescents and $\mathrm{CHCs}$ often speaks to the adolescent wanting to be normal and studies allude to an implicit understanding suggesting that for adolescents with a CHC, being normal means being the same as their healthy peers (Ferguson \& Walker, 2012; Michaud et al., 2007; Shaw \& McCabe, 2008). What emerges in the literature is that there is a strong need to be accepted by one's peers, to be seen as normal, and emphasis is placed on body image and appearance. The impact of illness, which may remit or relapse unexpectedly, and its treatment can be a source of contention and challenge for the young person as it can make the adolescent stand out from his friends or peers.

The approach towards the CHC adopted by family, health providers, specialists, and others who work with the adolescent in and out of school, can impact the young person with a CHC as well (Graça Pereira, Berg-Cross, Almeida, \& Machado, 2008; La Greca \& Mackey, 2009) . If a health provider sees the CHC as an illness or disease 'that is wrong' with the individual-the deficit approach-this approach may be assumed by the parents and individual and influence how the $\mathrm{CHC}$ is managed. This is not to say this approach is consciously adopted, and, as previously addressed, there are other approaches to CHCs. 
Health providers, however, are not a major influence of how an adolescent experiences a CHC. Family factors play a pivotal role in how a teenager adjusts and copes with a CHC.

\subsection{Family}

The family environment plays a vital role in the life of a teenager with a CHC (Eckert et al., 2009). Parents, while recognizing the need for independence in their children, may find themselves showing more concern and becoming overprotective of their child with a CHC to ensure medical compliance (e.g., Graça Pereira et al., 2008). For example, although studies show that parents who continue to show some guidance and supervision in adolescent management of their diabetes result in these teenagers having better metabolic control, it can be a challenge to find the degree of parental involvement necessary (Eckert et al., 2009; Mellin, Neumark-Sztainer, \& Patterson, 2004; La Greca \& Mackey, 2009). Parents may have more concern or fear relying on the adolescent to monitor his or her own blood glucose although teenagers are able to perform this task on their own (Eckert et al., 2009; La Greca \& Mackey, 2009). This concern does not occur only in families with adolescents with diabetes. Other studies of adolescents with asthma (Cashin, Small, \& Solber, 2008), IBM (Reed-Knight et al., 2010), or spina bifida (Sawin et al., 2003), for example, have also discussed parental overprotectiveness and compliance with treatment regimes. Studies have documented that tension and conflicts between adolescents and parents often arise regarding medical compliance and concerns as adolescents struggle with the need to be healthy and normal like their peers (e.g., Graça Pereira et al., 2008; Hayes-Bohn et al., 2004; Miller \& Jawad, 2014). In the studies cited above, it was not uncommon that teenagers resisted adherence to treatment regimens as a result of possible conflict with parents or their need to be like their healthy peers.

A variety of stress factors that impact family coping mechanisms range from difficulty in accepting the diagnosis to hospitalization of the child to the possible loss of career of a parent (Graça Pereira et al., 2008; Karlsson et al., 2006). Parental judgment can influence whether a child is in school or not (Mellin et al., 2004). A student with asthma may be deemed too sick to go to school, but not sick enough to require hospitalization (Shiu, 2001). Adolescents are in a stage in which they are supposed to become more autonomous, moving away from reliance upon parents. This step towards autonomy is seriously threatened as 
teenagers must depend upon their parents to take them to the doctors, stay with them during hospitalization, etc. (Abrams et al., 2007). Yet, where there is strong social support within the family structure, there is also better medical compliance, less behavioral difficulties at home and in school, and studies show these adolescents engage in positive decision-making (Graça Pereira et al., 2008; Karlsson, Arman, \& Wikblad, 2006; Rodenberg et al., 2005).

Another aspect of adolescent development is that of risk-taking. Risk-taking emerges in adolescence as teenagers become more autonomous from their parents and family (Leather, 2009). Advancements in neuroscience have found that there are cognitive changes occurring at the same time as structural changes within the brain during adolescence which affects risk-taking and decision making skills (Eckert et al., 2009; Sebastian, Burnett, \& Blakemore, 2008; Steinberg, 2007). Through risk-taking, teenagers learn about cause and effect and their limitations physically and psychosocially in their relationships with others. A strong familial connectedness can foster positive decisionmaking and risk-taking such as involvement in the arts (i.e., drama, art, music), academics, and/or athletics (rugby, swimming, football, etc.). These young people tend to have more confidence in themselves, better coping skills, positive decision-making and risk-taking skills, and better school achievement (Dusek \& McIntyre, 2003; Kyngäs, 2001).

When parents encourage and support teenagers in early adolescence being involved in health decision making, these same adolescents feel more confident to take on more responsibility for the management of their $\mathrm{CHC}$ and adhere to treatment regimens (Miller \& Jawad, 2014; Warner \& Hauser, 2009). Further, when adolescents are given tools to assist them in controlling symptoms such as migraine pain, this can lead to positive thinking and promote adaptive strategies for coping with it (Engel, 2009; Helvig \& Minick, 2013). Schwartz and Drotar (2006) examined the impact of goal setting in children and adolescents with a CHC. They found parent and child collaboration in goal setting had a positive role in the cognitive, emotional, and physical wellbeing of the child and adherence to treatment (Schlozman, 2002; Schwartz \& Drotar, 2006). When parents provide a supportive environment and actively involve the young person in health care decision making, this can assist in the development of coping strategies, positively influence adaption to the demands of the CHC, and contribute to a healthy family environment (Caplin, Austin, \& Dunn, 2009; Dobbie \& Mellor, 2008; Karlsson et al., 
2006; Miller \& Jawad, 2014; O’Donohue \& Tolle, 2009; Sawin et al., 2003; Suris et al., 2004; Williams et al., 2002).

\subsection{Chronic Illness and Education}

\subsubsection{Introduction}

The effects of a CHC on an adolescent are complex, involving his or her cognitive, physical, and psychosocial domain (Williams et al., 2000). There is also the interaction between the adolescent and the environment, be that environment school or home, with friends, teachers, staff at school, or with family. Where there is little knowledge of the $\mathrm{CHC}$ in these environments or little understanding of the effects of the $\mathrm{CHC}$ on the adolescent, success in the learning environment can become difficult. In school, a CHC can have certain impacts that can and often do influence a student's academic performance.

\subsubsection{Absenteeism}

Research has shown there is not necessarily a direct correlation between absenteeism and overall academic achievement (Joe et al., 2009; Shiu, 2004). Yet, an important issue within a CHC is being absent from school (Shiu, 2004). Some students may miss as much as $20 \%$ of their school year because of their illness and studies have found that absenteeism may result in depression (Joe et al., 2009; New Zealand Census, 2006; Thies, 1999). Absenteeism can range from one or more prolonged periods at a time due to hospitalization to one or two days missed a week (Holt et al., 2003; Shaw \& McCabe, 2008). Chronic absenteeism resulting from missing a day or so at a time can result in a student having to make up work as well as catch up on the current learning in the classroom. In addition to this, absenteeism affects the morale and education of students (Schlozman, 2002). Educationally, school is the adolescent's primary social environment and is where peer and friendship relationships are often defined and fostered. Frequent or extended absences can challenge and interrupt friendship formations (Dobbie \& Mellor, 2014; Williams et al., 2002). An educator is obviously aware of absences, but with chronic absenteeism, may feel helpless, because of time constraints, to assist the student in making up lost classroom time and missing assignments. As time passes, they may forget to remind the student what is missing or assume that the student is not going to complete the work. 
Holt et al. (2003) found, in their study of 445 patients, of which 118 were children aged 7-15 years, that there was poor asthma control with $10 \%$ of respondents having missed school or work because of their condition. In New Zealand, Free, Howden-Chapman, Pierse, Vigger and the Housing, Heating and Health Study Research Team (2010) investigated a possible connection between home heating and asthma related school absences. They found that while there is still ongoing discussion regarding absenteeism and poorer academic outcome, proper home heating did contribute to overall lower asthma incidence and lower school absenteeism. Missed school is missed opportunity for in-class learning (Shiu, 2004) and many subjects require the active presence of the student in the classroom.

\subsubsection{Educators}

International studies show that while there is information available regarding $\mathrm{CHC}$ and classroom implications, there is a perception amongst parents and teachers that there is a lack of information (Olson et al., 2004; Perrin, Lewkowicz, \& Young, 2000; Shiu, 2004). Understanding the effect of a specific disease process is an issue of getting the correct information. If an educator is not aware of the child having epilepsy, staring off into space may be mistaken as inattention or boredom (McNelis et al., 2005; Wodrich \& Cunningham, 2007). If a student has an emergency in the classroom such as an epileptic seizure in a student or hypoglycemia in a child with diabetics, a teacher must be knowledgeable of how to respond (Wishnietsky \& Wishnietsky, 2004).

Cognitive issues are another area of concern for educators. Students may do well academically and may be presumed not to need any kind of help. In school, this can create additional issues for the young person if teachers do not know of the $\mathrm{CHC}$ or its effects such as how pain or fatigue can affect academic ability. Goodman (2001), among others cited above, has discussed the effect treatments can have on cognitive abilities of students from the medical and psychological perspectives. In their respective studies, Perrin et al. (2000) and Shiu (2004) found the perception amongst parents and teachers was of a lack of understanding of the impact a CHC or its treatment can have on the cognitive abilities of the student. The participants in their studies felt this lack of information was an issue that needed to be addressed more often than it was in practice. 
Parents are encouraged in New Zealand schools to relay all pertinent medical information in a student's enrolment with access to this information limited for teachers. Yet they can request that medication or a mental condition such as depression be kept confidential or not shared with all of the students' teachers. This lack of information can lead to teachers not being informed about either the condition or its treatment, if there is one. Research has revealed that teachers are probably unaware of the effect of medications as well as the psychological impact of the disease (Bonner, Gustafson, Schumacher, \& Thompson, 1999; Goodman, 2001; Meuleners et al., 2002) and therefore are not aware of the needs of these students and do not know how to help them (e.g., Schlozman, 2002). Studies also show that teachers are not trained enough to cope with medical emergencies associated with chronic illnesses that can arise, such as an epileptic tonic clonic seizure (Cheung \& Wirrell, 2006; Reeve \& Lincoln, 2002).

Shiu's (2004) study of parents and teachers in New South Wales, Australia, found that many educators have some experience teaching students with a $\mathrm{CHC}$ but she found teachers expressed concerns of lack of information on a CHC or its impact on the student. Other international studies support this finding (e.g., Armstrong, 2006; Meuleners et al., 2002). Educators may not know that adolescents with diabetes have demonstrated poorer working memory than their healthier peers. Teachers may be aware of the effects of common illnesses such as asthma (inability to participate in some physical activity, shortness of breath), but know nothing about ITP (a blood disorder) or cystic fibrosis (Armstrong, 2006; Nabors, Little, Akin-Little, \& Iobst, 2008; Shiu, 2004). Another issue in this arena is that teachers may focus upon the health needs of the student and not place as much emphasis on education. Meuleners et al. (2002) conducted a study of teacher, parental and health professional perceptions of the quality of life of young people with a CHC. They found teachers did not rank future plans or school/academic achievement as important. In this type of situation, students are then doubly challenged by their health and education (Meuleners et al., 2002). Olson and colleagues shared that there were teachers in their study who felt uncomfortable with a child with a $\mathrm{CHC}$ in their classroom due to risk and liability (Olson et al., 2004). Teachers may not always be sympathetic or even understanding of the accommodations needed for these children because they do not understand the CHC, much less its complexities (Spinelli, 2004). 
Information available to nurses and physicians on medical databases is more difficult for educators to access and many briefs on a specific illness giving detailed descriptions are available only in medical journals. Although awareness campaigns are conducted (Asher et al., 2008) and guides and specialized briefs designed to aid educators are available, educators have noted they feel ill prepared to help many high school students with a CHC (Kliebenstein \& Broome, 2000; Olson et al., 2004; Spinelli, 2004). The Ministry of Education in New Zealand has developed the school student enrolment register (ENROL) for schools which encourages schools to record teaching notes "to highlight serious health issues which impact on the student's safety or learning abilities. These issues could include severe allergies, chronic illnesses, disability, e.g. hearing/vision, ongoing medication requirements" (Ministry of Education, 2009, p. 14). Yet, unless directly informed by an administrator or a parent, many times teachers may not be aware they have a student with CI (Kliebenstein \& Broome, 2000; Olson et al., 2004; Shiu, 2004).

Sharing health information with schools is an important tool in affecting positive change in the student's academic life. Parental consent and urging is necessary in this area, and when stress is high due to a particular health crisis, this can be difficult as it is competing with other needs (Perrin et al., 2000; Reed-Knight et al., 2010). It is all the more consequential when the illness is not apparent or rare. Teachers who have a child with prosthesis or a visible disability may be more inclined to accommodate a child (Shiu, 2004) but CHCs are not always visible (asthma, diabetes, epilepsy). Many adolescents with a CHC look like their peers, not ill. For example, an adolescent with a seizure disorder may simply look disinterested or have a daydream look on his face, when in reality he is experiencing an absence seizure (Cheung \& Wirrell, 2006). A sleep disorder will cause fatigue, but in the classroom this may be misunderstood as laziness or lack of motivation (Mitru et al., 2002). Awareness is growing that more information is needed for educators of students with a CHC.

School reintegration programs exist in some schools that perform the essential task of addressing the special educational needs of students with serious illnesses (e.g., Botcheva, Hill, \& Kane, 2004; St. Leger \& Campbell, 2008). These programs take into account the academic, cognitive, and psychosocial issues that can arise for students with 
a serious illness and whose treatment has affected them negatively in these areas. Recommendations, interventions or programs designed to assist these students are often discussed in psychological or health journals such as Psychology in the Schools, or Health Education, or Phi Delta Kappa Fastbacks (Shaw \& McCabe, 2008; Wishnietsky \& Wishnietsky, 2004; Wodrich \& Cunningham, 2008). In New Zealand, there are three regional health schools based in Auckland, Christchurch, and Wellington, which provide educational support and services for students who are either at home or in hospital due to illness in the form of home visits and teachers (Ministry of Education, 2008b).

\subsubsection{Nurses, Physicians, and School}

In New Zealand schools where there are nurses ${ }^{1}$, they are involved in the assessment, identification, implementation, and promotion of health and wellness in the school environment (Simmons, 2007). Nursing care provided to students is contracted by the schools with the Public Health Service. +Nurses' primary focus is health management in school, dealing with issues ranging from head lice to diabetes; screening for vision, hearing, and scoliosis to immunizations (Bigby, 2004; Farrant \& Watson, 2004; Simmons, 2007). Although nurses decide when to send children home, they may not always know about a child's CHC. They may only be aware of those instances when the child is sent home (Simmons, 2007). Adolescents with asthma, diabetes, or attention deficit hyperactive disorder (ADHD) often need to have medications administered to them at school. But the school nurse may not have up-to-date information pertaining to a particular illness and its impact on the student's education (Patterson et al., 1999). This requires communication between parent and nurse, even between primary health care provider and school nurse, obviously with parental consent.

The school nurse in New Zealand may not be involved in developing an Individualized Education Plan (IEP) (Simmons, 2007), yet they can assist in the analysis of why students may be struggling academically. The National Association of School Nurses in the United States prepared an issue brief in 2001 that stressed the important role

\footnotetext{
${ }^{1}$ In this study, the term school nurse refers to the Public Health Service's allocated health personnel attached to the school in New Zealand or, in the United States, nurses hired directly by the school or county.
} 
school nurses have in relationship to students' experiences in schools (NASN). It endorsed communication between nurse, classroom teacher, and guidance counselor, and encouraged nurses to serve as liaisons to the physician and monitor the student's progress in the school, always ensuring the student's confidentiality is not breeched. The Ministry of Education provides financial and educational support for schools with the special education grant and school-based resource teachers, however, not all chronically ill students in New Zealand secondary schools may have an IEP (Ministry of Education, 2008a). Therefore, a physician may not be consulted regarding how best to meet the student's educational needs. The family physician plays an important role in the education of an adolescent by identifying the impact of a medication or treatment on a child's cognitive ability, psychosocial adaptation, and giving the school supportive education services, such as in-service seminars on working with children with a specific $\mathrm{CHC}$ (Armstrong, 2006; Perrin et al., 2000). For example, for the adolescent, the importance of social activities may override medical compliance and there may be discrepancies between child and parent priorities. Schwartz and Drotar (2006) suggest that involvement with the health provider in the discussion may encourage and foster agreement and positive resolution. An important finding in Dickinson, Wrapson, and Water's (2014) study was that the relationship with a health provider is complex and requires more communication with others involved in the context of the child with a $\mathrm{CHC}$, such as school personnel. Where there is poor communication between the physician or nurse and the adolescent, this can add an element of powerlessness to the adolescent and contribute to feelings of isolation, or anxiety regarding the $\mathrm{CHC}$, which can influence learning (Dickinson et al., 2014; Warner \& Hauser, 2009). Pediatricians may be very involved in their practice. It may be difficult, because of this involvement, lack of time, or funding constraints, for doctors to attend school meetings. If the adolescent is not suffering obvious, debilitating symptoms, information from the pediatrician may not be seen as necessary. It is possible perceptions about what a student needs academically can differ quite dramatically within the circle of a physician, a teacher, a parent, and the student.

\subsubsection{Summary}

How an adolescent is taught about the CHC, its effects, and how treatment compliance can impact in the different domains allows the teenager to be a partner to his 
or her healthcare and can positively influence the adaption to the demands of the $\mathrm{CHC}$ (Caplin et al., 2009; Dobbie \& Mellor, 2014). These studies and others found the more knowledge adolescents had of their $\mathrm{CHC}$, the more empowered adolescents felt. While all schools do not have school nurses, and pediatricians may not actively participate in advising how an adolescent with a CHC can learn despite the impact of the particular $\mathrm{CHC}$, it is still possible for school personnel and educators to help these students learn and continue on with future plans. What is a necessary piece of information for these educators and school personnel to know is what are the learning experiences of these adolescents. In this way educators and school personnel can help young people continue learning and achieve their goals.

\subsection{New Zealand Context}

\subsubsection{New Zealand Research}

As I conducted my research in New Zealand, it was important to become familiar with New Zealand research conducted regarding adolescents and CHCs specifically. Much of the research completed in the last 20 years regarding children and young people was illness specific, such as asthma or rheumatic fever, with data gathered through questionnaires or surveys, but these did not address educational or learning concerns (Paterson at al., 1999; Asher, Barry, et al., 2001; Asher, Stewart, et al., 2008). Again, the range of ages varied. Paterson et al. (1999) used structured interviews with children 7 to 14 years, focused upon the children's understanding of colds and asthma, and analyzed the data quantitatively. Asher and colleagues' (2008) study included eczema, rhinoconjunctivis and asthma in children and adolescents. This was a follow up study after Phase 1 and Phase 2 of the International Study of Asthma and Allergies in Childhood (ISAAC), first conducted in 1992-1993, then repeated in 2001. In the ISAAC Phase 2 and Phase 3 studies, participants were aged 6 to 7 years old and were 13 to 14 years old with data collected via written questionnaires. The results from this last ISAAC study resulted in what the authors felt were high numbers of asthma (25\% and $30 \%$ each age group respectively), allergic rhinoconjunctivitis (10\% and 19\%) and atopic eczema (15\% and 13\%) (Asher et al., 2008). Although specifically looking at health issues, neither discussed an illness model underpinning their study. 
Research regarding rheumatic fever, an illness found in unusually high numbers in New Zealand, especially amongst the Māori and Pacific Island populations, used hospital or clinical data to show the increase in ARF rates in the Māori or Pasifika population (Gilbert et al., 2011; Milne, Stewart, Vander Hoorn, \& Scuffham, 2012). Milne and colleagues (2012) investigated the incidence of ARF in children and found a steady increase in the rise of rheumatic fever, primarily in Māori and Pacific children with the majority of the cases occurring in children 5 to 14 years old. Gilbert and colleagues (2011) examined hospital records regarding the severity of ARF and rheumatic heart disease (RHD) in children aged 5 to 15 years. An easily preventable disease, they found that many of the 36 children in their study went on to suffer heart failure and needing cardiac surgery. These studies did not address the impact of these CHCs on any specific domain.

It was not unusual to find studies which collected data from multiple clinical and research sources within New Zealand regarding a variety of health conditions such as diabetes, the incidence of traumatic brain injury (THI), and prevalence of childhood CHCs (Feigin et al., 2012; Monteith, Heppner, Woodfield, \& Law, 2005; Obaid, Britt, Wallace-Bell, \& Johnson-Elsmore, 2012; Scott, Whitcombe et al., 2004). These studies summarized numerical information regarding the incidence and age group of CHCs, but did not examine how these affected the education or learning of young people. Feigin and colleagues investigated the rise of THI and found $70 \%$ of these injuries occurred in those 34 years old and younger. With such a high percentage of THIs occurring in young people, looking at the effect of THIs on cognitive abilities could have provided useful information for vocational or tertiary education. Vogel and associates (1996) estimated the prevalence of $\mathrm{CHCs}$ based upon registry data and published data from studies or surveys collected from as far back as 1971. This study was the only one focused specifically upon CHCs in general in children, although it did not contain data on epilepsy incidence nor examine how the illness or the CHC impacted the learning of children.

Other quantitative research examined a variety of health issues in children and young people such as asthma, compliance with growth hormone treatment, traumatic brain injuries, glandular fever, or inflammatory bowel diseases (Buetow et al., 2005; Cutfield et al., 2011; Holt et al., 2003; Vogts, Mackey, Ameratunga, \& Stott, 2010; 
Wickens et al., 1999). Buetow and his colleagues were concerned with the rising rates of asthma in youth in New Zealand (2005). Using a questionnaire in ten Auckland schools, they looked at the frequency that teenagers aged 13 to 14 years old visited their general practitioners (GP) in the Auckland area (2005). Although they found half of these young people needed GP care, it was underused by about $40 \%$ of the sample. Cutfield et al., used a national survey to collect data regarding government funded growth hormone $(\mathrm{GH})$ treatment in 117 children aged 6 months to 12 years (2011). It is a costly treatment with high benefits if there is compliance, but "suboptimal growth" if not, with subsequent "considerable cost" (p. e16223). Farrant and Watson (2004) used a questionnaire to examine the perceptions of 53 students from 13 to 18 years and their parents regarding health care delivery. Young people overall had favorable experiences, but they emphasized the need for their health providers to discuss possible future plans for young people with CHC or disabilities (2004). That these participants wanted more information regarding their future can be interpreted positively-they see themselves as active and contributing citizens in their future.

Vogts et al. (2010) used a questionnaire regarding barriers to participation in their children with cerebral palsy in Auckland. Perceived discrimination from peers and teachers in their children's school as a barrier to participation were most commonly reported. The authors suggest that without a control group of parents of children without disabilities, this perception may not be correct. If one considers that the individual most affected by such discrimination is the child with cerebral palsy, it is notable that the children (aged 5 to 16 years) were not participants. Wu and colleagues compared data from clinical and research sources in the Canterbury District Health Board catchment area of 353 individuals 24 years and younger with Type 1 diabetes (2005). They used their results to provide a population estimate of the number of young people with T1D in New Zealand. The opportunity to further enhance these quantitative studies to look at the psychosocial effect, for example, of the respective $\mathrm{CHCs}$ in these different youth populations could have provided some useful information as to how the CHCs impacted them. None of the studies cited examined the impact of illness on psychosocial or cognitive abilities, or learning although they all found that the number of young people with these $\mathrm{CHCs}$ is increasing. 
While much of New Zealand research has been quantitative, some qualitative studies have investigated the impact of chronic illnesses on children, (Dickinson et al., 2006; Fraser, 2001; Lynch \& Spence, 2008). Dickinson et al. (2006) studied chronic illness and students in New Zealand using the hermeneutic phenomenological approach. They looked at the relationship between families and health providers for children from 9 months to 14 years old, from parents' and health providers' perspectives in a phenomenological study. During the course of the interviews these nurses held with parents and schools, to which the children with the $\mathrm{CHC}$ were often invited and present, it was interesting, they noted, that oftentimes the children's viewpoints were nearly absent from the discussion (Dickinson et al., 2006). Often the parents 'interpreted' what the children were saying. The researchers noted this point was a limitation as the parents may not have provided an accurate interpretation. Deborah Fraser (2001) interviewed parents and children from four to 15 years old with cancer and focused on friendships and peer relationships. Her results showed that continued friendships in school were difficult to sustain, yet important for children's psychosocial well-being and their academic achievement, a finding in line with international research of adolescents with $\mathrm{CHC}$ and peer relationships (e.g., Berntsson et al., 2007; Ferguson \& Walker, 2012). Lynch and Spence (2007) conducted a phenomenological study of 4 young people aged 16 to 21 years with Crohn's disease to learn about their experience of having and living with this disease. Although examinations were missed and school absence was discussed, school was not a dominant theme. These studies focused upon the young people's experiences and CHCs and these young people talked about school either due to missed classes or friendships in school. Missed school was a concern for these adolescents but was not pursued further by the researchers as school was not the focus of the study (Lynch \& Spence, 2007).

The Ministry of Health of New Zealand has conducted five national population-based health surveys since 1992/1993. In the surveys, children were considered from birth to 14 years and adults are considered 15 years and older (Ministry of Health, 2008a, 2013). These two groups were then subdivided into age groups: 2 to 4 years, 5 to 9 years, 10 to 14 years, and the young adult age group as 15 to 24 years. These surveys did highlight self-reported physical and mental health states for children and adults within the country and included general health trends such as hazardous drinking, smoking, watching TV, 
but did not did not provide useful information specifically regarding adolescents' CHCs because adolescents were not considered as a separate age group (Ministry of Health, 2008a, 2013). Craig and colleagues (2012) report also classified Māori young people as aged between 15 to 24 years. When adolescence is not taken into account as a separate age group, assessing accurate numbers of adolescents with a CHC in New Zealand can be a difficult undertaking. The Adolescent Health Research Group (2001) undertook a survey of students in year 9 to year 13 to study student health behaviors in secondary schools in New Zealand. Youth (adolescents) were considered 13 to 18 years. Diabetes, obesity, risk taking behavior, alcohol and drug abuse, sexually transmitted infections (STIs), and contextual factors were primarily discussed (Adolescent Health Research Group, 2008; Ministry of Health, 2008a, 2008b, 2013). Information within this study was statistical, rather than anecdotal, and did not focus specifically on CHCs other than diabetes and asthma. Several studies were published from this data but none discussed adolescents' perspectives regarding learning and CHC (e.g., Denny, Balhorn, Lawrence, \& Cosgriff, 2005; Denny, Clark, \& Watson, 2004; Purvis, Robinson, Merry, \& Watson, 2006). However, one study did compare the health of secondary school students in alternative education (AE) settings to those of regular secondary schools within the Northland and Auckland regions of New Zealand (Denny, Clark, et al., 2004). They found that AE students suffered from more adverse health conditions and engaged in more adverse health behaviours such as drug and alcohol abuse, than their counterparts in mainstream schools. They highlighted the need for health policies and programs specifically for AE schools. As they collected data through a youth health questionnaire, questions regarding their learning could have provided additional information in how policies and programs could include methods to boost their academic learning.

What marks the lower and upper age limits of adolescence within reports, surveys, and studies can vary greatly as mentioned before. In the New Zealand studies, as in the international literature, each study had its own age parameters, for example, in Wu et al. (2005) participants were 25 years and under, whereas in Asher et al.'s (2008) study, participants were 6 to 7 years and 13 to 14 years. Some of these studies grouped adolescents with children ( 0 to 14 years old) as well as with young adults (15 to 24 years), disregarding the fact that developmentally, rapid pubertal changes can begin occurring by 
age 10 or 11 years old, and, developmentally, 15 and 16 year old adolescents are neither cognitively nor psychosocially the same as young adults in their early 20's (Warner \& Hauser, 2009).

\subsubsection{Māori and Pasifika}

In New Zealand, Māori and Pasifika are disproportionally represented in the lower income levels of the population (Buetow et al., 2005; Holt et al., 2003; Ministry of Health, 2008b) and young people in these populations have higher rates for $\mathrm{CHCs}$, such as diabetes and asthma than European New Zealanders (Hale \& Sharpe, 2011; Milne et al., 2012). The 2006/2007 New Zealand Health Survey showed that over $41 \%$ of Māori children were diagnosed with a CHC. In the Pasifika population over $38 \%$ were diagnosed with diabetes and asthma and these rates are rising in both populations (Asher et al., 2008; Craig et al., 2012; Ministry of Health, 2008b; Scott, Toomath, et al., 2006). In their report on behalf of the NZ Child and Youth Epidemiology Service, Craig and colleagues (2012) noted the increase of asthma and the resurgence of tuberculosis between 1992 and 2001. The resurgence of acute rheumatic fever resulting in hospitalizations is ten times that of other New Zealanders (Craig et al., 2012). These studies also show a close correlation between lower SES and worse health issues while others cite the negative effects colonization and urbanization has had upon whanau in Māori (Craig et al., 2012; EllisonLoschmann \& Pearce, 2006; National Health Committee, 2007).

Young Māori and Pasifika, most of whom are already disadvantaged socioeconomically, are further disadvantaged when they have a chronic illness (Cram, Smith, \& Johnstone, 2003; National Health Committee, 2007). Gilbert and colleagues found that, in their relatively small sample of 36 children, the overwhelming number (35) of children with ARF or RHD were Māori and Pasifika. While their study's aim was not regarding education, an assumption may be made that when more time is spent ill with ARF or in hospital with RHD, the less time these children are able to attend school and receive an education. Milne et al.'s (2012) quantitative study looked at national hospital admissions and found a high correlation of ARF with low socioeconomic status (SES). ARF has largely disappeared in the developed world and is preventable, yet in the Māori 
and Pasifika population, it is increasing. This increase in ARF can lead to greater health issues later in life (Milne et al., 2012).

Several studies and literature reviews on children with a CHC have mentioned SES and the effect that low income has upon them academically as well as in health related issues (e.g., Free et al., 2010; Joe et al., 2009). Typically, students from a low SES are at higher risk for health issues, lower academic achievement and higher dropout rates from school (e.g., Free et al., 2010). Free and his associates found higher hospital admissions in lower SES, citing possible housing issues as well as parental education influencing how health is addressed. Joe et al. (2009) reported that while students with a CHC come from all economic levels, those from a higher SES tended to have more mental health issues, such as depression, than those from a lower SES, which tended to have more CHC issues. Adverse outcomes can occur where there is a socioeconomic disadvantage resulting in fewer opportunities for adequate and preventative treatment of a $\mathrm{CHC}$ as well as education.

In addressing $\mathrm{CHC}$ in young Māori and Pasifika, health care providers need to be aware of how concepts of health differ in Māori and Pasifika culture from the European New Zealander view (Cram et al., 2003; Simmons, 2007). Māori are the indigenous people of New Zealand and have an understanding of health that is unique to New Zealand. Hauora, the Māori philosophy of health, explains health as holistic and encompassing the wairua (spirit), as well as the tinana (physical element), the hinengaro (mental state) and whanau (the immediate and wider family). Wairua plays an important part in Pasifika culture as well (Counties Manukau Chronic Care Management Programme, 2004). With rising rates of CHC in Māori and Pasifika, it has become clear that medical care must integrate the cultural setting of the population in order to deliver appropriate services. Within Māori families and their approach to health, the different elements of family, school, peers, extended family, the spirit, the environment, and the mental state of the individual are interconnected (Cram et al., 2003). Health providers have not always considered cultural influence resulting in an atmosphere of distrust of Māori towards health providers (Counties Manukau Chronic Care Management Programme, 2004; Cram et al., 2003). When a whanau feels that a health provider has ignored essential parts of their culture, their whanau come away with a feeling of 
disrespect and are reluctant to seek further medical help, resulting in worsening health. Although the Ministry of Health (2008a) cites statistics showing higher CHC, absenteeism, and school dropout rates among Māori and Pasifika youth, no studies have been published discussing Māori or Pasifika youth views on health and if or how their health or environment have impacted their education. Lack of information can result with health providers and educators being unaware of how to facilitate communication with Māori and Pasifika families and meet the student's needs. Socioeconomic status and family culture of a student with a CHC have an effect upon academic achievement (Joe et al., 2009; Kral \& Brown, 2004).

Studies which had a high Māori or Pasifika youth populations (e.g., Buetow et al., 2005; Hohepa et al., 2004) did not discuss the impact of CHC upon adolescents and education, although the Ministry of Health (2008b) collected data on Māori and Pasifika youth leaving school early and having a higher degree of CHCs than their European New Zealand peers. Buetow and colleagues (2005) examined why Māori and Pacific children, aged 13 to 14 years, who experience asthma in higher numbers than European New Zealanders, had greater rates of hospitalizations, yet saw GPs less than European New Zealanders. They spoke with health care providers and found Māori and Pacific cultural influences regarding illness and health were important factors with negative beliefs leading to unwillingness to access health care managed by European New Zealanders. Buetow et al. suggested further research regarding this population should examine if there are barriers that prevent access to medical care which could lower CHC rates (2005).

Hohepa and colleagues (2004) discussed the rise in Māori and Pacific adolescent obesity and physical inactivity within New Zealand as it is one of the top four health priorities for the country. They proposed further investigations, especially targeted at risk groups, in order to inform health policy and reform. Cutfield et al. (2011), examining compliance with the expensive treatment of growth hormone, found that Māori compliance was lower than European New Zealanders, even though the treatment was government funded. As there is a higher incidence of $\mathrm{CHC}$ amongst this population, noncompliance is a concern. Examining this issue further could yield information that could assist health providers in working with this population in health related concerns, such as encouraging compliance with treatment regimes. 


\subsection{Conclusion}

The literature regarding students with $\mathrm{CHC}$ has involved quantitative and qualitative studies, using a variety of methodological approaches, and with perspectives from adolescents, health providers, educators, and parents. I found some of these studies of a $\mathrm{CHC}$, its treatment, and the impact on various domains of the adolescent were presented from one of three models of viewing illness; the medical model, the social model of disability, and the biopsychosocial model. When CHC impact on academic performance or school related issues was studied, the medical and biopsychosocial model were used. Generally, models of illness were not discussed unless specifically addressing disabilities. In this case, when illness models were mentioned, they were either the biopsychosocial model or approach (these terms were interchangeable in the literature used in this study) or the social model of disability. When researchers used an illness model approach, it was predominantly biopsychosocial. This last approach best corresponds to the ecological paradigm widely used in New Zealand schools, which view the child holistically, particularly in the area of special education.

Research in the area of adolescents with a CHC has often focused upon a specific illness and its impact upon one aspect of the adolescent, such as eczema's impact on sleep (Camfferman et al., 2010). Literature reviews or meta-analyses, when looking at chronic illness have often targeted a specific area, such as the impact of CHCs on psychosocial development or quality of life (e.g., Abrams et al., 2007; Martin-Herz, 2012). For this study, literature was sought in medical and educational databases. It is possible that some studies were not included in this literature review despite my endeavors to locate all relevant research with a variety of pertinent key words associated with this topic. Very few studies focused upon the learning experience from the adolescent's perspective (e.g., Hayes-Bohn et al., 2004; Lightfoot et al., 1999; Wodrich et al., 2006).

As shown, a CHC can impact the physical, cognitive, and psychosocial aspects of adolescents and their education. Previous studies often missed the interactions between all the different factors impacting the student's education as such studies could become excessively burdensome for in-depth analysis, contingent upon the number of participants. To date, within New Zealand, the study of adolescents and CHCs has been diverse, but 
generally illness specific studies examined a particular aspect, be it access to health care and health providers, psychosocial, quality of life, absenteeism, or peer relations to name a few. Research has provided the opportunity to access the perceptions of teachers, parents, nurses and other health providers, psychologists, counselors, school staff, and adolescents with a $\mathrm{CHC}$, have regarding these and other aspects of adolescents with a CHC.

This literature review aimed to provide examples of existing studies of adolescents with a CHC, and what was the focus of these studies. Generally, in-depth studies of adolescents with a $\mathrm{CHC}$ and their experiences regarding their education or learning are not as numerous as studies regarding quality of life or specific areas such as coping strategies. Specifically within New Zealand, this researcher did not find any published studies in this area. A search of theses and recent published articles in Australasia shows that to date, there are no published studies in New Zealand discussing students' learning experiences when they have a CHC. Today, internationally and in New Zealand, researchers understand that student voices regarding their health is sues should be heard. Where are these voices regarding what their experiences are like in school so that educators and administrators can support them in school? Where is the information available to an educator that clearly lets them know that students with a $\mathrm{CHC}$ do have needs that differ from their healthy counterparts within the classroom requirements? Are educators in New Zealand, in fact, already aware of these needs and making the necessary accommodations according to these students?

This research's goal was to contribute to research of adolescent voice regarding and highlighting the learning experiences of adolescents in New Zealand with a CHC. Specifically, this research, by accessing students' voices, was to ascertain what are the learning experiences of students with chronic health conditions. The sub questions were:

a) How, if at all, does their $\mathrm{CHC}$ affect their learning experience?

b) Where/what learning environments do they participate in and from whom are they learning? 


\section{CHAPTER THREE}

\section{METHODOLOGY}

\subsection{Introduction}

This study explored the experiences of secondary students with CHCs in the New Zealand context. The rate of diagnosed and treatable CHCs are on the rise in New Zealand and this affects how and where these students learn. It is useful for educators to learn how students experience learning when they have a CHC and where this learning occurs. This chapter describes the researcher's philosophical assumptions, ethical considerations, and methodology used to collect and analyze the data. Participant recruitment, the procedures involved in the collection of data, how data was analyzed, and trustworthiness in this study are also described.

\subsection{Research Questions}

The goal of this research was to ascertain what are the learning experiences of secondary school students with CHC? Sub questions were (a) How, if at all, does their $\mathrm{CHC}$ affect their learning experience? (b)Where/what learning environments do they participate in and from whom are they learning?

\subsection{Research Framework}

Research paradigms guide and set "the context for an investigator's study" (Ponterotto, p. 128). The main paradigm underpinning this research is constructivism. Constructivists hold that individuals build, construct, and interpret their own reality through their interactions with the world (Merriam, 2002). Individuals arrive at an understanding (meaning) of the world, their reality, by interactions with it and others. How each individual interprets his or her actions constructs their understanding and this understanding is constantly in flux, just as individuals do not remain in a fixed, static moment. Qualitative research looks to understand the experience of the participant. It allows the researcher to explore and interpret phenomena subjectively and this in-depth exploration results in a narrative that is rich in data, detail, and description (White, 2011). Because this understanding is relative and constructed by the individual, it is subjective. When the researcher enters the participant's world, knowledge is co-constructed by the 
knower (inquirer) and the respondent (Smith, 2008). The resulting subjectivity may lead to the issue of researcher bias and the question of how the researcher will avoid bias (Malterud, 2001). Research bias and avoidance of bias is discussed further below.

\subsection{Phenomenology}

Phenomenology is a twentieth century philosophical movement founded by Edmund Husserl (Denzin \& Lincoln, 2005). He believed that human consciousness is always aware of its consciousness of something, that it actively constructs, as much as it perceives, the world (Denzin \& Lincoln, 2005). Husserl believed scientific inquiry could provide a thorough description of things as they appear in order to reach an understanding of the human consciousness and experience (Dowling, 2007). This rich description of any phenomenon allows one to reach the essence of it and, thus, understand it. His student, Heidegger, believed this approach overlooked key elements of the subject (the individual) and the 'being' of the experience (Heidegger, 1962).

Heidegger diverged from Husserl and posited a rich description of the essence of the phenomenon is not enough. An understanding of the phenomenon is important because consciousness [my italics] is not separate from the world of human existence (Dowling, 2007). Heidegger was interested with human experience as it is lived, in Being and this understanding of the Being can be reached by allowing it to reveal itself (Dowling, 2007; Koch, 1999; Wilding \& Whiteford, 2005). This understanding of the Being, Heidegger (1962) believed, occurs when one is immersed in the experience (Koch, 1999). Heidegger argued that a fully detached reflection from personal experience was not possible as Husserl maintained, and required the researcher to set aside personal beliefs regarding that experience and engage in accepting the story told as the truth lived by the individual telling the story, including the historical and cultural contexts (Wilding \& Whiteford, 2005). In this way, a researcher could arrive at understanding the lived experience of another. Phenomenology, then, becomes more than a philosophical approach to knowledge or understanding. It becomes a methodology as it seeks to understand the being of the phenomenon. This philosophy influenced and was influenced by Gadamer, who believed that phenomenology allowed the exploration of this consciousness to occur at a deeper level, giving the individual 
and the researcher the opportunity to delve further into, and understand better, the lived experience of the individual by, once having reached the essence of the phenomenon, interpreting the experience (1989). Phenomenology, with its focus upon the individual, allows deeper exploration of his or her 'lived' experience (White, 2011).

There are two main branches of inquiry within phenomenology: descriptive (Husserl) and hermeneutic (Heidegger), but they both seek to reveal more about the individual's experience of a phenomenon. Descriptive phenomenologists provide rich descriptive accounts of the individual's experience of a phenomenon whereas hermeneutic phenomenologists attempt to understand the experience from the individual's point of view and make meaning of it; discover what the experience was for that individual, and what the meaning of it was. Whether descriptive or hermeneutic phenomenology, because the experience is the participant's, the narrative of it is subjective. The researcher does not seek to find an objective account, but rather, is well aware that the material is subjective, from the participant's perspective (Brocki \& Wearden, 2007; Smith, 1995). Phenomenologists realize that individuals "are not passive receivers of an objective reality" (Brocki \& Wearden, 2007, p. 88), but that whilst experiencing the phenomenon, the individual(s) come to make meaning of it in a form that makes sense to them. The phenomenologist, hermeneutic or descriptive, when seeking understanding of this experience through the participant's narrative, enters the participant's subjective world.

Researchers using a phenomenological methodology seek to understand the lived experience of a particular phenomenon within the individual's lifeworld in order to comprehend the inner experiences that are unprobed in everyday life (Dowling, 2007; Todres \& Wheeler, 2001). The value of phenomenological research is in how it addresses and explores common experiences. In fact, the researcher wants to present the participant's viewpoints in order to contribute to the knowledge of what the phenomenon is like for the participant (Todres \& Wheeler, 2001) hence, its strong idiographic emphasis. A descriptive phenomenological study might look at how teachers experience teaching and gather rich, dense descriptions of their experiences. A hermeneutic phenomenologist might look at what may be important experiences of a group (how adolescents experience illness), or seek understanding of how transitions are experienced, such as homosexuals 'coming out' to their families and, through the participants' narrative 
and with the participant(s), make meaning of the experiences. The key aspect is that there is an idiographic focus-it is not about the quantity of participants but rather about the indepth information gathered from the individual participant/s (Smith, 2004).

\subsubsection{Phenomenologists and Bracketing}

Husserl believed that understanding of the essential features of a phenomenon was only possible with a bracketing (epoch) of all pre-conceptions and presuppositions (Dowling, 2005; Koch, 1999). Understanding the essence could only occur when the researcher was able to see what the individual experienced pre-reflexively, without interpretation (Dowling, 2005). This could be done by acknowledging these preconceptions, or bias, making them as clear as possible and then setting them aside (Koch, 1999). By doing so, we "abandon culturally and socially derived understandings with which we operate in the natural attitude and which mask what is of the essence" of the phenomenon (McNamara, 2005, p. 679).

Heidegger disagreed with Husserl. Interpreting the lived experience was part of human existence and it was not possible to bracket presuppositions (Todres \& Wheeler, 2001). He and subsequently, Gadamer (1975) believed that researchers needed to engage in a reflexive and critical understanding of the research process (Koch, 1999). In fact, Gadamer held that we needed to reflect critically throughout the research process not only to form "anticipatory ideas, but to make them conscious" so we could monitor them judiciously (Koch 1999) otherwise, as Van Manen (1990) argued, "we might find that the presupposition persistently creep back into our reflections" (p. 47). In qualitative research reflexivity is a process of critical self-reflection the researcher engages in during the research project, by noting in field journals or digital recordings theoretical preferences, bias or prejudices, or theoretical predispositions so that the participant/s' ideas or understandings are included and the researcher's ideas are excluded (Dowling, 2005; McNamara, 2005). Researcher reflexivity is a key element throughout the process of data collection and analysis (Koch, 1999).

\subsection{Phenomenological Method Design}

In a phenomenological study, it is important to access the voice and narrative of the participant to reach an understanding either through description or interpretation of the 
phenomenon/subject (Johnson \& Christensen, 2008; Lopez \& Willis, 2004). Data are primarily collected by semi-structured interviews with individuals, although observation of the participant during the interview occurs and can be noted in post-interview briefs. Other opportunities to gather data for phenomenological analysis may include diaries (Smith \& Osborn, 2008). An interview schedule can outline certain areas the researcher may want to explore, but this is only an outline. It is possible that, through the participant's response, another area of interest within the narrative may arise and be explored (Smith, 2004). This flexibility allows the researcher and participant greater freedom to fully investigate the participant's experience from his or her perspective. It is important that time is allowed to establish rapport with the participants as well as greater flexibility in how questions are answered (Smith and Osborn, 2008). More descriptive and detailed, extensive data may be gathered and gives the researcher the opportunity to ensure that understanding is reached by seeking elucidation of what the participant says (Brenner, Brown, \& Canter, 1985. This may be done with additional prompting or cues (Huws \& Jones, 2008; Smith, 2010) for immediate feedback between interviewer and participant, so any possible misunderstandings can be cleared up immediately. In phenomenological research, the researcher's role is to seek understanding of the experience. When this occurs within a study using IPA, the researcher is aware that the understanding of the experience is being co-constructed by the participant and researcher working together (Larkin, Watts, \& Clifton, 2008; Smith \& Osborn, 2008). A double hermeneutic occurs during this two-stage interpretation process: participants try to make sense of their world, as the researcher tries to make sense of them trying to make sense of their world (Koch, 1999; Larkin et al., 2008; Smith \& Osborn, 2008).

Phenomenology is used extensively in physical and mental health research (Cashin et al., 2008; Dickinson et al., 2006; Huus \& Enskär, 2007; Lynch \& Spence, 2008; Reid, Flowers, \& Larkin, 2005; Schur et al., 1999; Wang et al., 2010). Reid and colleagues (2005) posit that much of its popularity may be due to its contributions to the biopsychosocial approach in health research as it permits deeper analysis of the data provided by the participants, which may encompass the physical, psychosocial and environmental factors. Although some phenomenological researchers did not specifically state they were using a biopsychosocial approach in their respective studies, 
thematic analysis and discussion of the findings did, in fact, discuss biological, psychosocial and/or environmental factors of the lived experiences (e.g., Cashin et al., 2008; Huus \& Enskär, 2007; Lynch \& Spence, 2008). For this study, collecting and analyzing data using a phenomenological methodology was deemed appropriate as it allowed the lived experiences of these students with a chronic health condition to be heard, analyzed, and interpreted (Moustakas, 1994; Smith, 1995). Specifically, as the emphasis of the research was to explore what were their learning experiences which potentially could contain physical, psychological, social, and environmental elements, phenomenology provided the opportunity to include all these elements if they surfaced in the data. Interviews with participants using semi-structured questions permitted the participant and me to fully explore questions and answers, with meaningful and wideranging data gathered (Brenner et al., 1985; Smith 2010). It also provided the opening for immediate feedback between the participant and myself, so possible misunderstandings could be and were resolved (Brenner et al., 1985).

IPA (Smith, 1995, 2010) was used throughout this study. Its idiographic focus on the individual also acknowledges the researcher's involvement in the research; the double hermeneutic. It has also been used extensively in health research as psychologists have found it a useful tool in accessing others' experiences of CHCs or mental health concerns: It has made a "distinctive contribution... to a corpus of research studies" ( Smith, 2004, p. 40), used in cognitive and clinical psychology (Glasscoe \& Smith, 2010; Hill, Higgins, Dempster, \& McCarthy, 2009; Huws \& Jones, 2008; Osborn \& Smith, 1998; Schur et al., 1999). With this study's focus on students with CHCs and their learning experience, I believe it is an appropriate and useful tool throughout the study.

For analysis of the interviews given by the participants, IPA allowed an exploration of the meaning making the participant gave to the experience of being an adolescent with a CHC in school while keeping in mind the theoretical foundation of phenomenology (Glasscoe \& Smith, 2010; Smith, 2004). Inherent within IPA is the premise that providing a rich description is useful in analysis, but it recognizes that the experience being discussed deserves more than mere description and should be interpreted in order to increase knowledge and awareness of the experience lived by the individual (Smith, 2004; Todres \& Wheeler, 2001). Sometimes the speaker may not have the vocabulary to express 
adequately what he or she actually mean. IPA recognizes that the researcher, through the process of the semi-structured interview, can seek further clarification throughout the interview of what the participant is saying, in keeping with phenomenological methodology. It recognizes two forms of understanding; an understanding showing the listener comprehends what the speaker is saying and a deeper understanding occurs of what is being conveyed, what the deeper meaning is. During the analytical process involving abstract thinking, the researcher can interpret a deeper meaning and bring to light additional information (Smith \& Osborn, 2008). IPA also allows the researcher to show the "uniqueness of the individual experience" (Smith, 2010, p. 24). Smith cedes that IPA is relatively new in research analysis (2010), but he believes there are criteria within IPA that, when met, provides trustworthiness and is good qualitative research. He lists the criteria as follows:

- Clearly subscribes to the theoretical principles of IPA and is phenomenological hermeneutic and idiographic.

- It is sufficiently transparent so the reader can see what was done.

- It has coherent, plausible, and interesting analysis.

- There is sufficient sampling from corpus to show density of evidence for each theme. (Smith, 2010, p. 17)

\subsection{Ethical Clearance and Informed Consent}

The four main ethical guidelines for conducting qualitative research were my guiding principles throughout my project (Christians, 2005). All participants gave informed consent; there was strict confidentiality, an avoidance of deception, and accurate collection and presentation of the data. All research, including information sheets, invitations, consent forms, and questions, was conducted in accordance to the ethical guidelines of Victoria University of Wellington. Permission from the University and all schools involved in the data collection was obtained before any research was initiated. All participants, their parent(s), and their educators, were given letters explaining the study, its purpose, and how the results would be utilized. Students were able to participate or withdraw at any point of the study. Informed consent was required for each phase of the 
research: survey, focus groups and interviews. Consent was sought and given by their parents and the students, if students were under 16 (Appendices 8, 11).

Questions within the survey, focus groups, and interviews were formulated so they were (1) not harmful psychologically to the student and (2) did not lead the student in their answers (Christians, 2005; Kirk, 2007). Students were given the option to participate only in the online survey or in the online survey and in focus groups or interviews. Discussing a CHC could have been sensitive to students thus; all care was taken to create an environment in which they could speak in confidentiality. Focus groups and semistructured interviews were conducted within the school setting, allowing students to take part easily. These were held in a private room set aside by the coordinating contact, thus ensuring privacy. All reasonable steps were taken to ensure participants were not subjected to anxiety or stress as a result of questions within the survey, focus groups, and interviews (Wilkinson, 2008). If, during the course of an interview, the participant looked, felt, or stated he or she was unwell, the interview would have been rescheduled, but this did not occur.

\subsection{Participants}

There has been a trend with phenomenological studies to use a small sample size and allow time to give participants the opportunity to describe their experiences with additional detail or depth (Huws \& Jones, 2008; Reid et al., 2005; Smith \& Osborn, 2008). Using small samples permits the researcher to make a more in-depth analysis of the experiences and the understanding of these experiences of the participants. (Larkin et al., 2008; Smith \& Osborn, 2008). Smith and Osborn (2008) posit there is no correct sample size and phenomenological study participant numbers have varied from five (Hill et al., 2009) to thirty (Collins \& Nicolson, 2002). IPA uses purposive sampling as that provides a "closely defined group" (Smith \& Osborn, 2008, p. 56) for which the research question

will be pertinent. In this phenomenological study, it was important that participants met the criteria of eligibility, that is, that they experienced the phenomenon of having a CHC. It was also important the questions asked were relevant to the participant and that they were willing to speak to a researcher about their experience (Smith \& Osborn, 2008). Purposive recruitment for this phenomenological study ensured the participants met the 
necessary criteria for this study. Participants were: (a) aged between 12 and 19 years, (b) diagnosed with an ongoing or recurring health condition that requires, or formerly required, medical intervention, (c) the health condition had lasted for longer than 3 months, and (d) the health condition was judged by a licensed health practitioner to have had a significant impact upon the student's life. Due to privacy concerns, I could not personally contact health providers and had to rely upon Learning Resource teacher or school contact person to ascertain this information.

Data were collected from nine participants through individual interviews and 20 participants in four focus groups. Krueger and Kendall (2001) support the use of focus groups in qualitative research as they provide a forum for participants to discuss and relate shared experiences. Dunne and Quayle (2001) used focus groups in their study the wellbeing of women with hepatitis C. They believed the findings which emerged from their focus groups would not have been different if each woman had been interviewed separately. Brocki and Wearden (2007) debate this, believing that Dunne and Quayle did not provide enough evidence in this regard.

Flowers, Duncan, and Frankis (2000) used focus group data with interview data in their study of understandings of 'community' amongst gay men. Flowers, Duncan, and Knussen (2003) looked at the consequences of learning of HIV status in gay men and again used focus group and individual interview data in their study. In both of these studies, they noted there were some differences in the data collected, but they presented the mixed data as a 'synergistic effect' (Flowers, Duncan, \& Knussen, 2003, p. 669) resulting in additional data being presented and supported by the convergence of the interviews. Smith (2004) recommends that when using focus groups in an IPA study, the researcher should carefully "parse transcripts at least twice, once for group patterns and dynamics and subsequently, for idiographic accounts" (p. 50). As I expected to go over transcripts several times, I was prepared to look for these patterns when analyzing data.

Purposive sampling was used for this study and I was dependent upon my school contact person to ask potential participants if they wished to take part of my study. I was aware there was a possibility that, within their school environment, the students would know each other if I used focus groups. I agree with Dunne and Quayle's argument that 
this is a viable method of data collection from "an accessible, circumscribed and homogenous population" (2001, p. 680), and I felt their use could potentially provide either new themes or support for emerging themes. I had some reservations as I agree with the critique of the possibility of group conformity occurring (Brocki \& Wearden, 2007; Kidd \& Paschal, 2002). There is also a possibility of interpersonal dynamics influencing the topic focus. Dunne and Quayle (2001) and Kidd and Paschal (2000) believe that if moderation of focus groups takes into consideration the possibility of group dynamic issues such as not all participants sharing their views due to prevailing opinions, these can be overcome (2001). Focus groups are not only used in education research, but in communication studies and public health programs (Colucci, 2007). As focus groups were used in previous IPA studies (Dunne \& Quayle, 2001; Flowers, Duncan, \& Frankis, 2000; Flowers et al., 2003) and I was aware of the potential issues which could arise, I determined the use of focus groups in this research was deemed appropriate and that I would carefully moderate the meetings to ensure all students were able to participate and voice their opinions or experiences freely.

\subsection{Recruitment}

Participants were recruited using a nine step process. First, all high schools located within Wellington, New Zealand and surrounding areas were identified accessing the New Zealand Ministry of Education webpage's Secondary School Directory. Step 1 was my initial contact made through telephone calls to secretaries and Learning Resource teachers of the schools. I introduced myself, my study, its purpose, and set up appointments with either the Learning Resource teachers and/or principals to explain further about the research and answer any questions. Information letters were sent to principals, Learning Resource teachers, and counselors of the schools in the area regarding the study (Appendices 1,2). Step 2 was a follow up personal visit to each schools to further clarify the purpose of the study to Learning Resource teachers or other staff member, (counselor or Dean) the principal designated I meet. These individuals were the primary contacts in the schools, during which letters seeking consent were distributed with self-addressed

envelopes (Appendix 3). In Step 3, if schools were then interested in participating, the school Learning Resource teachers and/or counselors were asked to identify any pupils with a $\mathrm{CHC}$ and invite them to participate (Appendix 5). They then gave possible 
participants invitation/information letters and consent forms for the online questionnaire and/or individual or focus group interviews (Appendices 4, 6). The letter described the nature of the study, included a definition of a $\mathrm{CHC}$, and gave access information for the online survey if they wished to participate in the study (Appendix 7). Within the online questionnaire, participants were asked if they wished to contribute further, either in a focus group, individual interview, or both. It was also possible for students who were given the information letters to participate in the focus group or individual interviews without taking the survey. The process identifying recruitment of participants is shown in Figure 1 below:

Figure 1 Recruitment of Participants

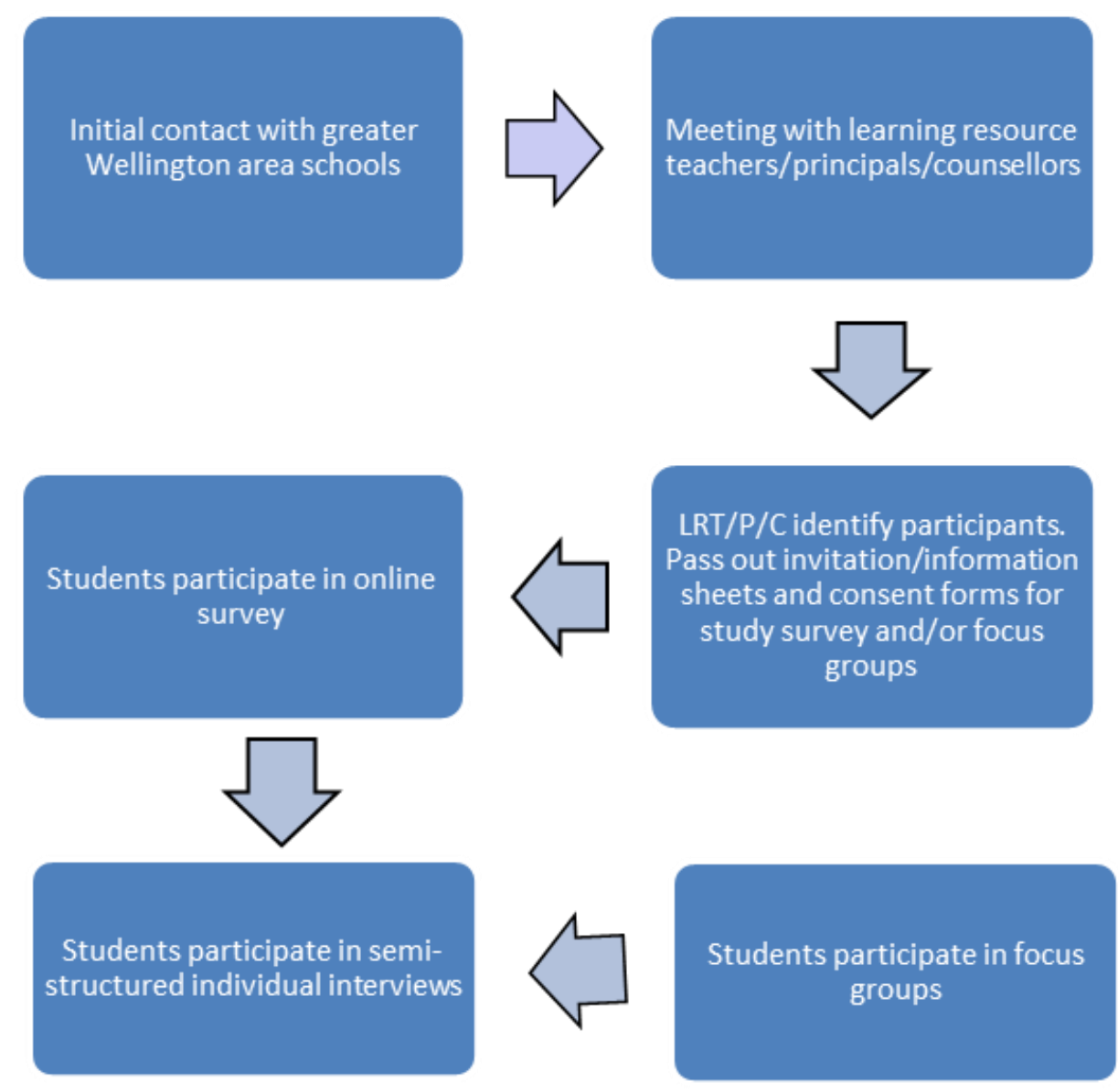

Participants were recruited between March 2011 and April 2012 at schools in the greater Wellington area in New Zealand. I contacted 63 schools in the Greater Wellington area of which 11 responded positively. Four schools subsequently declined to participate 
citing 'research fatigue' and time limitations on school personnel who were needed to identify students with a CHC. Another school later declined as the administrator was concerned there would be a stigma attached to being asked to participate in a study of students with CHCs. Six schools agreed to participate.

Participation was encouraged in various forms. Some schools published the information regarding the questionnaire in their school newspapers or put up flyers the Learning Resource teachers designed. The Learning Resource personnel in one school passed out information letters to all the teachers within the school and encouraged each teacher to identify any possible participants to do the online questionnaire. I was permitted to present the study in teacher meetings in two schools, listing eligibility requirements and distributing information and consent forms to the staff members. Initially, as seeking parental consent for minors under 16 years old as well as consent from the student himself could result in time delays, the initial age limit of the students was between 16 to 20 years old. However, using snowball recruitment, the Learning Resource teacher and/or counsellor in three schools found several students in a lower age bracket they believed might be interested in participating in the study. These students were then given the same information and opportunity to participate as their older peers. Information sheets and consent forms were given to their parents and collected by the contact individual in the school (Appendices 10,11). The principal in one school provided a list of unnamed possible participants who I then vetted to ensure the students met eligibility requirements.

\subsection{Procedures}

\subsubsection{Online questionnaire}

The online questionnaire was initially designed and developed to gather general information about the students with $\mathrm{CHCs}$ and recruit participants for individual and focus group interviews (Johnson \& Christensen, 2008). Questionnaires were used in this study as they have been used extensively in education and health research and were not going to be statically analyzed. The online and hard copy questionnaire were available for 11 months to all participants in the six participating schools, took 15 to 20 minutes to complete, and information could be given confidentially. I checked the status 
of the online questionnaire daily during the data collection phase to ascertain participation.

\subsubsection{Individual interviews}

Data collected via in-depth interviews and focus groups allowed me to collect and analyze in detail how a participant perceived and experienced his or her particular experience (Flowers et al., 2003; Smith \& Osborn, 2008). Initially, most students volunteered to participate through the online questionnaire and were contacted via email where I introduced myself and further explained the study. This also allowed me to confirm the student's interest in participating in this research. Two students preferred to be interviewed in a focus group while others volunteered for both. Time and place for interviews were agreed upon and subsequently confirmed via email. An information sheet, interview questions, and consent form were sent via email (Appendices 7, 8, 9). The interview guide allowed the participant to become familiar with the topic and issues to be discussed during the interview, time allowing. This was especially important due to time constraints and permitted me to make the best use of the time available. The questions posed were used as a guide to give flexibility that permitted variations with the order of the questions as well as the advantage of wording questions spontaneously, allowing a natural conversational style to develop (Patton, 2002).

When I met with the students for their interviews, they were given a detailed explanation of the study, their rights, and written consent was then obtained. Students were informed the interviews were going to be digitally recorded and had the opportunity to change or delete any part of their interviews when these had been transcribed. Interviews were conducted in participants' schools, in a private room at the student's convenience. Interviews occurred during a study hall time, after school, or during their lunch time and I provided either lunch or a healthy snack depending on the time. While they ate, there was time to establish a connection with the students. All interviews were digitally recorded and transcribed by a transcriber who signed a confidentiality agreement (Appendix 12) or me. 


\subsubsection{Focus group interviews}

In this study, once students were recruited by the schools' Learning Resource teacher or Dean to participate, letters introducing myself as the researcher, the study, its purpose, and the student's rights were given to these students by the Learning Resource teacher, counselor, or Dean. If a student was under 16 years old, information letters and consent was sought and given by participants and their parents (Appendices 10,11). Students and parents were informed focus groups would be digitally recorded.

\subsection{Data Collection}

\subsubsection{Questionnaire.}

I was able to speak in three school meetings to promote the study and school newspapers and newsletters promoted my research. Information sheets were passed out by Learning Resource personnel which contained the URL website. My contacts at each school informed me that they believed there were between 50 up to 150 possible participants.

\subsubsection{Pilot online questionnaire}

The wording of questionnaires is of vital importance to ensure the clarity of the instructions, questionnaire items, and ease of layout (Cohen, Manion, \& Morrison, 2007). Piloting a questionnaire allows the researcher to gather feedback on these items as well as on length and timing of the questionnaire, ease in answering, readability of the survey items, and to identify redundancy (Cohen et al., 2007). A pilot online questionnaire was conducted with nine participants ranging in age from 16 to 21 years old. All participants were former students of the researcher with $\mathrm{CHCs}$, as stipulated in the eligibility criteria. Changes were made to the questionnaire based upon their feedback, including clarification of some items and eliminating redundant questions (Appendix 13).

\subsubsection{Study questionnaire}

The self-administered online questionnaire was available for 11 months to all qualified participants. Students indicated consent at the beginning of the questionnaire, whether online or on the hard copy. The survey design allowed for branching questions so participants' responses would determine the next question where necessary and most 
questions could be answered by point-and-click with the mouse. The questionnaire contained some open-ended questions and sought information on what students felt worked in schools to assist students with a CHC. It asked what accommodations, if any, were in place at school that the student was aware of, if the student felt the CHC impacted learning, and if so, how. It also asked who assisted them in their learning success, including asking if family, health providers and friends were a part of this learning. The questionnaire enquired about the student's plan after high school, any dominant issues, concerns, solutions within and without the school environment, and accommodations or support from health provider, teachers, peers, and parents. Demographic information such as age, gender, year group in school, ethnicity, and parental education, was gathered. CHC related questions were asked regarding the nature of illness, its severity, treatment, and duration. I expected to discover various issues that were either new or related to the ones discussed in the literature review and this would enable me to refine interview and focus group questions used in the study.

The six participating schools received the description and invitation for students which were to be distributed to the students. Four schools distributed the information via Learning Resource teachers and/or counselors to eligible students. I was given approximate numbers of students with $\mathrm{CHCs}$, however, there was no way of my knowing how many possible participants there actually were. Five schools received 150 invitations each. One of these schools did not distribute the survey. At this school, the administrator preferred the students to complete the online questionnaire in hard copy form, therefore he invited qualified possible participants to meet in a hall and learn about the study. Forty students attended this meeting. After I was introduced, I explained the purpose of the study and students who chose to participate were invited to remain and fill out the hard copy questionnaire. Twenty students completed the questionnaire. None took the questionnaire home to return it later to me in sealed envelopes that I had prepared as a possibility this could occur.

Participation in this questionnaire phase of the study resulted in only 42 completed questionnaires, including the online version. Within the 42 completed surveys, ten students volunteered to participate in individual interviews or contacted me via my email provided in the information sheets. Two schools did not have any students who 
participated in the survey; however, in one of these two schools, student volunteers for individual and/or focus group interviews were recruited by the Learning Resource teachers, counsellors, or Year 12 Deans as explained previously. I was not given the exact number of students with CHCs in each school; there is no way of my knowing how many possible participants there were. As this was a phenomenological study with the intent to explore the learning experiences of secondary students with $\mathrm{CHC}$, neither statistical nor numerical analysis was required. I read these questionnaires to find commonalities that I thought could possibly assist with formulating semi-structured interview questions, but general commonalities did not emerge. Six of the 42 questionnaires were not completed. With such poor distribution and results, I found the survey was not a useful tool in this study and did not use it in my findings. However, it yielded student volunteers for individual interviews and/or focus groups.

\subsubsection{Individual interviews}

\subsubsection{Pilot Interview}

A pilot interview, like a pilot questionnaire, gives the researcher an opportunity to gather feedback on the comprehensibility of the questions, ease in answering, and the time needed for interviews to be conducted (Kirk, 2007; Sartain et al., 2000). All students who volunteered to participate in individual interviews through the online questionnaire were asked to give the researcher times that he or she would be available. The first student to respond, provide his email address, and meet the criteria was selected for the pilot interview. A letter explaining the purpose of the study, his rights as a participant, and a consent form was sent to his address confirming if he wished to participate in the study in a pilot interview. When he replied affirmatively, we agreed upon a time and place at the school that was convenient to him and ensured his privacy. During the first interview, in August 2010, we met in a private room away from the classrooms and I reiterated his rights regarding privacy and the opportunity to amend his answers either during the interview and when he had received the transcript. This student was interviewed twice and questions found to need a great deal of repetition or paraphrasing were subsequently rephrased to be better understood. 


\subsubsection{Individual Interviews}

Seventeen students initially volunteered for individual interviews either through the online questionnaire or through the Learning Resource teacher or Dean. I did not have access to their medical files for privacy reasons so I relied upon the criteria information I gave to the staff member for recruitment to be followed. During the initial email exchange, I ascertained the student's CHC diagnosis, which they repeated during the interviews and/or focus group meeting(s). Two students did not meet the criteria for this study, three students moved away before they could be interviewed, and five students changed their minds without providing a reason. One student did not show up at the two interviews scheduled; he later declined to participate, citing time limitations. This left me with six participants. Participation was voluntary and withdrawal could occur at any time; I did not press any student to participate if they chose not to do so. Three additional students volunteered to participate in individual interviews after they had taken part in the focus group interviews.

Students who volunteered through the online or hard copy questionnaire supplied their email address. I consequently wrote them an email and asked if they wished to participate in interviews. Initially, eight students agreed to be interviewed in August and September 2010. I met with three students for their first interview in August 2010. I introduced myself and the study, its importance, and the need for confidentiality was emphasized. Students were told each interview would be recorded and transcribed, either by myself or a transcriber who had signed a confidentiality agreement. At this time, students were given the option of leaving without being interviewed, none did. Students were given healthy snacks and juice at the beginning and end of the interviews which established rapport.

By the end of August, I met with three students for their first interviews, but unforeseen events prevented me from following up with a second interview at that time. Subsequently, interviews were postponed for over a month. When I resumed data collection at the end of September, three students who had previously volunteered declined to participate as they had moved away from the area. The three students whom I had already interviewed met with me for a second interview. Difficulties arose in 
scheduling further interviews due to school holidays. When students returned to school at the end of October 2010, other difficulties arose with scheduling due to upcoming examinations, however, two additional students were interviewed once. They were unable to be interviewed again due to examination conflicts. A counselor at a participating school informed a former student, who had recently graduated from high school, about the study and he contacted me. As he met eligibility requirements, we met once in November 2010, and again in January 2011. At this time, there were six participants.

School was not in session during most of December 2010 and throughout January 2011. It was not possible to recruit further participants for individual interviews. Contact was reestablished with participating schools for further recruitment of students when the school year commenced in February 2011. This did not yield positive results for individual interviews, but as students were recruited by my school contacts for focus group discussions, I began to meet with these students with the expectation these would yield data and possible participants for individual interviews. This resulted in three focus group students who volunteered to participate in individual interviews.

During interview discussions, it was important that I was an active and empathetic listener to establish trust with the participants (Kirk, 2007). Audiotaping was used, with prior consent, to ensure accuracy and transcribed interviews were reviewed several times to ensure accuracy in recording the students' voices. In this way, the original data were preserved. Interview times varied. Some interviews were shorter than others, due to time constraints however, main questions were answered Sample individual interview questions are listed in Table 1.

Table 1 Sample Interview Questions

Interview Questions
What do you think is helpful in or around the school setting?
What health issues do you feel impacts your learning?
How do they impact your learning?
How do you/Can you tell me how you feel about this/these?


In total, I had nine participants for individual interviews. Five students met with the researcher once and interview times varied between 42 minutes to 72 minutes. Three of these students also participated in student focus groups. Four students met with me twice and interview times varied from 74 minutes to 165 minutes total.

During and after these interviews, a review of their transcripts and initial data analysis provided me with evidence that there were several overlaps of themes and subthemes within the individual interviews and focus group discussions. Smith describes density of data as:

Sufficient sampling from corpus to show density of evidence for each theme include:

One to three extracts from every participant for each theme;

Four to eight extracts from at least three participants for each theme;

More than eight extracts from at least three participants for each theme or extracts from half the sample for each theme. (Smith, 2010, p. 17)

Time restrictions were pressing and with the convergence of similar themes, there appeared enough density of evidence of each theme, as Smith (2010) proscribes above, to move forward with my analysis. An example of density of data in this study is the subtheme coping in Section 4.3.4. There are over a dozen extracts from seven participants in individual interviews which meets the criteria of extracts from at least three participants in the individual interviews. The subtheme accept you for who you are in Section 4.4.2 contains over 14 extracts from two focus groups and seven individual interviews, which meets Smith's criteria. As will be shown in Chapters Four and Five, the superordinate themes contain ample extracts from individual and focus group participants to meet his criteria.

Interviews were transcribed either by me or by a transcriber who signed a confidentiality agreement. I reviewed the transcripts several times to ensure accuracy in recording the students' voices. Once transcribed, participants were sent a copy of the transcribed interview(s) for member checking, allowing them the opportunity to change 
or delete anything they had said if they so desired. Students were given the opportunity to see and comment upon the interpretations I made. This ensured the reliability and validity of my own interpretations and allowed them to see that their words and meaning were treated reliably (Seidman, 2006).

Nine students were individually interviewed in this study, seven boys and two girls, between 12 to 19 years old. Their CHCs were epilepsy $(n=1)$, migraines $(n=1)$, eczema $(n=1)$, diabetes $(n=1)$, traumatic brain injury and Celiac's disease $(n=1)$, ADHD $(n=2)$, cancer $(n=1)$, spina bifida/cerebral palsy $(n=1)$. One student (with ADHD) also revealed he was told he had Asperger's Syndrome (AS), part of the Autism Spectrum Disorders during the interview. He had participated in a focus group and did not mention then he had been diagnosed with AS. His mother subsequently told me medical personnel had confirmed Asperger's Syndrome after testing her son. Eight of the nine students were still under medical treatment and/or supervision for their CHC. Participant and original names of individuals have been changed to guarantee confidentiality. Demographic data for the student participants for interviews are presented in Table 2.

Table 2 Individual Interview Demographics

\begin{tabular}{|c|c|c|c|c|c|c|c|}
\hline Student & Gender & Age & $\mathrm{CHC}$ & $\begin{array}{l}\text { Time with } \\
\text { CHC }\end{array}$ & Medication & $\begin{array}{l}\text { School } \\
\text { Year }\end{array}$ & $\begin{array}{l}\text { School } \\
\text { Decile }\end{array}$ \\
\hline Andrew & Boy & 13 & $\begin{array}{l}\text { Type } 1 \text { Diabetes } \\
\text { (T1D) }\end{array}$ & 6 yrs. & Yes & 9 & 10 \\
\hline Anna & Girl & 12 & Epilepsy & $>4$ yrs. & Yes & 10 & 5 \\
\hline Bart & Boy & 17 & Eczema & All his life & No & 12 & 4 \\
\hline Bridget & Girl & 16 & Migraines & $>4$ yrs. & Not for 2 yrs. & 12 & 5 \\
\hline Esau & Boy & 19 & Cancer survivor & $8 \mathrm{yrs}$. & Yes & $\begin{array}{l}* \text { See } \\
\text { note }\end{array}$ & 10 \\
\hline James & Boy & 13 & $\begin{array}{l}\text { Traumatic Head } \\
\text { Injury (THI), Celiacs }\end{array}$ & $\begin{array}{l}<1 \text { yr., } \\
>3 \text { MThs }\end{array}$ & Yes & 9 & 10 \\
\hline Luke & Boy & 16 & ADHD, Asperger's & All his life & Yes & 12 & 4 \\
\hline Mark & Boy & 17 & $\begin{array}{l}\text { Cerebral Palsy (CP), } \\
\text { Spina Bifida (SB) }\end{array}$ & All his life & Yes & 13 & 4 \\
\hline Simon & Boy & 16 & ADHD & 9 yrs. & Yes & 12 & 10 \\
\hline
\end{tabular}

* Esau was in his first year at a technology school and was recruited by his counsellor. He was accepted as a participant because he wanted to share his experience of learning while in secondary school and having cancer. 


\subsubsection{Focus group interviews}

Focus groups are considered to be productive in data collection when studying a specific research population as this collective contribution can add credibility to the data and focus groups were used in this study (Flowers et al., 2003; Tomkins \& Eatough, 2010; Webb \& Kevern, (2001). There are some inherent difficulties in using focus groups as discussed above in Section 3.7. For example, possible coercion of opinions may occur (Kidd \& Paschal, 2000) or some individuals may not want to offer a dissenting opinion. To deter this possibility, I conducted one focus group at a time and offered specific questions for discussion, stepping in if one member of the group was dominating the discussion, to encourage further discussion or elicit the opinion of a quieter member of the group. Difficulties in scheduling student focus groups arose, but flexibility in time and numbers aided in creating a workable solution for all participants involved. Arrangements for focus groups meetings were coordinated with the schools' learning resource teacher and held in private rooms during the students' lunch breaks. The focus group meetings occurred in an informal setting and, in order to allow time for the students to relax and feel comfortable, I provided lunch. While they ate, I introduced myself, explained the study and answered questions. This informal atmosphere provided a laidback ambiance for them. Three students from one focus group volunteered to be individually interviewed after their focus group meeting.

Learning Resource teachers or year 12 Deans at their respective schools recruited participants for focus group interviews. There were 20 students, aged 12 to 17 years old, who participated in four focus groups, one of which met twice. Fifteen participants were boys and five participants were girls. Chronic health conditions varied: Two students were being treated for ADHD, asthma $(n=5)$, Crohn's disease $(n=2)$, diabetes $(n=4)$, eczema $(n=1)$, glandular fever $(n=1)$, migraines $(n=2)$, rheumatic fever $(n=1)$,

spina bifida/cerebral palsy $(n=1)$, and one student had a traumatic head injury and Celiac's disease. During Focus Group 3's meeting, three students disclosed they had eczema.

One school had student participants in focus groups but did not distribute the online survey. That school's Year 12 Dean identified students from years 10-13 with a CHC 
and asked those students if they wished to participate in the study through focus groups. Nine students volunteered. In other schools, students volunteered to participate in focus groups through the online survey. At the end of each focus group meeting, students were asked if they wished to contribute further in semi-structured interviews. Fifteen of the students who took part in focus groups did not participate in individual interviews. Difficulties in student focus groups occurred due to scheduling issues. Flexibility in time and numbers was essential in creating a workable timetable for all subjects involved. Of the 24 total participants in this study, three were Pacific Islanders, six students were Māori, and 15 students were European New Zealanders. Table 3 provides the demographic characteristics of the participants although neither Table 2 nor Table 3 provide ethnic information.

Table 3 Focus Group Student Demographics

\begin{tabular}{|c|c|c|c|c|c|}
\hline Focus Group & Gender & Age & Illness & School yr. & Time with $\mathrm{CHC}$ \\
\hline \multicolumn{6}{|c|}{ Pilot F. Grp 1 School 3 Decile 10} \\
\hline Rich & boy & 16 & Diabetes & 12 & Unknown \\
\hline Lyle & boy & 15 & Diabetes & 11 & $1 \mathrm{yr}$. \\
\hline James & boy & 13 & THI, Celiac's & 9 & $<1$ year \\
\hline Simon & boy & 16 & ADHD & 12 & Since little \\
\hline Kevin & boy & 15 & Diabetes & 11 & $1 \mathrm{yr}$ \\
\hline \multicolumn{6}{|c|}{$\begin{array}{ll}\text { F. Grp } 2 & \text { School } 5 \text { Decile } 4\end{array}$} \\
\hline Jenna & girl & 16 & Migraines & 12 & 2 yrs. \\
\hline Bart & boy & 17 & Eczema & 12 & Since little \\
\hline Luke & boy & 16 & ADHD, Asperger's & 12 & Since birth \\
\hline Mark & boy & 17 & Cerebral Palsy, Spina Bifida & 13 & Since birth \\
\hline \multicolumn{6}{|c|}{ F. Grp $3 \quad$ School 5 Decile 4} \\
\hline Angela & girl & 17 & $\begin{array}{l}\text { Glandular Fever, Eczema } \\
\text { Migraines }\end{array}$ & 13 & 4 yrs. \\
\hline Asher & boy & 17 & Asthma; Eczema & 13 & Since little \\
\hline Seth & boy & 17 & Asthma, Eczema & 13 & Since little \\
\hline Tabitha & girl & 17 & Migraines & 13 & 2 yrs. \\
\hline Philip & boy & 17 & Asthma & 13 & Since little \\
\hline F. Grp 4 & School 6 & Decile 2 & & & \\
\hline Bruce & boy & 16 & Diabetes & 12 & 6 yrs. \\
\hline Daniel & boy & 14 & Crohn's Disease & 10 & 6 yrs. \\
\hline Mahina & girl & 15 & Rheumatic Fever & 11 & $1+y r$ \\
\hline Haimi & girl & 14 & Asthma & 10 & Since little \\
\hline Chris & boy & 14 & Crohn's Disease & 10 & $1+y r$ \\
\hline Follow-up DJ & boy & 14 & Asthma & 10 & Since little \\
\hline
\end{tabular}


Students in the focus groups were given healthy sandwiches, fruit, and juice at the beginning of the meetings. Students were given the option of leaving without being interviewed if they so desired. None did so. I emphasized confidentiality be kept within the group and they readily agreed not to discuss who had attended the focus group sessions with other students to ensure the privacy of those involved. Paper and writing instruments were available for any participant who wished to share thoughts or feelings in writing. None did. All participants were very open to speaking about their $\mathrm{CHC}$ and sharing their experience of learning.

Although the main questions for each group were similar, each group had its own dynamic. There was a tight schedule regarding time and some areas were more discussed than others in each focus group. After lunch, the focus group meetings lasted between 32 and 50 minutes. At each group meeting I found that these students had not met as a group before and, initially, there was some shyness which dissipated by the time they finished eating lunch. When they expanded on a particular area naturally, my role was to ask for clarification occasionally or encourage students who were quieter than their peers to join in the conversation. Student focus group discussions were framed around the following ideas:

1. Does a chronic illness affect your learning? Can you describe how?

2. Can you describe what school is like when you have a chronic illness?

Focus group interviews were audiotaped, with prior consent, to ensure accuracy and subsequently transcribed by me and, at times, a professional transcriber. As with the individual interview transcripts, I reviewed the transcripts several times to ensure accuracy in recording the students' voices. Once transcribed, all focus group participants were sent a copy of the transcribed interview(s) giving them the opportunity to change anything they said if they wished and to read my interpretations. As with the individual interviews, this member checking ensured the reliability of my own interpretations and allowed the participants to see that their words and meaning were treated reliably (Seidman, 2006).

\subsection{Data Analysis: Interpretive Phenomenological Analysis}

The phenomenological method of analysis permits the researcher to understand what the experience is like from the participant's point of view and this assists the researcher 
to make sense of the participant making sense of his experience. It acknowledges the role the investigator plays in the research process by recognizing the insider (emic) and outsider (etic) worldviews. The participant tells his story in his words and the outsider, the investigator, makes sense of the experience through concentrated engagement with coding, organizing, integrating, and interpreting the data within from the verbatim transcript of the participant's interview. IPA (Smith, 1995, 2010) was used to analysis the interviews given by the participants. Semi-structured interview questions allowed me to prompt participants and provided the opportunity to seek further clarification during the interview. This interaction resulted in the consequence that when I rephrased any discussion points to clarify the meaning intended by the participant, the data were further constructed with the participant. It is, thus, important to acknowledge the active role the researcher plays in data collection.

After each student's interview was transcribed, I listened to each interview several times whilst reading the transcript to ensure reliability of the transcript. This gave me the opportunity to become familiar with the data (Smith, \& Osborn, 2008). There were moments in all the transcriptions when dialogue was either too soft to be heard or, in focus groups, the students were all speaking at once, making it difficult to understand what was said. Once I was assured of the veracity of the transcript, I continued reading and rereading the transcript a number of times. Initially, I noted any significant words or phrases on the margin; I also made notes of potential themes and began coding. Subsequently, I sent the transcribed interview with my initial summary to the student for member checking to ensure accuracy and rigor.

During consequent rereading of the transcript, patterns of similar ideas began to emerge which I noted on the printed copy of the transcript. Initially, I used NVivo8, a qualitative data analysis software, to enter and store concepts and themes extrapolated from field notes and transcripts from interviews and focus groups. NVivo8 was useful in that I engaged further with the texts, however, I found using tables I designed to be a more constructive tool to organize my coding (Appendix 14). With repeated readings of each interview I began to condense and define the codes into emerging clusters or subthemes (Appendix 15 provides codes and definitions). I carefully considered the emerging themes to see if there were interrelationships and continuously checked the subthemes against the 
students' interviews to ensure the themes were representative of what was being said. Minor subthemes emerged from the initial coding, but these were not always discussed by all the participants. Subthemes were synthesized into four superordinate themes emerging from the data and supported by participants' statements (see Appendix 14).

\section{Figure 2 Process of Interpretative Phenomenological Analysis}

Semi-structured interview set up with participant. Questions sent before interview.

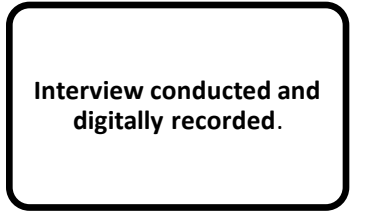

terview conducted and digitally recorded.

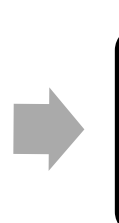

Transcription read severa times with notes, comments annotated beside interesting points or significant statements. Basic meaning making by researcher.

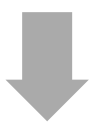

Comments listed then coded into words or phrases encapulating meaning of text (findings).

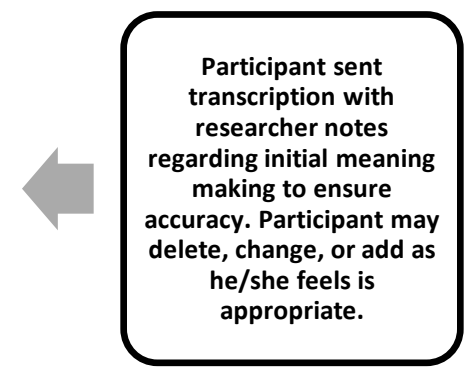

List of similar code words or ideas compiled into clusters/categories. Goal is to encapsulate meaning of text. Higher level of abstract thinking required.

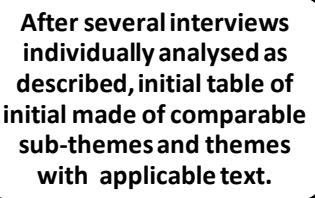
individually analysed as described, initial table of initial made of comparable sub-themes and themes with applicable text.

Remaining interviews analysed as described previously. comparable sub-themes
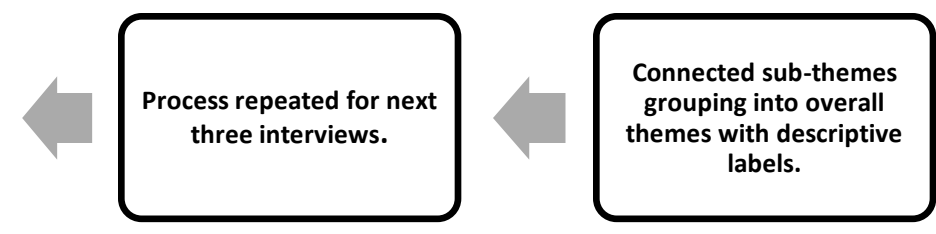
and themes with applicable text.
Master table used for writing up results. Participant quotes used to support findings.
Interview transcribed, then reviewed against digital recording to ensure accuracy.

Transcription initially read by researcher, general notes taken, summarized.
List of sub-themes compiled and connections between or amongst them sought.

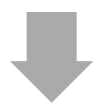

Connected sub-themes grouping into overall labels. 
All nine students' individual interviews were treated independently although, by the third interview, similar codes and clusters across the interviews became apparent. At this stage of my research, I sought out a professional with experience working with adolescents and young adults as a peer reviewer of my data analysis. We met several times and spent time reviewing and discussing most of the texts. Disagreements were also discussed and provided different perspectives of the same data, enabling me to see other possible interpretations.

\subsection{Limitations}

Phenomenology as philosophical inquiry seeks to understand the very essence of a phenomenon (Smith \& Osborn, 2008). In qualitative research, phenomenology is used quite frequently in research as a method for capturing the narrative of phenomenon. In this study, I wanted to understand what the learning experience is for adolescents with a CHC. I interviewed students individually as well as in focus groups. A possible critique of my study is the use of focus groups which are not generally used in phenomenological studies as usually it is the narrative of individuals that are sought. However, focus groups have been used in phenomenological studies using IPA (e.g. Dunne \& Quayle, 2002; Flowers et al., 2003; Tomkins \& Eatough, 2010).

A limitation in using focus groups is that they can sometimes be influenced by assertive individuals who may become de facto speakers for the group (Dunne \& Quayle, 2002; Tomkins \& Eatough, 2010). However, in this study, the students encouraged each other to share and I was careful to "honor the group and the individual" (Tomkins \& Eatough, 2010, p. 249). The focus groups were quite useful, not only for sharing their experiences with me, but for them as individuals. The students within the focus groups stated they had never had the opportunity before to discuss their $\mathrm{CHC}$ in a setting with peers like the one in which they participated. They felt comfortable enough with each other to speak quite openly about feeling pain, frustration, even experiences of being bullied. A limitation in working with the focus groups in this research was lack of time. The meetings were conducted during school lunch hours in order to maximize the number of possible participants. In two schools, the Dean informed teachers that the student was participating in my study and was excused from the class following their lunchtime. I was 
acutely aware these students were missing classroom time and endeavored not to go into class time. Two or three meetings for each group would have allowed more data to be collected. The difficulty I encountered when I invited the different schools in the region to participate was unfortunate as my approach towards the topic was positive. I was interested in understanding what the students' experiences were of learning and what was helping as well as who has helping them learn. Some administrators and principals, after we met, expressed concerned about the possibility of a student with a $\mathrm{CHC}$ feeling he or she would be stigmatized if asked to participate in this study. This perception from principals and administrators that a student with a CHC could feel stigmatized if invited to participate was, perhaps, the most discouraging limitation. I endeavored to reassure these individuals as I had anticipated this possibility. I specifically designed the study's approach with respect and sensitivity towards the young people I anticipated would take part. Although I was emphatic about the positive approach as well as the confidentiality of the research, they were not dissuaded from their stance that participating could 'brand' the student with stigma. It is possible that this concern educators or administrators have of stigma may be a lack of understanding or knowledge regarding $\mathrm{CHCs.}$

Another limitation is that this study did not explore the impact of culture on students' experiences. It may be that cultural influence has a role in how administrators and teachers approach or not approach students with a CHC or in how students understand and describe their experiences of learning or of having a CHC. In some schools, neither the invitation nor the questionnaire that I designed, were distributed properly, thereby limiting my ability to assess the questionnaire more rigorously as well as reducing the possibility of additional student participants either for individual or focus group interviews. Several schools cited 'research fatigue' as they told me they were often approached by other researchers to participate in various studies.

Another limitation of this study is that the sample was small, a total of 24 students, and findings cannot be generalized to a larger population. Phenomenological studies are conducted with small samples, but in this case it cannot be, and is not assumed, that all viewpoints were expressed regarding how learning is experienced when an adolescent has a CHC. Although the literature speaks to how development is impacted by a CHC, this was not broached by me or explored in this study. The age of the adolescents in this study 
ranged from 12 to 19 years old. Developmentally, Esau, at 19, and Tabitha, 17, were more capable of abstract thought and of understanding the possible future impact of their $\mathrm{CHC}$ than Andrew, at 13, and Anna, at 12, although Andrew and Anna appeared quite mature for their age. While some may argue the age range is a limitation due to possible developmental cognitive differences, I posit the age range was an advantage in that it allowed for the possibility of very diverse experiences and viewpoints. The limitations of this study can be used as considerations in designing or approaching schools for future studies.

\subsection{Trustworthiness}

It is critical in qualitative research to show trustworthiness. Research must be credible, have transferability, dependability, and be able to be confirmed (Malterud, 2001). Quantitative research is presented from a realist point of view with as little bias as possible and reliance upon statistical validation. Qualitative research is subjective, uses nonstatistical means and is open to interpretation (Johnson \& Christensen, 2008). In much of qualitative research triangulation is used to "reduce the likelihood of misinterpretation" and "various procedures are employed-redundancy of data gathering and procedural challenges to explanations" (Denzin \& Lincoln, 2008, p. 133) Reliability and rigor in qualitative research are shown through a thorough description of the data collection process, the depth and breadth of the analysis completed, a description of the methodological skill of the researcher and an in-depth engagement with the topic. Striving for qualitative research to be credible permits its findings to be trusted. "If they [findings] can be trusted, they must be confirmable, valid, and reliable" (Denzin, 2009, p. 149).

Triangulation involves "a process using multiple perceptions to clarify meaning, verifying the repeatability of an observation or interpretation" (Denzin \& Lincoln, 2008, p. 133). Creswell recommends different strategies for triangulation as he, too, considers it important "to examine evidence from different sources... to build a coherent justification for themes" (2003, p. 196). He recommends member checking, clarifying bias through self-reflection, peer debriefing, and rich detailed description to convey findings (2003).

Transferability (versus generalizability in quantitative research), in qualitative research, is the ability of the reader to generalize the findings of a study to another group 
(Graneheim, \& Lundman, 2003; Morrow, 2005). For transferability criteria to be met clear descriptions of the context, selection and criteria of the participants, data collection and analysis are necessary. Phenomenological research does not make generalizations due to the idiographic nature of the research, but it seeks to contribute to transferability to other settings through providing rich descriptions of contexts, participants, and phenomenon (Denzin \& Lincoln, 2005; Smith, 2004). Presentation of findings with participant quotes is essential to support transferability.

Field notes are essential, as is critical self-reflection about preconceptions before and after interviews digitally recorded. Credibility was established with observation in the field (field notes), engagement with the participants in interviews, the used of peer debriefing described below, and member checking emails regarding interpretations of data collected. Thematic commonalities amongst the participants' experienced is acknowledged, discussed, and supported with connections clearly made between themes and verbatim extracts (Earle 1999; Smith, 2004). In this study, the use of field notes, recordings and a diary in which I noted my personal and professional biases regarding CHCs and learning, and individual and focus group interviews and member checking provided and improved credibility.

Trustworthiness allows the reader to understand what actions were performed, and how and why these occurred (Graneheim \& Lundman, 2003; Krefting, 1991; Morrow, 2005). Various methods of showing this were through (1) an audit trail, (2) peer review, and (3) regular discussions with peer IPA researchers and supervisors throughout the process. Verbatim extracts in this study illustrate themes so the reader can see connections between the raw data and the interpretation (Morrow, 2005; Seale, 1999). I established an audit trail which ensures dependability by discussing availability of the raw data, how it was collected through stepwise procedures and a detailed description of the analysis showing how codes, patterns, and themes were developed in order to increase confirmability (Appendices 14, 15). The superordinate themes of this study emerged from and are supported by the data collected. It is possible, however, that others may find evidence of other themes. Confirmability acknowledges that this research was not objective but did represent as best as possible the phenomenon and its characteristics (Graneheim \& Lundman, 2005; Morrow, 2005). To ensure the integrity of the data, it was 
important to have the data, my analysis procedures, and the findings related so as to allow the reader to confirm the adequacy of the findings (Denzin \& Lincoln, 2005; Morrow, 2005).

The measures I adopted during the study that supported a self-reflexive stance (an approximated bracketing) included discussions with peers involved with young people, digitally recording my impressions, feelings, and thoughts after each interview, note taking during the interviews, de-briefing after interviews, and monitoring my preconceptions before, during, and after interviews and analysis (Koch, 1999; Smith 2004, 2010). Before commencing interviews with the student participants, after the interviews, and during analysis, I reflected at length on my presuppositions and concerns in writing field notes and in recordings I made on my phone or IPad. Acknowledging my concerns, etc. so I could consciously set them aside was helpful during my analysis (Smith, 2004). Not surprisingly, as someone working with IPA, I found myself moving between a desire to bracket my preconceptions and concerns through the self-reflexive process, and my awareness that whenever I asked for clarification of participants' statements a new construct could occur. I was especially conscious of this when my participants were younger. These young people, however, responded positively whenever this occurred and often went on to share more of their experience. I was very conscious these students' experience of their CHC was unique to them, and I was committed to the purpose of my study which was to allow their experience and voices to be heard.

During the interviews, I wrote brief notes describing their demeanor and noted any words they emphasized while speaking. After each interview, I recorded my thoughts describing the interview and my interaction with the student. This allowed me to note and set aside personal feelings that sometimes arose during the interviews. I met with a counsellor who worked with youth to debrief which afforded another opportunity to reflect and set aside any possible personal biases. This continuous reflection during data collection and analysis helped me set aside my experience of teaching students in my classes who had had a CHC and having two daughters with a $\mathrm{CHC}$, so I would not assume ideas that were not in evidence within the data. 
During transcription and analysis, I listened to the digital recordings frequently to ensure accurate transcription as well as note any possible emotion that was evident such as good humor (laughter). An initial analysis occurred during transcription, followed by a member check so that participants were able to review descriptions and the interpretations of their experience and/or change any statement therein. This task was performed to provide reliability, thus ensuring participants' perceptions were accurately recorded. Students did not respond that they wished to change anything within the written descriptions.

To further assure the reliability of my coding, I recruited a professional colleague with experience in counselling youth to independently code eight of the nine student transcripts and two of the four focus group transcripts. We then compared our coding and there was a high level of agreement but, like Barbour (2001), I found the disagreements interesting and valuable as they presented other interpretations for me to consider. Disagreements were helpful in that they propelled me to be thorough in my analysis and reinvestigate my data more in depth. I also met with a supervisor during my analysis to review and discuss coding. At this time I discussed concerns of bias or misinterpretations. Confirmability and dependability of this study was addressed through the detailed description of my research methods for stepwise replication, peer examination, coding procedures (each transcript was coded separately).

\subsection{Summary}

This chapter discussed the methodology chosen to gather and analyze the data in this study. Emphasis was placed upon phenomenology as this informed not only my theoretical construct, but was also used as a methodology for my research design and analysis. Data collection and analysis was based upon Interpretative Phenomenological Analysis (IPA) (Smith \& Osborn, 2008). Ethical approval and consent was sought and obtained and is described herein. Participant requirements and recruitment were described as were the procedures used to allow transferability in other qualitative research, for possible further research. Semi-structured interviews with nine individuals and four focus groups with 20 students provided me the opportunity to gather descriptions from my student participants and, during the process, seek clarification of any points in the 
discussion I did not understand. Member checking in the course of analysis also enabled me to avoid confusion or misinterpretation of the data. Steps used to ensure trustworthiness or rigor and credibility were described, as were limitations of this study. Findings from the data analysis of the individual and focus group interviews produced four main superordinate themes that will be presented in the following chapters. 


\section{CHAPTER FOUR \\ THE CHRONIC HEALTH CONDITION EXPERIENCE and IT'S SOMETHING THAT'S BECOME A PART OF ME}

\subsection{Introduction}

The aim of this study was to investigate the learning experiences of students with chronic illness regarding their schooling in a New Zealand context. Sub-questions were how, if at all, does their CHC affect their learning experience, and where/what learning environments do they participate in and from whom are they learning? This chapter and Chapter Five discuss my findings. Firstly, I briefly introduce the nine student participants and present the four superordinate themes. Two superordinate themes are discussed in this chapter. The first theme presents how, if at all, the students' felt their respective CHC affected their learning experience and the second theme presents what, if any, adjustments occurred in themselves and/or their learning as a result of their CHC. While discussing adjustments these students made, they also spoke about their identities and this will be presented in this chapter. A descriptive phenomenological methodology was employed to gather the data through individual and focus group semi-structured interviews questions that allowed me to prompt participants and provided the opportunity me to seek further clarification. Using IPA allowed me to explore the meaning making the participant gave to the experience of learning with a $\mathrm{CHC}$.

I interviewed nine student participants, seven boys and two girls, who were between the ages of 12 and 19 inclusive, attending Greater Wellington high schools in New Zealand. In this study, the different CHCs these students had varied. Anna was diagnosed with epilepsy although she had not had an absence seizure for a couple of years and was no longer taking medication for it. Andrew had Type I diabetes (T1D) and Bart had eczema; a few years prior to our interview he had had a tumor removed from his nose. Bridget suffered from migraines and James was diagnosed with Celiacs disease (CD) and had suffered a THI during a rugby match 6 months before his interview. Luke was diagnosed with ADHD and Asperger's Syndrome, and Simon also had been diagnosed with ADHD. Both boys were currently taking medication for the ADHD. Mark had cerebral palsy and spina bifida and was in a wheelchair. Esau had been diagnosed with cancer and had undergone chemo and radiation therapy. 


\subsection{Findings}

During the individual interviews, participants had more time to discuss their experiences of their particular $\mathrm{CHC}$ in school. In the focus groups, time was limited as were the questions to allow the students participating the opportunity to share their experiences. Four students had grown up with their $\mathrm{CHC}$ and did not discuss the impact of diagnosis as this occurred when they were very young. All students spoke of the impact of their CHC in one or more of the three domains, physically, cognitively, or emotionally. The first superordinate theme is presented; their chronic health condition experience, which consisted of the process of learning about their CHC and the impact(s) regarding the CHC itself. The second superordinate theme, it's a part of my personality, includes the subthemes of adjustments they had made in connection to their CHC and learning and being seen as no different than their peers. This included acknowledgement and acceptance of their CHC by their peers and teachers. The element of being different and yet the same as their peers without a CHC is incorporated. These students spoke of their $\mathrm{CHC}$ as a part of who they are, but did not define themselves solely through their CHC with the exception of Mark, a young man with spina bifida and cerebral palsy who was in a wheelchair and felt he was a role model for other students with disabilities.

The initial interview questions of the interview provided an opportunity to build a picture of the participants' learning context. This shall be discussed in Chapter 5 in conjunction with the superordinate themes it's hard and learning happens when you have help. The third superordinate theme of it's hard is concerned with the difficulties they encountered in their learning experience (LE) as a result of their $\mathrm{CHC}$. The fourth superordinate theme of learning happens when you have help describes their experiences of how learning continued regardless of their $\mathrm{CHC}$ and important elements that contributed to their learning. A summary of the superordinate themes and their subthemes is presented in Table 4 below. 
Table 4 Superordinate Themes and Subthemes

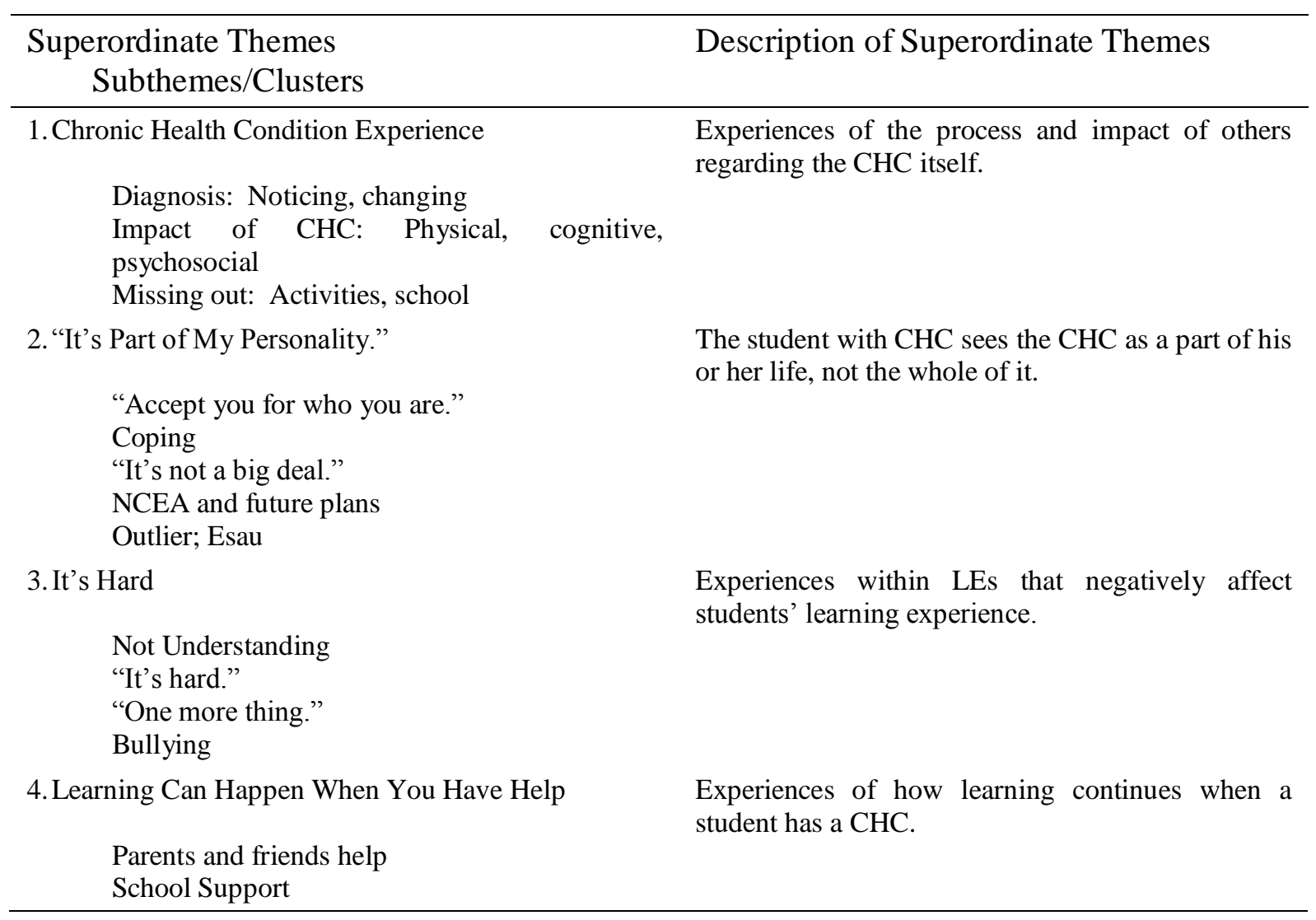

\subsection{The Chronic Health Condition Experience.}

A superordinate theme that emerged from the data was the students' chronic health experience and what that entailed for them. This involved the process and the impact of the $\mathrm{CHC}$ the student experienced while learning about it. It included their experience of noticing something different in their regular routine leading to diagnosis to determine if there was a CHC. Sometimes the effects of either the CHC or its treatment, had an impact upon them. For some students, the diagnosis and corresponding treatment regimen were rapid without a great deal of testing. For others, testing required time away from school, prolonging the diagnosis period and, once a diagnosis was reached, there sometimes followed a period during which treatment was trialed in order to ascertain correct medication and/or dosage. Students saw health providers such as nurses, doctors, and specialists involved in diagnosing or treatment of the $\mathrm{CHC}$ as helpful with the exception of Bridget who suffered from migraine headaches and felt frustrated that no one had been able to pinpoint the cause. The impact of the $\mathrm{CHC}$ and/or its treatment felt by these 
adolescents varied. Sometimes the $\mathrm{CHC}$ or its treatment affected the student physically as well as cognitively. Some students spoke of the emotional impact of the CHC. Almost every student's CHC resulted in the student 'missing out' on either class time, learning, being involved in activities, or being limited in what they could do. To help them manage their $\mathrm{CHC}$ or its treatment, these young people found coping strategies to help them.

\subsubsection{Diagnosis}

\subsubsection{Noticing and changing}

For all of the participants in the individual interviews, the $\mathrm{CHC}$ was diagnosed before they attended secondary school. Andrew, Anna, Bridget, and Esau were in primary school when they were diagnosed, whereas the other participants were diagnosed when they were too young to remember. Anna realized that there was an absence of continuity in what happened around her, James hit his head during a rugby match less than a year before year 9, and Esau was losing his balance.

Mum started to notice changes in me, like my balance went. I got to the point where you could basically blow on me and I'd fall over. (Esau, cancer)

I hit my head on a Monday. It wasn't bad at first....the next day I went home with a very sore head. (James, THI, Celiacs disease)

In year 7 I think when I was ten. I first started noticing something was wrong. And I just blanked out for a bit...Hey Mum I just missed what you said,' because usually I was quite a good listener...You've missed something but you're not sure what and it's like how could I have missed that, I was right here the whole time. (Anna, epilepsy)

I remember my Mum saying I went to the doctor, this doctor said that he knew something was different about me. That there was something wrong from the start that was, you know, I was a bit different and something happened and then that's when I was diagnosed with Asperger's Syndrome. (Luke, ADHD, Asperger's)

Esau went on later to explain how he felt when he heard the diagnosis:

Now it was an evening, an evening I was spending I believe at my Dad's partner's and we got a call from the hospital, come down to the hospital immediately. I remember my initial reaction was like shit. Something's up, something's come up [in the tests he had undergone]. And so we just headed off and I was thinking to myself I can remember this, please don't let it be cancer, please don't let it be cancer because whenever you hear the word 
cancer you instantly think oh how long have they got, how bad is it and that sort of thing. But, yeah, I got told that after a while it was cancer. They then proceeded to give me chemo. (Esau, cancer)

Most of the students did not go into much detail about finding out they had a CHC. This may be because for many of them, the diagnoses was made when they were very young, as many said they had had a CHC since they were little. For example, Bart was a toddler and Mark was diagnosed with his CHCs when he was born. The other students learned of their CHCs when they were older, from their physicians, and in the company of their mother. When they shared their experience of diagnosis, they did not mention being surprised or upset, and all spoke in matter of fact manner about it. The questions discussed by the students in the focus groups were not focused on when or how they had been diagnosed with a $\mathrm{CHC}$ due to time constraints.

Students spoke of the treatment for their respective CHCs with little emotion, generally viewing treatment as a way to mitigate their respective $\mathrm{CHC}$, although it did entail some change in their lives. Anna (epilepsy) and Luke (ADHD, Asperger's Syndrome) were aware of the benefits of treatment. Anna said, "I was on Epilin. Oh, it's just helped a bit...just helped me not blank out as much". Luke categorized himself as a "lab rat", but he believed the various trials were beneficial and helpful:

Well they've trialed me on different medications because I felt like a lab rat. They tested on me and that in a good way though and they see what worked and what didn't and then after a while my parents just said no, that they didn't want to trial any more on me, so then we just went back to the normal ones. (Luke, ADHD, Asperger's)

In Focus Group 4 (FG 4), the students had more varied CHCs and their treatment differed substantially:

Mahina: I just get blood tests not every day after school but every second day. (rheumatic fever)

Chris: Not at school, but I just need pills every day after my dinner. (Crohn's disease)

Daniel: I need to have an injection every fortnight on Friday and it hurts like crazy. (Crohn's disease)

Bruce: I have to have seven injections in my stomach every day. (T1D) 
Andrew's perceptions of his treatment for his Type 1 diabetes, which he self-administered, were neither negative nor positive and he was rather matter of fact regarding his treatment, "I can just get myself a juice...get myself a chocolate biscuit...if I'm feeling ... a bit low insulin”. Anna was not taking any medication for epilepsy, nor was she aware of having had any absence seizures for a year when I interviewed her. Mark only took medication for acute illnesses, not for his SB or CP, and James did not take medication to treat his Celiac disease, but took painkillers for his THI only when necessary. In the focus groups, as with the students in the individual interviews, students spoke of their treatment pragmatically.

\subsubsection{Bart, Bridget, Esau}

Bridget's experience was markedly different from that of the other students in this study. During the time health providers were attempting to ascertain which medications were helpful for her migraines she said she felt like a guinea pig.

They were just throwing me into....like going to see different specialist and getting like getting my eyes tested and the things and just nothing was helping. Nothing would make any difference....I was diagnosed at the end of year 6 and then in year 7 was when things kind of happening for it, so I went to specialists and all of that, and they had good ideas as to what they could help, like how they could help me, but none of them really worked...Like if I'm one little guinea pig and they're trying all these different things on to see what works....We still don't know why I get them. (Bridget, migraines)

For her the process of diagnosis and treatment had negative results and she felt frustration no one was able to pinpoint the cause. She went to different specialists who attempted to discover what triggered her migraines, but did not find either why she had them or relief from the pain. For Bridget, the side effects of some of her medications were not outweighed by any benefits:

[The medications had] quite bad side effects so they would make me quite ill. For a while I was given trammadol so that was like you get nausea and really really over tired. ...I was so limited to the days I was there [in school], the fact that the medication I was given was causing me to become even more ill, it meant I was missing even more days that I should have. (Bridget, migraines) 
Bart, Bridget, and Esau knew that the side effects of their treatment not only could have negative side effects, but particularly for Esau and Bridget, resulted in definite negative consequences. Bart and Esau viewed it as something that was necessary and helped them, in spite of the risks. Bart recalled that once diagnosed with eczema, when he was very young, he had been under treatment with medication and creams. Bart normally did not need to take prednisone or ciclosporim on a daily basis, but when he had severe flare ups of eczema, he was very aware of how long term usage of these could impact him:

It depends what I take. Cause like if I'm taking prednisone, that's like if I'm on it for a long period, that's really bad like with bones and that, but it just depends what I'm taking, because I don't take prednisone that often....I just get tired....For when it's really bad yep, then I'll be on it [prednisone] for about four weeks. I'm on a high dose as well and the doctors they don't really like putting me on it because the age that I'm at and then how it could affect me in the future. Yep, oh, and there's another one that's called ciclosporim you take, you're meant to take it if you have a kidney transplant and it stops your kidney from rejecting you but they also found out that it works for eczema, so when it's bad I'm on that every now and again, but I have to have a blood test like every month or something, because it can, it can do stuff to your body. (Bart, eczema)

Bart could not recall whether he was 12 or 13 when he was diagnosed with angiofibroma, a tumor which primarily occurs in male adolescents and is not generally fatal, but he was told no one in Wellington had had one in eight years. It was blocking his right nostril, caused pain and culminated in excessive bleeding. He was told he needed surgery, which was very risky.

Bart: $\quad$ So my health in general is pretty good, that's pretty much my skin. hard with that.

Me: $\quad$ How long did you have that for?

Bart: $\quad$ For about two years. Yes, it fully blocked my right nostril and I didn't know about it until like one night I was eating my dinner and my nose just started to bleed, just nonstop. Yes but I ended up being, it's like no one hardly ever gets it but it's common in teenagers so that was pretty out it when I got back. Yes, it's mainly teenagers because they said like the last person to have it in Wellington was like eight years ago then I had it. But no that's had an impact on my health because I had radiation afterwards, 
after the surgery because the tumor was attached to the main artery and that's the main, the main vein to your brain and they said if they operate on that in that area and just touch it a little bit then I could have died. (Bart, eczema)

Esau knew that chemo and radiation were necessary to treat his cancer and these had an impact on his learning as well as on his body. "[I am] disadvantaged, compromised in a sense. And it takes, oh, and time consuming. I mean it takes a lot longer to understand things and comprehend things than others." He went on to tell me the effects of his treatment:

[My mother] researched it [the cancer] and she looked at radiation and she was like, wow, that affects your learning, you can get cataracts because for radiation they were going, well, we're going to have to blast most of your head. Now that would make my eyeballs, the back of my eyeballs burn. I'd develop cataracts for the rest of my life. Come to think of it! I'm glad mum did research she did because now the back of my eyes don't burn, I can still see, and basically my learning isn't compromised and I still have my hair. See my hair started growing back through chemo. On the first night that after about a few days of being on chemo, waking up with hair in your mouth, in your eyes, up your nose and all that sort of thing, all over your face. And it's been great since I got it shaved off. Yeah. (Esau, cancer)

\subsubsection{Impact of $\mathrm{CHC}$}

The different CHCs affected these young people physically and/or cognitively, and/or psychosocially. Sometimes the treatment affected the student physically as well as cognitively. Some students spoke of the emotional impact of the CHC. The students, depending upon their CHC, felt these impacts differently. Several students felt their CHC did not have a major impact on their learning, but contradictions emerged as the interviews progressed. Most students who experienced a physical impact spoke of feeling sore or tired which led to being unable to concentrate or focus, or unable to attend school and participate in activities. Two students spoke of staying in class trying to concentrate through the pain either because their teacher did not believe them or they did not want to leave class.

\subsubsection{Physical impact}

For the majority of the participants in this study, their respective CHCs had definite physical impact upon the students that affected either their vision, concentration, or the 
ability to focus. In the individual interviews, six of the nine students spoke of the physical impact of their CHC. Bart, Bridget, James experienced severe pain which limited either their ability to do any physical activity and/or their learning in school. There were other physical impacts of a CHC such as having a loss of balance or being shorter than normal.

[I have four tumors, two located in my spine and two located in my brain. One of the brain stem one on my pituitary gland that's why I'm too short and the actual medical name for the tumors, type of tumor is Pilocytic Astrocytoma. There was another symptom as well. It was like headaches. (Esau, cancer)

Bart: $\quad$ Oh my skin might have and a big flare up and it would be hard like I'll be in bed and the next morning I just won't want to get up and my skin's all stiff, because from the moisture, oh yeah. (eczema)

\section{Me: $\quad$ Because, is it painful for you?}

Bart: $\quad$ Yeah it is, it can be, it can be like real sore and then when it gets infected as well, I just can't, can’t do much. (eczema)

That I just need to sleep, like sleep it [migraine] off, take some painkillers, I kind of just had to suck it up and deal with it at school and I was going to school every day but I would always go home. In year 8, I would go home most days in the afternoon just because my migraines got so bad...It just got so bad I couldn't concentrate and I wasn't, with my migraines I get quite like blurred vision as well, so I couldn't physically see what I was trying to do and then it was just a constant pain in the back of my head so I couldn't concentrate. I could see what I was trying to do so I was like unable to do the work. (Bridget, migraines)

With the concussion I had, a lot of times it was difficult for me to concentrate, I was very sore. I had lots of pain in the head. Sometimes I even managed to get some sleep cause it was very tiring. Very exhausting, with my head injury...or sometimes not even bothering cause there was quite a bit of pain. Quite a bit of pain. (James, THI, Celiacs)

After Bart had the angiofibroma removed, he had radiation:

So then I had to go through radiation and then, oh that was, that was really really hard on my body because I was only what 12 or 13 going through all that. (Bart, eczema)

Although pain and tiredness were often the effects of the CHCs upon the students in the individual interviews, Andrew and Simon's experiences were different. For Andrew, 
hypoglycemia because of diabetes was the main physical side effect, resulting in shakiness. "I sort of feel a bit shaky, don't really think that well. So I have a juice and I'm really fine within 5 or 10 minutes." Simon spoke of being fidgety without his medication.

I fidget, sort of thing like that. Even when I was undiagnosed, it would affect my learning cause...I was unmedicated. Especially cause of things like fidgeting and that. I'll still do it. I'll sort of focus how I've written a letter instead of actually doing the learning, I'll sort of go over that one letter and ingrain it and I sort of want constant movement and so at times, to learn and listen to want constant movement, it can be hard to do both. Especially unmedicated. Medicated, it's nowhere near as bad. (Simon, ADHD)

Luke and Anna did not see their respective CHC's impacting them physically. Anna took her cue from what her doctors had told her after recent testing.

...because recently I went for a brain scan at the start of this year and they said look the spikes aren't really that big and I wasn't really noticing it at all because lately I've just been getting really into my work and I did Scouts, I did abseiling and all those fun things and I just. She [the doctor] said that I don't really need to have another brain scan because it's not going to really change anything just still be careful and stuff. (Anna, epilepsy)

Luke qualified for learning support that had helped him with school exams which he appreciated, but he genuinely did not feel the Asperger's Syndrome impacted him. Throughout his interview, there was evidence that Luke struggled with more of an internal debate as to whether his particular CHC affected him or not. Even as he told me he felt the Asperger's Syndrome did not affect him in school, he contradicted himself.

Because I'm succeeding, I guess, despite what I have. Not that it really makes that much difference but I don't know eh... Sometimes when, I feel that it comes into my mind but, I don't blame it on that, or sometimes it's just me or something, but it doesn't really affect me that much... (Luke, ADHD, Asperger's Syndrome)

[Later]

At the start of this year yep, because they [doctors] decided that it wasn't really affecting me that much anymore because I'm still doing all of my schoolwork and stuff it's not really affecting me to a point where I need to be concerned any more. (Luke, ADHD, Asperger's Syndrome) 
In this study, each student who participated in the individual interviews had a different $\mathrm{CHC}$ than their fellow participants, unlike the focus groups in which it was possible to have two or three students with the same $\mathrm{CHC}$. As a result of the differences in $\mathrm{CHCs}$, it was possible the type of physical impact from them would be different although they all mentioned some impact and there were some commonalities such as pain.

Within the focus groups, some discussions focused more on one particular topic than others. The students within Focus Group 2 (FG 2) had more diversity regarding their respective CHCs than Focus Group 1. Mark had spina bifida and cerebral palsy, Jenna had migraines, Luke was diagnosed with ADHD and Asperger's Syndrome, and Bart had eczema. In this group of four, three of the students volunteered to be individually interviewed and expanded on their answers, but within the focus group, the descriptions they gave were more succinct.

Jenna: It can, if I get a really bad migraine, it can just wipe you out completely. And sometimes I feel like crying in class because it's been so bad and I have to go home. (migraines)

Luke: Well mine, it affects me if I don't take my tablets because I'm just distracted by everything and it's really hard to concentrate and that, so yeah it gets in the way of schoolwork and passing tests and stuff like that. (ADHD, Asperger's)

Mark: Well it doesn't, because like I mean if I do well in school and everything, it's just the way like getting in transportation somewhere or it might be slightly having trouble getting somewhere [inaudible on tape]. That's it. (cerebral palsy, spina bifida)

In Focus Group 3 (FG 3), students did spend some time discussing how their respective $\mathrm{CHCs}$ felt and found there were similarities in their experiences. Some students also discovered they had the same $\mathrm{CHC}$, something they were not aware of prior to the focus group meeting. One student suffered from migraines and another had glandular fever and eczema. The three boys, Philip, Seth, and Asher had asthma.

Philip: If you're feeling sometimes wheezy, like wheezy in class and I just get annoyed. Cause you can hear it. (asthma) 
Seth: Yeah. Oh especially at morning tea and lunch yeah. Just like heavy breathing and yeah. (asthma, eczema)

Asher: I'm basically the same as these two with sports and in class with my breathing; sometimes it's bad, sometimes it's good. Yeah. And I don't bring my pumps to school, so it's like harder for me when I'm trying to breath and all that because no one else has got the pumps. (asthma, eczema)

[A few minutes later]

Tabitha: Mine's always like behind my left eye it's this side, always on this side. (migraines)

Philip: What does it feel like? (asthma)

Tabitha: It's a piercing but it's like pounding at the same time. (migraines)

Angela: Because I've had headaches like that. Kind of like, something's kind of just playing round behind your eye. (glandular fever, eczema)

Tabitha: And right here in your temple and you're like, as it starts to hurt down here (shows it hurts below her eye). (migraines)

Angela: It's kind of numbing as well. (glandular fever, eczema)

Tabitha: Yes. (migraines)

Angela: I just get so sick of it. I can't stand this. (glandular fever, eczema)

Tabitha: It's like all the time. (migraines)

Asher: No I just go downhill....Yep. Like in class I'm real wheezy and I've just got to leave, then I just come here and lay on the sick bed because I just can't think. (asthma, eczema)

Seth: I get itchy, too. (asthma, eczema)

Angela: I don't have it at the moment. (glandular fever, eczema)

Seth: Aw, same as me. (asthma, eczema)

Asher: Itchy. (asthma, eczema)

Angela: I get it real bad in my joints and when I get glandular fever that comes up so bad, mm. (glandular fever, eczema)

Seth: Ah! (in sympathy) (asthma, eczema) 
Angela: All over my legs and my arms. (glandular fever, eczema)

Seth: $\quad$ Yeah, scabby too. (asthma, eczema)

Tabitha: Yeah cause it hurts and I just want to sleep or just sit down. (migraine)

Philip: Mm. I just want to lay in the sickbay. (asthma).

Philip (FG 3, asthma) experienced a similar feeling of difficulty in breathing as his asthma interfered with his ability to play sports. He later added "Sometimes you can't play touch when you're outside on the courts, like interval and stuff and play for a couple of minutes and then you're stuffed. You have to have a rest. Yep."

In Focus Group 4, two students had Crohn's disease, one student had Type 1 diabetes (T1D), another had asthma and another had had rheumatic fever. Chris, with Crohn's disease said, that physically, "I started sweating and getting a lot tired, when I woke up in the morning, start smelling a lot. Really terrible wind, cramps in the middle of the night." Before he was diagnosed with Crohn's disease, Daniel said,

When you wake up in the morning and you're sweaty and exhausted and you're really tired. That's what I felt when I went to hospital. I couldn't even walk to school actually. I was just too tired to. (inaudible). I had to have rides to school [normally would walk to school] when I was really ill, before I was diagnosed with it. (Crohn's disease)

Later, Haimi added, "You can't breathe. You stop. Your head just stops, your lungs just stop. It depends on where I am, it's like sorta scary." DJ also had asthma and said, "I get winded quite easily when we're doing PE, like the beat test. I try my best though it's kinda hard when you can't breathe. Yeah." Haimi later added, "Only at night it's hard for me to get up to my bunk bed. Quite hard to get up. When you go to sleep, you just don't wanna wake up...and when you get up there you start coughing heaps." Other physical effects, such as difficulty with sleep and exhaustion, were shared. "I have trouble sleeping," said Haimi (asthma). "Probably tiredness. Drowsiness," said Daniel.

Daniel: After I came out of hospital or during hospital, I couldn't eat anymore. I had to have these special shakes called Forta Zips to get back my calcium and stuff...til I got better. I'm just back to normal now. (Crohn's disease) 
Chris: $\quad$...except I was allowed to move around, but for an entire year I was not allowed to eat. (Crohn's disease)

Me: $\quad$ You had to be careful with what you ate?

Chris: I wasn't allowed to at all. (Crohn's disease)

Me: $\quad$ What were you on?

Daniel: Mortar zips. (Crohn's disease)

Chris: Nasal tube. (Crohn's disease)

Mahina: oh yeah. (rheumatic fever)

Haimi: Oh that tube thing. (asthma)

Chris: A little thin tube that has a hole in it. (Crohn's disease)

Haimi: Those little things you stick in your arm and you [Chris interrupts]

Chris: Yeah, except it goes up your nose, down your throat, and in your stomach. (Crohn's disease)

Daniel: Aw yeah. That. (Crohn's disease)

Chris: Then when you get a nasally thing, you get a drink out, it's called water sips. You put it in there. (Crohn's disease)

Daniel: I just drunk it ordinary. (Crohn's disease)

Haimi: Wouldn't you just like breathe it in, like (makes sniffing noise)? (asthma)

Chris: Nah, cause the tube was all the way down, at the end it was into my stomach, so [Haimi interrupts] (Crohn's disease)

Haimi: So you would automatically get fed. (asthma)

Chris: And if it got blocked. (Crohn's disease)

Daniel: Aw. Nasty. (Crohn's disease)

Haimi: Aw. Yeah, he still came to school. (asthma)

Chris: Yeah. (Crohn's disease)

Haimi: Only for a couple of weeks and then he didn't come back. (asthma) 
In spite of the different $\mathrm{CHCs}$ these young people had, there were common experiences amongst them. When this was revealed in focus group discussions, they found the commonalities less isolating and during the exchanges, the students looked relieved that the other participants understood their experiences (Field notes, 2011).

\subsubsection{Cognitive}

Cognitively, students in the individual interviews were more descriptive of how their $\mathrm{CHC}$ affected their ability to learn in school although this may have been due either to age differences or time availability as during individual interviews, students had more time to think about their answers. Mark (SP, CP), in his individual interview, shared that when not using a mechanized wheelchair, he found getting around was tiring and that feeling tired, in turn, affected his ability to learn. For him, there was a distinct connection between having a mechanized wheelchair in school versus a manual one. "If I'm using my manual one then that's gonna make me feel tired in class, make me exhausted, not focusing on my learning."

Several students had difficulty focusing or concentrating because of their CHC. Regarding his THI, James said, “It was very tiring and I couldn't think straight all the time at school and that affected my learning. And not being able to take it all in....It was difficult for me to concentrate." However, the impact of Celiacs on his learning was "Not a big deal. Not really." Bridget said the pain from her migraines interfered with learning, “...so I couldn’t concentrate.” Chris, in Focus Group 4 said, "Cause you could fall asleep in class, and [not be able to] concentrate and that" (Crohn's disease).

Luke believed the Asperger's Syndrome made him fixate on things, "Well it was partly Asperger's, as I said, I get fixated and things." Cognitively, the long-term effects of Esau's tumors began with his grades slipping, followed by physical manifestations as described above, and Simon felt he was unable to focus on any one thing unless he was taking his medication:

Yeah happened around when I was about 13 years old, I'm not too certain because I've sort of blocked out in my past, also there was the whole my grades were slipping. I went from A band to B band and I was a straight B band in secondary school and the teachers were getting very cross with me that I didn't understand things. (Esau, cancer) 
And it's like with my ADHD, I can't concentrate. It's that these things are so cluttered around my brain while I'm trying to learn, it won't happen. These are all in my brain and it grabs a whole of it I just can't get it out of my head. (Simon, ADHD)

Some students, such as Andrew, Anna, and Rich (FG 1) contradicted themselves when discussing how their respective CHCs affected them. Andrew said his T1D had “...not actually affected my learning that much," but later went on to say, "I...feel a bit shaky, don't really think that well" when he experienced a low in blood sugar. Anna did not feel having epilepsy had affected her learning even though she was aware she had missed instruction. "You know you've missed something but you're not sure what and it's like how could I have missed that, I was right here the whole time." She felt missing instruction did not have negative consequences for her learning; "I didn't really think it was much of a problem because I was getting good marks at school anyway. I'd just like catch up afterwards." Rich (FG 1, T1D) told his group:

Yeah, it gets a bit annoying, because I don't know when I'm low and it affects me with my schoolwork. Cause I get blurry vision and lose concentration a lot...If you're like high or low from diabetes and you have to like go out of class then that affects it because you're missing out on something, yet but otherwise there's nothing that's affecting it. (Rich, FG 1, T1D)

Students in two focus groups voiced the idea that the exhaustion resulting from their $\mathrm{CHC}$ affected them in school. Focus Group 3 initially said their $\mathrm{CHC}$ did not affect them but as they continued their discussion, they went on to talk about how the CHC did impact them:

Seth: Oh, it doesn't really affects us with schoolwork, but yeah. (asthma, eczema)

Philip: Sometimes like if I don't look after it and it gets worse and I got pneumonia the last time. So last time. (asthma)

Me: Sorry?

Philip: Using pumps and stuff. That's when I had a few weeks off school for that reason. (asthma)

Me: $\quad$ How did it affect you, how did it affect?

Philip: Oh I wasn't, really it was, oh, we had some exams and I missed out on the exams because of it. Yeah. (asthma) 
Me: $\quad$ Did that happen to you, Asher when you don't bring the ventolin to school?

Asher: No I just go downhill. (asthma, eczema)

Me: $\quad$ You just go downhill?

Asher: Yep. Like in class I'm real wheezy and I've just got to leave then I just come here and lay on the sick bed because I just can't think....(asthma, eczema)

Me: $\quad$ So it kind of affects you at school, you can't play the sports. Do you all like playing sports?

(Boys all say yes.)

Angela: No. (glandular fever, eczema)

Philip: You don't? (asthma, eczema)

Angela: No. (glandular fever, eczema)

Philip: You do PE. (asthma)

Angela: Yeah, I do PE, but I don't like sport. (glandular fever, eczema)

Me: $\quad$ Three of you like your sport?

Philip: I love it. It's my... [is interrupted by Seth] (asthma)

Seth: It's his life. (asthma, eczema)

Me: $\quad$ Ah, so the asthma does it.

Philip: Oh yeah, oh asthma with sports, yeah kicks in so hard. (asthma)

Me: $\quad$ So how do you feel about all of that?

Asher: Irritating, annoying. (asthma, eczema)

Seth: Bummed. (asthma, eczema)

Philip: Just because like you want to play your 100\%. (asthma)

Asher: Yeah, you want to be at your best, but you can't because of this illness. (asthma, eczema) 


\subsubsection{Psychosocial}

The psychosocial impacts of a $\mathrm{CHC}$ were varied and ranged from annoyance and embarrassment to more severe emotions such as depression. These emotions were either due to the physical impact of the $\mathrm{CHC}$, for example, being in pain quite often, because they were unable to participate significantly in class, having that 'extra thing to look after', or because of peer or teacher reactions. "How annoying it was to be on bed rest for nearly a month...because I always wanted to get up but then my dad would just tell me go back to bed" (Mahina, FG 4, rheumatic fever).

I guess it was kind of annoying having to take the medication everywhere because it's like don't forget the medication. Just take it everywhere. (Anna, epilepsy)

It wasn't just that I had a headache and it was annoying, I just couldn't do it; I couldn't see what I was supposed to be doing. (Bridget, migraines)

My learning has been screwed up, I went through an eight year sort of depression, medical depression and my balance went. Not real bad medical depression just still slight one you know. Where I lost my self-esteem and I just thought you know every day is just not worth living, it's just boring and that sort of thing. (Esau, cancer)

....and then it makes me feel like really down. Yes pretty much I just don't want to do anything. (Bart, eczema)

Having two separate $\mathrm{CHCs}$ with separate requirements also elicited frustration and feeling annoyed.

[Having CD means] Having to check all my food, having to resist eating foods, well sometimes it can be annoying at your friend's house. You go over to a friend's house and they have to cook you a special dinner and it feels, sometimes, kind of awkward and you feel quite bad cause they have to go out of their way for you that can sometimes make you feel...bad just cause they have to go through all this trouble. (James, THI, Celiac's disease)

[It] was sore and it was so frustrating at times. I got frustrated being in pain all the time. I was annoyed cause I wanted to get back into [sports], but I knew that I, if I hit my head it could come back again. And I did not want that cause it was not a good time while I had it, rugby and karate and ....softball and I couldn't get back into rugby and I'm....if I'm gonna do it next year and I'm sure, it's really my choice now. I would like to play rugby. I enjoy it. Fortunately it's not that ...physical. I'm not hitting people that much. I used to do fighting in karate and I'm not allowed to do that anymore. 
Even with headgear. Maybe next year I can do it again....But it was...I, sport is important to me... and...yeah. (James, THI, Celiac's disease)

Feeling embarrassed or annoyed could sometimes result in students not seeking clarification in class because they did not want to draw further attention to themselves. Anna felt embarrassed about 'missing out' on class instruction. She said, "[I] just felt embarrassed...if I'd missed something... Sometimes I'd be embarrassed from asking them too much so I just sat there.” Bridget said, "It was annoying I just couldn't do it; I couldn't see what I was supposed to be doing." Emotionally, Esau “...went through an eight year sort of depression, medical depression." Treatment was difficult for him, "I was going through chemotherapy and it's just so hard and stuff' (Esau, cancer).

\subsubsection{Missing Out}

\subsubsection{Activities}

Missing out on activities and class instruction was another aspect of the $\mathrm{CHC}$ experience. Students said they were "missing out" when they were not able to be in class to learn, do activities in or out of school, or were limited in what they were able to do because of the physical impact or medical appointments. James felt his Celiacs impacted him primarily in not being able to eat certain foods others were able to eat. "Sometimes, like at school there might be a morning tea and or lunch and I can't have all that and it has been tough." His THI meant he couldn't participate in active sports. James was told he had to continue resting to fully recover from his THI; "keep less active...I couldn't get back into rugby." He also felt frustration that, due to being absent, he was not able to earn the high marks he had previously received in a class. Bart felt deeply disappointed that he did not go to the Year 9 annual school camp or participate as actively in sports as he liked to do.

I missed out half a year because of my skin...Probably by missing out on a lot of stuff. I missed out on the school camp that year because of my skin... Oh school camp, yeah, which I was pretty gutted, and making some of the sports teams for school. Because I'm hard out into that stuff. And missing out on that I was pretty gutted as well. (Bart, eczema)

In business studies there was an assignment that I was having difficulty catching up on. Handed in a bit late...Design Tech., which is woodwork and all that. $(M e: h m m)$ It was a lot more the practical stuff. It was hard to catch 
up on that. And visual art. So mostly the arts, performing arts as well, cause it's mostly the group and coming up with things to put in your performance, coming up with or learning lines. So I was away when my group was doing all that....When I came back I had to learn everything that they'd all learn during the days that I was away and got that lesson.... I really enjoy performing arts and it annoys me when I don't get....cause in year 8 and year 9, I got merits, only merits. That was the time I wasn't away. And like an Achieve because I failed to be there and so my group, they got ahead of me, and that always annoyed me, was annoying. (James, THI, Celiac's disease)

During their second meeting, some of the students in Focus Group 4 revisited how not being in school had an impact on their learning adding that being absent also meant missing out on doing fun activities, even in school, although Bruce did not notice this as much because he was younger when he was first diagnosed.

Focus Group 4:

Daniel: Sometimes you can feel left out when you're away in hospital. (Crohn's disease)

Me: $\quad$ You can feel what, pardon?

Chris: Left out. (Crohn's disease)

Me: Left out?

Chris: Like everyone's doing fun work when you're in hospital and when you come back to school they're doing the hard work... (Crohn's disease)

Me: How about you, Bruce? What do you think?

Bruce: Hm. I'm not really sure how to describe it, cause it's like you do feel left out of certain things, but I guess I didn't really notice cause I don't as much, remember what it was like before I was diagnosed with diabetes. (T1D)

\subsubsection{School}

Focus group students reiterated this sense of missing out when they were asked how a $\mathrm{CHC}$ affected their learning. For the students in years 11, 12, and 13, missing learning had a greater impact on them. Focus Groups 2, 3, and 4 discussed the impact of "missing out" on schooling. 


\section{Focus Group 2:}

Bart: I think it does because depending how bad it is you can miss a lot of school from it and then because of that you're missing out on credits. (eczema)

Jenna: And when that happens, you miss out on, like every day's important and you miss out on so many things, you never catch up and then things just tend to build up sometimes. (migraines)

Focus Group 3 had a lively exchange as the students disclosed their experience.

Angela: But then at year 11 particularly was when it was kind of a pain for me because I'd missed, I'd missed like up to four months of school, like being told to go home, like doctors making me stay home. (glandular fever, eczema)

Tabitha: Even if I'm sick, I come to school...because I can't afford to miss out on my classes. Sometimes when I'm really sick then I just take a day off but even if I'm, like my head is like pounding, I will still come to school. (migraines)

Angela: Yeah I miss so much. Like last year I remember missing, I think about three, maybe two and a half months off school and pretty much I'm pretty sure most teachers, my teachers knew that it was because I had glandular fever reoccurrence. (glandular fever, eczema)

Philip: You don't really mind if you take school off, but then you realise that when you're in senior level you realize that school's more important. (asthma)

Seth: Yeah. (asthma, eczema)

Asher: Yep. (asthma)

In Focus Group 4, the students also felt the effect of not being in school due to absence had a direct effect on their learning.

Daniel: Sometimes it's hard to learn and catch up if like you've been away from school as much as I do. I've missed school tons of days now. (Crohn's disease)

Chris: $\quad$ Sometimes I kind of feel I've missed out on things actually. ) 
Mahina: Then I miss one day of school, now that I'm year 11, you still have to catch up and there's still heaps of stuff to...(Haimi finished the sentence). (rheumatic fever)

Haimi: Catch up on. (asthma)

Bruce: I had to go when I was diagnosed. I was in hospital a lot-the day and just in and out so I missed some school. (T1D)

Mahina: Annoyed...(rheumatic fever)

Daniel: Hard. (Crohn's disease)

Chris: Everyone else is doing other work and you're sitting there... (Crohn's disease)

Mahina: (cuts in) behind. (rheumatic fever)

Chris: Yeah. (Crohn's disease)

Bruce: When you're feeling ill, like in pain, you don't want to come to school and you fall behind in your work. (T1D)

Most students did feel they had missed out on doing activities or learning because of their CHC, as previously shown, but a few others, such as Anna, shown above, and Mark, had positive attitudes regardless of the CHC. Mark's attitude came across in his interviews even when he spoke about a negative impact, such as being in a wheelchair or missing school.

When I go to school I have to use my electric wheelchair. Cause if I'm using my manual one than that's gonna make me tired in class, make me exhausted, not focusing on my learning. But I can use my electric wheelchair cause it's a good example of giving me enough energy to focus on all the notes and all the learning, the teacher, the success criteria that...we always go for that at school. (Mark, CP, SB)

\subsubsection{Coping}

Adjusting and adapting to the demands of the $\mathrm{CHC}$ involved developing strategies so they could manage their $\mathrm{CHC}$, side effects from it or its treatment, continue to learn, and to be active in sports or other activities when possible. These young people adjusted and adapted to the demands and/or negative effects of the $\mathrm{CHC}$, if they were any, and were able to do well. James (THI) knew taking a rest was a viable option when either the pain 
from headaches or tiredness as a result of headaches became too great for him to remain in class. James said "If I got too tired from the headaches, I could go rest, go to sickbay, I could go home." Simon could feel when he was being wound up and his teachers were helpful when he told them he needed time away from the class. He knew he could go to "the library itself. There it's a place where I can be calm, I can just sit and read, go on....away from my classmate." Bart's eczema could be quite painful and troublesome for him, but he knew he had tools at his disposal to help him cope. "[Sports] it takes my mind off stuff and just helps me, helps me focus on that, and music. Because I play the guitar and saxophone and when I'm playing those everything just goes away pretty much."

Other strategies included eating or drinking in class if, for example, Andrew found he was feeling low. Andrew would test his blood sugar in class, and, while initially his classmates "found it quite odd. A bit different. Amazing", it became routine, "so they don't think too much about it if I do a finger prick or have a lolly or something." Extra reading and spending time on missed schoolwork were other useful strategies employed by these adolescents. "I had homework sent home to me. I could do that at home" (James, THI, Celiac's disease). "I keep myself in extracurricular activities such as kapa haka, Māori performing arts and apply myself to other activities that involve [sic] my school" (Mark, CP, SB).

All the students adapted to integrate management of their illness or its effects into their lives. These required different coping mechanisms dependent upon the CHC itself. The students found it was necessary to make changes either to diet, routine, learning, or simply make adjustments when and as needed, such as leaving the classroom when feeling tired, or needing insulin.

[The] school gave me a pass like they give to diabetics in the school that says that any time I can go to the sickbay, to send someone along with me, in case something happens along the way. And I could stay as long as I like until I feel better. I used that often cause I needed it. ... Having to check all my food, having to resist eating foods. (James, THI, Celiac's disease)

They [teachers] know I'm diabetic so if I start eating in class they don't hassle me. In my class I might often, occasionally have to eat. I'll just sit down and wait for five minutes then just sort of continue with my work. (Andrew, T1D) 
I had to be explained things twice. I can't be given a list of instructions, I can be given them one at a time or two at a time. I'd have to be you know shown how to do things and stuff but I'm a visual learner though being told something I'll forget like that. Having stuff written down helps and you know I'll be coming back to the teacher every time to make sure I get it right because I want to do the work to their standard and if I don't get it do the standard then I have to do it all over again. Quite scared myself to do it on my own because I'm not sure if it's right, there are other times when I do know what I'm doing, I do know yep can do this, that and the next thing done and I'll be sweet. But that's very few and far between. (Esau, cancer)

Individually interviewed students spoke more about personal accountability and responsibility for taking their medications and for their own learning than their counterparts in the focus groups. Simon (ADHD) was sensitive to changes in his medication and when it was "wearing off": "I can just know even when my tablets are just starting to wear off...I can notice the slightest difference in my medication even in changing the dosages, sort of thing." Andrew felt confident about his ability to manage his T1D, telling me more than once he knew how to manage his diabetes.

Yeah, yeah. It's just that I'm normally quiet. I know what I'm doing with this. In my class, I might often, occasionally have to eat. I'll just sit down and wait for 5 minutes then just sort of continue with my work. When I'm high, get a bit of insulin \& just continue on with my lunchtime. Yeah. I'm normally quite self-manageable. (Andrew, T1D)

\section{[Later]}

I know what I'm doing. If I'm low, I eat. ... so yeah, that's all it is, really...a bit of rest in class... I'll normally get the notes down or quickly do the exercise we have to do. I'm normally fine. I've got back up juices in the First Aid room. I've got insulin in the fridge in the staff room. (Andrew, T1D)

Later he added, "I'm sort of on top of that. No one can really realize that I'm low apart from me, yeah."

Luke (ADHD, Asperger's Syndrome) admitted that he sometimes did not take his medication as prescribed, but then pointed out a note on the wall of the kitchen, where the interview took place. The name of his medication, the dosage, and times he needed to take it were written on the note and was posted as an aid to help him remember to take it when he ate lunch at home, he told me. At school he went to a special needs room set up 
by the school which he used if he forgot to take his medication at home as well as at interval.

No, I stay at school for lunch. At interval I have to take a tablet which is at school. And at home. Yeah at lunchtime, I just take that but I just kept on forgetting to take them. They've [the school] got the special needs room and that's where they've got the kids and that they'll be doing whatever, there's a teacher ... or a teacher aide. I go into there and she's got my medication. I just take the tablet there and then I go back to class.

Luke felt he had some responsibility for what he had missed in learning:

Partly because I didn't try at primary school, so I don't have it in my head to remember it and that affects how I learn and that, but I reckon I've done pretty well at the moment because I've almost passed level one maths, so short by two credits. (Luke, ADHD, Asperger's)

Bart was aware that absence impacted his studies, but he felt confident he could catch up on missed learning, whereas Anna felt she was responsible for and determined to do well in school as a result of having epilepsy:

So it will probably be affected by the days that I'm off. That... would probably be the main thing because I find at school most of the time I can just catch up and work, just work hard as well. (Bart, eczema)

Yeah... Knowing that I had this thing and ... yeah I probably was driven more than if I didn't have it, I probably just slack off. I don't try to prove myself anymore, but I still work really hard because yep I just like working hard and try my best. I know that I tried my best or even if I got not achieved, I tried my best...yep, I just like working hard and try my best. (Anna, epilepsy)

James, when referring to his THI and its effects, told me "but it's also your responsibility as well to not just give up and say 'oh, I'm sick, I can't do any of this.' You yourself have to put in the extra effort." James felt he was responsible for getting any missed work when he was absent. "I have to catch up with all of 'em, I go around, make sure I have got everything I needed to get." Esau was pragmatic in his approach deciding to be positive instead of approaching his $\mathrm{CHC}$ from a negative perspective.

Well there's two ways to look at it. You see you could either look at it you know when you're told you have cancer you can think right well my life's over what's the point in doing anything anymore. I'm just going to die and stuff. Or you can look at it going, right, I'm not going to let this get to me. I am going to you know live my life to the full, make a few mistakes and go 
out with a bang. Why should you be scared of something that's going to happen eventually anyway? (Esau, cancer)

This kind of self-awareness and self-assurance was common to all the students in this study, the variety in their CHC notwithstanding.

Asking for help meant feeling comfortable with admitting they did not understand something in class. Anna (epilepsy) told me, "Well...sometimes I have to ask the teacher to repeat themselves for me. Just say I didn't get that." She added, "Because I get easily distracted by others, Ineed to...just block that out and take responsibility for my learning." The students felt they had the ability and were responsible enough to manage their treatments and could manage themselves in school. This, in turn, gave them confidence that they could also manage their learning. When asked, they credited their parents a great deal for the help they received regarding school. This is explored further in Chapter 5.

\subsubsection{Summary of Superordinate Theme The Chronic Illness Experience}

Like their healthy counterparts, when they were absent from school, students with a CHC missed out not only on learning, but on being able to participate in activities with their friends or peers. Unlike their healthy counterparts, their $\mathrm{CHC}$ had other effects upon them as well and these did not go away within a week or a month. The CHC experience for these students had physical, cognitive, and emotional effects. Physical effects varied in scope from dampness in the skin resulting in soreness and possible infection to severe pain and inability to participate in activities or learning. Cognitive effects also varied but in this study, students primarily spoke of having difficulty in being able to concentrate or see because of acute pain or low blood glucose.

An inability to focus on the task before them, physical pain, and tiredness, were not the only effects of their CHC, but extended to emotional consequences. Students discussed feeling annoyed or frustration because of the pain or embarrassed about drawing any unwanted attention to themselves. They missed out on learning and being with friends during periods when their $\mathrm{CHC}$ had acute episodes. Emotionally, their experiences ranged from feeling minor annoyance or embarrassment about asking too many questions to depression. For all the students, their CHCs had either a mild or pronounced impact on the students' learning experience, but there was always an impact. Due to their CHC they 
had to make some sort of adjustment, be it dietary, monitoring throughout the day, the need to take medications on a daily basis, undergo periodic testing, be in a wheelchair, or carry out appropriate treatment when the need arose, e.g. take appropriate mediation when experiencing pain.

\section{4 "It's Part of My Personality."}

\subsubsection{Introduction}

The second superordinate theme that emerged from the data were of the students seeing their $\mathrm{CHC}$ as a part of their lives, not the sum of their lives. They realized they could continue to learn, adjust to having a $\mathrm{CHC}$, and make plans for the future in spite of the physical, cognitive, or psychosocial impact of their CHC. For the majority of the participants, in spite of some students experiencing very negative physical effects from the $\mathrm{CHC}$ or its treatment, there was also a positive process of adapting to fit the situation of being a student with a CHC. They were aware of missing out on some activities, but almost every student felt they could manage their illness for the most part or at least manage themselves. Within the superordinate theme of it's a part of my personality were four subthemes.

The participants spoke about making adjustments and accepting their CHC. Some students felt different from their peers but did not want to be treated or seen as being different whether the $\mathrm{CHC}$ was visible or not, with the exception of Mark. An aspect contributing to their adjustment was that the $\mathrm{CHC}$ engendered a minimum reaction from their parents and/or health providers which, in turn, influenced the students' own reaction. Participants felt they had personal responsibility for themselves, their learning, and their CHC. As such, they made modifications in their activities if needed. Their CHC did not interfere with their motivation in learning nor their plans for the future. Only Esau spoke of the possibility that cancer could be fatal, but he, too, made plans for his future.

\subsection{2 "Accept You for Who You Are."}

A positive factor in adjustment to having a $\mathrm{CHC}$ in the secondary school environment was receiving acknowledgement and a favorable reception within themselves, from their family, their peers, and teachers regarding their CHC. Students interviewed individually and in the focus groups spoke of acceptance of their peers and friends. Several felt 
comfortable knowing their peers or friends were aware of the CHC. A sense of support and acceptance from their peers helped these students feel they were not any different than their healthy peers. For example, Anna shared, “They don't treat me differently." Being accepted meant not being judged, either for having a $\mathrm{CHC}$ or for looking or acting differently than their friends or peers. Diagnosis of a CHC did not impact friendships. Friends knowing and accepting these young people meant these students were no different from their peers in spite of having to take medication or looking different. This helped some students with their own attitudes towards their CHC. For Bridget, the possibility of having a label as the 'migraine girl' didn't prevent her from feeling confident in her friendships and in her own capabilities, although she did not like having that label attached to her.

I can remember not that long again going back to my old primary school for like a little reunion sort of thing with my friends and one person who I wasn't barely even friends with came out to me and said 'oh you're the migraine girl'. It's like I don't want to be known like that. Just cause I was out of school so often and every time I was out of school people would ask me why and I'd be 'oh my migraines'. So that's kind of almost a label I got. I knew that people, that if I wasn't out, if I didn't know them on a personal level they just kind of knew of me. I knew that people knew that about my migraines like it was quite, almost common knowledge, but I didn't realize there was an actual label to it. I didn't mind though, it doesn't affects me as far as what I get to do during the days and that, but at the end of the day..., it doesn't affect my friendships. (Bridget, migraines)

[Later]

Like they don't mind that I get migraines because it doesn't affect them either. ... Well for some of them it was just like I'd get a migraine and they'd ask what's wrong and tell them. So they kind of just from me having them, they kind of just worked out that I got them quite often. But that didn't even come across, they didn't even take a second look at me. They just, it didn't affect them at all. (Bridget, migraines)

Focus Group 1:

Rich: Most of my friends know about it and things. And that's really cool. (T1D)

Lyle: I'm known as a diabetic at school, so everyone knows about it, oh, besides the year sevens, but most everyone knows about it. (T1D) 


\section{Focus Group 2:}

Bart: What I like about it is like pretty much here they don't really care about how you look most of the time. They just like accept you for who you are. (eczema)

Mark: Because you don't have to be someone else, you don't have to pretend to be someone else. You can just be yourself. (CP, SB)

[Later]

Jenna: Mm. I mean my friends are really good about it, because they're really accepting... (migraines)

In his interview, Simon told me that friends being aware he had ADHD were helpful as they could assist him in school.

What I like about it is like pretty much here they don't really care about how you look most of the time. They just like accept you for who you are... It's the friends who understand how I act as well....they'll keep me engaged. (Simon, ADHD)

Andrew said there was no difference in his relationship with his friends.

[I] continued hanging out with my mates. Yeah. Nothing much changed.... They know I'm diabetic so they don't think too much about if I do a finger prick or have a lolly or something...yeah...normal friends. They know what it is and stuff. (Andrew, T1D)

Jenna (FG 2, migraines), Bart, (FG 2, eczema), felt their own positive perspectives influenced their peers' reactions. Bart said, 'Like my one's sport because I love my sport just hard out so that friends like, just, oh I, like, I see the good side of it and don't really focus on the negative."

Well if you're being positive everyone else takes as you being positive. So I don't really think about the stuff, because if you over exaggerate maybe like use it to your advantage, like trying to get people's, like, sympathy and stuff, people won't really, then they will think bad of you, whereas if you think more positively about it then people, they can give you more [inaudible] and they forget about it. (Jenna, FG 2, migraines)

Luke, at the end of his interview, told me, "It's part of my personality. It's how everyone sees it. It's how I see it." 
Although Bridget spoke of a skepticism occurring with some teachers, she also spoke positively about teachers who believed she was in pain from her migraines. "They accepted me for who I was and how I was and they knew why I acted the way I was" (Bridget). Bart discussed that although his skin could become quite sore and infected resulting in more pain, he still felt he could engage in any activity he chose, "No, I still go on and do everything. I don't really like letting my skin hold me back. I still want to go out there and enjoy life." It took Esau longer to reach this position. Esau found accepting his cancer a struggle.

It took a while just to get out of that whole negative sort of theory, like, I think...It was only last year I really cottoned on to what's there to say about, this is life, this is awesome. You get dealt a hand of bloody twos and threes and sixes you know, it's not that good, but then there's the times you're dealt a royal flush and....will be brilliant. (Esau, cancer)

He went on to say, a few minutes later:

And yeah there it was absolutely perfect, they accepted me for who I was and how I was and they knew why I acted the way I was even if I was only there for about what six monthish. (Esau, cancer)

Acceptance of the $\mathrm{CHC}$ from others encouraged the students with $\mathrm{CHC}$ in feeling their illness was not a deterrent to having friends. These students did not need to worry about their friendships. These adolescents were accepted by their friends and those teachers, who knew or understood the effects of the CHC.

Most participants felt they were the same as their peers without a $\mathrm{CHC}$ and often spoke about being 'normal', as in not different from their healthy peers. Some students, even while describing some of the negative aspects of their $\mathrm{CHC}$, felt it had no impact on themselves overall, or on their learning. "Cause generally I can be a bit slack and I can be easily distracted by other things. But I... will then stick to it." (Simon, ADHD). Luke (ADHD, Asperger's Syndrome) spoke about wagging, "My attendance has not been so perfect through high school and being a teenager, things like that." Bridget felt her struggles in her English class were not because of her migraines but because she was more skilled in mathematics than English, "Because I understand maths better because I can pick it [maths] up faster." Andrew felt his diabetes did not affect his learning or his life, "It doesn't really affect my school or anything. It doesn't affect my life. Not really." He 
went on to tell me, "I'm no different to any other student." Mark (CP, SB) spoke often about being "my true self", which included being disabled. "I focus on my learning and even though I still have my Māoriness and my disability, I still put that aside and come to work ready." Mark was patient, knowing that he would get help, "If I was struggling through....I would put my hand and wait until they want to come to me, cause there's other students that might struggle." Anna saw herself as a hardworking, independent person who would sometimes be a bit 'zoned out'. "I was... day dreamy type, I sometimes just zoned out even if it wasn't the epilepsy", “I'm a hard worker so that's good...I like being an independent person." Anna felt she had to prove she was just as capable a student as her peers without a CHC. "I just wanted to prove that I could just as well if not better than other people that didn't have illnesses."

When asked if they thought they felt they the same as their peers or different, students in Focus Group 2 said:

Bart: No, not really. [That I'm different] (eczema)

Jenna: I don't reckon, because there's other people that have it, it's normal in a way. (migraines)

Bart: $\quad$ Yep. (eczema)

Jenna: We still talk to other people, we still go to school, still do other stuff. (migraines)

Luke: Yeah, still have social lives. (ADHD, Asperger's)

In Focus Group 4, Bruce (T1D) did not see his CHC making him so very different from his peers. "Not really. I just, when I talk to people about it, I try not to make a big deal out of it."

Students with physical manifestations of their CHC, such as Mark (CP, SP) knew their CHC was obvious to others but they did not feel they were seen as different from their peers without a CHC. Mark, in a wheelchair, wanted to be an example of how to conduct oneself. "I want to learn how to be a good role model and have respect for other people because respect...if I respect them, they will respect me" (Mark, CP, SB). Esau acknowledged the cancer and tumors he had were part of his life, but he wanted to be treated the same as everyone else. He did concede that he wanted his friends to be aware 
they could not be too physically boisterous, but, "I wanted to be treated normally but I just wanted to be understood, yes I have cancer just treat me like you know you would normally treat me, just try not to cause me any head injuries." Bart saw himself as being the same as his peers without a CHC although his peers were aware of his eczema. He knew there were visible signs of his $\mathrm{CHC}$, but he did not feel judged on his looks. Bart felt comfortable in his school because his appearance did not stigmatize him. This thought was voiced in Focus Group 2 in which he and Mark also participated.

Jenna: At this school. Yeah, that's the main thing, yeah, no one looks down on someone else being different. (migraines)

Bart: $\quad$ Yeah and they don't judge you hard out. (eczema)

Mark: Because even like throughout the school for every single one of us, we don't get put down, we don't, like, get judged for what we are. $(\mathrm{CP}, \mathrm{SB})$

At the same time, Bart and Mark did think appearances affected the opinions of those outside of school. Bart felt anger because he felt judged by his appearance outside of school.

Bart: There's probably like the people outside of school, because normally people in school they know what you're going through, and then when you go out, it's just like how people because, especially, like going for a job, because they judge everything for looks, and all of that, which is real hard sometimes. (eczema)

Mark: $\quad$ Yeah. (CP, SB)

Bart: $\quad$ And straight up pisses you off, eh? (eczema)

At the same time, students were aware that sometimes the $\mathrm{CHC}$ did not have overt physical signs but required specific treatment such as having to test blood sugar during class or needing to leave the room for treatment, which could draw attention to them. Andrew and Bruce, both with T1D, felt comfortable with themselves and administering their treatment. But they had different experiences in school. Andrew said he was not treated any differently than or by his peers without a CHC. For Andrew, self-monitoring his blood sugar level was a common occurrence, in spite of having to test his blood sugar in class throughout the day and either eat or drink sometimes if he was low. "They know 
I'm diabetic, so if I start eating in class they don't hassle me." Andrew went on to tell me how his peers reacted to seeing him test his blood sugar.

When I first did the finger prick, everyone found me quite interesting ...but that was about all. They found it quite odd. A bit different. Amazing. They thought it was quite cool, the blood and stuff. They know I'm diabetic so they don't think too much about if I do a finger prick or have a lolly or something. Yeah...normal friends. They know what it is and stuff. (Andrew, T1D)

Bruce, in Focus Group 4, however, felt a bit more uncomfortable with it as there was, apparently, little privacy when he went to get his insulin shots in school in the nurse's office, the door of which was left open. ${ }^{2}$

I have to have seven injections in my stomach every day. Yeah around lunchtime, so it doesn't really affect class, but, but, usually it bothers me when people watch. (Bruce, FG 4, T1D)

\subsection{3 "It's Not A Big Deal."}

These participants felt they could cope with their $\mathrm{CHC}$ and it did not interfere with their activities, "it's no big deal". Even those who struggled with severe pain felt they were able to adjust and manage it, or at the very least, felt there was a supportive structure in place for them. For those students who learned they had a CHC when they were in school, the manner in which their parents reacted seemed to guide their own reactions. In spite of the varied impacts the different $\mathrm{CHC}$ had upon these young people, they shared that their parents were seen as taking the news calmly or quietly. Anna described her family's reaction thus:

They were ...'oh yeah that's fine, you've just got epilepsy'. They didn't really make a big fuss of it. That was good, they didn't really make a big fuss out of it, just kind of oh yeah you've got epilepsy you've got to go on these pills. [My parents] Made me feel happy, made me feel more normal, it wasn't a big deal. It was everyday life. Oh you've got epilepsy, that's fine....kind of felt different, but not like they didn't make me feel different. (Anna, epilepsy)

\footnotetext{
${ }^{2}$ While recruiting students at School 6, I had the opportunity to tour the premises and I was shown the room used for first aid and nurse's visits. The door was left open if the nurse was in the school and available. It was not shut unless the nurse stepped away from the room and students were not left alone within it.
} 
Later she repeated what her doctors told her and that having epilepsy was not a big deal:

I think it's because the doctors and people didn't really make a big deal of it, it was just like oh you've got absence seizures it's not that big of a deal, we can give you this medication or this and this has these effects and stuff. (Anna, epilepsy)

Andrew said "I've had a lot of help from my mom the first year or so and I've got the hang of it [self-management of diabetes]." He knew his mother "looks up stuff. She finds it quite interesting" and he could go to her if he had any questions. When it came to school, Andrew said, "It doesn't really affect my school life or anything." He was confident in his ability to control his diabetes, "I've got the hang of it, it doesn't really affect my work or sporting or stuff...I know what I'm doing with this." Mark had always had CP and SB. At home he was required to do his share of chores, like his siblings. "I've always done my chores properly, I'm able to clean, I'm able to wash the dishes and dry them, clean up my home, and just have fun." James, Luke, Simon, and Bridget did not feel they were different from their peers and generally had a sense of "it doesn't really bother me, eh" (Luke). Bart didn't go into detail about his parents' reaction to the tumor in his nose and its subsequent removal, but he had a generally positive attitude overall. When it came to his health, in spite of sometimes the pain from his eczema being so bad he could not go to school, he felt "my health, in general, is pretty good. It's pretty much my skin [that is unhealthy]."

Three of the boys felt, in spite of their CHC having had a definite physical impact upon them, there were others who had a more difficult time with CHCs. Bart, Luke, and Esau perceived themselves in a positive light in spite of, in Bart's and Esau's case, having had tumor(s) removed. Luke, who had ADHD, saw his own CHC as minor compared to "other stuff". Luke had been bullied in primary school, but felt that in high school his ADHD was not an issue that would cause him to be bullied. "But as I say at high school it's different because there are other people with more serious stuff than mine, so it takes the attention of what I have and that" (Luke, ADHD, Asperger's Syndrome). Esau, who had cancerous tumors removed and had lost friends to cancer, believed his lot could have been worse, "and I knew it could be worse I was just thinking like why should I be down about this. I mean I survived." 
It's probably like the stuff that has happened in my life. Because with some people they have stuff like what I've got, they pretty much just like look at life in a negative way. But when you have something like this and you grow up with it, it makes you realize how important everything is. (Bart, eczema)

When students were diagnosed with their CHC while still in primary school, their parents were present. For these students who said their health provider or specialist spoke with them and their parents, it appeared to them their parents' reaction to the news was low-keyed which appeared, in turn, to influence the students' own reaction. Anna shared, “They were, 'oh yeah, that's fine, you've just got epilepsy'. They didn't really make a big fuss of it. That was good..." Andrew was seven years old when diagnosed and recalled being told "it's quite a normal disease" and feeling "yeah, not too bad." Students generally faced their $\mathrm{CHC}$ with a sense of it being something routine.

Most of the students were involved in some kind of activity beyond attending classes. Bridget and Simon did not go into any detail about outside activities. Simon (ADHD) was the only participant who preferred solitude, but he felt he had friends at school (more on this in Chapter 5). Several of the other participants shared their enjoyment in being part of a team, socializing with others, or doing activities with friends. James, due to his THI, had been unable to continue to participate in rugby until recently, "And I only started playing rugby with my friends at lunch in the last two, three weeks." Anna said, "Like playing sports and stuff. I like doing like exhilarating things. I just like running around and having fun. I like social sports, where you can be with friends and make friends. I like playing sports" (epilepsy). For some participants, it was seen as especially important. They did not see their CHC as an impediment to being actively involved with sports or events around them. Mark saw his being in a wheelchair as the opportunity to show others that having a disability did not stop someone from being active in the community.

I'm just trying to encourage other disabilities kids and other students that kapa haka is the way you can encourage yourself and do hard work cause I want to set a good example to other disability students around New Zealand.

Mark spoke about playing the guitar, basketball, and swimming in his individual interview. 
Mark: We usually go play sports, we usually... well, for me and my other friend that used to come here, he and I used to be out all the time playing the guitar, singing away.

Me: $\quad$ What kind of sports do you do?

Mark: Usually we play just shoots or basketball and just play catch with the rugby ball and go for big walks. And just exercising.

James was still not able to participate in contact sports such as karate and he missed the exercise, but he spoke about the value of sports in reconnecting with others and getting energy back: "And there's other things like doing sports that will help you get more active after you've been sick, after you've been doing nothing for weeks. It can definitely help you get back out there to everything. Including socially.” Andrew, Anna, and Bart spoke with enthusiasm about sports.

I always do good...it's just, it's just fun. For rugby, I also run faster than most others. Or for athletics, faster than most others, so yeah it's quite good being fit. Cause if I'm by myself, I normally, I always just do it till I'm tired. I don't try any harder, but with a team, I always try to be the best, get a better time than last time... with other people. I do tennis, but that's sort of social. Not seriously. (Andrew, T1D)

Went abseiling. It was fun. It's not abseiling, but it's like walking through these wires and stuff and flying fox, I like heights. Other people find it scary but I don't. It's really funny because all my tall friends are like I hate heights and I'm really short and I love heights. I do netball and I did gymnastics for like five years and have ribbons and stuff for that. Like playing sports and stuff. I like doing like exhilarating things. I just like running around and having fun. I like social sports, where you can be with friends and make friends. I like playing sports. (Anna, epilepsy)

Oh school camp, yeah, which I was pretty gutted [when he was unable to attend due to an eczema flare up] and making some of the sports teams for school. Because I'm hard out into that stuff. (Bart, eczema)

Bart had eczema since he was a baby and had a tumor on his nose that had to be removed. His surgery and subsequent hospitalization meant he was out of school for a period of time. He missed not only learning during his stay in the hospital, but in being active in sports. He was often absent due to his eczema flare ups, yet Bart remained positive. "Yes. I don't really like letting my skin hold me back. I still want to go out there and enjoy life, mm." Bart believed the social skills he had learned in sports were 
important in helping him communicate with his teachers. Bart further explained, "because, because if you don't, like you won't really want to go up to a teacher and ask them for help and stuff like that." Mark and Jenna, in Focus Group 2, also enjoyed participating in activities with others and being in school.

Mark: We do kapa haka, I participate in many things regarding the school and I am pretty much disabled with the sickness cerebral palsy, spina bifida, and I've been with it all my life. (CP, SB)

Jenna: And, I don't know, it's where I feel like I can, I don't really have stuff that I'm good at. It's just doing well at school and it's what I feel like people can see what I really can do, that I am good at stuff. Whereas out of school I don't really do sports. I mean, I do soccer for school but I'm not very good at it. I just do it because it's fun, and yeah I just like going to school because of my friends, and yeah just because I can do well. I can focus on things and not everything else. (migraines)

Bart's statement that he still wanted to go out there and enjoy life encapsulates the general feeling of the students regarding their overall involvement in activities other than going to school. The students spoke about their involvement with basketball, swimming, abseiling, scouting, rugby, athletics, rowing, and/or hanging out with friends as the kind of happenings/activities they enjoyed. They talked about their $\mathrm{CHC}$ not, for the most part, interfering with their ability to enjoy being active participants in these kinds of events. James, who had suffered a severe concussion during rugby, was the only student who still had to be careful of what kind of athletic activity he engaged in. These students saw sports as a means of keeping fit and having fun. They seldom mentioned their CHC as any kind of deterrent to their active involvement in these activities.

\subsubsection{NCEA and Future Plans}

The students in the individual interviews felt personal responsibility in learning the material in order to complete NCEA requirements. These students had more time to discuss their future plans than their peers in the focus groups. For some students, motivation to learn was intrinsic, either to prove to themselves that they were the same as their peers without a $\mathrm{CHC}$ or because of a realization that outside of school, there was not always going to be the same kind of support. Anna "wanted to prove that I could just as well [sic] if not better than other people that didn't have illnesses. I wanted to prove it to 
myself." In fact, she felt motivated to do well because of having epilepsy: "Yeah, I guess knowing that I, that I had this thing and I wanted to like, yeah I probably was driven more than if I didn't have it, I probably just slack off." Mark was inspired by his desire to learn more: "I want to learn more and I want to get the job done and do well."

Luke said he did not want to make use of the accommodations provided to him previously, such as the reader/writer, because of his Asperger's Syndrome. He wanted to do his own written work on assignments and exams without the reader/writer because of his awareness that outside of school he would not have the same accommodations.

Luke: Last year I qualified to get a reader/writer because I know my writing ain't the best so they got this, a teacher aide that would write just what I said to them for me and at first I didn't really like it, because I know my writing ain't the best, but I want to try and you know learn how to write it better by doing it myself. They help me with the exams and stuff like that so I got my credits. That was good. But this year I can qualify for one but I don't want to because I want to write it out myself with my own words and that.

Me: Why?

Luke: Because it just feels that, I can't do that in the real world because you can't have somebody write it for you, so I decided might as well, you know, start off now so I'm ready for when I go out to work. (ADHD, Asperger's)

Simon knew it was important for him to take his medication, "Unmedicated it [ADHD] can be a hindrance....Medicated it's more akin to a natural asset, so medicated can help me learn." Absence from school due to hospitalization was not enough to keep students from learning necessary material. Bart said, "I was getting her [his sister] to get work for me to bring home so I could catch up and that."

Not all the students who participated in individual interviews spoke about their goals after completing secondary school, but several did discuss the importance of their NCEA qualifications and their need to prepare for these.

Oh because with NCEA they come up short and what our Dean did she, she used to help me just get just to full pass she just set up easy catch ups. So like write an incident report and that will give me my two or three credits. Just stuff like that as well, to help me. (Bart, eczema) 
Especially getting quite close to NCEA and so getting close to needing to have everything in and that there's lots of things they teach you and I just feel like 'I can't do this' and it's overwhelming, but I do keep going and I do keep trying and catching up...(James, THI)

It kind of affects that side and because I have to have two weeks off, about two weeks or a little bit less it's like it affects me with learning, especially anything like NCEA and CEA. (Angela, FG 3, glandular fever, eczema)

Different students in their focus groups also stressed the importance of being in school and getting their NCEA credits.

I get teachers telling me not to come to school when I have it [glandular fever]. It kind of affects that side and because I have to have two weeks off, about two weeks or a little bit less it's like it affects me with learning, especially anything like NCEA and CEA. (Angela, FG 3, glandular fever, eczema)

You have to catch up with it. It just makes it harder when you're a year 11 or 12, an older kid, cause you've got exams coming. (Haimi, FG 4, asthma)

Another element of students' adjustment was that of the students making plans for their future. The students' knowledge that getting NCEA credits was important for future plans, was a further inducement to be in school, get the necessary credits, and particularly so they would be able to pass NCEA examinations. Mark (CP, SB) told me:

Mark: I want to pass my Level 3 general English to get my English literacy credits in order to get into the points at Victoria University. (CP, SB)

Me: Why?

Mark: Because I want to teach other students and all the young people to come on how Māori people live in New Zealand and what they are like and I want to teach them all the skills and knowledge that I demonstrated when I was their age. (CP, SB)

While Luke (ADHD, Asperger's Syndrome) didn't feel as interested in learning while in primary, in secondary he felt learning was more important so he could get a decent job. "Now at high school that's where it all counts." He said "I've got to try and get the qualifications so I don't have a crap job.”

Like get, pass NCEA level one, two, and hopefully three cause next year if I pass level two I can go to WelTec next year, I'm gonna apply to go to 
WelTec and then when I pass level three so I can try and get a pre apprenticeship to become a qualified builder...So I can get a trade and then I can go to other countries and have a trade. (Luke, ADHD, Asperger's Syndrome)

Of the three boys who did speak about future plans after high school, two of them were in their last year of high school and one was at a tech trade school. Mark knew what university he wanted to go to as well as what career he wanted to have, "My aim is to do well at the end of year exams in order to go to Victoria University. I want to work myself and get my teacher's degree and diploma" (Mark, CP, SB). Esau told me "I have a dream where I'm going to own my own company, a multinational company and earn bucket loads..." None of them discussed their CHC as a factor standing in the way of achieving their goals. Andrew, 13 years old, said he wanted to own his own business because he was "quite good with money."

Not all the students spoke about what they wanted to do after completing secondary education, but they did all discuss having to learn and prepare for exams. They demonstrated that they did not view their $\mathrm{CHC}$ as a barrier to learning in spite of being aware of the different effects either their treatment or the CHC had upon them. Regardless of their age or when they had been diagnosed with their CHC, they all established they had adjusted to and accepted having a CHC. They were aware of any limitations imposed either by the $\mathrm{CHC}$ or its treatment, but accepted these. They participated in a variety of activities depending upon their personal interests, felt they could manage their treatment and their $\mathrm{CHC}$, and all wanted to either pass or excel in their school's or national assessments.

\subsubsection{Outlier, Esau}

Although Bart and Esau had tumors removed, and Bart had radiation treatment, he never mentioned cancer. Esau's experience is markedly different from the other students. In his case, he knew he had cancer and there was a real possibility of not surviving treatment of the tumors. The other adolescents who needed daily treatment (i.e., Andrew for his diabetes) were able to manage their $\mathrm{CHC}$ and, provided that they followed directions regarding treatment, were not in danger of dying. Esau's mother had been taking Esau to various health providers throughout an undetermined amount of time trying 
to ascertain the reason for different symptoms she noticed in Esau, such as his ability to balance, his grades slipping, and a rash of headaches. When he was diagnosed with his tumors, his mother went on to do research about his treatment and was actively involved as a parent, "She got on the hospital's arse about me being on chemo. She researched it like you wouldn't believe. She researched it and she looked at radiation and she was like wow that affects your learning, you can get cataracts." Her active involvement resulted in a positive outcome for Esau: "I'm glad mum did research she did because now the back of my eyes don't burn, I can still see and basically my learning isn't compromised and I still have my hair."

\subsubsection{Summary of Superordinate Theme "It's Part of My Personality."}

These young people spoke about the CHC simply being a part of who they were. Generally, these students found themselves in an environment that accepted them. Teachers and friends generally were receptive and amenable when the students needed an accommodation (this is further explained in Section 5.4.). Most were able to manage their illness or at least receive needed accommodations, such as leaving class when in too much pain or needing insulin (Andrew). They also felt they were the same as their peers without a $\mathrm{CHC}$ and were active in sports or other activities they were interested in doing.

These young people spoke about their plans for the future and were stimulated to learn in order to achieve their goals and there was commonly little fuss or a minimum reaction regarding their CHC from others. Not all the students spoke about what they wanted to do after completing secondary education, but they did all discuss having to learn and prepare for exams. They did not view their CHC as a barrier to learning in spite of being aware of the different effects either their CHC or its treatment had upon them. Regardless of their age or when they had been diagnosed with their CHC, they had adjusted to and accepted having a CHC. They were aware of limitations imposed either by the $\mathrm{CHC}$ or its treatment, but accepted these and felt they were normal. They participated in a variety of activities depending upon their personal interests, felt they could manage their treatment and their $\mathrm{CHC}$, and all wanted either to pass or to excel in their schools or national assessments. 


\subsection{Chapter Summary}

This chapter began with a brief overview of how the data were collected and a brief summary of the participants. The four superordinate themes emerging from the data collected through individual interviews and focus groups were listed in Table 2, with a brief description following. Two of these themes, the chronic health condition experience, and it's a part of my personality were presented, described and supported with quotes from the students in this study. The first superordinate theme presented how, if at all, the students' felt their respective chronic health condition affected their learning experience. The second superordinate theme presented adjustments they made in response to having a CHC. In Chapter 5, the learning environments described by these students will be presented as well as the two superordinate themes of it's hard and learning happens when you have help. 


\section{CHAPTER FIVE IT'S HARD AND LEARNING HAPPENS WHEN YOU HAVE HELP}

\subsection{Introduction}

In Chapter 4, a brief overview of the purpose of this study and its methodology were reintroduced, as were the student participants. Two of the four superordinate themes that emerged from the data were described and presented with supporting quotes from the participants. In this chapter students' definitions of their learning environment (LE) and who are the participants involved are presented. These definitions provided context for me to understand their experiences of where they learn and with whom: their learning context. Following this, the superordinate theme it's hard is presented. This theme contains experiences they found difficult regarding their learning and which could be considered as risk factors due to the physical or psychosocial effects they had on these young people. Teachers not understanding either what their $\mathrm{CHC}$ was or its impact, and adding one more thing or task to their daily routine, are two of the four subthemes presented here. Perceived teacher skepticism often connected to the $\mathrm{CHC}$ being invisible, or not evident, impacted students and appeared to be evidence of teachers not understanding. The pressures of missing school because of hospitalization or inability to concentrate in class due to pain or exhaustion, and having to include management of their $\mathrm{CHC}$ added to making learning hard. Four boys contended with bullying in their primary schools, which had the potential of negatively influencing their school experiences.

The fourth superordinate theme of learning happens when you have help, presents the hopeful and helpful experiences of how their learning continued regardless of their $\mathrm{CHC}$ and what were the elements that contributed to this. One subtheme was parents and friends helping in various ways. Parents played an important role in encouraging and providing confidence in building student confidence and coping skills. These participants appreciated their friends, peers, and teachers or staff members who saw there were additional challenges for these students and provided learning and/or emotional support. School support in offering a safe environment, free from bullying, and with at least one teacher or staff member doing whatever they could to help the student keep up with learning is another subtheme. Students recognized that there were individuals in their school who took a personal interest in them and this dynamic contributed to their 
constructive learning experience. Positive school and home environments were helpful factors in these students learning experiences.

\subsection{Learning Context}

Schools may report that students with CHCs are absent more often from school than their healthy counterparts, requiring them to learn outside the classroom. It is possible due to possible cognitive or physical impact from their $\mathrm{CHC}$, these adolescents may miss classroom instruction and need learning support from other sources. Thus, it is helpful to know what these students experience as their learning context when they have a CHC. Their individual interviews began with questions designed to elicit their viewpoint and definitions of a learning environment and who was involved within it. The participants varied somewhat in their replies, although they generally had a similar view regarding with and from whom they were learning. They spoke frequently of support they received from their parents. They shared their experiences with their Deans, or learning support teachers, or teacher aides and felt these individuals were also helpful. A few spoke of their friends helping them learn although most saw their friends and peers as fellow learners.

\subsubsection{Learning Environment Definition}

Students' definitions of a learning environment (LE) consisted of three main areas; home, school, and during activities. Esau, a cancer survivor, spoke of the Regional Hospital School as part of his learning environment because of his personal experience. Students who frequently missed school at some point did not initially associate home as a learning environment. Focus group students did not spend time discussing the definition of their LE, but throughout the conversations of their experiences, a picture emerged which provided insight into their points of view and what created these. During the individual interviews, the students gave brief succinct definitions. These definitions expanded as the students shared their thoughts and experiences. Learning environments were seen as the school setting although some saw their LE as limitless, encompassing the classroom, home, and sporting activities; anywhere.

Teachers teaching me whatever the curriculum is. (Andrew, T1D) 
Learning environment is when there's like a group of students together being taught by a teacher...also the resources you're able to have. (Bridget, migraines)

It can be anywhere. It can be at school, it can be in the community. (Mark, CP, SB)

School's a good learning environment... after school activities like if you do swimming or whatever or soccer or something. You could call anywhere a learning environment really. (Anna, epilepsy)

You can learn anywhere, you can learn at home with the parents, there's watching TV, so there's loads of learning, mostly at school. Learning is getting new information...being told, or finding new information. You can learn anywhere uh...that's it to me. It's just new information....in class, the teacher talking to you, that's learning. Writing things down, that's learning. Even at home on the internet, searching things up in the internet, that's learning. Looking for things....even just talking to anyone. Learning by yourself. You can learn anywhere with anyone. (James, THI, Celiac's Disease)

Luke saw his LE in much the same way as Andrew, and Bridget (above), but with the additional characteristic of friendliness, while Esau said that resources and being able to learn kinesthetically were important elements. Three students described their learning environment differently, either as a place that was healthy, or where speaking to teachers did not create tension for the student. Mark felt one could learn anywhere there was a sense of safety.

A place where questions are asked by teachers, kids answer them and everyone gets on and stuff like that, but sometimes that's not the case. (Luke, ADHD, Asperger's Syndrome)

A place where you have all the resources and capabilities to learn what you want to learn, where it is a quiet environment, you know, to the standards that you need to learn. Everything there. The environment which has all the resources that you need to learn or you are aiming to learn and that is beneficial to your capability of learning. We may understand the theoretical part of it, but we need hands on to actually understand how it works. (Esau, cancer)

It can be anywhere just as long as you, or myself feel safe in that kind of environment. (Mark, CP, SB) 
Bart began his description of a learning environment as being a healthy place and went on to explain that it could also be informal and a healthy contented one.

So a learning place for me would be like a healthy, a healthy environment, like, the kids are happy most of the time, not like down. So most of the time it's got a good vibe pretty much so when you're learning, like, everything just flows. (Bart, eczema)

Simon felt a learning environment consisted of being able to approach teachers directly and ask for assistance.

The environment is one where you can easily ask for help and get it and can easily talk to the teachers and easily learn better and it's an environment where you can easily request assistance for a single thing and get it without having to sort of think of how you're gonna ask it and be, are...cautious whether you can approach teachers, you can just approach them straight up. It's where the teachers [are]. (Simon, ADHD)

Later, when prompted by questions regarding their $\mathrm{CHC}$, learning, and parents, several students expanded their definitions and included their homes as part of it, which will be addressed in Section 5.4, learning happens when you have help. Age did not appear to influence their viewpoints. For example, Anna, 12, and James, 14, and Mark, 17, immediately spoke of learning as occurring anywhere, not just in the classroom. Andrew, 13, Simon, 16, and Luke, 16, said an LE consisted of the school setting Like their counterparts without a CHC, for these students, their LE consisted of a school setting with some believing it could also encompass informal settings such as being in town with friends or engaging in sporting activities. Additionally, four students spoke of their LE as being a place where it was safe to learn or where approaching teachers to ask questions or seek guidance did not involve anxiety or stress.

\subsubsection{Learning Environment Participants}

When asked who participated in their learning environment, all the participants, except for Bart, immediately mentioned teachers, then their friends or other students. Teachers were seen as knowledgeable and doing what they were supposed to do: teach. Every student at some point mentioned their fellow students as not only being part of their LE, but being integral to the actual learning process. During the initial phase of the interview, most students gave short concise answers, but sometimes expanded briefly. A 
few answers, while concise, also blended LE with learning participants, as seen below in Bridget's description. Other students felt there was a distinction; students were the learners and therefore the only participants. Later in the individual interviews, when asked if there was any school support, they discussed teacher aides, deans, or coaches as being very helpful in their learning. Several students did not initially think of their parents as LE participants, but subsequently discussed parental support as an important part of their learning. Support provided by parents, teacher aides, learning support teachers, deans, and friends are discussed later in this chapter, Section 5.4.

Learning environment is when there's like a group of students together being taught by a teacher. (Bridget, migraines)

Probably friends. My friends would be the main one. (Bart, eczema)

I think who's involved is my parents, my school, the teachers. (Mark, CP, SB)

Their parents, like family because they can teach the family thing so they can learn from their family. Everyone really. .. the students, the people that are learning. (Anna, epilepsy)

My teachers, my parents. (James, THI)

A place where questions are asked by teachers, kids answer them. (Luke, ADHD, Asperger's Syndrome)

And all the children around you helping or encouraging you and stuff...Teachers, students, the other pupils. (Andrew, T1D)

Esau and Simon immediately mentioned learning support personnel as participants, "Teachers, the other students as well and well, for me it's the help staff, in other words, the learning support people" (Esau, cancer). Simon (ADHD) said, "Mainly my six teachers that teach my six subjects and Ms. Y, who is my tutor teacher and learning support teacher." Simon mentioned leaving the classroom and going to another room such as the learning support room or the library to work/learn in solitude, which is what he preferred. Luke (ADHD, Asperger's Syndrome) went on to say, "And everyone gets on and stuff like that, but sometimes that's not the case." Other than these exceptions, students said participants were teachers and fellow students. 
Students considered communication with teachers and amongst students a helpful part of their LE. They experienced learning as an interactive community.

All the children around you helping or encouraging you. Curriculum around you when you're learning practically. (Andrew, T1D)

You're learning and you're also socializing at the same time. Not to the point where you sit chatting about things....but even just socializing by talking about how you do something, say in maths or English. (Simon, ADHD)

We always take time after to school to go to the library, do my homework and we just talk and explain...on how we understand. (Mark, CP, SB)

Bridget felt oral communication with the exchange of ideas being the best and an important part of learning although she believed that teacher talk with no classroom discussion was a preferred method for some of her teachers.

The best learning environment for me is generally not too much noise, but still able to talk and communicate with everyone, whereas some teachers don't like that...some teachers like dead silence and you have to do it by yourself and not many students that I know of learn like that, we work best communicating with each other. And like sharing ideas and discussing what we need to do. (Bridget, migraines)

The participants viewed teacher as imparting knowledge and the students, with their fellow pupils and/or friends, were receivers of this knowledge.

\subsection{It's Hard.}

\subsubsection{Introduction}

The third superordinate theme emerging from the data was that having a $\mathrm{CHC}$ caused everyday activities such as going to school, learning, and being active to be more difficult than it was for their healthy peers. There are four subthemes within this superordinate theme. The first subtheme consists of the participants experiencing their teachers not understanding. Students spoke of not being taken seriously because the CHC was not obvious, encountering skepticism from their teachers. These young people thought their teachers did not know about their illness, or did not understand it, or minimized its impact on the student's ability to come to school or to learn when in school. The second subtheme regards the physical impact of the $\mathrm{CHC}$ making learning hard because of the inability to 
focus or catch up on missed learning due to the $\mathrm{CHC}$. This subtheme also entails students needing more time to catch up properly on work. The third subtheme describes some of the students feeling that having a CHC added yet another task to what they had to do, or was one more thing they needed to think about whenever they did something. Not all the students spoke to or shared this experience, but it emerged as an important point for those who did, due to its impact on their learning experience. The fourth subtheme concerns a much smaller number of students who shared the experience of being bullied. Although only a few spoke about this occurring because of their $\mathrm{CHC}$, it left a lasting impression on them. The superordinate theme It's hard presents the experiences students had regarding how having a $\mathrm{CHC}$ had a direct effect on their learning, making it difficult.

\subsubsection{Not Understanding}

Students described teachers not understanding their CHC or being skeptical of it as hard. It was difficult for the students not to be taken seriously by their teachers because the condition itself was not obvious. Participants talked about wanting their teachers to not only know they had a CHC, but to understand what it was like for these students, to understand its impact. This contained two ideas that could make learning difficult: (1) that students had a visible $\mathrm{CHC}$ and teachers did not understand the effects of the $\mathrm{CHC}$ or made wrong assumptions, or (2) that teachers did not know of or were skeptical of the $\mathrm{CHC}$ or its impact because the $\mathrm{CHC}$ was invisible, again making learning difficult. Students spoke of feeling they were not treated with either understanding or consideration because they believed their teacher was skeptical concerning the CHC. Esau shared his experience of how his cancer was visible (others knew of it) but that their understanding of it was not evident. Esau felt he wanted to be treated the same as his peers without cancer, but that his teachers be aware of the very real impact cancer and its treatment had on him. He did not want to be pitied because of his $\mathrm{CHC}$, he wanted to be understood.

Yeah they meant well, but they didn't understand to the degree that they needed to. Basically they had all the right things but in the wrong order. I mean everyone was saying, oh he's got cancer, how long's he got. And really it's, oh he's got cancer, interesting. You know I'd rather be an interesting individual than for what I've got, than, you know, uninteresting character. Well when I found out [that I had cancer], teachers are more understanding. Yes, of the way I was. One thing you learn about having a sort of illness is you don't want sympathy. When everyone pretty much 
wants to give it to you, you don't want it back. You just want to be understood, well that's what I wanted to be, I wanted to be understood, I wanted to be, you know, just treated normally which I know is, you know, hopeless, cold chance in hell. (Esau, cancer)

On the other hand, Anna felt supported within her school and that she was understood. Nevertheless, she found that when she did miss school for medical tests, teachers did not always understand that, once she returned to class, it did not necessarily mean she was able to learn.

If you have too many days off school, you do miss a lot. If you do come back to school and you think you're over it, and you might still be too tired or something like to take it all in. And the teachers say you were here this day, you should have all that down and you have to do this, this, and this. (Anna, epilepsy)

Students in Focus Group 1 and 2 either spoke of teachers not understanding anything about their respective $\mathrm{CHC}$ s or of having wrong ideas what their $\mathrm{CHC}$ was. Focus Group 4 's conversation did not progress in that direction; as they spent more time sharing about the effects of their respective CHC as shown before. This resulted in the focus group educating each other throughout the interview as they shared their experiences.

Focus Group 1:

Kevin: If they don't understand what it's about then it's kind of painful. (T1D)

Lyle: Yeah if they don't understand the effects of it as well. (T1D)

Kevin: Yeah. (T1D)

Rich: And you don't actually always have to go to class, but I mean, they do treat you differently. (T1D)

Simon: Especially with the teachers if they don't know effects of the illness and like often just think you're slacking off or something like that. (ADHD)

[Later in the discussion]

Kevin: Oh just some teachers like told me off. Just cause they think that everything's meant to be under control...but after a while you should be able to do that but like (pause). Yeah, I think it's just like for some teachers don't, like, don't even know I have diabetes 
and stuff like that and so, then they kind of find out, it's kind of wrong for them to make claims about it. Sometimes it gets frustrating. (T1D)

Simon: The sort of thing and my writing disorder except the teachers don't really, it's not like you're just going to say to the teachers I have a writing disorder and this is what it does, because there's no real set level of this is what it would be without this is what it is with. So it's more just they don't know and it's just like 'you have messy writing'. (ADHD)

[Later in the discussion]

Lyle: Everyone thinks if you have diabetes you're not allowed anything like with high sugar content at all. (T1D)

Kevin: Or anything with sugar in it. (T1D)

James: People think you can die real easily because of eating something wrong. (THI, Celiac's)

Simon: If you have sugar, you'll go just nuts and all hypo and stuff. (ADHD)

Rich: Shouldn't you be fat? (T1D)

(Boys all laugh)

Kevin: With Type two diabetes maybe. They always get them mixed up, too. Like on the news they always say like the biggest loser you have a high chance of having diabetes, but they don't say diabetes type two. (T1D)

Simon: There are definitely some big misconceptions out there of just about everything and they reckon there are more misconceptions with things that are more common like diabetes and ADHD and that sort of thing. (ADHD)

James: And like understand a diabetic, if you're high or if you're low, when to take insulin and stuff. Before they'd ask you when you're low, if you take insulin. (THI, Celiac's)

Kevin: No, it's like when you have a low like, you tell and the teacher nd of confused, and doesn't know what you mean. (T1D)

Me So there's like a lack of knowledge?

Lyle: Yeah. (T1D) 
Kevin: Oh, like, it's alright for them not to know about, but if they don't, then it's, yeah it is wrong for them to make a claim about it and say you can't, you can't be like this or you shouldn't be doing that and stuff like that, because, yeah, they don't actually know. I guess they're not informed about it and stuff like that, and they don't actually know what it's like. (T1D)

Focus Group 2:

Jenna: Yeah I mean they go 'oh it's just a headache, I mean, get over it'. (migraines)

Bart: $\quad$ Pretty sore, eh. (eczema)

Jenna: A migraine's like intense and because I get like a stomach ache, it's like, everything at once, and sometimes I even like black out and people don't get that, they just think, 'Oh, she's being dramatic'. (migraines)

Focus Group 3:

Angela: The teachers think that if I'm off with glandular fever that I've just got a cold and they don't understand like what it is, because it's basically, I can't really explain it too well. It's kind of like once you get it, if you get sick you can get a cold or flu and it will just be like ten times worse than normal because it's like an infection that stays with you for life. So if you have a cold which can often be like sneezing and stuff, I'll probably be like in bed just like not moving, just tired, ten times worse. And so some teachers are just like, well she's just got a cold, why is she taking...two weeks off. (glandular fever, eczema)

Bart: Yep. (eczema)

Another student agrees [unable to hear who agreed]

Angela: And I'll come back and they're like oh she's fine. It's because once, yeah, once you've got glandular fever, it stays with you and it makes every other sickness you get ten times worse. So if I get a cold, I get a really bad cold. (glandular fever, eczema)

[Later]

Angela: The other day I was sick because I was feeling like my glands were swollen and I was like, oh great, I think I was like sick again, but because we've got this huge thing in drama at the moment and so, apparently he [the teacher] just sat in the class saying Angela's wagging today. (glandular fever, eczema) 
Tabitha: I didn't know it was him. (migraines)

Angela: Yeah, the whole class came to me yesterday and they were like 'yeah Mister thinks you're wagging, maybe you should tell him you have glandular fever.' (glandular fever, eczema)

Me: $\quad$ Oh, so do your teachers know about the illnesses?

Angela: No. (glandular fever, eczema)

Seth: No. (asthma, eczema)

Focus Group 4:

Haimi: Is that when you can only eat certain amount of sugar or something? (asthma)

Bruce: Pretty much. (T1D)

Daniel: Or do you need sugar? (Crohn's disease)

Haimi: To keep you going? (asthma)

Bruce: Most of it's really taking the medication. But the amount of sugar I eat doesn't really change. I just have to keep a close eye on it really. (T1D)

Teacher skepticism of the CHC because it was not visible made school more difficult for students. Just as not being understood, or the teachers lacking knowledge of the CHC made school a more difficult experience for them, feeling they were not believed when they said something did not engender a positive, accepting environment for them. This resulted in some students not managing their $\mathrm{CHC}$ as they needed to because of the disbelief or misconceptions their teacher had. In Focus Group 1, in one case, this resulted in non-compliance for a student as he felt it was more difficult to comply because of the lack of understanding from the teacher. Bridget's $\mathrm{CHC}$, having recurring migraines, was invisible, although the pain was very real. Her experience was that there were teachers who did not believe she was actually having a migraine and were dismissive towards her.

But for the teachers, if I got there and I wasn't, like I started to get a migraine at school, they would think it was just because I was trying to get out of certain subjects we were doing. So they'd just be 'oh Bridget's just, you know, doing the migraines again' so they just kind of thought I was making it up to get out of whatever subject I was doing. (Bridget, migraines) 


\section{Focus Group 1:}

Kevin: Yeah, because I used to have like a low like once a week, so I'd be out of class like once a week and apparently I was out every day, so I haven't been out of class the last year, and they still think, am I missing school and stuff like that. So now I never test it in class because I'm like, I don't want to be told off or anything. Yeah. (T1D)

[A pause in the conversation]

Kevin: Yeah, yeah. It's just, it's just weird, like they think, like I go out every day, go and I don't even know what it's called any more, medic room. Yeah, I'm in the medic room [sarcastically] and then they think I'm like there every day, but yeah. (T1D)

Me: $\quad$ But you're not doing it [testing] during class?

Kevin: Yeah, well, I haven't, (pause) tested in class or anything, I have to, oh I, like, wait. (T1D)

Focus Group 2 also discussed skepticism. If a CHC was clearly visible, as in Mark's case, there was no conflict with teachers. If a $\mathrm{CHC}$ was not visible, teacher response was not helpful to the student:

Jenna: Some can with mine because I'll be like, I have a migraine and they'll be like you know just go get a panadol. It's like "No!" Cause panadol doesn't really work. (migraines)

Mark: The teachers are very good. (CP, SB)

Jenna: You try and sleep it off and they just don't get that sometimes. They just say just go get a panadol and it's... (migraines)

Me: $\quad$ So you have... With the ADHD, with the eczema, with the spina bifida it seems like there's a lot more understanding by the teachers?

Luke: Mm. (ADHD, Asperger's Syndrome)

Mark: $\quad$ Yep. (CP, SB)

Me: $\quad$ But with the migraines you have, some [teachers] that are better more understanding than others?

Jenna: Yeah. I think it's more like they think it's not really, they don't consider it as an illness. They just don't think, have ever thought 
about it, because 'oh it's just a headache. Everyone gets like those'. But it's worse than that. (migraines)

Students believed there was a lack of understanding of their respective $\mathrm{CHC}$ or that teachers had doubts either of the CHC or its impact. Further, some did not manage their $\mathrm{CHC}$, ignoring or delaying treatment due either to a teacher not understanding or skepticism. Students whose $\mathrm{CHC}$ was not visible to others felt they were not treated with the same understanding or consideration as those with visible illnesses. They felt their CHC was not taken seriously. When students believed there was skepticism or a lack of understanding, this caused some students not to manage their CHC properly. For these students, not being taken seriously, encountering lack of understanding or knowledge by the teacher, even teachers not knowing the student had a $\mathrm{CHC}$, were elements that contributed to making their learning experience hard.

\subsection{3 "It's hard."}

Students in their individual and focus group interviews discussed difficulties they encountered concerning their learning. Many of these difficulties involved the lack of time. Students felt it was difficult for them when they were absent from school and had to catch up with missed learning. Time was needed for the students to catch up on missed learning, missed classwork and needed time to complete assignments. Students also encountered difficulties if they were in school, but still feeling adverse effects of their CHC. They found it difficult to catch up at times because, although physically present in class, effects from their $\mathrm{CHC}$ affected their ability to take in new learning. Some students came to school feeling ill because being absent from class or school for any amount of time made learning and catching up difficult. They thought teachers assumed that because the students were back in school, they were completely prepared to learn. This was not always the case. Students also saw nonattendance in school due to a CHC and how the absence affected learning as difficult.

I wouldn't sleep the night before [hospital testing] and I wouldn't be in a state to come back to school because I would be so tired. When I had the EEG, it was just one day a year, but it did affect my learning, because I'd have to catch up on five classes worth of work....If you have too many days off school, you do miss a lot. If you do come back to school and you think you're over it, and you might still be too tired or something like to take it all 
in. And the teachers say you were here this day, you should have all that down and you have to do this, this and this. (Anna, epilepsy)

It's like I'm not allowed to go. Like my doctor won't let me go and you come back and the teacher's like, well, you could have been doing this in your spare time and like I said, when you've got glandular fever, you're so tired. Like you just don't want to even get up, you don't even want to be awake because you're just so tired.... Yeah, year 13 it's just so hard. Even year 12 was hard too. (Angela, FG 3, glandular fever, eczema)

Yeah, since year 12 and year 13, I couldn't afford to miss of any of my classes. (Tabitha, FG 3, migraines)

Haimi, James, and Esau felt it was difficult to grasp all the material if there was not enough time to do so. Haimi (asthma) said, "Like and then when you come back to school, it's hard to catch up with your work. You still have, like lots of work to do." James believed that more time to study and learn was helpful and necessary.

... ask my friends to look at their books and it's tough getting them [the books] and also just learning all of it the one time. It's just hard and again, while I still had the headache, it was really tough cause it lasted the whole term...It was hard for me to catch up so much. It was straining and just hard to get it all in....If you've been off...you've had a hard time with it and (inaudible), not being able to study. A bit more time once you've been back and you're ready....A bit more time to go over everything....That really helps. (James, THI, Celiac's disease)

In Esau's case, he was receiving help through one of the Regional Hospital School because of his cancer treatment. He needed extra time to make up the missed work and to learn the material because of the late effects of his treatment. Esau felt there was a great deal to learn in a short amount of time, and the school workload was enormous.

I mean it takes [me] a lot longer to understand things and comprehend things than others. And they [the Regional Hospital School] got me my level two which is what I needed so of course I was rapt about that, although I hated the workload they gave you because it was nonstop work. They wanted me to succeed and I wanted to succeed too, but I mean the workload was ridiculous. (Esau, cancer)

Being absent from school when completely new material was presented, as opposed to new material based on previous learning, made catching up difficult. James felt being absent from his foreign language class quite keenly, "It's an actual whole different language rather than putting, adding thing to what you already know. It's learning 
something completely different and completely new. That was the hardest." The participants had an acute awareness that when they were not in school, the amount of missed learning and the need to catch up could be overwhelming. Bart (eczema) said, "And then sometimes it is really hard to catch up....when I'm off, it's just really hard to keep up." James shared more:

Definitely, there were moments I felt overwhelmed. Especially getting quite close to NCEA and so getting close to needing to have everything in and that there's lots of things they teach you and I just feel like 'I can't do this' and it's overwhelming, but I do keep going and I do keep trying and catching up. (James, THI, Celiac's)

Focus Group 2 discussed the difficulties that arose when a student was not in class.

Angela: It used to be, it used to be great. Because it would be like, oh okay, I don't really care if I miss this class and this class, but now it's kind of like really hard to take a day off because you just miss so much in one day. (glandular fever, eczema)

Seth: Yeah. (asthma, eczema)

Angela: Like one day feels like a week in year 10. (glandular fever, eczema)

Asher: And you've got to catch up on all the work. (asthma, eczema)

Philip: Yeah that's the other downfall. (asthma)

Angela: The teachers can be very like, don't understand why, so that's also a pain with learning. (glandular fever, eczema)

The students in Focus Group 4, as a whole group, spent more time in hospital than the other participants. This was not unusual taking into account the CHCs in this particular group; Crohn's disease and rheumatic fever.

Focus Group 4:

Mahina: I hate hospital. (rheumatic fever)

Chris: Not me. I have tons of friends there. (Crohn's disease)

Daniel: I've been there... about 40 times. (Crohn's disease)

Mahina: I was in hospital every two months. I missed term two. (rheumatic fever) 
Bruce: I had to go when I was diagnosed. I was in hospital a lot-[during] the day and just in and out, so I missed some school. (T1D)

When Bridget was absent, catching up on missed classroom instruction meant some selfteaching as well as asking her mother for assistance.

Unless you can step up and say look, I'm kind of struggling here, the teachers don't know what is going on...My teacher was still sending my Mum things that I could do at home but I wasn't having the teacher there to tell me what I was to do, I kind of had to self-teach because, yep, my Mum's a primary school teacher so she helped me quite a bit as well but the fact that I didn't have a teacher who was actually there and telling me you know this is what you need to do was quite challenging because I had to read through all the information and learn it myself which as a 11, 12 year old girl it's not exactly easy to do. (Bridget, migraines)

Young people in this study felt there was not always enough time for them to get to know the materials needed and that workloads to catch up on missed learning were cumbersome. What added to their difficulty in catching up was that, even when in class, their CHC could still impair their ability to learn. Being in the classroom did not necessarily mean they were fully able to take in new information.

\subsubsection{One more thing}

Some students felt that having to manage their CHC or its treatment was one more thing to take care of in their daily lives. Feeling ill, having to test for blood glucose if diabetic, not being able to get enough rest, or feeling intense pain could be overwhelming some days for the students. There were times these young people were tired of the intrusion of the demands or effects of the $\mathrm{CHC}$ or its treatment on their bodies and their time.

Not only annoying, it's just having to remember to take it. I had it twice a day. I'd have to remember to bring it with me, my Mum would remind me ...mostly. (Anna, epilepsy)

I had to take a bit of time off school because the first week of chemo was absolute hell. Vomited up a record of 11 times in three days. The first week was for me and then yeah five times in one day. (Esau, cancer) 
For these young people, there were moments when simply having the CHC was a difficult experience. For Rich, in Focus Group 1, it was not only that he had to manage his schoolwork, but his diabetes as well and sometimes it was tiresome to do this all the time.

Focus Group 1:

Rich: When you're first diagnosed it's like, oh no, it's going to be so much work I have to deal with then once you get used to it it's fine. After doing it for a while.

Lyle: At the start I was like, okay, this is all right, so I was doing it very day, but that's because it was in the holidays so I had a lot of time. But I don't actually have that much time in my day, because I've got sport and stuff like that and I have to get up really early and stuff like that. After a while it got really annoying, I'd much rather, I don't know, be... a lot simpler, we have to go through, like, three processes before you can actually get on with your day.

Kevin: It's more stuff to worry about as well. (T1D)

Lyle: It's that extra thing you need to look after. (T1D)

James: Everything just takes that little bit more effort. (THI, Celiac's disease)

Simon: It's a different routine as well. The fact that most of your classmates are all doing one thing, but then if you don't have your meds for one day sort of thing you've got to be able to stop, recognize that, go to the office and get everything sorted out, sort of thing and it's just, yep, it's just a whole different routine at times. (ADHD)

Rich: You've got to focus on, I guess, trying to keep on track with diabetes and schoolwork as well, but even though it may seem it takes a little bit of time out of your day, it gets kind of tedious after a while. Sometimes on bad days I think, oh well, why does this have to happen to me?...Like on a good day I can accept it. I know I've got to look after it. Then, like on a bad day, I've had enough. (T1D)

James: Well, like I have days where I was so tired because of all the headaches I just couldn't, I just like, get up, and I would be... I just couldn't really... it would be like I didn't want to go to school. I didn't think I would be able to get through the day. I was just so... and then I'd be all grumpy and I'd be, I just like, yeah, it would just be so hard. (THI, Celiac's disease) 
There was also the awareness for the teenagers that sometimes the $\mathrm{CHC}$ could become worse and require hospitalization.

But no that's had an impact on my health because I had radiation afterwards, after the surgery because the tumor was attached to the carotid artery and that's the main, the main vein to your brain and they said if they operated on that in that area and just touched it a little bit then I could have died.... I missed out, because I was in hospital for about two, three weeks and then I had to be off for ages just to recover and that would have been an extra four weeks on top of it. (Bart, eczema)

Focus Group 3:

Philip: You knew that other people have worse. (asthma)

Seth: Yeah. (asthma, eczema)

Asher: $\quad$ Like Philip, he had an asthma attack last year. (asthma, eczema)

Philip: Yeah. (asthma)

Me: $\quad$ So when he had the asthma attack and you saw...

Asher: Oh we didn't see it we just heard about it and then we seen him. (asthma, eczema)

Seth: Yeah, but when you hear about it from his friends they just, it reflects back to you that you might get that. You might be there. So that's another [thing] for you to think [about]. (asthma, eczema)

Several students knew that having a CHC could entail more than a daily routine. Sometimes they grew tired of the physical demands their respective conditions could entail and were also aware that a worsening of symptoms could result in hospitalization. They needed time to recover fully from an episode or treatment that resulted in requiring time away from school. They spoke about finding it difficult to have to add another task to what they felt was already a full schedule.

\subsubsection{Bullying}

Bullying was also an issue for four of these students. They said it occurred mainly in primary school with less and even no bullying occurring in secondary. For three of these boys, being visibly different had some negative consequences. Mark and Esau were 
bullied for looking different from their classmates. He said he did not mind it, that it was a part of being different. He also felt he was bullied for not being able to understand classroom instruction like his peers.

I got, I got, you know, for eight years as you know, with bullying for being different and for having a really large head because we measured it and it is pretty large....even though I got bullied there, it was okay I didn't mind. Taking rocks to the head, taking punches to the face; it was just part and parcel. Having kids make fun of you because you didn't understand, you had an abstract view to everyone else and you were teased for that. (Esau, cancer)

While Mark was in primary school, he experienced bullying: “...back in primary school, when they used to disrespect me and put me down and all that." Labels were part of the bullying experience. Chris and Daniel, both boys in Focus Group 4 who had Crohn's disease, were also bullied in primary school, although, for Daniel, it appeared to be still ongoing.

About like I was about nine that's when I first got diagnosed, and I was in hospital for a year and when I came back at school, everyone was picking on me and calling me Disease Boy and thought they could catch it and no matter how I tried, played their games and tell 'em that. That's it. I hated them. (Chris, FG 4, Crohn's disease)

Some people take advantage over me, like my weaknesses and all that. And so some people just bully me if I've done something wrong or anything. (Daniel, FG 4, Crohn's disease)

Luke shared that once his primary school classmates knew his diagnosis of having ADHD, they made fun of him, engaged in name-calling, and was told he should go to another school. However, he learned he could count on the adults at the school who would not allow negative behavior such as bullying.

At primary school I remember when people found out they used to just, not treat me the same as before because I had ADHD. They just used to call me ADHD and that and make fun of me for having it and stuff and saying that oh, that I was mental and that, and that I should be at a different school or something, not that one....The DP's and the deans, when I was being bullied, they'd tell the teachers in the staff meeting and the teachers would keep an eye out for what was happening and then they could put something in place to prevent it from happening. (Luke, ADHD, Asperger's Syndrome) 
Bullying by other students in primary affected these boys enough that they still spoke of those experiences. They were bullied physically as well as verbally. Being punched, made fun of, and called names were difficult experiences for these boys and made their learning harder than it was with their chronic health condition.

\subsubsection{Summary of Superordinate Theme "It's Hard."}

For students with a CHC, learning is made more difficult because the effects of their $\mathrm{CHC}$ add another layer of challenges all adolescents encounter. The students with a CHC in this study, used the phrase 'it's hard' to describe a variety of elements that made learning or attending school difficult for them, including not being understood, teacher skepticism, physical or cognitive impacts of their CHC, absenteeism, needing to learn missed learning, and for some of the boys, bullying. While bullying was experienced by a minority of students within this study, and it had a profound emotional impact as they spoke about it throughout their interviews. Bullying made their learning experience, principally in primary school, difficult. For some students it was difficult if their CHC was not visibly obvious or teachers did not understand their particular $\mathrm{CHC}$ and therefore, discounted the effects of it. Some students were more aware of the possibility of their CHC worsening, resulting in hospital stays. Students spoke of the difficulties incurred by a lack of time, either for learning material within a certain time frame or catching up on missed new material. Having a CHC gave them one more thing to think about over and above their healthy peers.

\subsection{Learning Can Happen When You Have Help.}

\subsubsection{Introduction}

The participants in this study continued to learn in spite of the difficulties they encountered and, in fact, spoke positively about the different aspects within their learning experiences that helped them continue their education. The fourth superordinate theme emerging from the data was learning can happen when you have help. This theme is supported by two subthemes; parents and friends help and school support. Students generally associated learning occurring in school, but they all had support from parents and/or particular staff members that helped them continue learning in spite of CHC impacts such as absenteeism, inability to focus or concentrate, or pain limiting their 
learning in school. Some students spoke of their parents teaching their children about their CHC. Others said their parents advocated for them, communicating with school personnel about the $\mathrm{CHC}$ or necessary accommodations. When they were absent from school, students saw their parents as helpful in a myriad of ways: from teaching materiel missed in school, to being encouraging, compassionate, and firm regarding schoolwork and learning. Friends were not only fellow learners, but provided notes from missed classes or social support. Some students relied on their friends to fill them in on missed information and reiterate what had been taught in school.

Parents and friends were not the only sources of learning support for these students. Students spoke about their school enabling learning to be successful. A community spirit within their school assisted the student with $\mathrm{CHC}$ by providing accommodations, sharing information within the faculty or other positive forms of support. Several students spoke of their deans or learning support teachers with great respect and appreciation. Teachers or staff members who knew the student personally and knew of the $\mathrm{CHC}$ were seen as especially helpful. These young people felt supported when school staff knew about the CHC and had personal interaction with the students. These individuals had a better understanding of the students and, subsequently, provided more support than staff or teachers who did not know the student or did not have any knowledge of the $\mathrm{CHC}$. In one case, in a religious school, prayer was seen as a positive form of support within the school ethos.

\subsubsection{Parents and Friends Help}

\subsubsection{Parents}

Students spoke of strong parental support not only in adapting to the CHC, but with learning as well. Parents seen as reacting calmly influenced the students' reaction in some cases. Students were supported by their parents not only in school, but in extracurricular activities. While students did not specifically say their parents encouraged them in this regard, student involvement in various activities such as music lessons or sports is evidence of this support. They trusted their parents and other family members to help them. Parental help was as a connector, a bond between the teenager and parent. 
I've had a lot of help from my mom the first year or so and I've got the hang of it [self-management of diabetes...My mum knows quite a bit about this stuff. so I can just ask my mum....Or ask for a doctor appointment. My mum is very, the biggest help. She would sort of like decide how much insulin I should have the next month and we would occasionally change it if I say I'm high or a bit low, but yeah.. normally, I'm quite self-manageable....oh I'll say oh I was low in school and she'll say "maybe you should increase your insulin a little bit." But nothing yeah, it's just, yeah, nothing much happens. I normally say I went low at school today and she'll say, "Oh. Did you do so and so?" She's at home. She knows more about it, she's more...looks up stuff. She finds it quite interesting as well, so ...yeah. (Andrew, T1D)

We would discuss it....Mum would take me for the brain scan and stuff...once a year. We'd talk about it ...the medication and stuff. Mum was helpful, she was good about it. (Anna, epilepsy)

One of the main reasons I'm learning, in term of studying, my dad is basically the main driving force behind my education. It's more that my dad connects to me with more things like mathematics that I do like... Dad knows more how to motivate me in terms of, in terms of answer a question and go into detail. He will happily do that. (Simon, ADHD)

That was, well, my Mum was wanting me to go to school as much as I could, but if I woke up in the morning and I really wasn't up to it, she would allow me to stay home.... The support, like, for the teachers and my Mum was very supportive... She hadn't been doing anything herself, but she knew that it was genuinely affecting me and so she was very helpful when it came to, like, making sure that if it was to do with my eating, I was eating right, and I was getting the right, like, getting the right amount of water into my body, like rehydrating. (Bridget, migraines)

They had the stuff at the hospital to help me, but because my sister was working at intermediate [school], she was like the receptionist, so I was getting her to get work for me to bring home so I could catch up and that, and I'd just get Dad to help me out, just work out what it is. (Bart, eczema)

Bridget, Anna, and Bart each had a parent who was currently a teacher, or had been a teacher and provided additional support. They knew they could rely on their parents and school personnel to get missed worked from school or assist in learning the materiel.

If something's happening and like with my skin, trying to sort things out my mum and dad can ring up school. (Bart, eczema)

The fact that my Mum's a schoolteacher generally helps quite a bit because if I am behind she can just, she kind of knows what she's teaching so she can help me. (Bridget, migraines). 
Parents had high expectations of these adolescents performing well in school or at least to the best of their ability. Parental assistance ranged from asking the student if their school work was complete to giving them school related tasks, to strong encouragement to 'try' to do well in school. Sometimes students described this as 'pushing', but it was not seen as a negative incentive. 'Pushing' could also be associated with getting back into socializing as well as staying involved with school.

My parents, very much them pushing me to do things, doing extracurricular activities. I haven't done sports in a long time with my injury afterwards the people at the clinic said 'you don't want to go into sports for basically the rest of the year.' But I've been taking a computer course during this holiday and my parents got me into that...I liked it a lot. Parents that help you along outside of school. Definitely. It got me back up doing stuff, afterwards. Cause that was straight after my head was fine and got me back into doing things...They just pushed me a bit to make sure I got caught up, even now they ask me, 'are you catching up? Have you got all the homework?' They're just making sure that I've caught up and that I've got everything. (James, THI, Celiac's disease)

My dad's been on my case ever since I started college and that about getting, you know, concentrating in class, and going to class, and that, and so has my mum , and that so they've helped me a lot to push me to try in my schooling and that, because in the past I didn't, but now at high school that's where it all counts and that. So yeah, they've helped me a lot to get where I am now. Well, my dad used to make me on Saturdays and Sundays do times tables from one to ten or one to twelve every Saturday and Sunday or every week and to get it stuck in my mind to remember it and that helped me a lot. Or Mum would make me read for half an hour and that not only calmed me down, but to get, you know, get ready for school. At the time it was annoying, but now I see it was real helpful. (smiles here). (Luke, ADHD, Asperger's Syndrome)

My mum and dad...always tell us to try our hardest. If others aren't doing the work, you don't have to...follow them and do no work. Just try the best you can do.... It's more of my family environment because my brother did very well at school. He was smart. He's good at maths and science and I wanted to prove that I could be as good as that [her brother skipped a year] because my family did have high expectations of us to try very hard. I guess I just want to prove that I could work just as hard as him. They do have high expectations. Yeah, I think it's good that they've got high expectations of us...(Laughter) He's like, there's no excuse. You've got all these resources here and you can do this, and this, and you can use this to get your information, there's no excuse not to be doing your best, yeah. (laughs good naturedly) (Anna, epilepsy) 
When he thinks I haven't done enough study, he won't come in and say 'right you won't go on the computer or do this. You're gonna have to study.' He's not trying to guilt trip me. It's more he's trying to me make me think of that. Just to make sure I understand that and he'll say, 'if you think that you've done enough, then sure, do it. But I think you need to study more.' He's not trying to guilt trip me. It's more that he's trying to focus me, to say to me I don't' think you're studying enough. But if you really think that you have it, sure go ahead and do what you want" sort of thing....And it's helped me by, it brings it to me a bit more, in the sense that by doing that, it stays there a bit more so the next day I think about it a bit more and so when thinking so have I done enough study, that comes up more. Without my dad I wouldn't be anywhere, really. (Simon, ADHD)

The impetus of being pushed did not only come from parents. While he was being taught by a teacher from the Regional Health School, Esau felt he was not only pushed to learn, but that it was key in his own attitude changing, "but if they hadn't pushed me, I don't think I would have the drive that I have now." Bart and Anna also had an inner impetus of wanting to do well. Bart said, "I just wanted to do well, so I just kept pushing myself." For Anna, working hard and trying her best was a mantra: "yep I just like working hard and try my best... You have to, like, try as hard to put my best effort into everything."

\subsubsection{Friends}

Friends had dual roles for some students; they understood how the CHC affected the student, and they were supportive in school. Students felt confident their friends understood the impact of the CHC and knew what to do if help was necessary. Students were comfortable asking for help and trusted friends to help them with missed learning regardless of the reason. Some students felt their CHC did not have any impact on them socially, their friends continued to be there. They trusted and depended upon their friends to remain in touch with them if they were not in school and not make a big deal when helping them in class.

Normally if I feel low, to just get food out of my bag... Yeah, nothing much happened between us, just continued being mates. (Andrew, T1D)

I think my friends help me a lot. As opposed to my peers. Like my tablets. If I forget to take it, I don't mind saying to my friends, I've gone off my tablets today, so I've taken it earlier. It's the friends who understand how I act as well...they'll keep me engaged. (Simon, ADHD) 
I would just ask my friends about what I'd missed and they would be quite cooperative. They would let me look at their book and they would tell me. They would say, 'oh, we've got this assignment or we're doing this in class or we've watched this.' So my friends were really good with that. (James, THI, Celiac's disease)

Oh well, they're texting me, like keep me up to date [when Bart was out of school]....because when people do help you out like that, you feel really good and you feel grateful about what you've got. It keeps you going pretty much. Keeps you wanting to do, like, to do good in life. (Bart, eczema)

If you just ask, most people are happy to kind of give you the work you've missed out on. (Bridget, migraines)

I had some friends, if I'd ask them what was like going on...or what did the teachers say, they'd just repeat it to me, they didn't make too much of a big deal of it. (Anna, epilepsy)

Students felt friends in school were also helpful in reinforcing learning, whether it was through discussing it or doing homework together.

Mostly I get help from my friends that really know it and they want to support me. (Mark, CP, SB)

Even if friend one says I don't know how to do this, but I think you do this. You get their opinion of it, it helps you get their perspective, wow they do it like that so maybe I should try it that way. (Simon, ADHD).

Parents and friends played a positive, supportive role for these young people. Parents encouraged these young people with a $\mathrm{CHC}$ to persevere in their learning, to meet their expectations and were not seen as cosseting them and expecting less scholastically because of any possible impact the of the CHC. These students were able to depend upon their friends in school, either with schoolwork, in a social setting, or if they needed some specific support for their $\mathrm{CHC}$, such as juice for a diabetic low.

\subsubsection{School Support}

\subsubsection{1 "They help you."}

The young people with a CHC in this study spoke of the different forms of school support they received. Although they described difficulties they encountered in school as a result of an impact from their respective $\mathrm{CHC}$, they also experienced positive assistance from school personnel and overall felt supported by their schools. These students had and 
appreciated teachers who acknowledged the students had a CHC and were mindful accommodations were needed. These teachers demonstrated 'understanding' and were seen as supportive and caring. This allowed students to feel more comfortable in asking for help or in managing their CHC in school. Communication with home or between students and teacher helped build this. Strategies and accommodations put in place by these teachers included allowing the student to leave the classroom as needed, writing on the board, repetition, giving assurance or clarification, following up on the student's progress, and being lenient with deadlines.

Sometimes, they would ask do you need more time. But it was mostly just checking up on you. They knew I needed a bit more. They would check up on me and see how I was going. (James, THI, Celiac's disease)

They gave me the leniency to do my work and they gave me the time to do my work. (Esau, cancer)

So like taking... taking up, like taking their own time to help me out for a lot of stuff that I missed out on, or that I'm really stuck on, stuff like that. (Bart, eczema)

You can tell them if you're having difficulty learning something or just, you don't, you don't get it or something, they're just there to help you, I guess....Just knowing I can talk to my teachers about it, I don't have to be embarrassed about it or shamed or anything....I'm not afraid to ask questions. (Anna, epilepsy)

She would email my Mum things that we had been doing in class so that if I was feeling up to it I could do it at home just so I wasn't completely behind. (Bridget, migraines)

During his interview, Luke explained how his teachers showed understanding.

Luke: They understand it [ASD] and they can help you with it...Because there's some teachers at school that have like either taught my Dad when he went there, or they know, like family members and stuff like that, that helps with that because you know there's, it's like you've got a teacher that's also a friend as well. That helps a lot. ....things that they do and that....if I was struggling in the class or something, they'd, you know tell them, the teachers that were teaching me in my classes, and they'd be able to help me out with stuff.

Me: $\quad$ What has been helpful? 
Luke: I can't describe that. I just don't know what, how to put it into words. Practically just the same really, eh, of teachers, family, friends, there's nothing really changed that much. Well, yes like, when I was being picked on and that, sort of they'd back me up, and they'd help me so it didn't, it wasn't on my mind too much because I know that they were there if anything happened, so it helped me concentrate more on school than on what was going to happen. (ADHD, Asperger's Syndrome)

Andrew's teachers knew he was diabetic, but he believed he did not get any special treatment. "Teachers make me do my work; they don't give me any special privileges just because I'm diabetic." Yet, he was allowed to have food or juice with him because of his diabetes: "If they ask me is there anything I can do, I just normally say, just let me eat in class," (Andrew). Andrew's confidence and awareness of his glucose levels allowed him to feel comfortable to self-advocate. "If it's a test, I'll have my juice and then I'll put my hand up and say, 'Teacher can I have an extra 5 minutes...and they'll say, yeah."

Teacher understanding of some of the difficulties these students faced was seen as encouraging and reinforced students' positive experience in school. Students interpreted teacher understanding in a variety of ways. I asked Esau if understanding occurred when the teachers understood the reason he needed everything repeated twice was due to the tumors. He emphatically agreed. When I sought further clarification regarding sympathy from his teachers, that they didn't sympathize and say pityingly, "Oh, poor Esau," but instead said "Oh okay I need to remember to repeat, I need to remember to give him the opportunity to show me physically," he also emphatically agreed with me. Students in the focus groups also shared how their teachers showed understanding, encouragement, or helped them with learning and, in the course of their discussions, reiterated what I had heard in the individual interviews.

Focus Group 4:

Me: $\quad$ Do you feel like your teachers do everything they can to help you?

Chris: Yeah. (Crohn's disease)

Bruce: Yup. (T1D)

Daniel: Yeah. (Crohn's disease) 
Me: What do you think those things are that they do to help you?

Daniel: They check. (Crohn's disease)

Haimi: They always check on you. (asthma)

Bruce: They try to understand you so they know. They try to learn as much as they can so they know what to do if anything happens. (T1D)

Chris: If you don't do all your work properly, they'll say, 'it's alright, maybe next time, good job.' (Crohn's disease)

When speaking of who aided with learning or dealing with the $\mathrm{CHC}$ within the school, the young people mentioned staff at the school and this included deans, teacher aides, and learning resource counselors. Andrew and Bart regarded their year level Deans as helpful and supportive by helping them get needed information when they were absent. Another way was by informing their teachers about their $\mathrm{CHC}$ or absences. "The Dean sent an email all around all my teachers so they know about my diabetes," (Andrew, T1D). Bart (eczema) told me, "and the deans or the DP can sort everything out, like help us to get through. Get everything sorted out. So it starts running smoothly even." Simon believed his ADHD did not affect his learning, saying "No, not massively. No," but felt his learning resource support teacher was instrumental in his teachers understanding ADHD and allowing him time away from others when he needed it. Simon's Learning Resource teacher's intervention also helped him change his own attitude.

I think that, even with people like Miss F., when I was first diagnosed with ADHD, when I started here at X, and found out about my ADHD, my parents once saying to me, that Miss $F$ had printed out a whole bunch of stuff giving them out and talked to the staff about ADHD and that I think it's her who's really helped.....Most of the teachers didn't know about ADHD. Because of Miss F., that has definitely changed a lot in both my attitude and the teachers'. I felt more understood. I...there wasn't a massive change like they started doing something different. They did, but it wasn't a massive one like they started, it was subtle. It was more leniency towards me, more willing to allow me to do things my way so that I understood it. And my attitude just got better, in terms of my cooperation with the teachers. (Simon, ADHD)

[Later] 
By being able to come to places like P1 [room where the interview took place] and the library, I can just do that, I can let go. I can just think. (Simon, ADHD)

Three students in this study needed or had teacher aides because of their CHC. In spite of having teacher aides, Mark felt the onus was on him to learn the material. As shown in Chapter 4, Section 4.7, Luke was provided with a teacher's aide was provided and a reader/writer. He saw the benefit of the reader/writer, but also struggled with the idea of having help with his reading and writing. He felt he needed to learn how to communicate in writing on his own. Because of the difficulty Simon had because of his writing disorder, coupled with the ADHD, he knew the aide and his Learning Resource teacher were needed.

They've helped me with my writing disorder and ADHD. (Simon, ADHD)

I had a teacher aide, well, I've still got a teacher aide this year. In school a couple of them come through with my subjects, like English, my Māori and Te waharoa....Yes, cause this year my skill is that I want to pass my Level 3 General English to get my English Literacy credits....I want to work myself and get my teacher's degree and diploma. (Mark, CP, SB)

Three of the four focus groups discussed the support they had within their school. Focus Groups 2 and 3 were from the same school. A feeling of community appeared to be fostered within the school environment.

Focus Group 2:

Bart: School's pretty good because like even if you've got that, it all depends on what you make out of it because why you could have a chronic illness and always think negative about it. But it's the way that you think how school's going to be and school is like pretty, pretty supportive. (eczema)

Jenna: Yeah. (migraines)

Bart: Especially the teachers. Like they know what you're going through and like do a little bit more to help out that's important, with friends and that. (eczema)

Jenna: Even the students are supportive, with what's important. (migraines)

Bart: Friends. (Students overlapping) (eczema) 
Bart: No, the teachers are really sensitive. (eczema)

Luke: Some understand it pretty good. (ADHD, Asperger's Syndrome)

Focus Group 3:

Me: Why do you like this school? [Follow up question]

Angela: Well I've been to three different colleges and so I'm like yeah this is my favorite but like with my other schools. This school's were very understanding when I'm sick. Like I don't know why, but like my other schools and stuff were very, a lot of them just thought I was completely bullshitting....cause there's understanding for me. (glandular fever, eczema)

Tabitha: I like school. I like school cause...(stops speaking) (migraines)

Student: (whispered) Support.

$\mathrm{Me}: \quad$ [After a long quiet pause, seeking clarification from overhearing the word] Do you feel like they're supportive here?

Tabitha: Well yeah. (migraines)

Seth: Cause the teachers are really awesome and text you. (asthma, eczema)

Asher: Yeah really cool. (asthma, eczema)

Philip: Yeah, they'll ring you up and see how you are...They wonder where you are. (asthma)

Me: $\quad$ They do wonder where you are.[seeking clarification]

Philip: Yes. They ask our friends and stuff. (asthma)

Angela I think that's real nice when teachers do that, a few...(glandular fever, eczema)

[Later]

Tabitha: There's a teacher in the school, who isn't even my teacher, that was Mr. C, and he's not even my teacher. (migraines)

Asher: He's like the computer, yeah. Yeah. (asthma, eczema)

Philip: He's always checking up...(asthma)

Angela: He looks after everyone. (glandular fever, eczema) 
Tabitha: Yeah, he does. (migraines)

Philip: And he talks to you like you're not a student. Like you're an actual person. (asthma)

Angela: Yeah he talks to me like... (glandular fever, eczema)

Asher: (cutting in) He does. (asthma, eczema)

[A few minutes later]

Tabitha: (overlapping) And he's one of those teachers that will check up on you. (migraines)

Philip: Yeah. (asthma)

Asher: Yeah. He helps you...(asthma, eczema)

Focus Group 4 shared that the ethos of caring was supported through school wide prayer as well as teachers or staff visiting students in hospital.

Haimi: They actually care for you if you're in hospital for a couple of months or something. (asthma)

Mahina: They care for you. (rheumatic fever)

Haimi: They pray for you. (asthma)

Mahina: And make sure you're okay. The principals have come see us. Or hers do. (rheumatic fever)

Daniel: They didn't come see me. (Crohn's disease)

Mahina: Yeah, yeah, we prayed for you. I remember. (rheumatic fever)

Haimi: I remember. All those people, they were prayed for....That your friends are always going to be there for you. Even the school will pray for you, if you've been in hospital for a long time. (asthma)

Chris and Daniel: Sending cards (Crohn's disease, Crohn's disease)

Me: $\quad$ Cards?

Daniel and Chris: Yup. (Crohn's disease)

Me: $\quad$ So you do have a feeling in this school that there is a sense of caring about you? 
Haimi: Yeah. (asthma)

Me: $\quad$ And how's that caring shown to you?

Haimi: By receiving cards. (asthma)

Mahina: Over the intercom. (rheumatic fever)

Me: $\quad$ Over the intercom. They pray for..?

Haimi: A lot of the teachers that come to school. (asthma)

Me: $\quad$ Oh, like at the hospital?

Chris: They come to the hospital and check if you're alright. (Crohn's disease)

Included in this subtheme is the support from national and local systems. Mark, in Focus Group 2, knew there was a policy in place regarding primary school teachers passing on portfolios of the students to the next school. He believed the policy was designed to assist the teachers with any students who needed assistance. National policies regarding students and $\mathrm{CHCs}$ were also seen as helpful. Mark's mobility was restricted to places accessible to a wheelchair. His school provided this ease of accessibility. "cause it's a good place and it's got easy access for me wheeling up the ramps up to my classroom and it's easy doors to get through and desks to go through" (Mark). His school was also supportive in helping Mark receive an electrical wheelchair; having an electrical wheelchair made his learning a better experience so he was not as tired from travelling classroom to classroom, as he was when he used a manual wheelchair.

Yeah, and the understanding between ADHD and spina bifida is that teachers, like before we started school, our primary school teachers gave the high school like a portfolio about ourselves and what we are capable of and what is our conditions and the school has like the teachers that understand how we feel and what kind of disability or disease we have and that's why the school has a good understanding for us to be in a safe environment for the students and to feel safe with the teachers and the students....It's a good thing cause it's my school suggested that I have one of these chairs....I got it special made by Enable New Zealand....That's the wheelchair industry that makes different types of wheelchairs, specially made for the people....Cause if I'm using my manual one than that's gonna make me tired in class. (Mark, $\mathrm{CP}, \mathrm{SB}$ ) 


\section{Focus Group 4:}

Daniel: When I was in hospital I just catched [sic] up with what my class was doing cause I had that teacher who... (Crohn's disease)

Haimi: She comes in hospital. (asthma)

Mahina: Yeah. She just comes to school and just asks for work and stuff. (rheumatic fever)

Although Esau had to repeat sixth form, he did not see it as a bad experience. This may be because he was repeating it and some of it was familiar to him. During this time, he decided what he wanted to be and realized he needed to achieve necessary credits to reach his goal. His frequent absences, due to chemotherapy and subsequent radiation treatment, required him to receive learning support services from the Regional Health School. During this period, Esau also learned about CanTeen, an international support group for adolescents fighting cancer. The emotional support provided by CanTeen helped Esau change his initial negative outlook and attitude to a healthier, positive one.

Esau: They [CanTeen] do much more than that, they're a huge support. Well, okay, basically when you're first diagnosed, right, you're thinking the world's over, you're a goner right. You know that's it, you've batted your last innings. You're done, finito. But I came into CanTeen right and I was like all doom and gloom. Everyone is. Then you get welcomed into this environment which, yeah, everyone may be dying, everyone may have the same illness as you, but it's not negative, it's not all doom and gloom. I mean some of them are suffering from cancer, some of them are siblings, some of them are bereaved siblings, in fact, most of them are, as far as I remember. But the fact is everyone is positive. People wouldn't go, oh you've got cancer what type, how long have you got. It's more like right, okay, hey mate, what cancer have you got, sweet as. (Esau, cancer)

\section{[Later]}

Me: $\quad$ Okay so that would be, that's a lot to have to repeat sixth form.

Esau: Not really. It wasn't as bad as I thought it was.

Me Why is that?

Esau: I suppose because I had all the necessary stuff I needed for what I wanted to do, because I decided then what I wanted to do and just 
to keep on chugging along you know. I eventually got the credits that I needed within the first year and I got more credits than I needed in the second year, and then I transitioned into the Regional Health School. Yeah.

Me: $\quad$ That would be because you were absent quite often?

Esau: Yes. When I went back in there [where he lived in the South Island] I went to Regional Health School, and they basically got me the rest of the credits that I needed because I realized, right, I want to become an engineer, a good industry like a trade. A lot of hands on stuff. Yeah, but I needed the credits and I looked at it and said, that's where I want to go, what do I need? And I needed, you know, a few more credits than I had, or something like that, I don't know if you get what I mean.

Me: $\quad$ You needed a few more credits to get to where you needed to be.

Esau: Yes, yes that's it. That's it perfect. And yep makes sense. Through the Regional Health School, they got me my level 1, I think, yep. And they got me my level 2 which is what I needed so of course I was rapt about that...

Having systems available to these students such as the organization that provided a mechanized wheelchair for Mark and the Hospital Schools for Esau, Daniel, and Haimi, allowed the students to continue with their learning and stay engaged with what was happening with their peers in the regular classroom. CanTeen provided an environment made up of other adolescents undergoing the same experiences as Esau and in which he no different from his peers. More importantly, CanTeen gave him a positive environment, providing normalcy and hope.

Those students who spoke about health providers such as nurses, their doctors, and specialists were seen as helpful with the exception of Bridget who suffered from migraine headaches. Overall, health providers or those involved in the testing process were seen as helpful and in a position to offer good advice to the students and their CHC. "They tell you what not to do and what to do. So they help and they give a guideline with what you should be able to do with what you've got" said James (THI, Celiac's). Anna (epilepsy) said, "[The] doctor was helpful and the person who did my EEG's was helpful and she was nice." Luke (ADHD, Asperger's) also felt the doctors were helpful. "The doctors have, because they've prescribed me the right medicine to help me concentrate." 


\subsubsection{Safe}

Students with a CHC who were bullied in their primary schools felt safe and protected from ridicule, negative judgment, and bullying in their secondary school. Safe also included these boys knowing there were places they felt protected or where they could be alone and undisturbed, such as the library. Not all the students in this study were bullied, but for the boys who were, it had a definite impact. Mark, Luke, and Esau found their respective schools had anti-bullying strategies and they received support from teachers and peers within the school. They made a point of clarifying how different their secondary school environment was and that it was better for them because they felt safe from bullying. They were certain of their friends' support and understanding of their $\mathrm{CHC}$ if anyone tried to bully them in their secondary school, although they all felt it was not prevalent there. For Luke, the security of having this support allowed him to concentrate more on learning instead of feeling fearful.

Like one of my mates I've known since like pretty much since he was born and he understands what it, what I have and that and he's helped me through it and so if people give me a hard time about it he'll just tell them to get lost or something....The teachers get it more, they understand because we're not so young, not so you know gullible and they, they understand it and they can help you with it and the kids they understand it too and they know, they have an idea of what it's[ADHD and Asperger's] like....Like, what is it, when I've been bullied and that, the DPs and the deans when I was being bullied, they'd tell the teachers in the staff meeting or something, and the teachers would keep an eye out for what was happening, and then they could put something in place to prevent it from happening....Well, yes like, when I was being picked on and that sort of they'd [teachers] back me up, and they'd help me so it didn't, it wasn't on my mind too much because I know that they were there if anything happened, so it helped me concentrate more on school than on what was going to happen. (Luke, ADHD, Asperger's Syndrome)

Just the library and others places that makes you feel safe and happy....protected from the harm and violence that other people would give you just because you're different.... Friends, the ones who haven't disrespect me, try to pushed them [bullies] away and let me forget about them, has really helped me and always supported me....Actually no one ever disrespects me anymore. They...respect me and they like me because of who I am. It doesn't matter what my disability does, it's my true self that counts. (Mark, CP, SB) 
Then I moved up to Wellington right. I was just settling into the boys' college, oh the best place in the world. I loved it. Hardly any bullying so whatever....Like my best mate was this guy, a Tongan guy named Time, he was my tech, he was an absolute brilliant guy, best mate. Him and I got on like a house on fire and he was a big guy and it was great. (Esau, cancer)

These boys were bullied when younger because they were different from their peers (presented in Section 5.3.5), but found, in their secondary school, that neither the school nor their peers tolerated bullying. Simon was surprised that other students would stand up for him and defend him. "I've been surprised someone standing up for me. Cause guys can be idiots and try to wind me up, but (long pause)... [Me: they're supportive?] Exactly, that sort of thing, like that" (Simon). Students felt safe and protected from negative behavior from others in school.

\subsubsection{Summary of Superordinate Theme "Learning Can Happen When You Have Help."}

The nine students with a CHC interviewed in this study found positive support and encouragement at home as well as in school. Support at home came primarily from parents who expected these young people to continue their education and meet parental expectations. Communicating with the school regarding their $\mathrm{CHC}$, going over learning materiel, and 'pushing' were seen as helpful strategies used by parents. Students had positive reactions to being 'pushed', seeing it as impelling them forward. Friends also were helpful-they kept the students informed of what was happening in the classroom with notes, texts, or other materiel.

When teachers demonstrated they knew about the $\mathrm{CHC}$ and its effects on the student, students felt understood. Students felt this understanding by teachers was constructive, that this knowledge led to teachers being more tolerant and considerate of the impact of their CHC. Teachers were not the only source of school support. Staff support, in some cases, was a key component of students' learning. Learning Resource teachers provided information about illnesses to the teachers and other staff, which created a positive, accepting climate for the students. Two students benefited from outside school supportin one case an electronic wheelchair was provided for Mark, increasing his mobility and his ability to engage in learning so he was not as tired from the manual labor of a non- 
electric wheelchair. Regional Health Schools provided individual instruction to students who were absent from school over a long period and, in Esau's case, personal motivation to continue his education. CanTeen, an international cancer organization for young people with cancer, offered positive emotional support as well as hope for the future for Esau.

\subsection{Summary}

In this chapter, the learning context as described by the participants and the superordinate themes it's hard and learning can happen when you have help were presented. The description of the learning context for these students was generally seen as the classroom or school with fellow students and teachers seen as the primary participants. The superordinate theme it's hard was concerned with the difficulties they encountered in their learning experience as a result of their CHC. Students found a lack of understanding from teachers, a lack of time, teacher skepticism, the need to catch up on missed learning, and bullying were challenging. Yet, while sharing their frustrations with me or in a focus group, these young people also spoke of the positive influences that was in their lives. These were usually a parent, followed by an influential teacher or staff member in the school. The fourth superordinate theme, learning can happen when you have help is comprised of these affirmative, constructive people, including friends and outside resources such as CanTeen. Students described their parents' assistance as helpful, motivating, firm, and part of their overall learning success. Students described a helpful, caring school environment with supportive, understanding teachers and staff, friends, and peers as contributors to their learning. Two students appreciated the impact of two local community resources (CanTeen and Enable New Zealand) as two other helpful elements in their learning environment.

Students with a CHC may be able to learn much as their peers without a CHC. The primary differences for the students in this study were accommodations they saw carried out by either teachers or staff. Students spoke of the understanding their teachers or individual staff members demonstrated towards them. These young people saw this understanding shown through extra accommodations provided by the teacher or staff member. The following chapter discusses these findings and their implications as well. 


\section{CHAPTER SIX DISCUSSION}

\subsection{Introduction}

This qualitative phenomenological study sought to investigate the learning experiences of New Zealand secondary students with a chronic health condition and to ascertain what are the learning experiences of students with chronic health conditions. The sub questions were:

a) How, if at all, does their $\mathrm{CHC}$ affect their learning experience?

b) Where/what learning environments do they participate in and from whom are they learning?

The adolescents shared their experiences of what it was like to learn with a CHC. Four superordinate themes emerged from the data. In their chronic health experience they spoke about the different affects their respective $\mathrm{CHCs}$ had on them when learning. They saw their CHC as part of my personality sharing how they were accepted by others and themselves, and adjusted to the demands of their CHC. They described the difficulties they had with concentration, pain, perceived teacher disbelief, which made learning hard, the third superordinate theme. And they described the support they had from their parents and their friends and the help they received in school, finding that learning can happen when you have help.

The four superordinate themes were presented separately with subthemes, but together they offer an integrated portrait of the complexities adolescents with a $\mathrm{CHC}$ experience when learning, albeit perhaps a miniature portrait as the study is of a small sample. The portrait which emerged was of an adolescent who looks in the mirror and sees someone who wants to be the best they can be, someone who can overcome personal suffering and adversity with strong parental support, trusted friends and who can learn despite the challenges a CHC can present, who sees a normal young person looking back. In the mirror, this adolescent sees the strength that comes from parents, friends and, most importantly, themselves. These New Zealand adolescents with a CHC, in spite of the difficulties they encountered, were confident in their abilities to learn, and did not show any sign they found the difficulties insurmountable, even when the pain was unbearable 
or they felt worn out. The experience of learning with a $\mathrm{CHC}$ has an array of challenges that can be painful, tiring, and, as they said, hard. But it is one these students in particular did not find so arduous they were not able to overcome it. They encountered difficulties in school with teachers who did not know, much less understand, much, if anything, about their particular $\mathrm{CHC}$. There were moments they were not able to be participants in school activities because of their $\mathrm{CHC}$, sometimes missing out on school milestones. Yet, they still felt they belonged to their school community, they could continue to learn, and that, in spite of the difficulties, they could make plans for the future. Despite the diversity of CHCs in my study, the students' descriptions form a picture of their learning experiences full of coping strategies, strong parental support, an understanding, helpful teacher or staff member, and a positive outlook for themselves.

A wide range of $\mathrm{CHCs}$ were represented: ADHD, Asperger's, cancer, Type 1 diabetes, eczema, epilepsy, migraines, traumatic head injury (THI), cerebral palsy and spina bifida, Crohn's disease and colitis, glandular fever, and rheumatic fever. Chronic health conditions such as diabetes, irritable bowel disease (BID), and asthma are increasing within New Zealand (Craig et al., 2012; Yap, Wesley, Mouat, \& Chin, 2008) and these impact and add additional challenges to youths' developmental process, which is already challenging, physically, cognitively, and psychosocially. In my study I asked students with a CHC how they experienced learning. The 24 secondary school students who participated in my study shared the difficulties and positive experiences they had when learning. In spite of the negative impact of either their $\mathrm{CHC}$ or its treatment, teacher skepticism or lack of knowledge of the CHC experienced, missing out on school or activities, and being different than their peers, these students were supported by and used protective factors around them to adapt and meet the challenges with which they were presented. This chapter discusses the findings.

\subsection{The Chronic Health Condition Experience}

In my study, although I did not ask what coping strategies they used to deal with their $\mathrm{CHC}$, emergent data showed these students used strategies as part of their daily routines to deal with the difficulties their CHC presented when learning, which resulted in their belief their learning not impacted by their CHC. As a result of the physical or cognitive 
effects from their respective CHCs, students needed to leave the classroom due to pain or other reasons associated with the $\mathrm{CHC}$ which resulted in missing classroom instruction and activities. This meant an increase in workload, needing to self-teach, or relying more heavily on parents and friends for aid in catching up with the class. In my study, to manage their pain and other affects from their $\mathrm{CHC}$, including missing out on learning and activities, participants engaged in active problem-solving adaptive coping strategies. These included asking for help in catching up on assignments, asking a teacher or parent for assistance, and not focusing on the negatives aspects of their $\mathrm{CHC}$, or leaving the class when necessary. These young people used positive coping strategies and were selfassured and confident in dealing with any of the negative $\mathrm{CHC}$ impacts such as pain, the wearing off of medication for ADHD, or diabetic lows.

Lazarus and Folkman define coping as "constantly changing cognitive and behavioral efforts to manage specific external and/or behavioral efforts to manage specific external and/or internal demands that are appraised as taxing or exceeding the resources of a person" (1984, p. 19). Moos (2002) suggests, in his discussion of coping responses in adolescents, that the focus of coping is how teenagers approach and act in response to a stressor, with the focus on resolving it, trying to avoid it, or concentrating on how to manage the emotions surrounding the stressor. There is some difficulty when discussing coping as the literature varies in its definition of coping as well as how to measure it (Garcia, 2010) but there is some agreement considering coping effectiveness as productive or adaptive, or unproductive or maladaptive coping approaches (Frydenberg \& Lewis, 2009; Hampel \& Petermann, 2006; Meijer et al., 2002; Wu, Chin, Haase, \& Chen, 2009). Maladaptive or unproductive coping strategies are problem avoidance or withdrawal and can result in behavior problems or depression (Frydenberg \& Lewis, 2009; Meijer et al., 2002). An adaptive approach can be problem-focused/problem-solving which centers around gaining control of a stressful situation, problem solving, giving oneself positive self-instruction, and seeking social support (Frydenberg \& Lewis, 2009; Meijer et al., 2002).

Much like the students in my study, positive or problem solving coping strategies involved physical recreation, investing in close friendships, seeking social support, seeking to belong, and focus on the positives were found in a number of studies (Bauld et 
al., 1998; Frydenberg \& Lewis, 2009; Meijer et al., 2002; Wang et al., 2010). Bauld et al. (1998) compared coping mechanisms in 32 adolescent cancer survivors and 34 healthy adolescents (aged 12 to 17 years), and found cancer survivors used more productive coping strategies than their healthier peers. Bauld et al. (1998) suggest this may be due to the cancer survivors having a more extensive and mature range of coping skills than the control group. Frydenberg and Lewis (2009) examined two independent data sets totaling almost 2000 adolescents. They found that the strategies related to problem-solving were those focusing on the positive and accepting one's best efforts. Similarly to my findings, they suggested that the teenagers in their study may have focused on school-related problem-solving which is associated with academic success, although, as my study looked at how students experience learning, my participants spoke primarily to this from a positive perspective. Wang et al.'s (2010) investigation discovered their two participants and adjusted their thinking in believing their diabetes had little impact on their school lives, but, their participants kept their diabetes a secret (2010). Wang et al.'s study was conducted in Taiwan and cultural mores may have had an influence regarding sharing diabetes knowledge with peers and teachers in the classroom setting. The students in my research did not keep their $\mathrm{CHC}$ a secret with the exception of one student in the focus group who suffered from migraines.

Participants in my study did not want to be different than their peers and they had positive expectations and outlooks, resulting in their positive coping styles. Coping strategies of teenagers with inflammatory bowel disease (IBD) were investigated by van der Zaag-Loonen, Grootenhuis, Last, and Derkx (2004) in 65 adolescents aged 12 to 18 years. They, like Frydenberg and Lewis (2009), found their respondents used much the same coping skills as healthy peers when dealing with day-to-day pressures. However, when dealing with their IBD, they used a maladaptive coping style; avoidant behavior such as brushing aside the problem or leaving things the way they were. This may have been due to the overt physical manifestations of their CHC. Similarly, der Zaag-Loonen et al.'s (2004) respondents did not want to be different than their peers and if they had positive expectations or a positive outlook, they had positive coping styles. In spite of difficulties their CHC presented, participants in my study normalized their $\mathrm{CHC}$ and its 
management through self-talk, for example by telling themselves there were others who had the same CHC, so having it was "normal in a way".

In my study, neither the younger students, aged 12 to 14 years, nor the older adolescents discussed coping strategies which could be described as maladaptive with two exceptions. One positive coping mechanism used by students in my study when experiencing pain or discomfort in school, involved either leaving class or school to rest and they were not reluctant to do this when in school. This may be because they understood that attending to their CHC's resulted in a positive outcome (less pain and a return to school or class). This also suggests maturity on the part of the participants regardless of their age; they were aware that attending to their $\mathrm{CHC}$ sooner was preferable than possible negative outcomes as a result of not doing so. Hampel and Peterman investigated age and gender effects coping with interpersonal stressors in 286 Austrian adolescents aged 10 to 14 years (2006) and found maladaptive coping behavior in middle adolescents (12 to 14 years) was more prevalent than in the younger children. Wu et al.'s (2009) phenomenological study of ten adolescents aged 12 to 18 years in Taiwan had similar findings to my own study. Their respondents spoke of the physical and psychosocial impact from having cancer, but had positive coping skills. $\mathrm{Wu}$ and colleagues postulate that culture is influential in pain management and in Taiwan, adults have a negative attitude towards medicine controlling pain, thus influencing the adolescents' reliance upon other means such as strong familial encouragement, to manage and cope with their pain. Cultural background or influence did not emerge in the data in my study. Parental support is discussed further in Section 6.4. Students in my study used adaptive strategies to help them deal with the stressors from their $\mathrm{CHC}$ so they could continue to learn.

Cartwright, Fraser, Edmunds, Wilkinson, and Jacobs (2014) reported similar findings of how CHCs affect adolescents. Cartwright and colleagues' (2014) phenomenological study focused on ten adolescents (aged 13-17 years) with juvenile idiopathic arthritis (JIA). Their participants experienced the same pain experiences as the students in my research. Similarly, the young people in their research spoke of feeling accepted by their peers, having a sense of normalcy and believed in their ability to manage their treatment and CHC. They wanted to be like their peers and this meant controlling of their JIA and 
normalizing their experiences (Cartwright et al., 2014). Participants in my study found support from their friends by being accepted as one of them and not being considered different. This was indicted by the use of phrases such as "They just like accept you for who you are," or "you can just be yourself". The young people in Cartwright et al.'s (2014) study thought likewise which Cartwright et al. suggest is an adaptive mechanism.

The adolescents in my study appeared to engage in an internal dialogue by moderating the difficulties they encountered with positive thinking and actions. Examples of this are "If you're positive everyone else takes you as being positive" or "I don't really like letting my skin hold me back, I still want to go out there and enjoy life." When they missed class due to their $\mathrm{CHC}$, they believed they were able to catch up although time was necessary. They could rely on their friends and classmates taking notes for them, friends allowing them to copy lessons, and using break time and lunchtime to get caught up with schoolwork. These can also be interpreted as examples of showing responsibility, and independence, key constructs in adolescents' development towards autonomy (Williams et al., 2002). Much like the students in Woodgate's study (1998) which explored the experiences of 23 adolescents aged 13 to 16 years in Canada, and described hardships encountered in school, students in my study used strategies that helped to modify their thinking. Woodgate posits that when the participants struggled with difficulties related to their CHCs, they downplayed these and relied on strategies that influenced their 'subjective psychological state" (p. 221).

Other studies examining adolescents with CHCs and coping strategies have found seeking help from peers, parents, and school coaches was an adaptive strategy (Huus \& Enskär, 2007; Karlsson et al., 2008). However, in Huus and Enskär's interpretative phenomenological study of eight participants (aged 14 to 18 years) with Type 1 diabetes their participants sometimes felt this help was irritating. Karlsson et al. (2008) investigated autonomy in 32 adolescents, aged 14 to 18 years, and had similar findings. There were times when parental support was seen as nagging and created conflicts between adolescents and parents. Parental support was not seen negatively by any of the participants in my study. Positive coping strategies in these studies and used by participants in my study focused on problem solving and fostering internal positive 
thinking. These strategies were interwoven into adapting and accepting their CHC as being 'normal', discussed below.

\subsection{It's Part of My Personality.}

The superordinate theme of subtheme of it's part of my personality contains elements which involve students' $\mathrm{CHC}$ and acceptance of themselves with the CHC by others as well as themselves. Adolescent development contains a great many challenges because of the variety of changes which occur physically, cognitively, and psychosocially (e. g., Michaud et al., 2007). For these students being in school was as normal for them as it was for their healthy peers. The students saw themselves much the same as their peers without a $\mathrm{CHC}$ despite knowing their respective $\mathrm{CHC}$ affected them in various ways. Their $\mathrm{CHC}$ experience with learning involved an inability to concentrate, more absences, or the illness itself making the student different from those without a CHC. They spoke about their CHC as a characteristic, something they had, but that did not define who they were. For example, Andrew did not call himself $a$ [my italics] diabetic but used diabetic as a descriptor ("I'm diabetic"), to explain why he had to do finger pricks or eat in class. The young people in my study believed they were the same as their healthy peers, yet were well aware they were different because of their respective $\mathrm{CHC}$, and having a $\mathrm{CHC}$ was not a 'big deal'. A possible explanation for this is that the students minimized their $\mathrm{CHC}$ and had a sense of normalcy.

Students spoke of their CHC as "no big deal". For them, having a CHC, regardless of the physical or psychosocial effects on their learning was a trait, something they had or experienced but did not define who they were. For these participants, adjustment to the $\mathrm{CHC}$ included the acknowledgement of their $\mathrm{CHC}$ by their teachers and classmates and this made them feel accepted, not as someone different, but rather as themselves, but with another trait: their CHC. Anna said having epilepsy was 'no big deal'. For her, epilepsy did not interfere with her capacity to learn or her ability to participate in activities. Positive support, encouragement, and acceptance from friends and teachers in school can contribute to a sense of belonging and normalcy for young people with CHC (Vitulano, 2003). Studies have shown that social acceptance by the students' peers plays an 
important role in how adolescents with chronic conditions perceive themselves (Shaw \& McCabe, 2007; Sheffield et al., 2004).

Bart, who had eczema, accepted regardless of his physical appearance. Bart felt 'gutted' when he could not fully participate in activities when suffering a severe eczema outbreak, but he was determined he was not going to be limited by his CHC. He felt he had a choice. He could let his skin keep him from participating in activities or he could be active and unhindered by his eczema. He preferred to be actively involved in sports. Other students similarly expressed their belief that they did not differ from their healthy peers. Feeling accepted by peers, having the CHC acknowledged by peers and teachers, and not being ostracized by others was helpful in adjusting to having a CHC regardless of whether the student could or could not actively participate in school. For example, for Simon, his friends acceptance meant that they understood how ADHD impacted him (he couldn't focus, he would become fidgety), so if he missed a dosage and was not behaving appropriately in school, he believed his friends understood, and acted in a helpful way, helping him to stay engaged with his school work. Karlsson et al.'s (2008) study supports the finding that peer acceptance is helpful in one's acceptance of $\mathrm{CHC}$, in adapting to compliance activities or limiting activities as well as decreasing feelings of being different from their peers.

These participants realized their CHC required some accommodation(s) at school, and, at the same time, they did not want to stand out as being different from their peers. These young people were aware of their limitations and accepted them. This knowledge and acceptance resulted in seeing the limitations as routine. This was their normal. Berntsson et al.'s (2007) study found similar results. Their 15 participants, aged 12 to 19 years, felt they were the same as their peers, accepted limitations imposed by their CHCs, but were capable of engaging in activities. This can occur when illness treatment becomes routinized; it becomes normal (Berntsson et al., 2007). Their participants were accepted as equals amongst their peers, which positively informed their sense of wellbeing. Huus and Enskär (2007) found conflicting themes in their study. While minimizing their $\mathrm{CHC}$ and describing themselves as normal, participants also said they were different from their peers. Their participants felt more mature than their peers as they had more knowledge of the importance of healthy living and eating and they had to 
be aware of how strenuously they could engage in activities. I found this to be the case with the participants in my study. They had to manage their respective $\mathrm{CHC}$ in some form or another or, in some cases, it was evident to others that they had a CHC. They knew they were different than their healthy peers. However, participants' feelings of being the same as their peers, as being 'normal', became quite evident when they spoke about their learning experience with a CHC. Being in school and learning was part of being normal and thus, they were the same, or as 'normal' as their peers without a CHC.

The students in my study, regardless of their age, valued school, realized the importance of learning, and endeavored to be in school as much as possible. The findings suggest that one reason students felt school was important to them was that they needed to do well in order to achieve NCEA credits and qualifications that would affect future plans and to accomplish this, they needed to learn. The older students in my study shared goals and expectations for the future and realized they needed to achieve necessary credits so they could continue with their education. Schwartz \& Drotar (2006) and Meuleners et al. (2002) also found goal setting to be a positive factor for children and teenagers with a CHC. Although not all the students spoke about their future plans, they all said missing school due to their $\mathrm{CHC}$ presented challenges.

In New Zealand, it is quite usual to hear "harden up" on sports programs and amongst children playing. The phrase "harden up" has been found in published studies and Master's or doctoral dissertations within New Zealand on a variety of subjects, i.e. regarding online race talk (August \& Liu, 2014), mental health or emotional wellbeing (Campbell \& Longhurst, 2013; Clelland, 2013; Keppel, 2012; Wellstead \& Norriss, 2014), and parental and student perceptions of teacher-student interactions (Kayes, 2012). John Kirwan (2010) devoted a chapter in his book to this phrase in which he discusses his struggles with depression and how he was told quite often to "harden up". He believes the phrase was not meant harshly, but was prevalent nonetheless. Wellstead and Norriss (2014) discuss possible barriers faced by some individuals or groups in society which may contribute to them not accessing resources of information services to assist them. None of the participants in my study used this particular phrase, but it is possible that the idea of a New Zealander 'hardening up' when faced with adversity may have influenced the students in my study. This may be the case particularly for the male participants in my 
study as the above studies were predominantly male-oriented or the phrase was used when speaking to a male. The essence of 'harden up', similar to 'get over it', may be argued to mean the feeling of inner personal strength in not succumbing to the demands of a CHC. That all the students felt positive, accepted, and saw themselves as normal, in spite of describing hardships and difficulties in learning as a direct result of their $\mathrm{CHC}$, may be a result of the New Zealand cultural notion of 'harden up'.

For the participants in my study, being in school and managing their $\mathrm{CHC}$ and learning gave them a sense of competency and responsibility, a sense of having power over what happens to them in spite of their CHC. Being responsible for their learning and/or the management of their illness indicated they had some control over themselves, that the $\mathrm{CHC}$ was not in control of their future. Most of these students with a $\mathrm{CHC}$ knew how to advocate for their specific needs, for example, asking for more time on a test in order to check sugar levels, or asking questions regarding possible missed information. $\mathrm{CHC}$ did not limit them or their opportunities. This sense of belonging, having choices, and social support from peers and friends were also found to be key elements in the development and maintenance of adjusting for adolescent students with CHCs in other studies (Huus \& Enskär, 2007; Olsson, C., Lyon, Hörnell, Ivarsson, \& Sydner, 2009; Piko, 2001; Schwartz \& Drotar, 2006).

\subsection{It's Hard}

As stated previously, students with a CHC face more challenges in learning than their healthier peers. Difficulties can be barriers to positive well-being and development (Huebner, 2009; Shiu, 2004). Encountering skepticism from their teachers created an environment in which the student could not attend appropriately to his or her CHC's needs, such as leaving class to monitor blood glucose. This disbelief from the teachers resulted in eroding student trust of his or her teacher. Students also encountered a lack of knowledge and understanding of the CHC impact in teachers resulting in some students not leaving the classroom when necessary and causing non-compliance with necessary treatment. For students who felt that treatment compliance was "one more thing" they had to add to their daily chores, skepticism or lack of understanding from their teachers eroded their commitment to treatment compliance. When it came to learning, participants 
in my study discussed the difficulties in missing class as affecting their NCEA results. Another aspect of the difficulties in missing school time was less time spent with their peers or being engaged in meaningful activities. Other studies have also found that students with a CHC are have a heightened awareness of the actions of others in social situations and positive, meaningful time with peers, either in or out of school is an important part of building social skills in adolescence (Boydell et al., 2008; Huebner, 2009; Shiu, 2004; Suris et al., 2004). Social skills are necessary in society where opportunities are dependent upon social competence (Boydell et al., 2009).

In my study, several students who experienced teacher skepticism were trying to learn in spite of severe pain or side effects resulting from either noncompliance with a medical regime or not paying attention to medical needs. Participants spoke of teacher skepticism interfering with their CHC management and subsequently, learning was more difficult. For example, one incident involved overt teacher skepticism, with a teacher publicly telling a student her migraine was just a headache. This had the effect of diminishing the student's real symptoms and dismissing the CHC. In three of the focus groups, a lack of understanding from teachers resulted in students feeling less respect for their educators. In one of the focus groups, a lack of understanding by teachers of the difference between Type 1 and Type 2 diabetes lead to students (three of whom had T1D) feeling frustrated that teachers made comments about diabetes without having a clear understanding of it. Other studies had similar findings (Cartwright et al., 2014; Gregory \& Ripsky, 2008; Olsson, C., 2009; Wang et al., 2010). For example, Olsson et al. (2009) investigated students with Celiac disease and how these adolescents felt stigmatized by their CHC in Sweden. When students experienced lack of knowledge on behalf of their teachers, it increased the young people's sense of either enacted or felt stigma. Conversely, when students had teachers who knew them as individuals, students were more engaged with their learning, felt trusted, and were comfortable leaving the class for $\mathrm{CHC}$ management. Cartwright et al. (2014), Wang et al. (2010), and Gregory and Ripski (2008) found higher course engagement in classes where there was student trust in their teachers.

In my study, when students encountered a lack of trust or understanding in some teachers, this generally resulted when students had a CHC that was not visible to others. It is possible students who experienced this may have felt they were not treated with the 
same understanding or consideration as those with visible illnesses. What did emerge from the data was that not understanding to the students meant teachers did not know the symptoms of their respective $\mathrm{CHC}$ and this created a barrier against learning and treatment compliance. Participants shared their belief there were teachers who either did not know about their $\mathrm{CHC}$ or were skeptical of its impact and thus, were not supportive. When knowledge from teachers was missing, learning was affected. Students were in class suffering pain, fatigue, an inability to concentrate and found their learning was made more difficult when teachers assumed they were well because they were in class or did not appear ill. When a CHC was invisible, students felt frustration and dismissed by their teacher. In my study, teacher skepticism, disregard of their invisible symptoms, or publicly scoffing them with remarks such as “...Angela's wagging today”, conflicted with the students' efforts in building positive self-esteem and in building trust in their teachers.

When loss of trust in teachers or parents occurs, disruptive behavior, lack of motivation, and non-compliance with treatment routines resulting in added stressors may result. Other studies discuss the impact of teacher lack of understanding or knowledge (Boydell et al., 2008; Sawyer et al., 2007; Suris, Michaud, Akre, \& Sawyer, 2008). Boydell et al. (2008) found their respondents spoke of teachers having a lack of understanding regarding experiences of cancer which resulted in frustration and needing encouragement in school from others. These survivors of childhood brain tumors wanted to be treated the same as everyone else but felt it was reasonable for teachers to have some special consideration of how their illness affected them. Boydell et al. (2008) suggest that if the environment is not prepared to deal with students with a $\mathrm{CHC}$, difficulties are added to the stressors these young people already have with their CHC. Olsson, C., et al. (2009) found when students experience misconceptions or lack of knowledge in others, students felt enacted or felt stigma, they felt 'diminished'.

In my study, participants wanted teacher understanding but did not want to be singled out in class. Students felt they were the same as their peers in school but wanted understanding of the $\mathrm{CHC}$ and how it affected them thus; it was important to them that their teachers see them as individuals, and understand the effects of their respective $\mathrm{CHC}$. Researchers exploring youth and CHCs have had similar findings (Frydenberg \& Lewis, 2009; Hayes-Bohm et al., 2004; Karlsson et al., 2008; Meijer et al., 2002). Hayes-Bohm 
et al. (2004) interviewed 30 adolescents with T1D and their parents or guardians. Not all of the students find lack of education in their teachers or disbelief to be an issue, but for those who did, staff education of the $\mathrm{CHC}$ was seen as a remedy that would promote student freedom in T1D management. Participants in their study preferred their teachers to know they had a CHC and that they understood its impact while, at the same time, not draw attention to the $\mathrm{CHC}$, a sentiment very prevalent in my study.

The superordinate theme hard also spoke to the difficulty of CHC management being 'one more thing' to do besides learn. In my study there were students who spoke to the lack of privacy when having to take medication or inject insulin at school. They did not see it as a barrier to taking their medication, but instead accepted it as fact and the majority who had to leave class for $\mathrm{CHC}$ treatment in school did not mention feeling embarrassment or shame. One student, in one of the focus groups, shared he did not leave the classroom either to test for glucose or possibly take a needed dose of insulin as he felt disbelieved by his teacher who drew attention to the student by publicly pointing out the student left class often. Other studies have shown that adolescence is a time when teenagers may be more prone to be non-compliant with treatment routines (e. g., Dashiff et al., 2006). Smith, Taylor, Newbould, and Keady (2008) and Wang et al. (2010) had similar results in their respective studies. Smith and colleagues (2008) examined the experiences and concerns of students and medicines at school. Participants discussed feeling they were disbelieved which created a barrier for them in accessing their medicines and complicated their medical regiments. In addition, another barrier to compliance with treatment was a lack of privacy for the students who had to take their treatment publicly. In my study, one student commented upon the lack of privacy although other students alluded to treatment compliance occurring in a room with others nearby. They did not appear to see this as a deterrent to treatment. Wang et al.'s (2010) study found teacher skepticism an obstacle to treatment management and students felt their school environment was not as supportive of their $\mathrm{CHC}$ and its treatment as it ought to have been.

Bullying experienced by a few of the students in my study occurred in primary school but was not necessarily a result of appearing different from their peers. Mark was in a wheelchair and had two dominant disabilities which impacted him. Luke, diagnosed with ADHD, and Daniel, diagnosed with Crohn's disease, were called names. Luke was 
emphatically told he did not belong in his school. This finding mirrors Sentenac et al.'s (2010) international study, which investigated bullying of students with a disability or a $\mathrm{CHC}$ in France and Ireland where bullying occurred more often to younger children than in older students. Bullying because of appearance, especially amongst younger children, was found to be a risk factor for youth involvement in social activities and building social skills, and interfering with self-esteem (Magin, Adams, Heading, Pond, \& Smith, 2008; Sentenac et al., 2010). Bart alluded to looking different because of his eczema, but he associated negative reactions more to girls his age and, when looking for a job, being judged by his appearance. However, Bart did not feel judged by his peers, unlike Daniel, Luke, and Esau.

While the incidence of students being bullied was discussed by only four students and, for three of them, had ceased to be an issue, other studies have observed that students can and do feel stigmatized as a result of having a $\mathrm{CHC}$ and their $\mathrm{CHC}$ may be perceived as making them different from their peers (Cheung \& Wirrell, 2006; Wang et al., 2010). Cheung and Wirrell (2006) interviewed 41 teenagers (13 to 18 years) with CHCs regarding their perceptions of teenagers with epilepsy. These adolescents had a higher degree of viewing others with epilepsy more negatively than those with other CHCs. They suggested those with a $\mathrm{CHC}$ may be more apt to view others with a $\mathrm{CHC}$ negatively and feel more empathy for them because of this perceived bias. In my study, however, Luke experienced bullying when younger and felt enacted stigma without looking different. His CHC, ADHD, was invisible. A result of feeling stigmatized and being bullied can interfere with learning as students worry more about being teased or physically hurt than learning. It is noteworthy that only one student in my study still felt he was bullied as a result of his $\mathrm{CHC}$ while the other participants, including those with the same $\mathrm{CHC}$ in his school, did not feel this way. Time constraints did not permit further exploration of his bullying experience which could have shed further light on his particular experience.

\subsection{Learning Can Happen When You Have Help}

All participants who participated in the individual interviews felt strong parental support with their learning. They described various factors in how parental support was a positive feature for them. Students who remembered their diagnosis of the $\mathrm{CHC}$ recalled parental lack of fuss during this period and considered it as a reason of why their own 
reactions were minimal. They saw parental involvement and emphasis at home such as "pushing" them to complete school tasks as caring and beneficial. Students usually described one parent being the primary person helping the student with schoolwork or, in their words, "pushing" the student to complete assignments or study in preparation for school, although participants quickly acknowledged the support from the other parent during the interviews. They appreciated parental pushing because it enabled them to be successful in learning and suggests that this fostered their belief they were not limited by their $\mathrm{CHC}$ in spite of absences or the physical effects such as pain, etc. They did not say they felt the encouragement received from parents was overbearing, overprotective, or getting in the way of their own autonomy. Participants felt comfortable asking for help from parents when needed and were appreciative of the aid and impetus in studying and completing assignments their parents provided. Their feeling of not being limited by their $\mathrm{CHC}$, appeared to contribute to confidence in believing they were in control and taking responsibility for their learning.

In my study, meeting CHC needs and learning needs was challenging. Moos (2002) in his conceptual framework of personal and social resources which assist young people manage chronic and acute stressors, found that parental support helps adolescents build coping skills which can lead to a sense of competency. High expectations of adolescents has a positive association with students' long-term educational success as well as fewer maladaptive strategies (Froiland \& Davison, 2013). These students felt competent in managing themselves, their $\mathrm{CHC}$, and their learning. Participants in my study appeared comfortable with themselves and their CHC. They felt independent, capable of achieving their goals, and were aware there were certain accommodations in school for them, such as being able to leave the classroom when necessary either for treatment or because of the CHC's physical impact (i.e. painful headache from a migraine or THI), which did not detract from their sense of independence and ability to self-manage. Miller and Jawad (2014) discuss that when parents teach children how to manage illness, to know what factors to consider, and enable these young people to make decisions regarding their treatment, adolescents tend to be more adherent to treatment plans. Involving the young person in discussions through negotiation gives the young person the sense of greater control and self-efficacy and promotes independence. 
The data in my study supports the premise these students valued the help they received from others, whether the help came from friends, parents, or a teacher, as a method of overcoming missing class time. The literature supports this finding of parental support being a key aspect of students coping strategies (Karlsson et al., 2008; Lightfoot et al., 1999; Mellin et al., 2004). Participants in Karlsson et al.'s (2008) study believed learning about their diabetes and engaging in open discussions with their parents was important and this resulted in positive coping skills. Mellin et al. (2004) found parents of adolescent girls who promoted open communication and were involved with these girls' efforts in managing their diabetes had daughters with higher compliance in $\mathrm{CHC}$ management and fewer hospitalizations than those who were not as involved. Lightfoot and colleagues (1999) also found that students used parental support as a method of coping and adapting to having a CHC. They investigated support for 33 students aged 11 to 16 years and found some adolescents felt unhappiness in school at having to depend upon others for assistance. This unhappiness was not mirrored in my study, as the young people did not see asking for help as a negative burden of needing to rely upon others.

My study found students spoke of a strong parental influence about learning within the individual interviews. Sometimes a parent was a teacher, which was seen as an added benefit in learning the materiel for the student even if the parent did not teach in that area. Parental support for the students in keeping up with school work enabled these adolescents to feel capable of learning. These particular students saw the parent/teacher as someone with an inside track in the school who could speak for the student and advocate more often and productively for the student. If a participant did not appear to be ill, suffering from a migraine for example, the parent as a staff member was able to support the student more meaningfully in the school environment. If neither parent was a teacher, the student still felt supported in his learning because the parent promoted learning at home. Students described their parents with great affection and respect. They felt their parents were very helpful to them with learning and their CHC. Research has shown a positive correlation between strong familial cohesiveness, adolescent positive outcomes, and adolescent adjustment to a CHC (Froiland \& Davison, 2013; Frydenberg \& Lewis, 2009; HayesBohn et al., 2004; Reeve \& Lincoln, 2002). For example, Hayes-Bohn et al. (2004) found, in their study of adolescent girls' parents, that the higher the parental involvement, the 
higher adherence to medical compliance and adaptation, which led to fewer hospitalizations. Students wanted to be in school.

The overwhelming majority of participants in my study did not speak to feeling isolated, nor did they share experiences of negative health behaviors other than a few students who were non-compliant due to felt teacher skepticism. Studies in the area of adolescents with a $\mathrm{CHC}$ have indicated adolescents with a $\mathrm{CHC}$ are at higher risk of engaging in adverse health behaviors (e. g., McNelis et al., 2005; Suris, Michaud, Akre, et al., 2008). Isolation from friends and classmates, feeling overwhelmed, and bullying were amongst some difficulties encountered by the students who were hospitalized, had to leave class or school due to $\mathrm{CHC}$ impact such as pain or medical testing (McNelis et al., 2005). Peer interaction is a critical component for adolescents and missing class or activities due to their $\mathrm{CHC}$ or its management resulted in missing time for an important step in their learning and fine-tuning their social skills and development (Olsson, C. A. et al., 2005). Craig A. Olsson et al. (2005) found that when students had active peer support, they had "greater self-confidence and self-acceptance". Their article described and examined an Australian peer support program for adolescents with a CHC. Participants in my study did not have the benefit of any school or Ministry of Health sponsored program to foster peer support for them. However, the students in my study all spoke of a high level of acceptance and support from friends. This level of acceptance and support may have contributed to a high sense of normalcy and trust in others.

My study included the subtheme of bullying although only a minority of students experienced it. Those students who had endured bullying still felt affected by the experience, it had occurred in school, either physically or emotionally, and had been painful for them. Other studies have spoken about bullying or feeling stigmatized due to the presence of a CHC (e.g., Saunders, 2014). In my study, the majority of the students did not experience or, at least, did not share experiences of being bullied or feeling stigmatized by their peers while in high school. This may be due to a strong anti-bullying message within their school community. My field notes from participating schools noted that either the principal or the learning resource teacher had spoken to me about antibullying, I found anti-bullying literature in the school lobbies, or the students spoke about it in their interviews. Such a low incidence of bullying may be due to the presence of 
strong adult supervision so that bullying is curtailed on school grounds. It may be due to the school culture to which some students alluded. That only four students spoke of bullying may lend support that it was not a concern for the other 20 students with $\mathrm{CHC}$, which may be interpreted as meaning that stigma, felt or enacted, was not an issue for them and was not a deterrent to focusing on learning. With the competing needs these adolescents have, worrying about being bullied because of a $\mathrm{CHC}$ or appearing different than their peers was not an issue. This may be interpreted as supportive of the argument that for students, with or without a CHC, feeling safe in their learning environment is an important element in being able to learn. These students were able to rely upon their friends. Feeling safe from being bullied because of their $\mathrm{CHC}$ or because they were different than their peers was not only part of being able to adapt as adolescents in high school with a CHC. They also knew there were systems and people in place who would step in and keep them from being bullied.

Support from school staff featured as another element that the young people in my research experienced. Students spoke of a particular teacher or staff member such as their Dean or the resource teacher advocating for them with other teachers or providing a place for them to unwind and relax. There was only one student who believed the school nurse in his school did not adequately understand T1D enough to be helpful to him, although there were only part-time school nurses in three of the other schools. Lightfoot et al.'s (1999) research discussed young people not seeing schools nurses as sources of support. Engagement with learning was facilitated by a strong positive adult who was interested in the student with $\mathrm{CHC}$ in school.

Feeling accepted, knowing there was someone in the school who understood how their CHC affected them and who advocated for them helped build trust in caring adults. Szcześniak, Colaço, and Rondón (2012) write that teenagers "especially appreciate those teachers who let them know that they trust them" (p. 56). Snyder (1994) stressed that trust between teacher and students is built when students believe teachers listen to the student and is seen as trying to do what is in the student's best interest (Snyder, 1994). He argued that if teachers demonstrated behavior that was seen as ironic or sarcastic, students felt disrespected, lost their trust in these adults and felt their dignity was at risk. Studies point to the importance of adolescents developing trusting relationships with adults 
involved in their lives (Froiland \& Davison, 2013; Szcześniak et al., 2012). Lightfoot et al. (1999) and Shiu (2004) speak of the positive reinforcement of protective factors when teachers provide on-going support for students who have missed school. This support may be teachers giving up lunchtime to work with the student or providing a quiet place for the student apart from others. This may also be modification of assignments or being flexible with due dates of assignments. These young people felt accepted, believed, and supported when teachers trusted them. They felt safe, secure. Teachers, like good friends, created trust between the student and teacher or staff member.

\subsection{Conclusion}

When examining the superordinate themes for understanding of the experiences of students with $\mathrm{CHCs}$, it is clear that for this particular set of participants, learning involves and requires more than a cognitive understanding of school-based material. For them, learning involves others' participation and support as well as their own physiological and psychosocial well-being. Physically, for them to learn, these young people needed to be able to manage their $\mathrm{CHC}$. When their $\mathrm{CHC}$ flared up physically, learning became harder, more difficult to achieve. But psychosocially, when teachers were understanding and accommodating, parents were encouraging and reassuring, and friends and peer relationships were helpful and loyal, participants felt able to continue learning. They did not feel lonely, dispirited, but, instead they felt capable, normal like their healthy peers and able to weather the physiological duress and continue learning. The superordinate themes of this research all speak to the use of the biopsychosocial model as a suitable method of considering the different yet intertwined areas of the learning experiences of adolescents with a CHC.

Adolescent students with a CHC may find challenges in school that can create extra stressors at a time that is challenging enough for them psychologically, physically, and cognitively. How those around them, in their learning environment, act and react can influence their own actions and reactions. The young people in my study, even as they shared the difficulties they faced in school as a result of their respective CHCs, had positive attitudes and coping strategies. They saw themselves as normal and accepted by their peers. They adjusted their lives to incorporate necessary management of their $\mathrm{CHC}$, regardless of what that was. The $\mathrm{CHC}$, for them, was a part of life. Their incorporation 
of coping strategies allowed a positive adaptation to their $\mathrm{CHC}$ and its necessary management.

Regardless of their CHC, the young people in my study faced similar impediments to their learning. Their learning experiences proved to consist of a variety of difficulties ranging from the impact of the $\mathrm{CHC}$ itself, to attitudes encountered in teachers. These participants revealed that pain interfering with their ability to concentrate, teachers not understanding their $\mathrm{CHC}$, teacher skepticism, bullying for some students, missing class instruction, and needing to self-teach concepts/ideas due to unavoidable absenteeism were difficulties they encountered when learning. Teacher skepticism undermined their own sense of well-being, adding to the stress they felt by not being well. However, when their schools did not place any stigma or conditions on accessing food/juice/treatment, the students found it easier to see their $\mathrm{CHC}$ as no big deal. Being allowed to rest or have time away from the other students promoted compliance and helped the students pay attention to their needs. Students in my study did not appear to abuse this privilege. In spite of the negative issues which arose in school, these students used adaptive strategies, found acceptance from their peers, had strong parental support, and trust in some teachers, which allowed the majority of participants to develop positive attitudes. These adolescents were in a stage in which more independence from parents is the norm, yet reliance upon parental help in new learning was seen as supportive, neither negative nor intrusive. Students acknowledged and were grateful they were able to continue learning primarily due to parental influence/push or a particular teacher/staff member in the school who invested the time in supporting the student. Being in school was important to them, not simply for socializing with their friends, but to learn in order to be able to reach their future goals. 


\section{CHAPTER SEVEN CONCLUSION}

\subsection{Introduction}

Just as the numbers of adolescents with CHCs is increasing, so is qualitative research in this area concerning parent, teacher, health provider, and adolescent perspectives. International studies of adolescents and CHCs using quantitative, qualitative, and mixed methods have often focused upon one CHC and its impact on a targeted domain, be it physical, cognitive, or psychosocial. Generally, studies within New Zealand have looked at either statistical data regarding the prevalence, increase in specific CHCs, or at the impact CHCs can have on individuals or a target group, such as the Māori population.

Young people spend a great deal time of time in school, but a student with a CHC differs from healthy peers with additional challenges that can influence and affect their life trajectory (Michaud et al., 2007). The numbers of students with CHCs are increasing in New Zealand (Hohepa et al., 2005; Milne et al., 2012; Wu et al., 2005) and with this increase, the number of New Zealand teachers who will have students with $\mathrm{CHC}$ will also rise. My study set out to discover students with $\mathrm{CHC}$ experiences of learning in schools in the Greater Wellington area. Young people with a CHC may require more help from parents or other influential adults during this important stage in their development and a $\mathrm{CHC}$ can make the student feel different from his peers. Students who adapt to their CHC positively are better equipped to deal with the stressors. Adolescents spend a great deal of time in school and, developmentally, are more influenced by peers as they seek autonomy and independence from parents. A positive, supportive learning environment, be it the classroom, school activity, or at home with parents, can assist students who must cope with the challenges a CHC can present. Knowing what these students experience while learning may aid parents and schools in mitigating challenges.

The students in my study had strong protective factors, such as trust from adults around them, acceptance from peers and friends, and parents who provided a cohesive, encouraging learning environment. These elements were helpful to their choosing of adaptive coping strategies, enabling them to develop positively. Risk factors, making poor decisions, and non-compliance with treatment regiments can result from a poor 
environment such as an unsafe school where they are bullied or ridiculed, teachers who do not know how to provide accommodations for students with a $\mathrm{CHC}$, or are skeptical of the student. My study found that these students did not engage in negative risk-taking and poor decision making in regard to their learning. Learning was necessary for them, for their future, for their academic achievement. The positive school and home environments and the coping strategies these students used were important factors for them to experience learning success and have positive, resilient attitudes that enabled them to learn when in school and at home. Psychosocially, the provision of a stable, safe, trusting, understanding environment permits the student to adhere more closely to treatment compliance and consider themselves normal (Shaw \& McCabe, 2002). It is vital teachers, who may be role models for these students, be trained and offered tools to ensure that when student or students with CHCs are present in their classroom, they can provide these adolescents with these key elements, allowing the student to be able to focus on his education.

\subsection{Strengths and Contributions}

Research concerning youth with CHCs continues to grow. In my study, I used IPA to explore and understand the learning experiences of secondary school students who have a $\mathrm{CHC}$ in New Zealand. While studies within New Zealand have explored the impact of particular CHCs on quality of life issues such as adjustment, research in the area of how CHCs affect student learning in the New Zealand context is a new area. A strength of my study is its contribution of New Zealand's literature of CHCs in adolescents. I found several commonalities of learning and CHC experience amongst 24 adolescents with a range of CHCs. Sawyer et al. (2007) believe that a rising awareness of similarities between $\mathrm{CHCs}$ can positively inform practice and policy. My study contributes to that rising of consciousness in the educational arena.

Another strength of my study was that it provided an opportunity for these students a voice to share their $\mathrm{CHC}$ experiences. With the exception of one participant, my study was an opportunity for them to speak about their experiences of having a $\mathrm{CHC}$ and how they learned. They were able to be heard and their experiences, how they felt about them, and thought about them mattered. In spite of sometimes very succinct replies, all the young people who participated in individual interviews were actively engaged in 
responding to my questions during individual interviews. Within the focus groups, relaxing while eating lunch together, the young people were animated and expressed good humor throughout the interviews. At the end of each focus group session and interview, students told me they had never had an opportunity to talk about their CHC with others and they were glad, in spite of the differences of the CHCs within the groups, of the opportunity to talk about their CHCs by participating in this research. Amongst all 24 participants, only Esau had ever had contact with any kind of support group. As the students relaxed, their body language and spontaneous laughter as they helped each other clarify their thoughts were evidence of trust being built amongst them. They no longer felt that, as individuals, they were the only ones experiencing difficulties. This appeared to make them feel more positive about being in school, knowing there were others in school who, despite whatever $\mathrm{CHC}$ they had, understood what it was like.

In Section 2.7.2 statistical evidence from the Ministry of Health reported that Māori and Pasifika children have a disproportionate number of $\mathrm{CHCs}$ in comparison to their European New Zealander peers. This disproportionality was present in my study as there were six Māori and three Pasifika participants with CHCs who volunteered to participate. Ethnicity was neither brought up by me nor by any participants. I suggest that the active participation of these students in my study (two of these students also participated in individual interviews) provides further evidence that the issues, difficulties, and strengths which emerged from the overall data are experienced by adolescents regardless of ethnicity. My study provided these adolescents with a forum of agency-to speak, be heard, and to be understood. For some, the focus group encounter enabled them to discover their experiences were shared by others and gave them the knowledge that their experiences were not single, solitary events, and there were others (peers) who had undergone and understood similar experiences. At the end of every focus group meeting, while leaving the room, each student thanked me for giving them the opportunity to talk about their CHC. They felt an enhanced sense of normalcy when they discovered others experienced their difficulties within their specific focus group. This is another strength of the study: adding to the corpus of IPA research and the use of focus groups within it.

Although the sample of students with a CHC is small, another strength is its contribution in international and New Zealand education literature. My study provided 
New Zealand secondary school students a much needed voice in the discussion of what is currently performed in schools to assist their learning. The numbers of students with a $\mathrm{CHC}$ are increasing and students with a $\mathrm{CHC}$ are an understudied population as a whole within New Zealand. My study addresses this understudied population and highlights the commonalities experienced by students of various ages who had a range of CHCs. This research also found that the physical, cognitive, and psychosocial components that emerged from the participants' experiences validate the usefulness and strength of a biopsychosocial model when looking at health and education for children and youth. This research adds to the international discussion of how learning is impacted by CHCs and, for New Zealand health providers and school personnel, it can aid in raising awareness of how to contribute to students' success when they have a CHC. Another strength of my study is the age range of the participants (12 to 19 years). This was an advantage in that it allowed for the possibility of very diverse experiences and viewpoints. Although this is a small sample, and the findings cannot be generalized, the commonalities in the learning experiences of these students provide evidence that regardless of age or $\mathrm{CHC}$, students with $\mathrm{CHC}$ will benefit from teachers training in this area. The more educators know how a CHC affects their students, the better they will be able to meet their educational needs

\subsection{Implications and Recommendations}

Learning is important to the adolescent students with a CHC who participated in my study. Learning can occur, in spite of the cognitive, physical, and psychosocial affects resulting from a $\mathrm{CHC}$ where there is a supportive learning environment. School is the primary learning environment for students, but for young people with a $\mathrm{CHC}$, missing class or school due to pain, testing, or treatment compliance can negatively impact this learning. Teachers must be prepared to have a basic understanding of how CHCs affect students in school. Barriers to learning, such as misconceptions as to the impact of a CHC, skepticism from the teacher and the subsequent lack of trust in the student that is experienced, as well as the direct impact of the $\mathrm{CHC}$, makes learning difficult. When students experience pain, fatigue, or memory loss, among other CHC effects, learning becomes harder. The participants in my study all shared that a teacher not understanding 
how their CHC could affect them made their learning more challenging than it was already for them.

Parent and teacher communication is vital in promoting understanding of $\mathrm{CHCs}$. A supportive and trusting learning environment can foster and promote a positive attitude and belief about their identity and that learning success is possible for them. Fostering a positive learning environment furthers student faith in her or his ability to learn and that learning is achievable. Educators desire to encourage student discovery and acquisition of knowledge. Teacher lack of knowledge in how a CHC or its treatment can affect students creates unfortunate barriers to this discovery and acquisition. Barriers to learning make it more difficult to achieve success. Currently in New Zealand there is no requirement that teachers have any training in special education although those training to be teachers can choose to take coursework in that area. The findings in my study show students' belief in teacher lack of knowledge of how a $\mathrm{CHC}$ or its treatment can affect students. This highlights the need for more training in New Zealand regarding how a CHC and/or its treatment can affect students in order to assist them in being successful in their learning. Further studies into this subject area in rural and other highly populated areas within New Zealand will continue to contribute to the necessary knowledge base of educators and health providers.

Within the school environment, administrators' support for teacher in-service days focusing on this area can further educate teacher understanding in this area. In-school training seminars provide another opportunity for educators to access information and learn how to accommodate the needs of young people with CHCs and should be strongly encouraged by the New Zealand Ministry of Health and Ministry of Education to meet the growing numbers of students with a $\mathrm{CHC}$ who need and deserve learning support. Wide availability in schools of internet access provides educators with the opportunity to access online websites of national health centers, hospitals, and illness support groups such as diabetes, Crohn's disease, asthma, and rheumatic fever and can help educators increase their knowledge base.

Although it would require a change in policy, the more teachers learn about special education or chronic health condition needs, the better prepared they are to meet the needs 
of their students. When educators know what challenges in learning these students face, the better we are able to mitigate some of these challenges within the classroom. Further studies in this area can continue to add knowledge, not only for the international community researching this area, but for policy makers and teacher educators in New Zealand. The use of a methodology currently used more in the health field than in educational research, IPA is an ideal and useful tool to study this population. Best used with small samples, this methodology can provide rich descriptions of student learning experiences that can continue to increase educator knowledge in this area. A strong point of the biopsychosocial model in medicine is in its facilitation and promotion of examining different factors that can affect the individual with a CHC. The use of this model in education can better inform educators and staff members in school as it encourages investigating the surrounding environmental factors of the individual, including cultural influence, very much in line with the Bronfenbrenner bioecological model favored by education in New Zealand. Future studies could incorporate further inquiry into this area.

Encouraging teachers to learn more regarding students with a $\mathrm{CHC}$ and how their learning is affected could enhance understanding and mitigate any possible stigma attached to a $\mathrm{CHC}$. The students with a $\mathrm{CHC}$ who participated in this research felt valued and respected when their voices were heard. They appreciated being able to speak about their conditions with others, either with me or in focus groups. It is possible that in my study, culture also plays a role. In my study there was a high level of acceptance and support from others as well as strong coping strategies in spite of physical and psychosocial hardships. I suggested that the acceptance and support may have contributed to a high sense of normalcy and trust in others. The strong coping strategies and positive outlooks these students shared may be due to the cultural context of New Zealand, which did not emerge in the data but may have contributed to the participants' outlook and experiences. A possible future study could examine if and how Māori and Pasifika contexts influence adolescents' education and CHC behavior.

A final recommendation is more sensitive in nature and would require time and patience on behalf of the appropriate staff member in school, and that is the possibility of providing a safe place for students who feel isolated or stigmatized because of their respective $\mathrm{CHCs}$ where they can express concerns or positive experiences and support 
each other. In the future, the use of focus groups in research of young people with CHCs can open possible dialogues amongst students that may not otherwise occur and allow for further exploration of the topic. Organizing two or three meetings would permit additional time for these students to share and discuss areas of commonality amongst them.

As educators, we often are called upon to do more than teach. We must be role models, keep students engaged in their learning, and meet a diverse range of learning needs and disabilities. Students with a CHC are tomorrow's workforce, inventors, teachers, and leaders. We, as their teachers, must endeavor to reach them, teach them, and understand them to support their intellectual and psychosocial growth. It requires additional time and resources when educators already feel stretched thin by the competing demands of their profession. But, as this study shows, when students with a CHC are supported in school, when there is understanding and acceptance by their teachers and peers, the resultant confident emotional and intellectual growth builds a stronger foundation for these students to remain positively and actively engaged in their learning and development. As teachers, the more time we invest in learning about these students and how their CHCs may affect them in school, the better teachers we become and the more students with $\mathrm{CHCs}$ can learn. As these participants have shown, not only do they continue to invest in their learning, they continue to invest in their future. That, in itself, is a just and satisfying reward for educators. 


\section{REFERENCES}

Abrams, A. N., Hazen, E. P., \& Penson, R. T. (2007). Psychosocial issues in adolescents with cancer. Cancer Treatment Reviews, 33, 622-630. doi:10.1016/j.ctrv.2006.12.006

Adolescent Health Research Group. (2008). Youth'07: The health and wellbeing of secondary school students in New Zealand. Initial findings. Auckland: The University of Auckland.

Armstrong, F. D. (2006). Neurodevelopment and chronic illness: Mechanisms of disease and treatment. Mental Retardation and Developmental Disabilities Research Reviews, 12(3), 168-173. doi:10.1002/mrdd

Archer, C. B. (2013). Atopic eczema. Medicine, 41(6), 341-344. doi:10.1016/j.mpmed.2013.04.002

Asher, M. I., Stewart, A.W., Clayton, T., Crane, J., Ellwood, P., MacKay, R., ...Pearce, N. (2008). Has the prevalence and severity of symptoms of asthma changed among children in New Zealand? ISACC phase three. The New Zealand Medical Journal, 121(1284), 52-63. Retrieved from http://www.nzma.org.nz/journal/121 $1284 / 3309 /$

Asher, M. I., Barry, D., Clayton, T., Crane, J., D’Souza, W., Ellwood, T., ...\& Stewart, A. W. (2001). The burden of symptoms of asthma, allergic rhinoconjunctivitis and atopic eczema in children and adolescents in six New Zealand centres: ISAAC phase one. The New Zealand Medical Journal,114(1128), 114-120.

Atatoa-Carr, P., Lennon, D., \& Wilson, N. (2008). Rheumatic fever diagnosis, management, and secondary prevention: A New Zealand guideline. The New Zealand Medical Journal, 121(1271), 59-69. Retrieved from http://www.nzma.org.nz/journal/121-1271/2975

August, C., \& Liu, J. H. (2014). The medium shapes the message: McLuhan and Grice revisited in race talk online. Journal of Community \& Applied Social Psychology doi:10.1002/casp.2212

Baca, C. B., Vickrey, B. G., Vassar, S. D., \& Berg, A. T. (2011). Seizure recency and quality of life in adolescents with childhood-onset epilepsy. Epilepsy \& Behavior, 23(1), 47-51. doi:10.1016/j.yebeh.2011.10.010

Bauld, C., Anderson, V., \& Arnold, J. (1998). Psychosocial aspects of adolescent cancer survival. Journal of Paediatrics and Child Health, 34(2), 120-126.

Bellin, M. H., Zabel, T. A., Dicianno, B. E., Levey, E., Garver, K., Linroth, R., \& Braun, P. (2009). Correlates of depressive and anxiety symptoms in young adults with spina bifida. Journal of Pediatric Psychology, 35(7), 778-789. doi:10.1093/jpepsy/jspo94

Berntsson, L., Berg, M., Brydolf, M., Hellström, A.-L. (2006). Adolescents' experiences of well-being when living with a long-term illness or disability. Scandinavian 
Journal of Caring Sciences, 21(4), 552-563. doi:10.1111/j.14716712.2006.00490.x

Buetow, S., Richards, D., Mitchell, E., Gribben, B., Adair, V., Coster, G., \& Hight, M. (2005). Teenage use of GP care for moderate to severe asthma in Auckland, New Zealand. The New Zealand Medical Journal, 118(1218), 1-8. Retrieved from http://www.nzma.org.nz/journal/118-1218/1558/

Boice, M. M. (1998). Chronic illness in adolescence. Adolescence, 33(132), 927-939.

Bonner, M. J., Gustafson, K. E., Schumacher, E., \& Thompson, Jr., R. J. (1999). The impact of sickle cell disease on cognitive functioning and learning. The School Psychology Review, 28(2), 182-93.

Botcheva, L., Hill, K. E., Kane, J. (2004). School reintegration for children in different phases of serious illness. The Journal of School Health, 74(2), 68-71. doi:10.1111/j.1746-1561.2004.tb04203.x

Boydell, K. M., Stasiulis, E., \& Greenberg, M., Greenberg, C., \& Spiegler, B. (2008). I'll show them: The social construction of (in)competences in survivors of childhood brain tumors. Journal of Pediatric Oncology Nursing, 25(3), 164-174. doi:10.1177/1043455208315547

Brenner, M., Brown, J., \& Canter, D. V. (1985). Introduction. In M. Brenner, J. Brown \& D. V. Canter (Eds.), The Research Interview, Uses and Approaches (pp. 1-8). London and Orlando: Academic Press.

Brocki, J. M., \& Wearden, A. J. (2006). A critical evaluation of the use of interpretative phenomenological analysis (IPA) in health psychology. Psychology \& Health, 21(1), 87-108. doi:10.1080/14768320500230185

Brown, C., Pikler, V. I., Lavish, L. A., Keune, K. M., \& Hutto, C. J. (2008). Surviving childhood leukemia; Career, family, and future expectations. Qualitative Health Research, 18(19), 19-30. doi:10.1177/1049732307309221

Bury, M. (2002). Sociological theory and chronic illness: Current perspectives and debates. Österreichische Zeitschrift für Soziologie, 27(4), 7-22.

doi:10.1007/s11614-002-0017-0

Cashin, G. H., Small, S. P., \& Solberg, S. M. (2008, October). The lived experience of fathers who have children with asthma: A phenomenological study. Journal of Pediatric Nursing, 23(5), 372-385. doi:10.1016/j.pedn.2007.08.001

Camfferman, D., Kennedy, J. D., Gold, M., Martin, A. J., \& Lushington, K. (2010). Eczema and sleep and its relationship to daytime functioning in children. Sleep Medicine Review, 14(6), 359-369. doi:10.1016/j.smrv.2010.01.004

Camfferman, D., Kennedy, J. D., Gold, M., Simpson, C., \& Lushington, K. (2013). Sleep and neurocognitive functioning in children with eczema. Sleep Medicine Review, 89(2), 265-272. doi:10.1016/j.ijpsycho.2013.01.006. 
Campbell, R. \& Longhurst, R. (2013). Obsessive-compulsive disorder (OCD): Gendered metaphors, blogs and online forums. New Zealand Geographer, 69, 83-93. doi:10.1111/nzg.12011

Caplin, D. A., Austin, J. K., \& Dunn, D. (2009). Epilepsy. In W. T. O’Donohue \& L. W. Tolle (Eds.), Behavioral approaches to chronic disease in adolescence: A guide to integrative care (pp. 143-154). Nevada: Springer.

Cartwright, T., Fraser, E., Edmunds, S., Wilkinson, N., \& Jacobs, K. (2014). Journeys of adjustment: The experiences of adolescents living with juvenile idiopathic arthritis. Child: Care, health and development. doi:10.1111/cch.12206

Cheung, C., \& Wirrell, E. (2006). Adolescents' perception of epilepsy compared with other chronic diseases: "Through a teenager's eyes". Journal of Child Neurology, 21(3), 214-222. doi:10.2310/7010.2006.00053

Christians, C. G. (2005). Social dialogue and media ethics. Ethical Perspectives, 2(3), 182-193. doi:10.2143/EP.7.2.503805

Cigularov, K., Chen, P., Thurber, B., \& Stallones, L. (2008). What prevents adolescents from seeking help after a suicide education program? Suicide \& Life Threatening Behavior, 38(1), 74-86.

Clelland, T. J. (2011). "I'll do it from the top, like popular/cool, in-between/normal, loser and nerd" Factors that influence the emotional wellbeing of a group of year 8 boys from one Christchurch intermediate school. Unpublished master's thesis, University of Canterbury, Christchurch, New Zealand.

Cohen, L., Manion, L., \& Morrison, K. (2004). A guide to teaching practice. New York: Psychology Press.

Colucci, E. (2007). "Focus groups can be fun": The use of activity-oriented questions in focus group discussions. Qualitative Health Research, 17(10), 1422-1433. doi:10.1177/1049732307308129

Counties Manukau Chronic Care Management Programme. (2004). Making the right thing the easiest thing to do for people with chronic conditions and their clinicians. Retrieved from http://www.cmdhb.org.nz/funded-services/ccm/documents.htm

Craig, E., Adams, J., Oben, G., Reddington, A., Wicken, A., \& Simpson, J. (2012, February). Te ohonga ake the health status of Màori children and young people in New Zealand (NZ Child and Youth Epidemiology Service Report). Retrieved from http://dnmeds.otago.ac.nz/departments/womens/paediatrics/research/nzcyes/māor i.html

Cram, F., Smith, L., \& Johnstone, W. (2003). Mapping the themes of Māori talk about health. The New Zealand Medical Journal, 116(1170). Retrieved from http://www.nzma.org.nz/journal/116-170/357/

Cutfield, W. S., Derraik, J. G. B., Gunn, A. J., Reid, K., Delany, T., Robinson, E., \& Hofman, P. L. (2011). Non-compliance with growth hormone treatment in 
children is common and impairs linear growth. PLoS One, 6(1), e16223. doi:10.1371/journal.pone.0016223

Denny, S., Balhorn, A., Lawrence, A., \& Cosgriff, J. (2005). Student access to primary health care and preventive health screening at a school-based health centre in South Auckland, New Zealand. The New Zealand Medical Journal, 118(1218). Retrieved from http://www.nzma.org.nz/journal/118-1218/1561

Denny, S., Clark, T., \& Watson, P. (2004). The health of alternative education students compared to secondary school students: A New Zealand study. The New Zealand Medical Journal, 117(1205). Retrieved from http://journal.nzma.org.nz/journal/117-1205/1147/

Dashiff, C. J., McCaleb, A., \& Cull, V. (2006). Self-care of young adolescents with type 1 diabetes. Journal of Pediatric Nursing, 21(3), 222-232. doi:10.10.16/j.ped.2005.07.013

Denzin, N. K. (2009). The elephant in the living room: Or extending the conversation about the politics of evidence. Qualitative Research, 9, 139-160. doi:10.1177/1468794108098034

Denzin, N. K., \& Lincoln, Y. S. (2008). Collecting and interpreting qualitative materials (Vol.3). London: Sage

Denzin, N. K., \& Lincoln, Y. S. (Eds.). (2005). The sage handbook of qualitative research. London: Sage.

Dickinson, A. R., Smythe, E., \& Spence, D. (2006). Within the web: The familypractitioner relationship in the context of chronic childhood illness. Journal of Child Health Care, 10(4), 309-325. Retrieved from http://chc.sagepub.com/cgi/content/refs/10/4/309

Dickinson, A., Wrapson, W., \& Water, T. (2014). Children's voices in public hospital healthcare delivery: Intention as opposed to practice. The New Zealand Medical Journal, 127(1405), 24-31. Retrieved from https://www.nzma.org.nz/journal/read-the-journal/all-issues/2010-2019/vol-127$1405 / 6346$

Dickinson, J. K., \& O'Reilly, M. M. (2004, January, February). The lived experience of adolescent females with type 1 diabetes. The Diabetes Educator, 30(1), 99-108.

Dobbie, M., \& Mellor, D. (2008). Chronic illness and its impact: Considerations for psychologists. Psychology, Health \& Medicine, 13(5), 583-590. doi:10.1080/13548500801983041

Dowling, M. (2007). From Husserl to van Manen. A review of different phenomenological approaches. International Journal of Nursing Studies, 44(1), 131-142. doi:10.1016/j.ijnurstu.2005.11.026

Dusek, J. B., \& McIntyre, J. G. (2003). Self-concept and self-esteem development. In G. R. Adams \& M. D. Berzonsky (Eds.), Blackwell handbook of adolescence. (pp. 290-309). Malden: Blackwell Publishing. 
Eatough, V., \& Smith, J. A. (2006). Interpretative Phenomenological Analysis. In C. Willig \& W. S. Rogers (Eds.) Handbook of qualitative psychology (pp. 179195). London: Sage.

Eckert, K. L., Loffredo, V. A., \& O’Connor, K. (2009). Adolescent Physiology. In W. T. O’Donohue \& L. W. Tolle (Eds.), Behavioral approaches to chronic disease in adolescence: A guide to integrative care (pp. 29-45). Nevada: Springer.

Edwards, T. C., Patrick, D. L., \& Topolski, T. D. (2003). Quality of life of adolescents with perceived disabilities. Journal of Pediatric Psychology, 28(4), 233-241. doi: 10.1093/jpepsy/jsg011

Eiser, C. (1990). The psychological effects of chronic disease. Journal of Child Psychology, 31(1), 85-98. doi:10.1111/j.1469-7610.1990.tb02274.x

Elkind, D. (1967). Egocentrism in adolescence. Child Development, 28(4), 1025-1034. Retrieved from http://www.jstor.org/stable/1127100

Ellison-Loschmann, L., \& Pearce, N. (2006). Improving access to health care among New Zealand's Māori population. American Journal of Public Health 96(4), 612-617.

Engel, J. (2009). Migraines/chronic headaches. In W. T. O’Donohue \& L. W. Tolle (Eds.), Behavioral approaches to chronic disease in adolescence (pp. 155-161). Nevada: Springer.

English, L., Barnes, M. A., Fletcher, J. M., Dennis, M., \& Raghubar, K. P. (2010). Effects of reading goals on reading comprehension, reading rate, and allocation of working memory in children and adolescents with spina bifida meningomyelocele. Journal of the International Neuropsychological Society, 16, 517-525.

Erickson, K., Freeborn, D., Roper, S. O., Mendleco, B., Anderson, A., \& Dyches, T. (2014). Parent experiences raising young people with type 1 diabetes and Celiac disease. Journal of Pediatric Nursing, 30(2), 1-11. Retrieved from http://dx.doi.org/10.1016/j.pedn.2014.09.011

Farrant, B., \& Watson, P. D. (2004). Health care delivery: Perspectives of young people with chronic illness and their parents. Journal of Paediatrics and Child Health, 40(4), 175-179. doi:10.111/j.1754.2004.00333x

Feigin, V. L., Theadom, A., Barker-Collo, S., Starkey, N. J., McPherson, K., Kahan, M., ...Ameratunga, S. (2013). Incidence of traumatic brain injury in New Zealand: A population-based study. The Lancet Neurology, 12(1), 53-64. doi:10.1016/S1474-4422(12)70262-4

Ferguson, G. (2004). You'll be a man if you play rugby. Palmerston North, New Zealand: Dunmore Press.

Ferguson, P., \& Walker, H. (2014). 'Getting on with life': Resilience and normalcy in adolescents living with chronic illness. International Journal of Inclusive Education, 18(3), 227-240. doi:10.1080/13603116.2012.676082 
Flowers, P., Duncan, B., \& Frankis, J. (2000). Community, responsibility and culpability: HIV risk-management amongst Scottish gay men. Journal of Community and Applied Social Psychology, 10(4), 285-300. doi:10.1002/10991298(200007/08)10:43.0.CO;2-7

Flowers, P., Duncan, B., \& Knussen, C. (2003). Re-appraising HIV testing: An exploration of the psychosocial costs and benefits associated with learning one's HIV status in a purposive sample of Scottish gay men. British Journal of Health Psychology, 8(2),179-194. doi: 10.1348/135910703321649150

Fraser, D. (2001, December). The educational needs of children with cancer: Friendships and peer relationships. Paper presented at the NZARE Conference, Christchurch, New Zealand.

Free, S., Howden-Chapman, P., Pierse, N., Viggers, H., \& the Housing, Heating and Health Study Research Team. (2010). More effective home heating reduces school absences for children with asthma. Journal of Epidemiology and Community Health, 64(5), 379-386. doi:10.1136/jech.2008.086520

Frieman, B. B., \& Settel, J. (1994). What the classroom teacher needs to know about children with chronic medical problems. Childhood Education, 70(4), 196-201.

Froiland, J. M., \& Davison, M. L. (2014). Parental expectations and school relationships as contributors to adolescents' positive outcomes. Social Psychology of Education, 17(1), 1-17. doi:10.1007/s11218-013-9237-3

Frydenberg, E., \& Lewis, R. (2009). The relationship between problem-solving efficacy and coping amongst Australian adolescents. British Journal of Guidance \& Counselling, 37(1), 51-64. doi:01.1080/03069880802534054

Gadamer, G.H., (1989). Truth and Method ( $2^{\text {nd }}$ ed.). Sheed and Ward: London.

Garcia, C. (2010). Conceptualization and measurement of coping during adolescence: A review of the literature. Journal of Nursing Scholarship,42(2), 166-185. doi:10.1111/j.1547-5069.2009.01327.x

Gilbert, O., Wilson, N., \& Finucane, K. (2011). Early cardiac morbidity of rheumatic fever in children in New Zealand. The New Zealand Medical Journal, 124(1343), 57-64. Retrieved from http://journal.nzma.org.nz/journal/124$13443 / 4880 /$

Gill, M. J. (2014). The possibilities of phenomenology for organizational research. Organizational Research Methods. doi:10.1177/1094428113518348

Gill, S., \& Coad, J. (2007). An exploratory study into nurses' understanding and knowledge of children and young people with eczema. Journal of Research in Nursing, 12(5), 567-58. doi:10.1177/1744987107079586.

Glasscoe, C. \& Smith, J. A. (2010). Unravelling complexities involved in parenting a child with cystic fibrosis: An interpretative phenomenological analysis. Clinical Child Psychology and Psychiatry. doi:10.1177/1359104510383207 
Goffman, E. (1963). Stigma: Notes on the management of spoiled identity. Harmondsworth: Penguin.

Goodman, R. F. (2001). Children with a chronic illness-the interface of medicine and mental health. The New York University Child Study Center Letter, 5(4). Retrieved from http://www.aboutourkids.org/aboutour/letter/marapr01.pdf

Graça Pereira, M., Berg-Cross, L., Almeida, P., \& Machado, J. C. (2008). International Journal of Behavioral Medicine, 15(3), 187-193. doi:10.1080/10705500802222436

Graneheim, U. H. \& Lundman, B. (2004). Qualitative content analysis in nursing research: Concepts, procedures and measures to achieve trustworthiness. Nurse Education Today, 24(2), 105-112

Gregory, A., \& Ripski, M. B. (2008). Adolescent trust in teachers: Implications for behavior in the high school classroom. School Psychology Review, 37(3), 337353.

Grigg-Damberger, M. (2004). Neurologic disorders masquerading as pediatric sleep problems. Pediatric Clinics of North America, 51(1), 89-115.

Grinyer, A. (2007). The biographical impact of teenage and adolescent cancer. Chronic Illness, 3(4), 265-277. doi:10.1177/1742395307085335

Hale, M., \& Sharpe, N. (2011). Persistent rheumatic fever in New Zealand-a shameful indicator of child health. The New Zealand Medical Journal, 124(1329), 6-8. Retrieved from http://www.nzma.org.nz/journal/124-1329/4530/

Halfon, N., Houtrow, A., Larson, K., \& Newacheck, P. W. (2012). The changing landscape of disability in childhood. The Future of Children, 22(1), 13-42. doi: $10.2307 / 41475645$

Hampel, P., \& Petermann, F. (2006). Perceived stress, coping, and adjustment in adolescents. Journal of Adolescent Health 38, 409-415. doi:

10.1016/j.jadohealth.2005.02.014

Hayes-Bohn, R., Neumark-Sztainer, D., Mellin, A., \& Patterson, J. (2004). Adolescent and parent assessments of diabetes mellitus management at schools. Journal of School Health, 74(5), 166-169. doi:10.1111/j.1746-1561.2004.tb08215.x

Heidegger, M. (1962). Being and time. (J. Macquarrie \& E. Robinson, Trans.) New York: Harper and Row.

Helvig, A. W., \& Minick. (2013). Adolescents and headaches: Maintaining control. Pediatric Nursing, 13(1), 19-25.

Herman, J. (2005). The need for a transitional model: A challenge for biopsychosocial medicine? Families, Systems, \& Health, 23(4), 372-276. doi: 10.1037/10917527.23.4.372 
Hohepa, M., Schofield, G., \& Kolt, G. (2004). Adolescent obesity and physical inactivity. The New Zealand Medical Journal, 117(1207). Retrieved from https://www.nzma.org.nz/journal/117-1207/1210/

Holmes, C. S., Cant, M. C., Fox, M. A., Lampert, N. L., \& Greer, T. (1999). Disease and demographic risk factors for disrupted cognitive functioning in children with insulin-dependent diabetes mellitus (IDDM). The School Psychology Review, 28(2), 215-227.

Holt, S., Kljakovic, M., \& Reid, J. (2003). Asthma morbidity, control and treatment in New Zealand: Results of the patient outcomes management survey (POMS), 2001. Journal of the New Zealand Medical Association, 116(1174). U436.

Huebner, A. J. (2009). An introduction to adolescent development. In W. T. O'Donohue \& L. W. Tolle (Eds.), Behavioral approaches to chronic disease in adolescence: A guide to integrative care (pp. 7-14). Nevada: Springer.

Hughes, B., \& Paterson, K. (1997). The social model of disability and the disappearing body: Towards a sociology of impairment. Disability \& Society, 12(3), 325-340. doi: 10.1080/09687599727209

Husserl, E., (1970). The idea of phenomenology. Njihoff: The Hague.

Huus, K., \& Enskär, K. (2007). Adolescents' experience of living with diabetes. Pediatric Nursing 19(3), 29-32.

Huws, J. C., \& Jones, R. S. P. (2008). Diagnosis, disclosure, and having autism: An interpretative phenomenological analysis of the perceptions of young people with autism. Journal of Intellectual \& Developmental Disability, 33(2), 99-107. doi:10.1080/13668250802010394

Jackson, M. (2012). The special educational needs of adolescents living with chronic illness: A literature review. International Journal of Inclusive Education, 17(6), 543-554. doi:10.1080/13603116.2012.676085

Joe, S., Joe, E., \& Rowley, L. L. (2009). Consequences of physical health and mental illness risks for achievement in grades K-12. Review of Research in Education, 33, 283-309. doi:10.3102/0091732X08327355

Johnson, B., \& Christensen, L. (2008). Educational research: Quantitative, qualitative, and mixed approaches. Los Angeles: SAGE Publications.

Karlsson, A., Arman, A., \& Wikblad, K. (2008). Teenagers with type 1 diabetes-a phenomenological study of the transition towards autonomy in self-management. International Journal of Nursing Studies, 45, 562-570. doi:10.1016/j.ijnurstu.2006.08.022

Kayes, D. T. (2012). Associations between parents' and students' perceptions of the quality of teacher-student interactions in a New Zealand primary school. Unpublished master's thesis, Curtain University, Science and Mathematics Education Centre. 
Kearney, C. A. (2008). School absenteeism and school refusal behaviour in youth: $A$ contemporary review. Clinical Psychology Review, 28(3), 451-471. doi:10.1016/j.cpr.2007.07.012

Kelly, L. M., Zebracki, K., Holmbeck, G. N., \& Gershenson, L. (2008). Adolescent development and family functioning in youth with spina bifida. Journal of Pediatric Rehabilitation Medicine, 1(4), 291-302.

Keppel, J. J. (2012). Re-imaging the 'kiwi bloke': Low places and anxious spaces in Aotearoa New Zealand. Unpublished master's thesis, The University of Waikato, Hamilton, New Zealand

Kidd, P. S., \& Paschall, M. B. (2000). Getting the focus and the group: Enhancing analytical rigor in focus group research. Qualitative Health Research, 10(3), 293308. doi:10.1177/104973200129118453

Kirk, S. (2007). Methodological and ethical issues in conducting qualitative research with children and young people: A literature review. International Journal of Nursing Studies, 44(7), 1250-1260.

Kirwan, J. (2010). All Blacks don't cry: A story of hope. New Zealand: Penguin.

Kliebenstein, M. A., \& Broome, M. E. (2000). School re-entry for the child with chronic illness: Parent and school personnel perceptions. Pediatric Nursing, 26(6), 579585 .

Koch, T. (1999). An interpretive research process: Revisiting phenomenological and hermeneutical approaches. Nurse Researcher, 63(3), 20-34.

Kral, M. C., \& Brown, R. T. (2004). Transcranial Doppler ultrasonography and executive dysfunction in children with sickle cell disease. Journal of Pediatric Psychology 29(3), 185-195. doi:10.1093/jpepsy/jsho20

Krueger, M., \& Kendall, J. (2001). Descriptions of self: An exploration study of adolescents with ADHD. Journal of Childhood and Adolescent Psychiatric Nursing, 14(2), 61-72. doi:10.1111/j.1744-6171.2001.tb00294.x

Kyngäs, H. (2001). Predictors of good compliance in adolescents with epilepsy. Seizure, 10, 549-553. doi:10.1053/seiz.2001.0557

Kyngäs, H. (2000). Compliance with health regimens of adolescents with epilepsy. Seizure, 9(8), 598-604. doi:10.1053/seiz.2000.0470

La Greca, A. M., \& Mackey, E. R. (2009). Type 1 diabetes mellitus. In W. T. O’Donohue \& L.W. Tolle (Eds.), Behavioral approaches to chronic disease in adolescence: A guide to integrative care (pp. 85-100). Nevada: Springer.

Larkin, M., Watts, S., \& Clifton, E. (2008). Giving voice and making sense in interpretative phenomenological analysis. Qualitative Research in Psychology, 3(2), 102-120. doi:10.1191/1478088706qp062oa 
Lazarus, R. S., \& Folkman, S. (1984). Stress, appraisal and coping. New York: Springer.

Levy, R. O., Olden, K. W., Naliboff, B. D., Bradley, L. A., Francisconi, C., Drossman, D. A., et al. (2006). Psychosocial aspects of the functional gastrointestinal disorders. Gastroenterology, 130, 1447-1458. doi:10.1053/j.gastro.2005.11.057

Lightfoot, J., Wright, S., \& Sloper, P. (1998). Supporting pupils in mainstream school with an illness or disability: Young people's view. Child: Care, Health \& Development, 25(4), 267-283. doi:10.1046/j.1365-2214.1999.00112.x

Lopez, K. A., \& Willis, D. G. (2004). Descriptive versus interpretive phenomenology: Their contributions to nursing knowledge. Qualitative Health Research, 14(5), 726-735. doi:10.1177/1049732304263638

Lynch, T., \& Spence, D. (2008). A qualitative study of youth living with Crohn disease. Gastroenterology Nursing, 31(3), 224-30. doi:10.1097/01.SGA.0000324114.01651.65

Machalicek, W., O’Reilly, M. F., Beretvas, N., Sigafoos, J., \& Lancioni, G. E. (2008). A review of interventions to reduce challenging behaviour in school settings for students with autism spectrum disorders. Research in Autism Spectrum Disorders, 1, 229-246. doi:10.1016/j.rasd.2006.10.005

Magin, P., Adams, J., Heading, G., Pond, D., \& Smith, W. (2008). Experiences of appearance-related teasing and bullying in skin diseases and their psychological sequelae: Results of a qualitative study. Scandinavian Journal of Caring Sciences, 22(3), 430-436. doi:10.0000/j.1471-6712.2007.00547.x

Malterud, K. (2001). Qualitative research: Standards, challenges, and guidelines. The Lancet, 358(9280), 483-488. doi:10.1016/S0140-6736(01)05627-6

Mandel, L. A., Qazilbash, J. (2005, October). Youth voices as change agents: Moving beyond the medical model in school-based health center practice. Journal of School Health, 75(7), 239-242.

Martinez, W., Smith Carter, J., \& Legato, L. J. (2011). Social competence in children with chronic illness: A meta-analytic review. Journal of Pediatric Psychology, 36(8), 878-890. doi:10.1093/jpepsy/jsro35

Martin-Herz, S. P., Zatzick, D. F., \& McMahon, R. J. (2012). Health-related quality of life in children and adolescents following traumatic injury: A review. Clinical Child \& Family Psychology Review, 15(3), 192-214. doi:10.1007/s10567-0120115-x

McNelis, A. M., Johnson, C. S., Huberty, T. J., \& Austin, J. K. (2005). Factors associated with academic achievement in children with recent-onset seizures. Seizure, 14(5), 331-339. doi:10.1016/j.seizure.2005.04.005

Meijer, S. A., Sinnema, G., Bijstra, J. O., Mellenbergh, G. J., \& Wolters, W. H. G. (2002). Coping styles and locus of control as predictors for psychological 
adjustment of adolescents with a chronic illness. Social Science \& Medicine, 54(9), 1453-1461. doi:10.1016/S0277-9536(01)00127-7

Mellin, A. E., Neumark-Sztainer, D., \& Patterson, J. M. (2004). Parenting adolescent girls with type 1 diabetes: Parents perspectives. Journal of Pediatric Psychology, 29(3), 221-230. doi:10.1093/jpepsy/jsho23

Mergler, A., \& Patton, W. (2007). Adolescents talking about personal responsibility. Journal of Student Wellbeing, 1(1), 57-70.

Merriam, S. B. (2002). Introduction to qualitative research. Qualitative research in practice: Examples for discussion and analysis, (pp. 3-17). San Francisco, CA: John Wiley \& Sons, Inc.

Meuleners, L. B., Binns, C. W., Lee, A. H., \& Lower, A. (2002). Perceptions of the quality of life for the adolescent with a chronic illness by teachers, parents and health professionals: A Delphi study. Child: Care, Health \& Development, 28(5), 341-349. doi:10.1046/j.13656-2214.2002.00283.x

Michaud, P.-A., Suris, J. C., \& Viner, R. (2004). The adolescent with a chronic condition. Part II: Healthcare provision. Archives of Disease in Childhood, 89(10), 943-949. doi:10.1136/adc.2003.045377

Miller, V. A., \& Jawad, A. F. (2014). Relationship of youth involvement in diabetesrelated decisions to treatment adherence. Journal of Clinical Psychology in Medical Settings, 21(2), 183-189. doi:10.1007/s.10880-014-9388-1

Milne, R. J., Lennon, D. R., Stewart, J. M., Vander Hoorn, S., \& Scuffham, P. A. (2012). Incidence of acute rheumatic fever in New Zealand children and youth. Journal of Paediatrics and Child Health, 48(8), 685-691. doi:10.1111/j.14401754.2012.02447.x

Ministry of Education. (2008a). Individual Education Program (IEP). Retrieved from http://www.minedu.govt.nz/NZEducation/EducationPolicies/SpecialEducation/S ervicesAndFunding/IndividualEducationProgramme.aspx

Ministry of Education. (2008b). Regional health schools. Retrieved from http://www.minedu.govt.nz/NZEducation/EducationPolicies/SpecialEducation/F orms AndGuidelines/RegionalHealthSchools.aspx

Ministry of Education. (2009). Principals Guide to ENROL-The school student enrolment register. Retrieved from http://www.minedu.govt.nz/.../EducationPolicies/Schools/SchoolOperations/EN ROLAndEnrolment.aspx

Ministry of Health. (2008). A portrait of health: Key results of the 2006/07 New Zealand health survey. Retrieved from http://www.health.govt.nz/publication/portraithealth-key-results-2006-07-new-zealand-health-survey

Ministry of Health. (2008b). Pacific youth health: A paper for the Pacific health and disability action plan review. Retrieved from 
www.health.govt.nz/system/files/documents/publications/pacific-youth-healthmay08.pdf

Ministry of Health. (2013). New Zealand health survey: Annual update of key findings 2012/13. Retrieved from http://www.health.govt.nz/publication/new-zealandhealth-survey-annual-update-key-findings-2012-13

Mitru, G., Millrood, D. L., \& Mateika, J. H. (2002). The impact of sleep on learning and behaviour in adolescents. Teachers College Record, 104(4), 704-725. http://www.tcrecord.org/content.asp?contentid=10893

Monteith, S. J., Heppner, P. A., Woodfield, M. J., \& Law, A. J. J. (2005). Paediatric central nervous system tumours in a New Zealand population: A 10-year experience of epidemiology, management strategies and outcomes. Journal of Clinical Neuroscience, 13(7), 722-729. doi:10.1016/j.jocn.2005.08.013

Morrow, S. (2005). Quality and trustworthiness in qualitative research in counselling psychology. Journal of Counseling Psychology, 52(2), 250-260. doi:10.1037/0022-0167.52.2.250

Moustakas, C. (1994). Phenomenological research methods. Thousand Oaks: SAGE.

Murphy, N., \& Young, P. C. (2005). Sexuality in children and adolescents with disabilities. Developmental Medicine \& Child Neurology, 47, 640-644

Mushtaq, T., \& Ahmed, S. F. (2002). The impact of corticosteroids on growth and bone health. Archives of Disease in Childhood, 87(2), 93-96. Retrieved from $\mathrm{http} / / /$ search.proquest.com/docview/196870256?accountid=14782

Nassau, J. H., \& Drotar, D. (1997). Social competence among children with central nervous system-related chronic health conditions: A review. Journal of Pediatric Psychology, 22(6), 771-793.

National Association of School Nurses. (2001). Issue brief: School health nursing services role in health care. Retrieved from http:www.nasn.org/briefs/2001brief504.htm

National Health Committee. (2005). People with chronic conditions. (A discussion paper). Retrieved from http://www.moh.govt.nz/NoteBook/nbbooks.nsf/0/E33794CF7BCC0639CC2570 03000DD689/\$file/chronicconditions-discussionpaper.pdf

National Health Committee. (2007). Meeting the needs of people with chronic conditions. Retrieved from http://nhc.health.govt.nz/resources/publications/meeting-needs-people-chronicconditions

Neinstein, L. S. (2001). The treatment of adolescents with a chronic illness: Physicians must go beyond the medical model. (Op-Ed.). The Western Journal of Medicine, $175(5), 293$. 
Obaid, B., Britt, E., Wallace-Bell, M., \& Johnson-Elsmore, S. (2012). The demographics and prevalence of youth (15-24 year olds) with type 1 diabetes in the Canterbury District Health Board catchment area in 2010: Has the prevalence changed since 2003? The New Zealand Medical Journal, 125(1363), 22-28. Retrieved from http://journal.nzma. org.nz/journal/125-1363/5370/

O’Donohue, W. T., \& Tolle, L. W. (Eds.). (2009). Behavioral approaches to chronic disease in adolescence: A guide to integrative care. Nevada: Springer.

Olson, A. L., Seidler, A. B., Goodman, D., Gaelic, S., \& Nordgren, R. (2004). School professionals' perceptions about the impact of chronic illness in the classroom. Archives Pediatric Adolescent Medicine, 158(1), 53-58. Retrieved from www.archpediatrics.com

Olsson, C. A., Boyce, M. F., Toumbourou, J. W., \& Sawyer, S. M. (2005). The role of peer support in facilitating psychosocial adjustment to chronic illness in adolescence. Clinical Child Psychology and Psychiatry, 10(1), 78-87. doi:10.1177/1359104505048793

Olsson, C., Lyon, P., Hörnell, A., Ivarsson, A., \& Sydner, Y. M. (2009). Food that makes you different: The stigma experienced by adolescents with celiac disease. Qualitative Health Research, 19(7), 976-984. doi:10.1177/1049732309338722

O'Neill, J. (2014, November 20). Voice and the ethics of children's agency in educational research. New Zealand Journal of Educational Studies, 49(2), 219232 .

Paddison, C. A. M., Alpass, F. M., \& Stephens, C. V. (2008). Psychological factors account for variations in metabolic control and perceived quality of life among people with type 2 diabetes in New Zealand. International Journal of Behavioural Medicine, 15, 180-186. doi:10.1080/10705500802222295

Paterson, J., Moss-morris, R., \& Butler, S. (1999). The effect of illness experience and demographic factors on children's illness representations. Psychology and Health, 14(1), 117-129. doi:10.1080/08870449908407318

Patton, M. Q. (2002). Qualitative research and evaluation methods (3rd ed.). Thousand Oaks, CA: Sage Publications

Perrin, E. C., Lewkowicz, D., \& Young, M. H. (2000). Shared vision: Concordance among fathers, mothers, and paediatricians about unmet needs of children with chronic health conditions. Pediatrics, 105(1), 277-285.

Piko, B. (2001). Gender differences and similarities in adolescents' ways of coping. The Psychological Record, 51(2), 223-235. Retrieved from http://web.b.ebscohost.com/ehost/pdfviewer/pdfviewer?sid=aee6906b-08a24ac4-ae67-34b23c282c79\%40sessionmgr113\&vid=0\&hid=116

Polvere, L. (2014). Agency in institutionalised young: A critical inquiry. Children \& Society, 28(3), 182-193. doi:10.1111/chso.12048 
Ponterotto, J. G. (2002). Qualitative research methods: The fifth force in psychology. The Counselling Psychologist, 30(3), 394-406. doi:10:1177/0011000002303002

Powers, S. W., Patton, S. R., Hommel, K. A., \& Hershey, A. D. (2003). Quality of life in childhood migraines: Clinical impact and comparison to other chronic illnesses. Pediatrics, 112(1), e1-e5.

Purvis, D., Robinson, E., Merry, S., \& Watson, P. (2006). Acne, anxiety, depression and suicide in teenagers: A cross-sectional survey of New Zealand secondary school students. Journal of Paediatrics and Child Health, 42(12), 793-796. doi:10.1111/j.1440-1754.2006.00979.x

Quick, V. (2013). Social theory applied to body image and chronic illness in youth. American Journal of Lifestyle Medicine, 8(1), 15-20. doi:10.1177/1559827613505408

Rao, P. A., Beidel, D. C., \& Murray, M. J. (2008). Social skills interventions for children with Asperger's syndrome or high-functioning autism: A review and recommendations. Journal of Autism and Developmental Disorders, 38(2), 353361 .

Reed-Knight, B., Lewis, J. D., \& Blount, R. L. (2011). Association of disease, adolescent, and family factors with medication adherence in pediatric inflammatory bowel disease. Journal of Pediatric Psychology, 36(3), 308-317. doi:10.1093/jpepsy/jsq076

Reeve, D. K., \& Lincoln, N. B. (2002). Coping with the challenge of transition in older adolescents with epilepsy. Seizure, 11(1), 33-39. doi:10.1053/seiz.2001.0574

Reid, K., Flowers, P., \& Larkin, M. (2005). Exploring lived experience. Psychologist, 18(1), 20-23.

Rey-Casserly, C., \& Meadows, M. E. (2008). Developmental perspectives on optimizing educational and vocational outcomes in child and adult survivors of cancer.

Developmental Disabilities Research Reviews, 14(3), 243-250. doi:10.1002/ddrr.31

Rhee, H., Fairbanks, E., \& Butz, A. (2014). Symptoms, feelings, activities and medication use in adolescents with uncontrolled asthma: Lessons learned from asthma diaries. Journal of Pediatric Nursing, 29(1), 39-46.

doi:10.1016/j.pedn.2013.04.009

Richter, D. (1999). Chronic mental illness and the limits of the biopsychosocial model. Medicine, Health Care and Philosophy, 2(1), 21-20.

Rose, B. M., \& Holmbeck, G. N. (2007). Attention and executive functions in adolescents with spina bifida. Journal of Pediatric Psychology, 32(8), 983-994. doi:10.1093/jpepsy/jsm042

Sartain, S. A., Clarke, C. L., \& Hayman, R. (2000). Hearing the voices of children with chronic illness. Journal of Advanced Nursing, 32(4), 913-921. 
Saunders, B. (2014). Stigma, deviance and morality in young adults' accounts of inflammatory bowel disease. Sociology of Health and Illness, 20(20), 1-17. doi:10.1111/1467-9566.12148

Sawin, K. J., Bellin, M. H., Roux, G., Buran, C., Brei, T. J., \& Fastenau, P. S. (2003, November/December). The experience of parenting an adolescent with spina bifida. Rehabilitation Nursing, 28(6), 173-185.

Sawyer, S. M., Drew, S., Yeo, M. S., \& Britto, M. T. (2007, April 28). Adolescents with a chronic condition: Challenges living, challenges treating. The Lancet, 369,1481-89. doi:10.1016/S0140-6736(07)60370-5

Sawyer, M. G., Reynolds, K. E., Couper, J. J., French, D. J., Kennedy, D., Martin, J., ...Baghurst, P. A. (2004). Health-related quality of life of children and adolescents with chronic illness: A two year prospective study. Quality of Life Research, 13(7),1309-1319.

Scambler, G. \& Hoplins, A. (1986). 'Being epileptic': Coming to terms with stigma. Sociology of Health and Illness, 8(1), 26-43.

Schlozman, S. C. (2002). When illness strikes. Educational Leadership, 60(1), 82-83.

Schur, H. V., Gamsu, D. S., \& Barley, V. M. (1999). The young person's perspective on living and coping with diabetes. Journal of Health Psychology, 4(2), 223-236. doi:10.1177/135910539900400215

Schwartz, L., \& Drotar, D. (2006). Defining the nature and impact of goals in children and adolescents with a chronic health condition: A review of research and a theoretical framework. Journal of Clinical Psychological Med Settings, 13, 393405. doi:10/1007/s10880-006-9041-8

Scott, A., Whitcombe, S., Bouchier, D., \& Dunn, P. (2004). Diabetes in children and young adults in Waikato Province, New Zealand: Outcomes of care. The New Zealand Medical Journal, 117(1207). Retrieved from http://www.nzma.org.nz/journal/117-1207/1219/

Seale, C. (1999, December). Quality in qualitative research. Qualitative Inquiry 5(4), 465-478. doi:10.1177/107780049900500402

Sebastian, C. L., Burnett, S., Blakemore, S-J. (2008). Development of the self-concept during adolescence. Trends in Cognitive Sciences, 12(11). 441-4446. doi:10.1016/j.tics.1008.07.008

Seidman, I. (2006). Interview as qualitative research: A guide for researchers in education and the social sciences $\left(3^{\text {rd }}\right.$ ed.). New York: Teacher's College Press.

Sentenac, M., Gavin, A., Arnaud, C., Molcho, M., Godeau, E., \& Gabhainn, S. N. (2010). Victims of bullying among students with a disability or chronic illness and their peers: A cross-national study between Ireland and France. Journal of Adolescent Health, 48(5), 461-466. doi:10.1016/j.jadohealth.2010.07.031 
Shaw, S. R., \& McCabe, P. C. (2008). Hospital-to-school transition for children with chronic illness: Meeting the new challenges of an evolving health care system. Psychology in the Schools, 45(1), 74-87. doi:10.1002/pits.20280

Sheffield, J. K., Fiorenza, E., \& Sofronoff, K. (2004). Adolescents' willingness to seek psychological help: Promoting and preventing factors. Journal of Youth and Adolescence, 33(6), 495-507. doi:10.1023/B:JOYO.0000048064.31128.c6

Shiu, S. (2001). Issues in the education of students with chronic illness. International Journal of Disability, Development, and Education, 48(3), 269-81. doi:10.1080/10349120120073412

Shiu, S. (2004). Positive interventions for children with chronic illness: Parents' and teachers' concerns and recommendations. Australian Journal of Education, 48(3), 239-253. doi:10.1177/000494410404800303

Simeonsson, R. J., McMillen, J. S., \& Huntington, G. S. (2002). Secondary conditions in children with disabilities: Spina bifida as a case example. Mental Retardation and Developmental Disabilities Research Reviews, 8(3), 198-205. doi:10.1002/mrdd.10038

Simmons, D. R. (2007). Child Health Issues in New Zealand: An overview. The Journal of School Nursing, 23(3), 151-157. doi:10.1177/105984050230030501

Simmons, R. D. (2010). Life issues in multiple sclerosis. Nature Reviews Neurology, 6(10), 603-610.

Simpson, R. L., Mundschenk, N. A., \& Heflin, L. (2011). Issues, policies, and recommendations for improving the education of learners with autism spectrum disorders. Journal of Disability Policy Studies, 22(3), 3-17. doi:10.11771044207310394850

Smith, A. B., Gaffney, M., \& Nairn, K. (2004). Health rights in secondary schools: Student and staff perspectives. Health Education Research, 19(1), 85-97. doi:10.1093/her/cyg007

Smith, J. A. (1995). Semi-structured interviewing and qualitative analysis. Rethinking Methods in Psychology, 9-26.

Smith, J. A. (2004). Reflecting on the development of interpretative phenomenological analysis and its contribution to qualitative research in psychology. Qualitative Research in Psychology, 1(1), 39-54. doi:10.1191/1478088704qp0040a

Smith, J. A. (2010). Evaluating the contribution of interpretative phenomenological analysis, Health Psychology Review, 5(1), 9-27. doi:10.1080/17437199.2010.510659

Smith, J. A., \& Osborn, M. (2008). Interpretive phenomenological analysis. In J. A. Smith (Ed.), Qualitative psychology: A practical guide to research methods (pp. 53-80). London: SAGE. 
Smith, J. J., Taylor, K. M. G., Newbould, J., \& Keady, S. (2008). Medicines for chronic illness at school: Experiences and concerns of young people and their parents. Journal of Clinical Pharmacy and Therapeutics, 33(5), 537-544. doi:10.1111/j/1365-2710-2008.00944.x

Snyder, C. R. (1994). The psychology of hope: You can get there from here. New York: Simon \& Schuster.

Spinelli, C. G. (2004). Dealing with cancer in the classroom. Teaching Exceptional Children, 36(4), 14-21.

St. Leger, P., \& Campbell, L. (2008). Evaluation of a school-linked program for children with cancer. Health Education, 108(2), 117-129. doi:10.1108/09654280810855577

Steinberg, L. (2007). Risk taking in adolescence: New perspectives from brain and behavioral science. Current Directions in Psychological Science, 16(2), 55-59.

Sturdevant, M. S., \& Spear, B. A. (2002). Adolescent psychosocial development. Journal of the American Dietetic Association, 102(3), S30-S31.

Suris, J., Michaud, P., Akre, C., \& Sawyer, S. M. (2008). Health risk behaviours in adolescents with chronic conditions. Pediatrics, 122(5), e1113-e1118.

Suris, J. C., Michaud, P. A., \& Viner, R. (2004). The adolescent with a chronic condition. Part I: Developmental issues. Archives of Disease in Childhood, 89(10), 938-942. doi:10.1136/adc.2003.045369

Thies, K. M. (1999). Identifying the educational implications of chronic illness in school children. Journal of School Health, 69(10), 392-297. doi:10.111/j.17461561.1999.tb06354.x

Thies, K. M., \& Walsh, M. E. (1999). A developmental analysis of cognitive appraisal of stress in children and adolescents with chronic illness. Children's Health Care, 28(1), 15-32. doi:10.1207/s15326888chc2801_2

Todres, L., \& Wheeler, S. (2001). The complementarity of phenomenology, hermeneutics and existentialism as a philosophical perspective for nursing research. International Journal of Nursing Studies 38(1), 1-8. doi:10.1016/S0020-7489(00)00047-X

Tomkins, L. \& Eatough, V. (2010). Reflecting on the use of IPA with focus groups: Pitfalls and potentials. Qualitative Research in Psychology, 7(3), 244-262. doi:10.1080/14780880903121491

Vallido, T., Peters, K., O’Brien, L., \& Jackson, D. (2009). Sleep in adolescence: A review of issues for nursing practice. Journal of Clinical Nursing, 18(13), 18191826. doi:10.1111/j.1365-2702.2009.02812.x

Van der Zaag-Loonen, H. J., Grootenhuis, M. A., Last, B. F., \& Derkx, H. H. F. (2004). Coping strategies and quality of life of adolescents with inflammatory bowel disease. Quality of Life Research, 13(5), 1011-1019. 
Vitulano, L. A. (2003). Psychosocial issues for children and adolescents with chronic illness. Child and Adolescent Psychiatric Clinics of North America, 12(3), 585592. doi:10.1016/S1056-4993(03)00027-0

Vogts, N., Mackey, A. H., Ameratunga, S., \& Stott, N. S. (2010). Parent-perceived barriers to participation in children and adolescents with cerebral palsy. Journal of Paediatrics and Child Health, 46(11), 680-685. doi:10.111./j.14401754.2010.01818.x

Wallander, J. L., \& Varni, J. W. (1998). Effects of pediatric chronic physical disorders on child and family adjustment. Journal of Child Psychology \& Psychiatry \& Allied Disciplines, 39(1), 29-46. doi:10.1111/1469-7610.00302

Warner, D. E., \& Hauser, S. T. (2009). Unique considerations when treating adolescents with chronic illness. In W. T. O'Donohue \& L. W. Tolle (Eds.), Behavioral approaches to chronic disease in adolescence: A guide to integrative care (pp. 15-28). Nevada: Springer.

Warrington, T. P., \& Bostwick, J. M. (2006). Psychiatric Adverse Effects of Corticosteroids. Mayo Clinic Proceedings, 81(10), 1361-1367.

Wang, Y.-L., Brown, S. A., \& Horner, S. D. (2010). School-based lived experiences of adolescents with type 1 diabetes: A preliminary study. Journal of Nursing Research, 18(4), 258-265. doi:10.1097/JRN.0b013e3181fbe107

Webb, C., \& Kevern, J. (2001). Focus groups as a research method: A critique of some aspects of their use in nursing research. Journal of Advanced Nursing , 33(6), 798-805.

Wellstead, P. \& Norriss, H. (2014). Information-seeking to support wellbeing: A pilot study of New Zealand men. International Journal of Wellbeing, 4(2), 32-44. doi: 10.5502/ijw.v412.3

White, B. (2011). Mapping your thesis. The comprehensive manual of theory and techniques for masters and doctoral research. Victoria, Australia: ACER Press.

White, B., Driver, S., \& Warren, A.-M. (2008). Considering resilience in the rehabilitation of people with traumatic disabilities. Rehabilitation Psychology, 53(1), 9-17. doi: 10.1037/0900-5550.53.1.9

Wickens, K. L., Crane, J., Kemp, T. J., Lewis, S. J., D’Souza, W. J., Sawyer, G. M., ...Pearce, N. E. (1999). Family size, infections, and asthma prevalence in New Zealand children. Epidemiology, 10(6), 699-705. Retrieved from http://www.jstor.org/stable/3703510.

Wilding, C., \& Whiteford, G. (2005). Phenomenological research: An exploration of conceptual, theoretical, and practical issues. OTJR: Occupation, Participation and Health, 25(3), 98-104.

Wilkinson, S. (2008). Focus groups. In J. A. Smith (Ed.), Qualitative psychology: A practical guide to research methods (pp. 186-206). London: SAGE. 
Williams, P. G., Holmbeck, G. N., \& Greenley, R. N. (2002). Adolescent health psychology. Journal of Consulting and Clinical Psychology, 70(3), 828-842. doi:10.1037/0022-006X.70.3.828

Wishnietsky, D. B., \& Wishnietsky, D. H. (2004). Helping students with diabetes management. Phi Delta Kappa Fastbacks, 517, 7-47.

Wodrich, D. L. (2005, Fall). Disclosing information about epilepsy and type 1 diabetes mellitus: The effect of teachers' understanding of classroom behaviour. School Psychology Quarterly, 20(3), 288-303. doi:10.1521/scpq.2005.20.3.288

Wodrich, D. L., \& Cunningham M. M. (2008). School based tertiary and targeted interventions for students with chronic medical conditions: Examples from type 1 diabetes mellitus and epilepsy. Psychology in the Schools, 45(1), 52-62. doi:10.1002/pits.20278

Wodrich, D. L., Kaplan, A. M., \& Deering, W. M. (2006). Children with epilepsy in school. Special service usage and assessment practices. Psychology in the Schools, 43(2), 169-181. doi:10.1002/pits.20123

Wodrich, D. L., \& Spencer, M. L. S. (2007). The other health impairment category and health-based classroom accommodations. Journal of Applied School Psychology, 24(1), 109-125. doi:10.1300/J370v24n01_06

Woodgate, R. L. (2006). Living in the shadow of fear: Adolescents' lived experience of depression. Journal of Advanced Nursing, 56(3), 261-269. doi:10.1111/j.13652648.2006.04020.x

Woodgate, R. L. (1998, August). Adolescents' perspectives of chronic illness: "It's hard". Journal of Pediatric Nursing, 13(4), 210-223. doi:10.1016/S08825963(98)80048-1

Wu, D., Kendall, D., Lunt, H., Willis, J., Darlow, B., \& Frampton, C. (2005). Prevalence of type 1 diabetes in New Zealanders aged 0-24 years. The New Zealand Medical Journal, 118(1218), 1-6. http://www.nzma.org.nz/journal/118/118-1218/1557/

Wu, L.-M., Chin, C.-C., Haase, J. E., \& Chen, C.-H. (2009). Coping experiences of adolescents with cancer: A qualitative study. Journal of Advanced Nursing, 65(11), 2358- 2366. doi:10.1111/j.1365-2648.2009.05097.x

Yap, J., Wesley, A., Mouat, S., \& Chin, S. (2008). Paediatric inflammatory bowel disease in New Zealand. The New Zealand Medical Journal, 121(1283), 1-8, http://journal.nzma.org.na/journal/121-1283/3287

Ziaian, T., Sawyer, M. G., Reynolds, K. E., Carbone, J. A., Clark, J. J., Baghurst, P. A., ...\& French, D. J. (2006). Treatment burden and health-related quality of life of children with diabetes, cystic fibrosis and asthma. Journal of Paediatrics and Child Health, 42(10), 596-600. doi:10.1111/j.1440-1754.2006.00943.x 


\section{APPENDICES}

Appendix 1: Introduction letter to Principals/Board of Trustees

Appendix 2: Information letter to Principal/Board of Trustees

Appendix 3: Consent from Principals/Board of Trustees

Appendix 4: Invitation/Information to Students

Appendix 5: Referral letter to Students from Staff

Appendix 6: Information letter to Parents/Caregivers

Appendix 7: Information sheet Interview/Focus Group for Students

Appendix 8: Consent form Interview/Focus Group Students

Appendix 9: Individual Semi-structured Interview/Focus Group/Questions for Students

Appendix 10: Information Sheet for Parents/Caregivers of Students under 16 Appendix 11: Consent form for Parents/Caregivers (Students under 16) Appendix 12: Confidentiality Research Assistant Agreement Appendix 13: Questionnaire Appendix 14: Examples of Codes with Definitions and Student Text Appendix 15: Definitions of Codes, Clusters, and Themes 


\section{APPENDIX 1: INTRODUCTION LETTER TO PRINCIPALS}

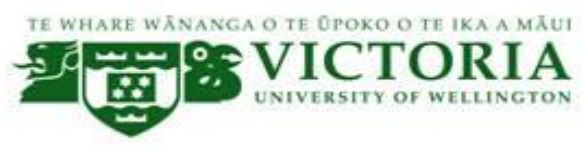

Dear Principal

I am an experienced Middle School teacher (7 years, Virginia certified, U.S.A.). I am currently a PhD student in the Faculty of Education, School of Educational Psychology and Pedagogy at Victoria University of Wellington. I am conducting a study which explores the perceptions of adolescent students with chronic illness such as asthma or diabetes and their teachers regarding their learning environment and how it supports these students to be academically successful.

I am asking adolescents with chronic illness from colleges throughout the Wellington area to take part in this study, beginning with a brief online survey. Apart from a 2-page report to participants and schools upon completion of my study, I am prepared to come to speak to the Board of Trustees, parent and whanau gatherings, and/or staff professional development about the findings of my study and the implications for various stakeholders. A study of this nature has not been published in New Zealand. As teachers and parents, we must know what is working to help students with asthma, diabetes, rheumatic fever, and other illnesses be academically successful and stay in school.

I have attached the Information sheet for School Principals and Boards of Trustees, Parents/Caregivers, Consent Forms, and copies of all other relevant forms for teachers, caregivers, and adolescents. This research has been assessed and approved by Victoria University Faculty of Education Ethics Committee.

I obtained information about your school through your school's website. I would greatly appreciate the opportunity to conduct my research with children in your school.

I look forward to meeting you and your school participating in this study.

Kind regards,

Mabél R. Hamon - PhD Student

School of Educational Psychology and Pedagogy,

Victoria University

Contact phone number: (04) 4635233 ext 8127 or 021522312

Email: mabel.hamon@vuw.ac.nz 


\title{
APPENDIX 2: INFORMATION SHEET FOR PRINCIPALS/BOARD OF TRUSTEES
}

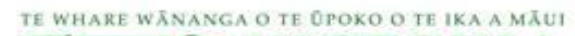

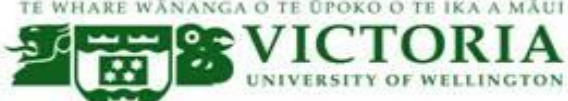 \\ THE LEARNING ENVIRONMENT FOR STUDENTS WITH CHRONIC \\ ILLNESS IN NEW ZEALAND \\ INFORMATION SHEET FOR PRINCIPALS AND/OR BOARDS OF \\ TRUSTEE (BOT)
}

\section{Date 18 April 2011}

I would like to invite students in your school to take part in a study of the learning environment for students with chronic illness in New Zealand. This study will look at what students' and staff/teachers' perceptions are regarding what is the students with chronic illness educational environment, what works in schools, how their learning is impacted by chronic illness (i.e., asthma, diabetes, rheumatic fever, head injury) and who provides what support for their educational success. This sheet will provide you with information so that you may make an informed choice about whether you will allow students and staff to take part or not. You are required to sign the consent form if you allow your school to participate.

The aim of this study is to gain increased knowledge and awareness of how a student with chronic illness and his or her teacher feel and interpret the chronic illness and instruction, describing this experience from his or her own point of view. There will be an online 10 minute confidential survey available separately for staff/teachers and students to take, at their leisure. By asking teachers and, separately, the students themselves about their experiences and perceptions, it provides us with opportunities to gather information that would otherwise not be available and to assist in continuing in providing strong foundations, services, and support for these students. It also recognizes teachers' and adolescents' rights to be heard and to have their opinions taken into account.

My name is Mabel Hamon. I am a PhD Student in the Faculty of Education at Victoria University of Wellington. I am an experienced Middle School teacher in the United States. Dr. Lex McDonald from Victoria University of Wellington is my Supervisor for this study. My decision to study this particular area is due to my personal experiences as a mother of two children with chronic illness as well as a teacher who has had several students with a variety of illnesses requiring different accommodations. A study of this nature has not been published in New Zealand. As teachers and parents, we must know what is working to help them be academically successful and stay in school.

I am asking staff/teachers and, separately, students with chronic illness from different Wellington colleges to take part in this study. Each group will be asked if they wish to participate further in a focus group and/or interview. Subsequently, if there are volunteers from your school, with your permission, I would like to conduct an interview in the school for approximately 1 hour. Interviews will be conducted separately, at the teachers' and students' convenience.

If participants volunteer for a focus group, the discussion will include various topics such as what impact has this condition had upon the student's learning, what aids the students to be academically successful. Interviews will expand on these questions. Staff/teachers and students 
do not have to take part in all the discussion topics, may say as little or as much as they wish, and may also stop participating at any point. All focus groups and interviews will be audio taped and participants will be able to review their transcript. Data collected in this study will be presented at conferences and in publications.

Your decision for your school to take part in this study is entirely voluntary. As the researcher, I will treat all information that is given me as confidential and no information which could personally identify anyone or the school will be used in any reports in this study. All the information collected from this study will be kept in a locked file cabinet in my office at Victoria University of Wellington. The information will be safely stored for 5 years after the study and will then be destroyed. Towards the end of this study, a 2-page report will be available to all participants and student's parents/caregivers, as well as the Principal and Board of Trustee members of the school.

\section{Any questions?}

If you have any queries or concerns regarding this study, contact details are below.

Thank you for your support.

Sincerely,

Mabel Hamon

Principal Investigator:

Mabel Hamon, PhD Student, School of Educational Psychology and Pedagogy, Karori Campus, Victoria University of Wellington, Tel: (04) 463-5233 x 8127.

Email: mabel.hamon@vuw.ac.nz.

Supervisor: Lex McDonald, Head of School, School of Educational Psychology and Pedagogy, Victoria University of Wellington, Tel: (04) 463-5173.

Email: lex.mcdonald@vuw.ac.nz

Jeff Sigafoos, School of Educational Psychology and Pedagogy, Victoria University of Wellington, Tel: (04) 463-9772

Email: jeff.sigafoos@vuw.ac.nz

This research has been assessed and approved by Victoria University Faculty of Education Ethics Committee. 


\title{
APPENDIX 3: CONSENT FROM PRINCIPALS/BOARD OF TRUSTEES
}

\author{
TE WHARE WRNANGA O TE OPOKO O TE IKA A MAUI \\ 5. \\ [X] $\because$ UNIVERSITY OF WELLINGTON \\ CONSENT FORM FOR SCHOOL PRINCIPALS AND/OR BOARDS OF \\ TRUSTEES (BOT) \\ Name of Study: The learning environment for students with chronic illness in New \\ Zealand: Students with chronic illness and their teachers' perceptions
}

Tick box

We have read and understand the information sheet (dated 25 March, 2011) for Principals and Boards of Trustees (BOT) of schools. We have had the opportunity to discuss this study. We are satisfied with the answers we have been given.

We understand that it is the student's choice to take part in the study and that he/she has to consent to participate. We also understand that he/she may withdraw from the study at any time.

We understand that in order for a student over the age of 16 to participate, their parent/caregiver may give their consent, but it is not necessary.

We understand that no reports from this study will be able to personally identify any student or the school which they attend.

We know that the discussions/interviews will be audio-taped.

We understand that the data collected will be presented at conferences and in publications.

We understand that this research will take place at school during and after school time.

We know who to contact if we have any questions about the study.

We have had time to consider whether to give our consent for the participation of students from this school.

We would like to receive a report about the study when it is finished YES/NO

(1) I .... ..(full name of Principal) and/or

(2) I of (full name of School) ..(full name of Member of BOT)

hereby consent to students from this school taking part in this study.

Date.

Signatures (1) and/or

\section{(2)}

Principals/Members of Boards of Trustees to keep a copy of this consent form See back of this sheet 
Principal Investigator:

Mabel Hamon, PhD Student, School of Educational Psychology and Pedagogy, Karori Campus, Victoria University of Wellington, Tel: (04) 463-5233 x 8127.

Email: mabel.hamon@vuw.ac.nz

Supervisors: Lex McDonald, Head of School, School of Educational Psychology and Pedagogy, Victoria University of Wellington, Tel: (04) 463-5173.

Email: lex.mcdonald@vuw.ac.nz

Jeff Sigafoos, School of Educational Psychology and Pedagogy, Victoria University of Wellington

Tel: (04) 463-9772 Email: jeff.sigafoos@vuw.ac.nz

This research has been assessed and approved by Victoria University Faculty of Education Ethics Committee. 


\section{APPENDIX 4: INVITATION/INFORMATION TO STUDENTS}

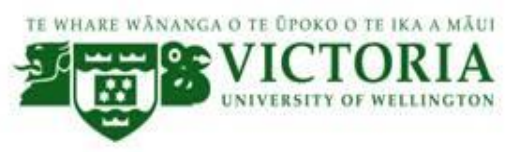

\section{Research Invitation Sheet for Students}

Researcher: Mabél R. Hamon: School of Education, Victoria University of Wellington

Hi! I'm an experienced middle school teacher in the United States and a PhD student at Victoria University of Wellington. I'm doing research for my $\mathrm{PhD}$ and want to learn about the learning environment of students who have an ongoing illness like asthma or diabetes or something that makes you miss school. I want to ask you and your teachers (separately) what you think about your experiences of learning when you're going through that. I'm inviting you to take part in this research. The decision to participate is up to you and you can change your mind about being involved at any time up until all the data is collected. I hope this study will help you and other students with illnesses as well as their teachers. I'm asking students and staff/teachers from different secondary schools in the Wellington region to take part in this study.

All research findings reported will be on an anonymous basis; this means your real name will not be used. Any information about you obtained during the survey will be kept confidential, only accessible by me, you, and my supervisors. The information will be kept securely at my office. There is no penalty for not participating or for withdrawing from participation at any stage.

If you agree to take part in this study, you can answer an online questionnaire, taking about 15 minutes It asks specific questions on your ideas about learning and who and what helps you learn. The URL for this survey is: http://vuw.qualtrics.com/SE/?SID=SV_bI6Zhk6iZfjK1b6

You'll be asked during the survey if you want to take part in a 1 hour focus group interview or one on one 1 hour interview. All volunteers for these will be randomly selected after the survey. All focus groups and interviews will be audio taped and you'll have the opportunity to review your transcript (what you have discussed). Focus groups and interviews will run about an hour and I'll provide snacks and non-alcoholic drinks. The data collected will be presented at conferences and in publications.

If you are interested in taking part in this research, you can go to the url attached and sign the attached consent form which you put in the envelope provided and drop off to the person who gave you this.

If you have any questions, feel free to call me at $+044635233 \times 8127$ or email me at mabel.hamon@vuw.ac.nz

You can also contact my supervisors, Dr. Jeff Sigafoos at Jeff.Sigafoos@ vuw.ac.nz or Dr. Lex McDonald at Lex.McDonald@ vuw.ac.nz for further information about the project.

Thank you,

Mabél R. Hamon

This research has been assessed and approved by Victoria University Faculty of Education Ethics Committee. 


\section{APPENDIX 5: REFERRAL LETTER TO STUDENTS FROM STAFF}

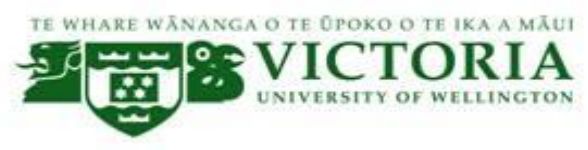

DATE

Dear

I was approached recently by a researcher named Mabél R. Hamon, from Victoria University of Wellington, who would like to involve a number of students in a research project on teenagers with chronic illness (i.e., asthma, diabetes) to learn how you see and understand your learning environment. There is a full explanation within this envelope and I am hoping that you will think about this project and discuss it with Mabél so that you may be a part of this study.

The entire study involves 3 phases, but you can choose to be involved in only the first phase, an online confidential survey which should only take about 10 or 15 minutes. If you like, you can also choose to be involved in a follow up focus group or an interview, or both. The beginning date of the online survey will be 25 May, 2011.

You must not feel obligated to do this, but I feel that the experience will do no harm and is a good opportunity for teenagers to engage in some thoughtful and worthwhile discussion about how illnesses have impacted their academic success. It also recognizes your rights to be heard and have your opinions taken into consideration.

There is also an information sheet and a consent form for you if you wish to take part.

Yours sincerely,

Principal Investigator: Mabel Hamon, PhD Student, School of Educational Psychology and Pedagogy, Victoria University of Wellington, Tel: (04) 463-5233 x 8127.

Email: mabel.hamon@vuw.ac.nz

Supervisor: Lex McDonald, Head of School, School of Educational Psychology and Pedagogy, Victoria University of Wellington, Tel: (04) 463-5173.

Email: lex.mcdonald@vuw.ac.nz

Jeff Sigafoos, School of Educational Psychology and Pedagogy, Victoria University of Wellington, Tel: (04) 463-9772

Email: jeff.sigafoos@vuw.ac.nz

This research has been assessed and approved by Victoria University Faculty of Education Ethics Committee. 


\title{
APPENDIX 6: INFORMATION LETTER TO PARENTS/CAREGIVERS
}

\author{
a

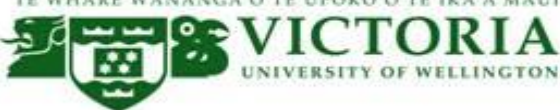

\section{THE LEARNING ENVIRONMENT FOR STUDENTS WITH CHRONIC ILLNESS IN NEW ZEALAND}

\section{INFORMATION SHEET FOR PARENTS/CAREGIVERS OF CHILDREN ASKED TO TAKE PART IN THE STUDY}

Date: 25 March, 2011

The Principal and/or Board of Trustees of your child's school have given me permission to approach students to take part in a study of the learning environment for students with chronic illness in New Zealand. Your child has been invited to participate in the study which will look at what their perceptions are regarding their learning environment, how their learning is impacted by chronic illness (asthma, diabetes, rheumatic fever, head injury, etc) and who provides what support for their academic success. This sheet will provide you with information so that you can discuss the study with your child and support them in making an informed choice about whether they want to take part or not. Although students 16 and older do not need parental consent if they wish to participate in a study, I do wish parents to be informed.

The aim of this study is to gain increased knowledge and awareness of how a student with chronic illness and his/her teacher feel about chronic illness in the learning environment, describing this experience from his or her own point of view. Asking students themselves and, separately, their teachers, about their experiences and perceptions, provides an opportunity to gather information that would otherwise not be available and can assist in providing strong foundations and improving services and support for these students. It also recognizes adolescents' rights to be heard and to have their opinions taken into account.

My name is Mabel Hamon. I'm a PhD Student in the Faculty of Education at Victoria University of Wellington. I am an experienced Middle School teacher in the United States. Dr. Lex McDonald from Victoria University of Wellington is my Supervisor for this study. My decision to study this particular area is due to my personal experiences as a mother of two children with chronic illness as well as a teacher who has had several students with a variety of illnesses requiring different accommodations. A study of this nature has not been published in New Zealand. As teachers and parents, we must know what is working to help them be academically successful and stay in school.

I am asking adolescents (aged between 16 and 19 years old) from different Wellington colleges to take part in this study as well as, separately, teachers and staff from their schools.

If your child agrees to participate in this study, he/she will be asked to answer a 10 minute online questionnaire asking specific questions on his/her perceptions of their education and learning environment, and can be done at any time in an 8 week period. Within the survey, there will be various questions including: what is your health condition, how long have you had it, what impact has this condition had upon your learning, if any. Students will also be asked if they wish to contribute further to the study, either in a focus group which will be held at school, an interview, or both. All focus groups and interviews will be audio taped and participants will be able to review their transcript. Your child may say as little or as much as they wish, and may also stop participating at any point. The data collected will be presented at conferences and in publications. The duration of this project will be 5 months, although your child is not required to participate any more than he/she chooses. Your child has also 
received an information sheet as well as a consent form. I hope that you will take time to discuss the study with your child so that they can make an informed decision. They are required to sign the consent form if they wish to participate in an interview or focus group. If they take part in the survey, they will be able to show their consent online.

Your child's decision to take part in this study is entirely voluntary (their choice). There is no penalty for not participating or for withdrawing from participation at any stage. As the researcher, I will treat all information that students give me as confidential and no information which may personally identify your child or the school they attend will be used in any reports in this study.

All the information collected from this study will be kept in a locked file cabinet in my office at Victoria University of Wellington. The information will be safely stored for 5 years after the study and will then be destroyed. Towards the end of this study, a 2-page report will be made available to all participants and their parents/caregivers, if they so desire, as well as the Principal and Board of Trustee members of the school.

\section{Any questions?}

If you have any queries or concerns regarding your rights or your child's rights as a participant in this study, please contact me to discuss the study further. My contact details are below.

Thank you for your support.

Sincerely,

\section{Mabel Hamon}

\section{Principal Investigator:}

Mabel Hamon, PhD Student, School of Educational Psychology and Pedagogy, Victoria University of Wellington, Tel: (04) 463-5233 x 8127.

Email: mabel.hamon@vuw.ac.nz

Supervisor: Lex McDonald, Head of School, School of Educational Psychology and Pedagogy, Victoria University of Wellington, Tel: (04) 463-5173.

Email: lex.mcdonald@vuw.ac.nz

Jeff Sigafoos, School of Educational Psychology and Pedagogy, Victoria University of Wellington, Tel: (04) 463-9772

Email: jeff.sigafoos@vuw.ac.nz

This research has been assessed and approved by Victoria University Faculty of Education Ethics Committee.

If you would like to receive a copy of the study when it is concluded, please write to me at mabel.hamon@vuw.ac.nz 


\section{APPENDIX 7: INFORMATION SHEET INTERVIEW/FOCUS GROUP STUDENTS}

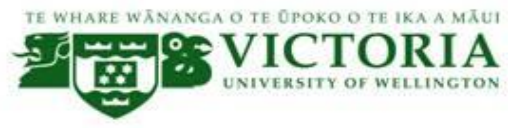

Interview/Focus Group Information Sheet for Student Participants

My name is Mabél R. Hamon and I'm a doctoral student at Victoria University of Wellington in New Zealand. I am doing research for my Ph.D. I want to examine the learning environment of students who are chronically ill (you have asthma or diabetes or something like that) and ask you and your teachers what you think about your experiences of learning when you are feeling unwell. In the online survey, you indicated that you would like to take part in an interview or focus group. You have received this information sheet as well as a consent form. Please read this sheet so you can make an informed decision. You are required to sign the consent form if you wish to take part.

Interview/Focus Group Information: Volunteers have all been randomly selected. If you are being interviewed, it will be about 1 hour, after school, or when we can set up a time. I'll ask you about different aspects of how you learn and how your illness may or may not have had an effect on how you learn. I'll also ask who or what has helped you learn and how you feel about it all. In the focus group, you may be part of a discussion group made up of up to 5 other students which will take approximately 1 hour, after school. You will all be talking about different topics continuing the discussion about how you learn, who or what has helped you learn and what you think and feel about it. All focus groups and interviews will be audio taped and you'll be able to review your transcript. You don't have to take part in all the discussion topics, may say as little or as much as you wish, and can also stop participating at any point.

All research findings reported will be on an anonymous basis; this means your real name will not be used. Any information obtained during the interview will be kept confidential, only accessible by me, you, and my supervisors. No information which could personally identify you or your school will be used in any reports in this study. The data collected will be presented at conferences and in publications. There is no penalty for not taking part or for withdrawing from the study at any time. All the information collected from this study will be kept in a locked file cabinet in my office at Victoria University of Wellington. The information will be safely stored for 5 years after the study and will then be destroyed. Towards the end of this study, a 2-page report will be made available to all participants and your parents/caregivers, if you or they so desire, as well as the Principal and Board of Trustee members of the school.

If you have any queries or concerns regarding your rights as a participant in this study, you may contact me or my supervisor. Details are posted below. This research has been assessed and approved by Victoria University Faculty of Education Ethics Committee. Thank you for being a part of this study.

Sincerely,

Mabel Hamon

School of Educational Psychology and Pedagogy, Victoria University of Wellington, Tel: (04) 463-5233 x 8127. Email: mabel.hamon@vuw.ac.nz

Supervisors: Lex McDonald, Head of School, School of Educational Psychology and

Pedagogy, Victoria University of Wellington, Tel: (04) 463-5173.

Email:lex.mcdonald@vuw.ac.nz

Jeff Sigafoos, School of Educational Psychology and Pedagogy, Victoria University of Wellington, Tel: (04) 463-9772 Email: jeff.sigafoos@ vuw.ac.nz 


\section{APPENDIX 8: CONSENT FORM INTERVIEW/FOCUS GROUP STUDENTS}

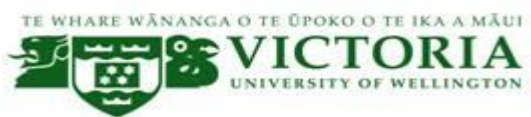

\section{CONSENT FORM FOR ADOLESCENTS (Focus Group or Interview) Name of Study: The learning environment for students with chronic illness in New Zealand; Students with chronic illness and their teachers' perceptions}

Tick box

I have read and I understand the information sheet for adolescent volunteers asked to participate in the study about students with chronic illness and my learning environment.

I have had the chance to talk it through and to ask questions so that I understand the study. I am satisfied with the answers I have been given.

I have had the chance to ask questions and to talk it through with my family/whanau.

I understand that it is my choice to take part in this study.

I understand that I can choose not to be part of the study at any time and that no one will mind what choice I make.

I understand that no one who hears or reads about this study will be able to tell who I am or which school I go to.

I know who to speak to if I am at all worried or have any questions about anything to do with this study.

I have had enough time to think about whether I want to take part in this study.

I understand that the data collected will be presented at conferences and in publications.

I understand that the focus group/interview will be audio-taped and may be transcribed by a professional who will sign an agreement to keep all information from the research confidential.

YES/NO (circle one) I would like to receive a report about the study when it is finished.

Date Signature

Adolescents keep a copy of the assent form.

Principal Investigator: Mabel Hamon, PhD Student, School of Educational Psychology and Pedagogy, Victoria University of Wellington, Tel: (04) 463-5233 x 8127.

Email: mabel.hamon@vuw.ac.nz

Supervisors: Lex McDonald, email: lex.mcdonald@vuw.ac.nz

Jeff Sigafoos, email: jeff.sigafoos@ vuw.ac.nzProject explained by: Mabél R. Hamon

This research has been assessed and approved by Victoria University Faculty of Education Ethics Committee. 


\section{APPENDIX 9: INDIVIDUAL SEMI-STRUCTURED INTERVIEW/FOCUS GROUP QUESTIONS FOR STUDENTS}

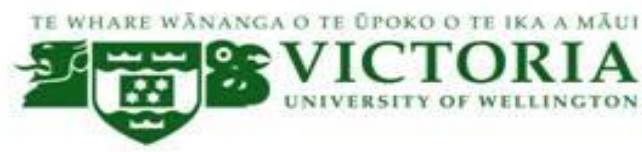

\section{THE LEARNING ENVIRONMENT FOR STUDENTS WITH CHRONIC ILLNESS IN NEW ZEALAND INDIVIDUAL SEMI-STRUCTURED INTERVIEWS/FOCUS GROUP QUESTIONS FOR STUDENTS}

\section{Preamble}

"Thank you for taking part in this study. I am doing research for my $\mathrm{PhD}$. I want to examine the learning environment for students who are chronically ill and ask you and, separately, your teachers what you think about your experiences of learning. This will increase the understanding of your experiences of what and who helps teens with chronic illness learn. The goal is to keep what is working and to build an educational environment that is helpful for you to continue to learn."

Introduction (Researcher and participant will discuss the following)

- Length of interview time

- Ground rules - confidentiality; the child's identity and school will not be identifiable in any reports on the study; note taking, audio taping and use of data; choice to answer questions or not

- Researcher will assist any participant who might, as a result of topics covered in the interview, want/need further support within/without the school by providing contact details of counsellors and help lines.

- Any questions participant might have.

The following questions have been developed as a general guide to facilitate the interview/focus group.

What do you think is your educational environment?

Who is involved in your educational environment?

What do you think is helpful in or around the school setting?

What works to help you be successful academically in or around the school setting?

What helps you be successful academically outside the school setting?

Who helps you be successful academically outside the school setting?

What influences/help your academic success?

How does it influence/help?

Who influences your academic success? (Is it family? Peer support? School staff? Health practitioners? Social workers/Psychologists?

How do you feel these individuals influence your academic success?

What health issues do you feel impacts your learning? How do they impact your learning?

What is your feeling about this/these issue(s)?

This research has been assessed and approved by Victoria University Faculty of Education Ethics Committee. 


\section{APPENDIX 10: INFORMATION SHEET FOR PARENTS/CAREGIVERS OF STUDENTS UNDER 16}

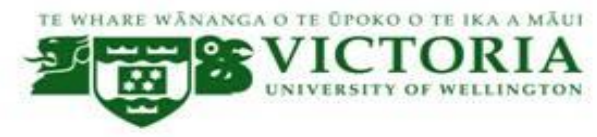

\section{THE LEARNING ENVIRONMENT FOR STUDENTS WITH CHRONIC ILLNESS IN NEW ZEALAND}

\section{INFORMATION SHEET FOR PARENTS/CAREGIVERS OF STUDENTS UNDER 16}

\section{Date 1 March 2012}

The Principal and/or Board of Trustees have given me permission to approach students to take part in a study of the learning environment for students with chronic illness in New Zealand. Your child has been invited to participate in the study which will look at what their perceptions are about their learning environment, what works in schools, how their learning is impacted by chronic illness (i.e., asthma, diabetes or another chronic illness) and who provides what support for their academic success. This sheet will provide you with information so you can discuss the study with your child and support them in making an informed choice about whether they want to take part or not. Students under 16 must have parental consent if they wish to take part. The consent form is attached.

The aim of this study is to learn how a student with chronic illness and his/her teacher feel about chronic illness in the learning environment, describing this experience from his or her own point of view. Asking the students themselves and, separately, their teachers, about their experiences and thoughts will provide an opportunity to gather information that would otherwise not be available. This will help in building strong foundations and improving services and support for these students. It also recognizes students' rights to be heard and to have their opinions taken into account.

My name is Mabel Hamon and I'm a PhD Student in the Faculty of Education at Victoria University of Wellington. I'm an experienced Middle School teacher in the United States. Dr. Lex McDonald and Dr. Jeff Sigafoos from Victoria University of Wellington are my Supervisors for this study. My decision to study this particular area is due to my personal experiences as a mother of two children with chronic illness as well as a teacher who has had several students with a variety of illnesses requiring different accommodations. A study of this nature has not been published in New Zealand and it is important to know what is working to help them be academically successful and stay in school.

I'm asking adolescents from Wellington region colleges to take part in this study as well as, separately, teachers and staff from their schools. However, students under 16 may participate if they choose to and have parental consent.

If your child agrees to participate in this study, he/she will be asked to answer an online 15 minute questionnaire asking specific questions on his/her perceptions of their education and learning environment. Students will also be asked if they wish to contribute further to the study, either in a focus group which will be held in school, an interview, or both. All focus groups and interviews will be audio taped and students will be able to look over what they've said. Your child may say as little or as much as they wish, and may also stop 
participating at any point. Data collected from this study will be presented at conferences and published.

Your child's decision to take part in this study is entirely their choice. There's no penalty for not participating or for withdrawing from participation at any stage. As the researcher, $\mathbf{I}$ will treat all information that students give me as confidential and no information which may personally identify your child or the school they attend will be used in any reports in this study.

All the information collected from this study will be kept in a locked file cabinet in my office at Victoria University of Wellington. The information will be safely stored for 5 years after the study and will then be destroyed. Towards the end of this study, a 2-page report will be made available to participants and their parents/caregivers, if they so desire, as well as the Principal and Board of Trustee members of the school.

If you have any questions or concerns regarding your rights or your child's rights as a participant in this study, you may contact me or my supervisor. Details are posted below.

I hope that you'll take time to discuss the study with your child so that they can make an informed decision.

Thank you for your support.

Mabel Hamon

\section{Principal Investigator:}

Mabel Hamon, PhD Student, School of Educational Psychology and Pedagogy, Victoria University of Wellington, Tel: (04) 463-5233 x 8127.

Email: mabel.hamon@vuw.ac.nz.

Supervisor: Lex McDonald, Head of School, School of Educational Psychology and Pedagogy, Victoria University of Wellington, Tel: (04) 463-5173.

Email: lex.mcdonald@vuw.ac.nz

Jeff Sigafoos, School of Educational Psychology and Pedagogy, Victoria University of Wellington, Tel: (04) 463-9772

Email: jeff.sigafoos@vuw.ac.nz

This research has been assessed and approved by Victoria University Faculty of Education Ethics Committee. 


\section{APPENDIX 11: CONSENT FORM FOR PARENTS/CAREGIVERS (STUDENTS UNDER 16)}

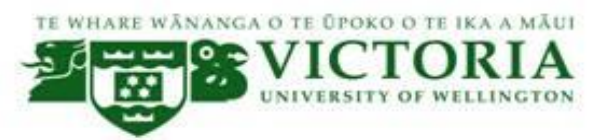

\section{CONSENT FORM FOR PARENTS/CAREGIVERS OF STUDENTS UNDER 16}

Name of Study: The learning environment for students with chronic illness in New Zealand: Students with chronic illness and their teachers' perceptions

Tick box

O I have read and understand the information sheet (dated 25 March, 2011) for parents/caregivers of students with chronic illness. I have had time to consider whether to give my consent for the participation of my child.

O I understand it is my child's choice to take part in the study and he/she has to consent to participate.

O I understand in order for a student under the age of 16 to participate, parental consent must be given. I also understand he/she may withdraw from the study at any time up to the end of data collection.

O I understand that no reports from this study will be able to personally identify any student or the school which they attend.

O I know the discussions/interviews will be audio-taped, may be transcribed by a professional who will sign an agreement to keep all information from the research confidential, and data collected will be presented at conferences and in publications.

I I understand this research will take place at school during and after school time.

I know who to contact if I have any questions about the study.

O I would like to receive a report about the study when it is finished

I .................................................. (printed full name of parent/caregiver) consent to my child taking part in this study.

(Signature) Date

Parent/caregiver to keep a copy of this consent form.

Principal Investigator: Mabel Hamon, PhD Student, School of Educational Psychology and Pedagogy, Karori Campus, Victoria University of Wellington, Tel: (04) 463-5233 x 8127. Email: mabel.hamon@vuw.ac.nz

Supervisors: Lex McDonald, Head of School, School of Educational Psychology and Pedagogy, Victoria University of Wellington, Tel: (04) 463-5173. Email: lex.mcdonald@vuw.ac.nz. Jeff Sigafoos, School of Educational Psychology and Pedagogy, Victoria University of Wellington Tel: (04) 463-9772 Email: jeff.sigafoos@vuw.ac.nz This research has been assessed and approved by Victoria University Faculty of Education Ethics Committee. 
APPENDIX 12: CONFIDENTIALITY RESEARCH ASSISTANT AGREEMENT

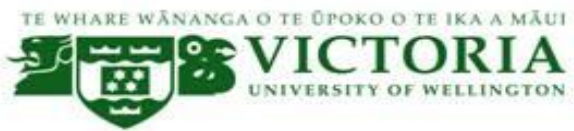

\section{CONFIDENTIALITY AGREEMENT FOR RESEARCH ASSISTANT}

$\mathrm{I}$, (Transcriber) agree to keep all information derived from my participation in the study entitled "THE LEARNING ENVIRONMENT FOR STUDENTS WITH CHRONIC ILLNESS IN NEW ZEALAND" confidential to myself and the Researcher, Mabel Hamon.

I also agree to take all possible precautions at every stage of research to guarantee the participant anonymity as indicated in their Consent Forms.

This undertaking includes all aspects of the gathering, handling, storage and publication of research materials during and subsequent to the research.

Mabel Hamon

Researcher

Transcriber

Date:

Date

This research has been assessed and approved by Victoria University Faculty of Education Ethics Committee. 


\section{APPENDIX 13: QUESTIONNAIRE FOR ADOLESCENTS THE LEARNING ENVIRONMENT FOR STUDENTS WITH CHRONIC ILLNESS IN NEW ZEALAND}

Thank you for taking part in this study. I want to increase our understanding of adolescents' perceptions of what and who helps teens with chronic illness learn. This will help us continue to build an educational environment that is productive for your learning.

This survey will take about $10-15$ minutes to complete and is confidential: you will not be identified. The results of this study will be shared with schools and presented at conferences and in publications. This research has been assessed and approved by Victoria University Faculty of Education Ethics Committee.

Taking part in this survey signals your consent. Click >> to begin.

This section asks about how you feel about practices that or people who may be helpful to you in school.

\begin{tabular}{|c|c|c|c|c|c|}
\hline $\begin{array}{l}\text { I feel I can talk about my } \\
\text { illness with my teacher }\end{array}$ & Always & Jften & Sometimes & Never & $\begin{array}{l}\text { Don't } \\
\text { know }\end{array}$ \\
\hline $\begin{array}{l}\text { I feel there are times I } \\
\text { can talk about my } \\
\text { progress in school with } \\
\text { my teachers }\end{array}$ & Yes & No & Not relevant & $\begin{array}{l}\text { Don't } \\
\text { know }\end{array}$ & \\
\hline $\begin{array}{l}\text { I feel my teacher helps } \\
\text { me with schoolwork } \\
\text { when I'm absent }\end{array}$ & Always & Often & Sometimes & Never & $\begin{array}{l}\text { Don't } \\
\text { know }\end{array}$ \\
\hline $\begin{array}{l}\text { I feel my teacher gives } \\
\text { me extra help at school. }\end{array}$ & Always & Often & Sometimes & Never & $\begin{array}{l}\text { Don't } \\
\text { know }\end{array}$ \\
\hline $\begin{array}{l}\text { I feel my teachers give } \\
\text { me extra time to } \\
\text { complete tasks }\end{array}$ & Always & Often & Sometimes & Never & $\begin{array}{l}\text { Don't } \\
\text { know }\end{array}$ \\
\hline $\begin{array}{l}\text { I feel my teachers give } \\
\text { me extra explanations if I } \\
\text { ask for them }\end{array}$ & Always & Often & Sometimes & Never & $\begin{array}{l}\text { Don't } \\
\text { know }\end{array}$ \\
\hline $\begin{array}{l}\text { I get extra help from a } \\
\text { visiting teacher }\end{array}$ & Yes & No & & & \\
\hline $\begin{array}{l}\text { I feel my teachers } \\
\text { motivate me to do my } \\
\text { best }\end{array}$ & Always & Often & Sometimes & Never & $\begin{array}{l}\text { Don't } \\
\text { know }\end{array}$ \\
\hline $\begin{array}{l}\text { I feel my teachers have } \\
\text { reasonable expectations } \\
\text { of my ability }\end{array}$ & Always & Often & Sometimes & Never & $\begin{array}{l}\text { Don't } \\
\text { know }\end{array}$ \\
\hline $\begin{array}{l}\text { I feel my teachers know } \\
\text { how my illness affects } \\
\text { me in school }\end{array}$ & Yes & No & Don't know & & \\
\hline $\begin{array}{l}\text { I feel my teachers } \\
\text { encourage me }\end{array}$ & Always & Often & Sometimes & Never & $\begin{array}{l}\text { Don't } \\
\text { know }\end{array}$ \\
\hline $\begin{array}{l}\text { There is a special } \\
\text { arrangement available }\end{array}$ & Always & Often & Sometimes & No & $\begin{array}{l}\text { Not } \\
\text { relevant }\end{array}$ \\
\hline
\end{tabular}




\begin{tabular}{|c|c|c|c|c|c|}
\hline $\begin{array}{l}\text { for me when I sit for } \\
\text { tests or exams }\end{array}$ & & & & & \\
\hline $\begin{array}{l}\text { There is a computer is } \\
\text { available to me when I } \\
\text { need it for school work. }\end{array}$ & Always & Often & Sometimes & No & $\begin{array}{l}\text { Not } \\
\text { relevant }\end{array}$ \\
\hline $\begin{array}{l}\text { There is special } \\
\text { equipment available that } \\
\text { I need when I need it. }\end{array}$ & Always & Often & Sometimes & No & $\begin{array}{l}\text { Not } \\
\text { relevant }\end{array}$ \\
\hline $\begin{array}{l}\text { There is individual class } \\
\text { work especially to suit } \\
\text { my specific needs }\end{array}$ & Always & Often & Sometimes & No & $\begin{array}{l}\text { Not } \\
\text { relevant }\end{array}$ \\
\hline $\begin{array}{l}\text { I feel I attend every class } \\
\text { and activity that I want. }\end{array}$ & Always & Often & Sometimes & No & $\begin{array}{l}\text { Not } \\
\text { relevant }\end{array}$ \\
\hline $\begin{array}{l}\text { I feel my teacher asks } \\
\text { me how to make my life } \\
\text { easier in school }\end{array}$ & Always & Often & Sometimes & No & $\begin{array}{l}\text { Not } \\
\text { relevant }\end{array}$ \\
\hline $\begin{array}{l}\text { There is a school nurse in } \\
\text { my school }\end{array}$ & Always & $\begin{array}{l}\text { Sometimes } \\
\text { (please tell me } \\
\text { when) }\end{array}$ & No & & \\
\hline $\begin{array}{l}\text { a. I see the school nurse } \\
\text { in my school }\end{array}$ & Every day & $\begin{array}{l}\text { Whenever I need } \\
\text { to (please } \\
\text { specify) }\end{array}$ & & & \\
\hline $\begin{array}{l}\text { I feel I can talk about my } \\
\text { illness with the nurse }\end{array}$ & Always & Often & Sometimes & Never & $\begin{array}{l}\text { Don't } \\
\text { know }\end{array}$ \\
\hline $\begin{array}{l}\text { I feel the nurse } \\
\text { understands me }\end{array}$ & Always & Often & Sometimes & Never & $\begin{array}{l}\text { Don't } \\
\text { know }\end{array}$ \\
\hline $\begin{array}{l}\text { I feel the nurse helps me } \\
\text { when I need it }\end{array}$ & Always & Often & Sometimes & Never & $\begin{array}{l}\text { Don't } \\
\text { know }\end{array}$ \\
\hline $\begin{array}{l}\text { There is a counsellor in } \\
\text { my school }\end{array}$ & Yes & No & & & \\
\hline $\begin{array}{l}\text { I meet with the } \\
\text { counsellor in my school }\end{array}$ & Yes & No & & & \\
\hline $\begin{array}{l}\text { a. (if yes) How often do } \\
\text { you see the } \\
\text { counsellor? }\end{array}$ & $\begin{array}{l}\text { Regularly } \\
\text { (please } \\
\text { specify) }\end{array}$ & $\begin{array}{l}\text { Whenever I need } \\
\text { to (please } \\
\text { explain) }\end{array}$ & Never & $\begin{array}{l}\text { Other } \\
\text { (Please } \\
\text { explain) }\end{array}$ & \\
\hline $\begin{array}{l}\text { b. I can talk to the } \\
\text { counsellor about how I } \\
\text { feel about my illness }\end{array}$ & Always & Often & Sometimes & Never & $\begin{array}{l}\text { Don't } \\
\text { know }\end{array}$ \\
\hline $\begin{array}{l}\text { I am invited to attend } \\
\text { review meetings }\end{array}$ & Always & Often & Sometimes & No & $\begin{array}{l}\text { Not } \\
\text { relevant }\end{array}$ \\
\hline $\begin{array}{l}\text { When I attend review } \\
\text { meetings, I am } \\
\text { encouraged to express } \\
\text { my views }\end{array}$ & Always & Often & Sometimes & No & $\begin{array}{l}\text { Not } \\
\text { relevant }\end{array}$ \\
\hline
\end{tabular}

This section asks about you and your illness

\begin{tabular}{|l|l|l|l|l|l|}
\hline $\begin{array}{l}\text { What chronic illness do you } \\
\text { have? }\end{array}$ & & & & & \\
\hline How long have you had it? & & & & & \\
\hline $\begin{array}{l}\text { What kinds of medicines do } \\
\text { you take for it/them? }\end{array}$ & & & & & \\
\hline $\begin{array}{l}\text { When do you take these } \\
\text { medicines? }\end{array}$ & Once a day & Twice a day & $\begin{array}{l}\text { Once a } \\
\text { week }\end{array}$ & $\begin{array}{l}\text { Once a } \\
\text { month }\end{array}$ & $\begin{array}{l}\text { when } \\
\text { needed } \\
\text { (please } \\
\text { specify) }\end{array}$ \\
\hline
\end{tabular}




\begin{tabular}{|c|c|c|c|c|c|}
\hline $\begin{array}{l}\text { Where do you take these } \\
\text { medicines (tick all that apply) }\end{array}$ & At home & In school & $\begin{array}{l}\text { In a clinic } \\
\text { outside of } \\
\text { school }\end{array}$ & & \\
\hline \multicolumn{6}{|l|}{$\begin{array}{l}\text { How long have you been } \\
\text { taking this medication? }\end{array}$} \\
\hline Do you feel any side effects? & Yes & No & & & \\
\hline $\begin{array}{l}\text { a. If so, what are they? (tick } \\
\text { all that apply) }\end{array}$ & Headache & Blurry vision & Drowsiness & $\begin{array}{l}\text { Hard to } \\
\text { concentrate } \\
\text { /Upset } \\
\text { stomach }\end{array}$ & $\begin{array}{l}\text { Other } \\
\text { (please } \\
\text { specify) }\end{array}$ \\
\hline $\begin{array}{l}\text { I am involved in activities } \\
\text { outside of school }\end{array}$ & Yes & No & & & \\
\hline $\begin{array}{l}\text { Do you feel your illness } \\
\text { affects you in school? }\end{array}$ & Yes & No & Unsure & & \\
\hline \multicolumn{6}{|l|}{$\begin{array}{l}\text { If yes, how does it affect you } \\
\text { in school? }\end{array}$} \\
\hline $\begin{array}{l}\text { Do you feel your illness } \\
\text { affects how you learn? }\end{array}$ & Yes & No & Unsure & & \\
\hline \multicolumn{6}{|l|}{$\begin{array}{l}\text { Describe briefly how you feel } \\
\text { your illness affects how you } \\
\text { learn }\end{array}$} \\
\hline $\begin{array}{l}\text { I am responsible for taking the } \\
\text { needed treatment (medicine) }\end{array}$ & Yes & No & & & \\
\hline $\begin{array}{l}\text { I am involved in managing my } \\
\text { treatment (making decisions } \\
\text { about my treatment) }\end{array}$ & Always & Usually & Sometimes & Never & \\
\hline $\begin{array}{l}\text { I can talk to my parents about } \\
\text { managing my treatment }\end{array}$ & Always & Usually & Sometimes & Never & \\
\hline $\begin{array}{l}\text { I have dreams for my future } \\
\text { after college }\end{array}$ & Yes & No & & & \\
\hline $\begin{array}{l}\text { I feel confident about my } \\
\text { future after college }\end{array}$ & $\begin{array}{l}\text { Very } \\
\text { confiden } \\
\mathrm{t}\end{array}$ & $\begin{array}{l}\text { Quite } \\
\text { confident }\end{array}$ & $\begin{array}{l}\text { Not } \\
\text { confident }\end{array}$ & Don't know & \\
\hline I have an interest in & $\begin{array}{l}\text { Helping } \\
\text { others }\end{array}$ & $\begin{array}{l}\text { Being in the } \\
\text { medical } \\
\text { profession }\end{array}$ & $\begin{array}{l}\text { Being an } \\
\text { educator }\end{array}$ & $\begin{array}{l}\text { Other } \\
\text { (please } \\
\text { specify) }\end{array}$ & \\
\hline
\end{tabular}

This next section asks about you and your relationship with friends/peers

\begin{tabular}{|l|l|l|l|l|l|}
\hline $\begin{array}{l}\text { My friends think my illness is } \\
\text { contagious }\end{array}$ & Yes & No & & \\
\hline $\begin{array}{l}\text { My friends think I am fun to } \\
\text { hang out with }\end{array}$ & Always & Sometimes & Usually & No & Unsure \\
\hline $\begin{array}{l}\text { Some of my schoolmates } \\
\text { seem reluctant to be my } \\
\text { friend }\end{array}$ & $\begin{array}{l}\text { Very } \\
\text { reluctant }\end{array}$ & $\begin{array}{l}\text { A bit } \\
\text { reluctant }\end{array}$ & $\begin{array}{l}\text { Not at all } \\
\text { reluctant }\end{array}$ & Unsure & \\
\hline $\begin{array}{l}\text { I feel my friends are loyal } \\
\text { Very } \\
\text { confident }\end{array}$ & $\begin{array}{l}\text { Quite } \\
\text { confident }\end{array}$ & Unconfident & $\begin{array}{l}\text { Don't } \\
\text { know }\end{array}$ & Never & $\begin{array}{l}\text { Don't } \\
\text { know/no } \\
\text { t } \\
\text { applicabl } \\
\text { e }\end{array}$ \\
\hline $\begin{array}{l}\text { I feel like I can talk about my with friends at school } \\
\text { illways }\end{array}$ & Often & Sometimes & Nen't \\
know/ \\
\hline $\begin{array}{l}\text { I feel my friends help me with } \\
\text { schoolwork when I'm absent }\end{array}$ & ys Alwa & Often & Sometimes & Never & Don't \\
\hline
\end{tabular}




\begin{tabular}{|c|c|c|c|c|c|}
\hline & & & & & $\begin{array}{l}\text { Not } \\
\text { applica- } \\
\text { ble }\end{array}$ \\
\hline I belong to a support group & Yes & No & & & \\
\hline a. I attend meetings & $\begin{array}{c}\text { Once a } \\
\text { week }\end{array}$ & $\begin{array}{l}\text { Once a } \\
\text { month }\end{array}$ & Occasionally & $\begin{array}{l}\text { It's hard } \\
\text { for me to } \\
\text { attend } \\
\text { meetings }\end{array}$ & \\
\hline \multicolumn{6}{|l|}{$\begin{array}{ll}\text { b. } & \text { (if there is } \\
\text { difficulty) } & \text { Why is it hard? }\end{array}$} \\
\hline $\begin{array}{l}\text { I feel my friends motivate me } \\
\text { to do my best }\end{array}$ & Always & Often & Sometimes & Never & $\begin{array}{c}\text { Don't } \\
\text { know }\end{array}$ \\
\hline $\begin{array}{l}\text { My friends have reasonable } \\
\text { expectations of my ability } \\
\text { when we do things outside of } \\
\text { school }\end{array}$ & Always & Often & Sometimes & Never & $\begin{array}{l}\text { Don't } \\
\text { know }\end{array}$ \\
\hline $\begin{array}{l}\text { I feel like my friends know } \\
\text { how my illness affects me in } \\
\text { school }\end{array}$ & Yes & No & Don't know & & \\
\hline My friends encourage me & Always & Often & Sometimes & Never & $\begin{array}{l}\text { Don't } \\
\text { know }\end{array}$ \\
\hline
\end{tabular}

This part is about you and your life outside of school.

\begin{tabular}{|c|c|c|c|c|c|}
\hline $\begin{array}{l}\text { I am involved in activities } \\
\text { outside of school }\end{array}$ & Yes & No & & & \\
\hline After school I usually & $\begin{array}{l}\text { Hang out } \\
\text { with } \\
\text { friends }\end{array}$ & $\begin{array}{l}\text { Play on a } \\
\text { team }\end{array}$ & Go home & \multicolumn{2}{|c|}{$\begin{array}{l}\text { Other (please tell me } \\
\text { what it is) }\end{array}$} \\
\hline $\begin{array}{l}\text { My parent/ } \\
\text { caregiver(s) helps me with } \\
\text { schoolwork when I'm } \\
\text { absent }\end{array}$ & Always & Often & Sometimes & Never & $\begin{array}{l}\text { Don't } \\
\text { know }\end{array}$ \\
\hline $\begin{array}{l}\text { I feel my parent/ } \\
\text { caregiver(s) motivate me to } \\
\text { do my best }\end{array}$ & Always & Often & Sometimes & Never & $\begin{array}{l}\text { Don't } \\
\text { know }\end{array}$ \\
\hline $\begin{array}{l}\text { I feel my parent/ } \\
\text { caregiver(s) worry about my } \\
\text { health }\end{array}$ & Always & Often & Sometimes & \multicolumn{2}{|c|}{ Other (please explain) } \\
\hline $\begin{array}{l}\text { I feel my siblings (brother } \\
\text { and/or sister) understand } \\
\text { my illness }\end{array}$ & Always & Often & Sometimes & Never & $\begin{array}{l}\text { Don't } \\
\text { know }\end{array}$ \\
\hline $\begin{array}{l}\text { feel my parent/caregiver(s) } \\
\text { have reasonable } \\
\text { expectations of my ability }\end{array}$ & Always & Often & Sometimes & Never & $\begin{array}{l}\text { Don't } \\
\text { know }\end{array}$ \\
\hline $\begin{array}{l}\text { My parent/ caregiver(s) } \\
\text { know how my illness affects } \\
\text { me in school }\end{array}$ & Yes & No & Don't know & & \\
\hline My siblings encourage me & Always & Often & Sometimes & Never & $\begin{array}{l}\text { Don't } \\
\text { know }\end{array}$ \\
\hline $\begin{array}{l}\text { I think it is hard for my } \\
\text { siblings to understand about } \\
\text { my health }\end{array}$ & Yes & No & Sometimes & & \\
\hline
\end{tabular}

This section asks about you and is the last part. Please remember that this survey is confidential and will be used for my research analysis. 
This section asks about you.

\begin{tabular}{|c|c|c|c|c|c|}
\hline $\mathrm{Iam}$ & Male & Female & & & \\
\hline In school I am in year & 10 & 11 & 12 & 13 & $\begin{array}{l}\text { Other (please } \\
\text { tell me what it } \\
\text { is) }\end{array}$ \\
\hline I go to a a & $\begin{array}{l}\text { Co-ed } \\
\text { school }\end{array}$ & $\begin{array}{l}\text { Boys' } \\
\text { school }\end{array}$ & $\begin{array}{l}\text { Girls' } \\
\text { school }\end{array}$ & & \\
\hline It is a & $\begin{array}{l}\text { Public } \\
\text { school }\end{array}$ & $\begin{array}{l}\text { Private } \\
\text { school }\end{array}$ & & & \\
\hline I am & 16 yrs old & $\begin{array}{l}17 \text { yrs } \\
\text { old }\end{array}$ & 18 yrs old & 19 yrs old & $\begin{array}{l}\text { Other (please } \\
\text { state age) }\end{array}$ \\
\hline $\begin{array}{l}\text { I live with my (check all } \\
\text { that apply) }\end{array}$ & Mother & Father & Stepmother & Stepfather & $\begin{array}{l}\text { Other (please } \\
\text { specify) }\end{array}$ \\
\hline $\begin{array}{l}\text { Which ethnic group do } \\
\text { you belong to? } \\
\text { Tick the box or boxes } \\
\text { which apply to you. } \\
\text { NZ } \\
\text { European } \\
\text { Māori } \\
\text { Samoan } \\
\text { Cook Island Māori } \\
\text { Tongan } \\
\text { Niuean } \\
\text { Chinese } \\
\text { Indian } \\
\text { other (such as DUTCH, } \\
\text { JAPANESE, TOKELAUAN). } \\
\text { Please state. }\end{array}$ & & & & & \\
\hline \begin{tabular}{lr}
\multicolumn{1}{c}{ How } & many \\
sister(s)/brother(s) & do \\
you have? &
\end{tabular} & & & & & \\
\hline \multicolumn{6}{|l|}{ sisters } \\
\hline \multicolumn{6}{|l|}{ brothers } \\
\hline \multicolumn{6}{|l|}{ stepsisters } \\
\hline \multicolumn{6}{|l|}{ stepbrothers } \\
\hline \multicolumn{6}{|l|}{ Other (please specify) } \\
\hline $\begin{array}{l}\text { Do you have any siblings } \\
\text { with an illness? }\end{array}$ & Yes & No & & & \\
\hline \multicolumn{6}{|l|}{$\begin{array}{l}\text { a. What illness does } \\
\text { your sibling have? }\end{array}$} \\
\hline $\begin{array}{l}\text { b. Do your } \\
\text { caregivers work outside } \\
\text { your home? }\end{array}$ & Yes & No & & & \\
\hline
\end{tabular}

Thanks so much for answering these questions! If you would like to talk with me more about this - be interviewed or be a part of a focus group - please follow the directions below.

Please enter your email address if you would like to be interviewed.

Please enter your email address if you would like to take part in a focus group.

Thank you for taking time to participate in this study! This will help us continue to build a learning environment that works for you! 


\section{APPENDIX 14: EXAMPLES OF CODES WITH DEFINITIONS AND STUDENT TEXT}

\begin{tabular}{|c|c|c|}
\hline Diagnosis & Discovering this is a CHC, what it is, testing for it. & $\begin{array}{l}\text { Bridget: I was diagnosed at the end of year } 6 \text { and then in } \\
\text { year } 7 \text { was when thing, kind of happening for it, so I } \\
\text { went to specialists and all of that. }\end{array}$ \\
\hline It's Hard & $\begin{array}{l}\text { Effect of CHC on cognitive abilities such as impaired } \\
\text { concentration, inability to focus. }\end{array}$ & $\begin{array}{l}\text { James: a lot of times it was difficult for me to } \\
\text { concentrate. }\end{array}$ \\
\hline Responsibility & $\begin{array}{l}\text { Managing/dealing with different impacts of the CHC } \\
\text { such as taking rest when needing, making academic } \\
\text { progress in spite of } \mathrm{CHC} \text { and its effects. }\end{array}$ & $\begin{array}{l}\text { James: If I got too tired from the headaches, I could go } \\
\text { rest, go to sickbay, I could go home. }\end{array}$ \\
\hline "Missing out" & $\begin{array}{l}\text { Not being able to be in class, learn, do activities, be with } \\
\text { friends, and/or being limited in what one can do because } \\
\text { of CHC. }\end{array}$ & $\begin{array}{l}\text { Bart: I was missing out mainly a lot on English } \\
\text { Bridget: missing class is quite difficult sometimes } \\
\text { because you do have to catch up and understand it. }\end{array}$ \\
\hline $\begin{array}{l}\text { "I can manage } \\
\text { myself" }\end{array}$ & Self-monitoring and being self-reliant. & $\begin{array}{l}\text { Andrew: she doesn't know anything big about diabetes } \\
\text { so I just manage myself. }\end{array}$ \\
\hline Safe & $\begin{array}{l}\text { Feeling valued, respected, protected from ridicule, } \\
\text { negative judgement, physical attack from others possibly } \\
\text { due to } \mathrm{CHC} \text {, but not always. }\end{array}$ & $\begin{array}{l}\text { Mark: You feel safe with your peers, the peers that really } \\
\text { respect you and you're safe with the teachers that want to } \\
\text { help you with your education. }\end{array}$ \\
\hline Different & $\begin{array}{l}\text { Student's perception that appearance, ability to } \\
\text { concentrate or learn, more absences, and illness makes } \\
\text { the student different than those without a CHC }\end{array}$ & $\begin{array}{l}\text { Luke: In the past at primary school I remember when } \\
\text { people found out they used to just, not treat me the same } \\
\text { as before because I had ADHD. }\end{array}$ \\
\hline "Suck it up" & $\begin{array}{l}\text { The message the student perceives from teacher if he/she } \\
\text { has physical pain or cognitive issues because of CHC. } \\
\text { This includes teacher lack of knowledge, non- } \\
\text { understanding of CHC and/or student's needs. }\end{array}$ & $\begin{array}{l}\text { Bridget: but some of the other teachers would be like } \\
\text { suck it up and do what you're supposed to be doing. } \\
\text { Esau: the teachers were getting very cross with me that I } \\
\text { didn't understand things. They just thought that I was } \\
\text { lazy and stuff }\end{array}$ \\
\hline Bullying & $\begin{array}{l}\text { Names/labels given to students because of CHC or } \\
\text { bullying. }\end{array}$ & $\begin{array}{l}\text { Luke: make fun of me for having it and stuff and saying } \\
\text { oh that I was mental }\end{array}$ \\
\hline
\end{tabular}




\section{APPENDIX 15: DEFINITIONS OF CODES, CLUSTERS, AND THEMES}

\begin{tabular}{|c|c|c|c|c|}
\hline & Definition of Individual Code & Code & Cluster and Definition & Theme \\
\hline 1. & $\begin{array}{l}\text { Where students learn varies: home, school, activities. } \\
\text { Acquisition, understanding, application of knowledge and can } \\
\text { occur in a social constructive setting. }\end{array}$ & $\begin{array}{l}\text { Learning Environment } \\
\text { Learning }\end{array}$ & \multirow{4}{*}{$\begin{array}{l}\text { Learning Environment- } \\
\text { Where students with } \\
\text { chronic health conditions } \\
\text { learn and the participants } \\
\text { in this environment, } \\
\text { including teachers and } \\
\text { learners. }\end{array}$} & \multirow{4}{*}{$\begin{array}{l}\text { Learning } \\
\text { environment and } \\
\text { participants: who } \\
\text { is involved in } \\
\text { learning and } \\
\text { where does it } \\
\text { occur. }\end{array}$} \\
\hline 2. & $\begin{array}{l}\text { Learners are student and classmates who are discovering } \\
\text { knowledge from those who know more than they do. }\end{array}$ & $\begin{array}{l}\text { Participants in } \\
\text { Learning Environment }\end{array}$ & & \\
\hline 3. & $\begin{array}{l}\text { Knowledge is taught/given to learners by-teachers, parents, } \\
\text { coaches. }\end{array}$ & Learners & & \\
\hline 4. & Teachers are adults who have knowledge to impart. & Teachers & & \\
\hline 5. & Discovering there is a CHC, what it is, testing for it. & Diagnosis & \multirow{6}{*}{$\begin{array}{l}\text { CHC Experience-the } \\
\text { process, individuals, } \\
\text { impact that the student } \\
\text { with CHC has } \\
\text { experienced regarding } \\
\text { the CHC itself. }\end{array}$} & \multirow{6}{*}{$\begin{array}{l}\text { The Chronic } \\
\text { Health } \\
\text { Experience: } \\
\text { Experiences of } \\
\text { the process and } \\
\text { impact of others } \\
\text { regarding the } \\
\text { CHC itself. }\end{array}$} \\
\hline 6. & $\begin{array}{l}\text { Nurses, technicians, general practitioners \& specialists involved in } \\
\text { diagnosing, assisting, guiding, prescribing, treating CHC. }\end{array}$ & Health Providers & & \\
\hline 7. & $\begin{array}{l}\text { Description and effects of Treatment of/for various CHC. Needing } \\
\text { to try variations of treatment to accommodate individual student. }\end{array}$ & Treatment & & \\
\hline 8. & $\begin{array}{l}\text { Effect of CHC on student's cognitive abilities such as impaired } \\
\text { concentration, inability to focus. }\end{array}$ & Cognitive Impact & & \\
\hline 9. & Physical effects of CHC on student, i.e., pain, fatigue, lack of sleep. & Physical Impact & & \\
\hline 10. & $\begin{array}{l}\text { Emotional effects of CHC on student's psyche such as annoyance, } \\
\text { embarrassment, frustration, grumpiness, shock, upset. }\end{array}$ & Psychosocial & & \\
\hline 11. & $\begin{array}{l}\text { Receiving recognition, acknowledgement, and a favorable reception } \\
\text { from others of CHC as well as within self. }\end{array}$ & Acceptance of CHC & \multirow{5}{*}{$\begin{array}{l}\text { Adaptation-the positive } \\
\text { process of changing to fit } \\
\text { the situation of being a } \\
\text { student with CHC. }\end{array}$} & \multirow{5}{*}{$\begin{array}{l}\text { It's Part of My } \\
\text { Personality: The } \\
\text { student with CHC } \\
\text { sees the CHC as a } \\
\text { part of his or her } \\
\text { life, not the whole } \\
\text { of it. }\end{array}$} \\
\hline 12. & $\begin{array}{l}\text { Personal accountability, reliability for taking medications or } \\
\text { learning. }\end{array}$ & Responsibility & & \\
\hline 13. & $\begin{array}{l}\text { Incentive, inspiration, personal drive or enthusiasm to learn } \\
\text { necessary material in school. }\end{array}$ & Future Plans & & \\
\hline 14. & $\begin{array}{l}\text { Knowing the impact of } \mathrm{CHC} \text {, getting used to, and making } \\
\text { necessary changes to deal with the impact. }\end{array}$ & Adjusting & & \\
\hline 15 . & $\begin{array}{l}\text { CHC symptoms manageable, making academic progress in spite of } \\
\text { CHC \& its effects. Managing and dealing with the different impacts } \\
\text { of the CHC such as taking rest when needed. }\end{array}$ & Managing & & \\
\hline 16. & $\begin{array}{l}\text { No one reacting in agitated or worrisome manner regarding } \mathrm{CHC} \text {, } \\
\text { Minimum reaction, no big fuss. }\end{array}$ & "No Big Deal" & It's not a big deal & \multirow[t]{2}{*}{$\begin{array}{l}\text { It's part of my } \\
\text { personality }\end{array}$} \\
\hline 17. & $\begin{array}{l}\text { Student's experience of CHC of no impact of CHC on self, learning } \\
\text { environment, learning, being with friends/peers/others his/her age. }\end{array}$ & "Normal" & Normal & \\
\hline
\end{tabular}




\begin{tabular}{|c|c|c|c|c|}
\hline 18. & $\begin{array}{l}\text { Student is the same as friend/peers, knows CHC has some impact } \\
\text { (i.e., taking medication, being in a wheelchair, testing blood sugar). }\end{array}$ & $\begin{array}{l}\text { Same but Different } \\
\text { Normal }\end{array}$ & $\begin{array}{l}\text { It's part of my } \\
\text { personality }\end{array}$ & $\begin{array}{l}\text { It's part of my } \\
\text { personality }\end{array}$ \\
\hline \multirow[t]{2}{*}{19.} & \multirow{2}{*}{$\begin{array}{l}\text { Student describe trying to get missed knowledge as work. Having } \\
\text { to make up work missed due to CHC (effects, absence, appts., etc.). }\end{array}$} & One more thing & \multirow[t]{2}{*}{ One more thing } & \multirow{5}{*}{$\begin{array}{l}\text { It's Hard: } \\
\text { Experiences } \\
\text { within LEs that } \\
\text { negatively affect } \\
\text { students' learning } \\
\text { experience. }\end{array}$} \\
\hline & & Catch up & & \\
\hline 20. & Being picked on, harassed by other students because of appearance. & Bullying & \multirow[t]{3}{*}{ It's hard } & \\
\hline \multirow[t]{2}{*}{21.} & $\begin{array}{l}\text { Lack of knowledge, no accommodations, non-understanding of } \\
\text { CHC and/or student's needs. }\end{array}$ & Not understanding & & \\
\hline & $\begin{array}{l}\text { CHC has caused student to "miss out" being with friends, doing } \\
\text { school activities and is seen by the student as a negative experience. }\end{array}$ & Missing out (Social) & & \\
\hline 22. & $\begin{array}{l}\text { Primary caregivers (mother, father) communicating to school } \\
\text { personnel about } \mathrm{CHC} \text { and/or limitations, advocating for } \\
\text { accommodations. Aid in understanding school material. }\end{array}$ & Parents & \multirow{3}{*}{$\begin{array}{l}\text { Family and friends help- } \\
\text { the individuals who } \\
\text { make up the family of } \\
\text { the student with CHC } \\
\text { and friends. }\end{array}$} & \multirow{9}{*}{$\begin{array}{l}\text { Learning happens } \\
\text { when you have } \\
\text { help: Experiences } \\
\text { of how learning } \\
\text { continues when a } \\
\text { student has a } \\
\text { CHC. }\end{array}$} \\
\hline 23. & $\begin{array}{l}\text { Classmates, friends of student with CHC who assist by sharing } \\
\text { learning or giving emotional or physical support. }\end{array}$ & Friends & & \\
\hline 24. & $\begin{array}{l}\text { Strong encouragement by parent(s), teacher, self. Urging (student } \\
\text { with CHC) to do what is necessary for learning. }\end{array}$ & Push & & \\
\hline 25. & $\begin{array}{l}\text { Writing on board, repetition, clarification given, assurance, } \\
\text { following up, giving extra time, providing choices, including } \\
\text { class/school modifications made in response to student having CHC }\end{array}$ & Teacher help & \multirow[t]{3}{*}{ School support } & \\
\hline 26. & $\begin{array}{l}\text { Teachers/students believe symptoms are real, the student feels } \\
\text { trusted, feels can confide, rely on teacher/others, provision of } \\
\text { consideration, tolerance. Positive teacher aspects regarding } \\
\text { expectations of what student can achieve; knowledge of the CHC. }\end{array}$ & Understanding & & \\
\hline 27. & $\begin{array}{l}\text { Members of school such as teacher aides, learning resource } \\
\text { counsellors, nurses who aid with learning or dealing with the CHC. }\end{array}$ & Staff Support & & \\
\hline 28. & $\begin{array}{l}\text { Valued, respected, protected, safe from ridicule, negative } \\
\text { judgement, physical attacks from others based on physical/social } \\
\text { impact of CHC. }\end{array}$ & $\begin{array}{l}\text { Feeling Safe } \\
\text { Or Safe }\end{array}$ & School support & \\
\hline 29. & $\begin{array}{l}\text { N.Z. Govt provides a Regional Health School for those who are } \\
\text { absent due to health, what RHS does for students. }\end{array}$ & Organizations in Place & \multirow[t]{2}{*}{ Support } & \\
\hline 30. & $\begin{array}{l}\text { School system in place to assist student with CHC involving } \\
\text { sharing information, accommodations, other forms of support. }\end{array}$ & $\begin{array}{l}\text { School Quality-Ethos? } \\
\text { Positive Environment }\end{array}$ & & \\
\hline 31. & $\begin{array}{l}\text { Asking for repetition, help, clarification, checking understanding, } \\
\text { trying harder, using free time in school, active involvement in } \\
\text { learning, cooperative learning with classmates. }\end{array}$ & Student Strategy & Coping & CHC Experience \\
\hline 32. & Effect of CHC on cognitive, physical, psychosocial aspects. & "It's hard" & It's hard & It's Hard \\
\hline
\end{tabular}




\begin{tabular}{|r|l|l|l|l|}
\hline 33 & $\begin{array}{l}\text { Being limited in what one can do because of CHC, not being in } \\
\text { school and/or not able to learn. }\end{array}$ & "Missing out" (code) & It's hard (sub-theme) & It's Hard \\
\hline 34 & Self-monitoring and being self-reliant & "I can manage myself" & It's not a big deal & $\begin{array}{l}\text { It's Part of My } \\
\text { Personality }\end{array}$ \\
\hline 35 & $\begin{array}{l}\text { Student perception that appearance, inability to focus, absenteeism, } \\
\text { CHC makes student different than those without a CHC }\end{array}$ & Different & CHC experience & $\begin{array}{l}\text { The CHC } \\
\text { Experience }\end{array}$ \\
\hline 36 & $\begin{array}{l}\text { The message the student perceives from a teacher if there is } \\
\text { physical pain or cognitive issues resulting from the CHC. }\end{array}$ & "Suck it up." & Not understanding & It's Hard \\
\hline
\end{tabular}

